Prepared for the U.S. Department of Energy

under Contract DE-AC05-76RL01830

\title{
Hanford Internal Dosimetry Program Manual, PNL-MA-552
}

\author{
EH Carbaugh \\ DE Bihl \\ JA MacLellan
}

September 2009

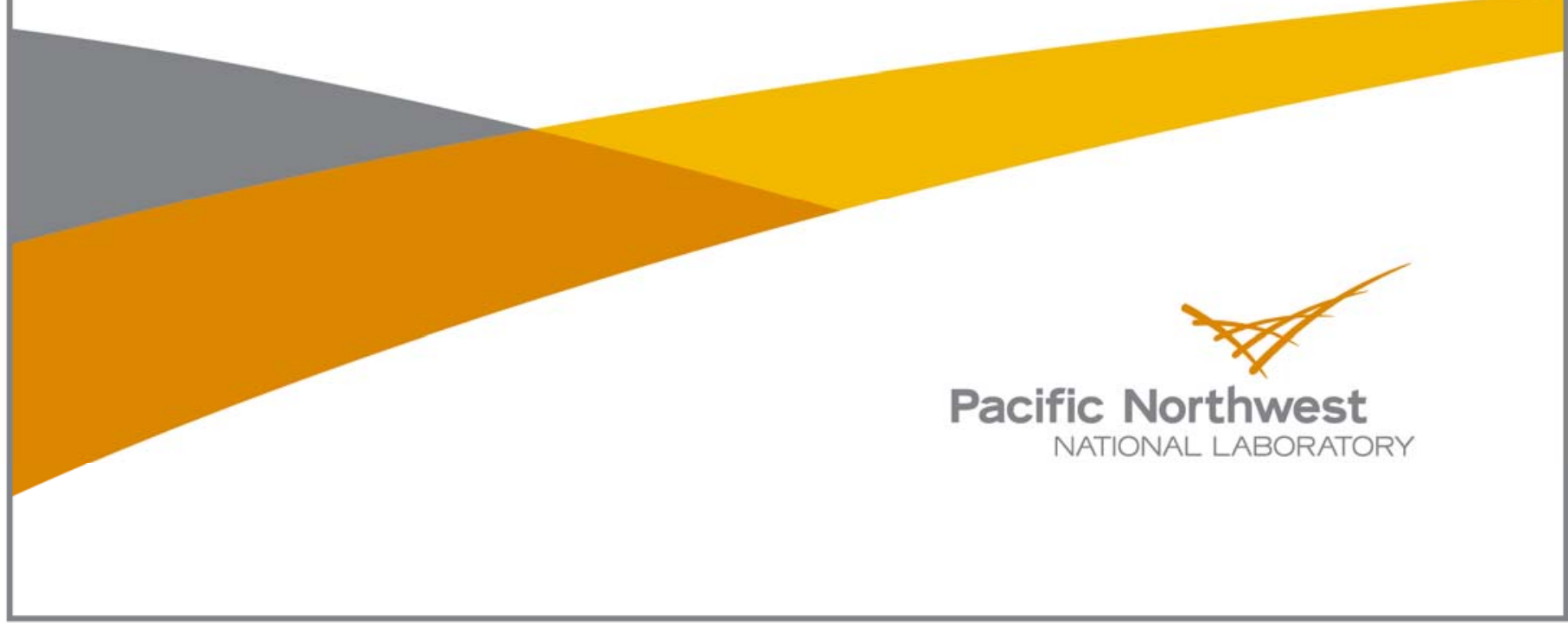




\title{
Hanford Internal Dosimetry Program Manual, PNL-MA-552
}

\author{
EH Carbaugh \\ DE Bihl \\ JA MacLellan
}

September 2009

Prepared for

the U.S. Department of Energy

under Contract DE-AC05-76RL01830

Pacific Northwest National Laboratory

Richland, Washington 99352 


\section{Hanford Internal Dosimetry Program Manual}

In case of termination, return this manual to document control: Ronda Biaggi (MSiN B1-60)

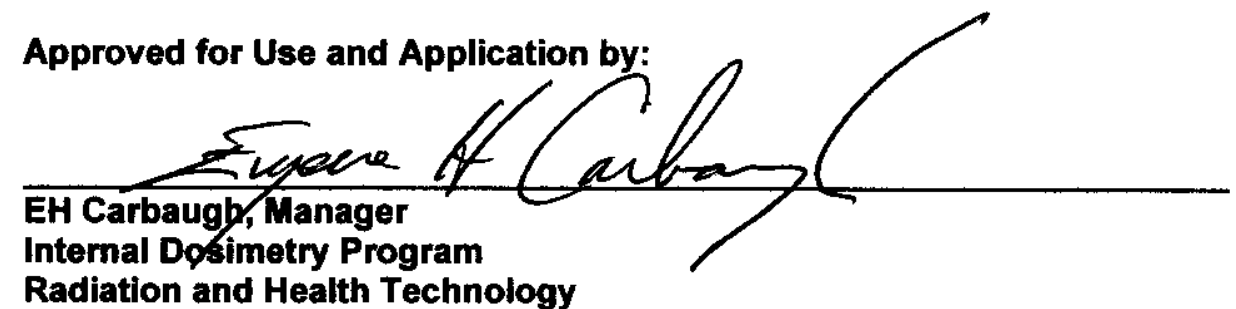

Battelle

Pacific Northwest National Laboratory

Richland, Washington 99352 


\section{HANFORD INTERNAL DOSIMETRY PROGRAM MANUAL \\ PNL-MA-552}

PREFACE

\section{Issued for implementation effective 01/01/2010}

Supersedes: $12 / 2006$

Use Category: Not applicable

\section{Approval Signatures:}

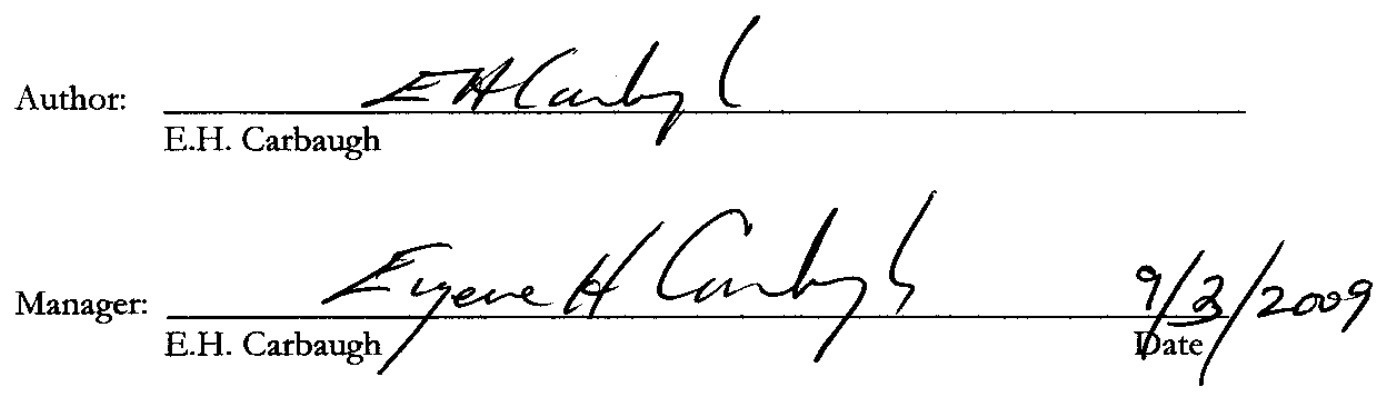

Reviewer Signatures:

Reviewer \#1:

Approval of this section by the Hanford Personnel Dosimetry Advisory Committee is not required, per Section 1.0 of this manual. 


\section{Preface}

This manual is a guide to the services provided by the Hanford Internal Dosimetry Program (HIDP), which is operated by the Pacific Northwest National Laboratory ${ }^{(a)}$ for the U.S. Department of Energy Richland Operations Office, Office of River Protection, Pacific Northwest Science Office, and their Hanford Site contractors. The manual describes the roles of and relationships between the HIDP and the radiation protection programs of the Hanford Site contractors. Recommendations and guidance are also provided for consideration in implementing bioassay monitoring and internal dosimetry elements of radiation protection programs.

A systematic review of the entire manual with appropriate updates to chapters and appendices occurs at three-year intervals. Minor revisions to individual subsections of this manual are made as the need arises.

The manual underwent complete review and revision in 2009 to incorporate the 2007 amendment to 10CFR835. These revisions become effective on January 1, 2010, but were released prior to that to support contractor implementation efforts.

The recommendations in this manual are provided as guidance, not requirements, to contractor organizations and personnel responsible for designing and operating bioassay monitoring programs. Each contractor determines the extent to which these recommendations apply to the Radiation Protection Program and assigns individual workers to bioassay programs.

The contact person for questions or comments regarding the content of this manual is Eugene $\mathrm{H}$. Carbaugh at 376-6632.

(a) Pacific Northwest National Laboratory is operated by Battelle Memorial Institute for the U.S. Department of Energy under contract DE-AC06-76RL0 1830. 


\title{
HANFORD INTERNAL DOSIMETRY PROGRAM MANUAL PNL-MA-552 \\ SECTION 1.0, INTRODUCTION
}

\author{
Issued: For implementation effective 01/01/2010
}

Supersedes: 12/2006

\section{Use Category: Not applicable}

\section{Approval Signatures:}

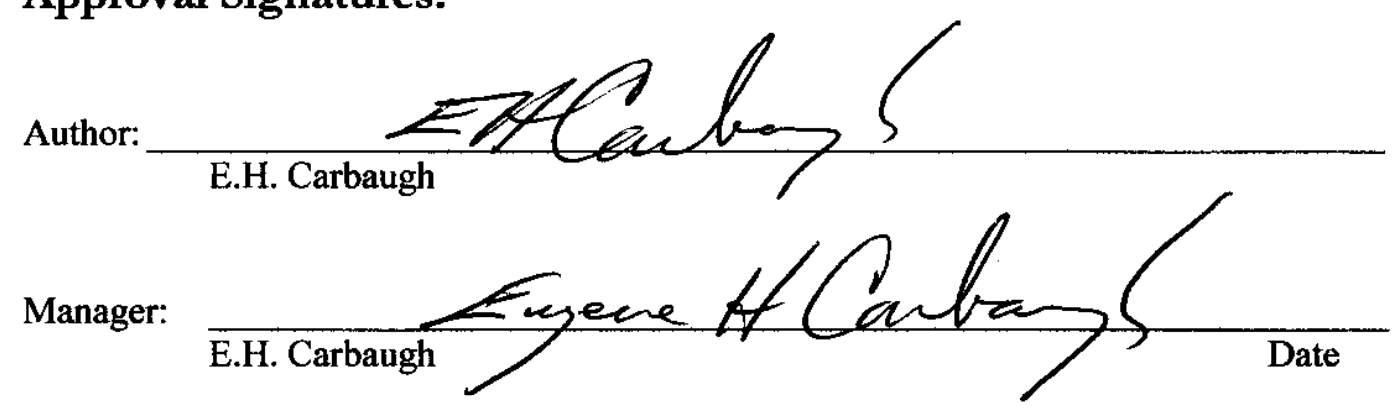

Reviewer Signatures:

Reviewer \#1:

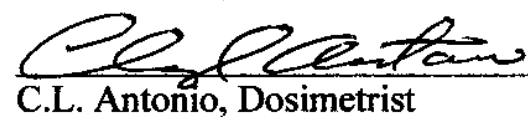

Approved by the Hanford Personnel Dosimetry Advisory Committee on May 27, 2009. 


\section{Contents}

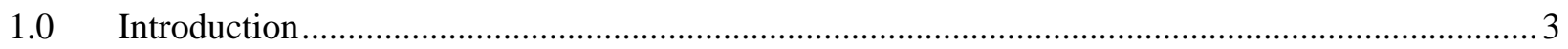

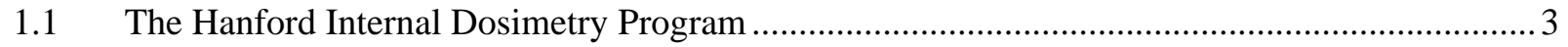

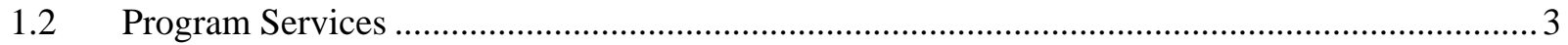

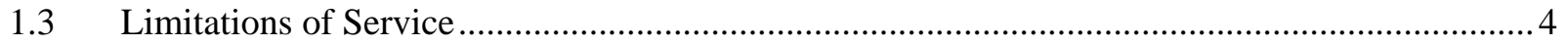

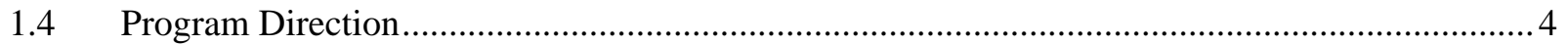

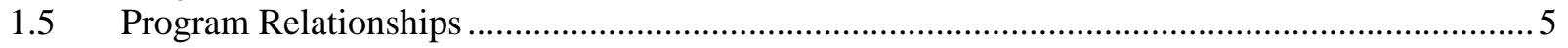

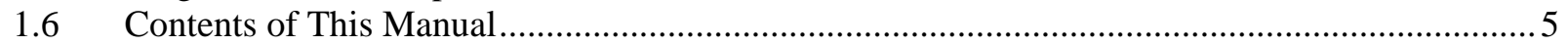

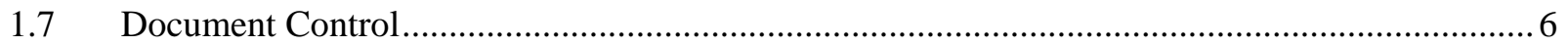

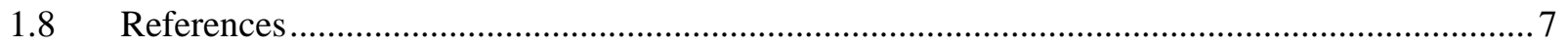




\subsection{Introduction}

\subsection{The Hanford Internal Dosimetry Program}

The Hanford Internal Dosimetry Program (HIDP) was initiated in late 1944. By 1946, a routine program had been established at Hanford to assess and document occupational doses to employees from intakes of radionuclides.

The HIDP is a sitewide service program operated by the Pacific Northwest National Laboratory (PNNL) for all Hanford U.S. Department of Energy (DOE) and DOE-contractor personnel. The program is funded by Hanford Site contractors and is subject to oversight by the DOE through the Richland Operations Office (RL), the DOE Office of River Protection (ORP), and the Pacific Northwest Site Office (PNSO). It is administered and staffed by Radiation \& Health Technology.

Historically, the Hanford Site Services Handbook (DOE 1993) assigned, by charter, the following responsibilities to PNNL:

- $\quad$ Assessing and documenting occupational doses from intakes of radionuclides.

- Determining compliance with applicable internal dose standards.

- Administering the routine bioassay monitoring program required by site contractors.

- $\quad$ Providing technical guidance to contractors on internal dosimetry matters.

- Establishing models for evaluating internal radionuclide deposition.

- Performing or initiating actions for prompt evaluation of the internal exposure of personnel involved in accidents or emergencies.

The Site Services Handbook was rescinded in 1995, and the HIDP now provides the above functions, as specified by the Hanford contractors through contractual statements of work and the Hanford Radiological Health and Safety Document (DOE 2001).

\subsection{Program Services}

The HIDP provides the following services for the benefit of all site employees:

- Administering the routine bioassay monitoring program for internally deposited radionuclides.

- Investigating and documenting evaluations of potential intakes for exposure record files and contractor staff.

- Arranging for excreta analysis services and ensuring that the Analytical Services Laboratory conforms to the technical requirements of the analytical services contract.

- Maintaining accreditation for indirect radiobioassay services under the Department of Energy Laboratory Accreditation Program (DOELAP). DOELAP accreditation for direct radiobioassay measurements is maintained by the In Vivo Monitoring Program. 
- Selecting and applying appropriate models, procedures, and practices for evaluating internal radionuclide deposition and the resulting dose.

- Guiding and supporting Hanford contractors in technical matters regarding internal dosimetry.

Additional specialized services are provided as negotiated with individual contractors.

The HIDP is committed to providing cost-effective, quality service that meets or exceeds DOE regulations, uses methods and practices recommended by appropriate national and international organizations, actively explores needed improvements in technology and techniques, and meets DOE guidance to the extent practicable subject to agreement by Site contractors.

\subsection{Limitations of Service}

HIDP capabilities are limited by the degree to which contractors use the available services. The HIDP provides consultation and advisory services to contractors for developing and establishing bioassay programs. However, the contractor bears the direct responsibility for ensuring that workers receive adequate and appropriate bioassay monitoring. This includes identifying needs for bioassay monitoring and determining when potential intakes have occurred. The HIDP is not responsible for initially reviewing air sampling data or other workplace monitoring data to identify potential intakes. However, review of such data by the HIDP is considered germane to an investigation of a potential intake once a potential intake has been identified.

Air sampling, contamination surveys, and other field monitoring techniques provide the primary means of identifying evidence of potential intakes at Hanford facilities. Bioassay monitoring is considered the primary means for confirming intakes, but a secondary means of initially identifying intakes.

It is assumed that each contractor communicates to the workers the need for bioassay measurements and the need to address questions regarding measurements. The HIDP staff discuss measurement results with workers on an individual basis if so requested by the contractor, and also deal with specific questions if contacted directly by workers. It is the intent of the HIDP that the contractor dosimetry organization be the focal point for all communication with workers regarding dosimetry needs and concerns.

The HIDP provides bioassay services that, if properly used, should be capable of identifying and evaluating an intake resulting in a committed effective dose of 100 mrem or less. However, the capability for such sensitivity depends, in some cases, on prompt identification of potential intakes by the contractor, using workplace monitoring and personnel survey techniques. Periodic bioassay monitoring does not necessarily provide adequate sensitivity to detect intakes resulting in a 100-mrem committed effective dose.

\subsection{Program Direction}

Direction for the HIDP comes from 10 CFR 835 and the Hanford Radiological Health and Safety Document (DOE 2001). The DOE Radiation Protection Programs Guide (DOE 2008) is used as general guidance for meeting the requirements of 10 CFR 835. However, in some cases, alternate methods may be used that provide similar protection or more cost-effective compliance with 10 CFR 835, provided these alternate methods meet all applicable requirements. 
Additional technical guidance is found primarily in the recommendations and standards of the International Commission on Radiological Protection (ICRP), the National Council on Radiation Protection and Measurements (NCRP), the American National Standards Institute (ANSI), the Health Physics Society (HPS), and the DOE. Specific citations are included where appropriate in this manual.

Specific requirements for individual contractors or clients are contained in Statements of Work or equivalent requirement documents.

\subsection{Program Relationships}

The HIDP works closely with Hanford contractor dosimetry organizations to provide a comprehensive internal dosimetry service. However, the HIDP has no direct responsibility to ensure protection of workers, to monitor or conduct surveillance of work environments, to operate facilities, or to assure worker cooperation with bioassay measurement requests. Such items are considered to be the responsibility of the contractor.

The HIDP also interfaces with other sitewide service programs operated by PNNL, including the Hanford Radiation Records Program (HRRP), the In-Vivo Monitoring Program, and the Hanford External Dosimetry Program.

The HIDP is a member of the Hanford Personnel Dosimetry Advisory Committee (HPDAC), an advisory body consisting of DOE, contractor, and dosimetry program representatives. The HPDAC has been established to review substantive current issues and proposed changes to Hanford personnel dosimetry programs. Its purpose is to identify technical, political, and/or administrative issues necessary to maintaining long-term continuity of such programs, and to ensure technical quality and consistency of dosimetry practices.

\subsection{Contents of This Manual}

This document, the Hanford Internal Dosimetry Program Manual, is one of three programmatic documents of the HIDP. The other two are the Methods \& Models of the Hanford Internal Dosimetry Program (PNL-MA-860) and the Hanford Internal Dosimetry Procedures Manual (PNL-MA-565). The purposes, scopes, and interrelationships of these three documents are described in Chapter 9.0.

This manual includes both technical basis and program description content. The technical basis content deals with establishing program design capabilities and goals, and the assumptions and methodologies used to accomplish those goals. As such, the technical basis material is subject to approval by the program manager and the HPDAC. The program description material in this manual consolidates summary explanations, descriptions, or listings of items pertinent to those using the services of the program, but that are governed by procedures or documents outside the scope of HPDAC approval. The program description material is subject to the approval of the program manager and HPDAC is advised when changes are made to that material, however specific HPDAC approval of descriptive changes is not required. Table 1.1 provides a listing of the chapters of this manual and identifies the approval requirements and the basis for those approval requirements. 
Table 1.1. Approval and Documentation Requirements for Hanford Internal Dosimetry Program Manual (PNL-MA-552)

\begin{tabular}{|c|c|c|c|c|}
\hline Section & Title & $\begin{array}{c}\text { Program } \\
\text { Manager } \\
\text { Approval* }\end{array}$ & $\begin{array}{l}\text { HPDAC } \\
\text { Approval** }\end{array}$ & Basis for Approval Requirement \\
\hline & Table of Contents & No & No & Simple listing of contents \\
\hline & Preface & Yes & No & Descriptive only \\
\hline 1 & Introduction & Yes & Yes & Addresses scope \& relationships of users \\
\hline 2 & Practices of the HIDP & Yes & Yes & $\begin{array}{l}\text { Establishes basic program criteria and } \\
\text { practice as a basis for program design and } \\
\text { operation }\end{array}$ \\
\hline 3 & Assessment of Internal Dose & Yes & Yes & $\begin{array}{l}\text { Specifies default assumptions, models, and } \\
\text { computer codes }\end{array}$ \\
\hline 4 & $\begin{array}{l}\text { Recording and Reporting } \\
\text { Internal Doses }\end{array}$ & Yes & Yes & $\begin{array}{l}\text { Specifies primary internal dose record and } \\
\text { delineates HIDP reporting from Hanford } \\
\text { Radiological Records Program reporting }\end{array}$ \\
\hline 5 & Bioassay Monitoring & Yes & Yes & $\begin{array}{l}\text { Provides recommendations for bioassay } \\
\text { monitoring for implementation by Site }\end{array}$ \\
\hline 6 & Bioassay Services & Yes & No & $\begin{array}{l}\text { Describes bioassay services available under } \\
\text { subcontract or as provided by In Vivo } \\
\text { Monitoring Program. }\end{array}$ \\
\hline 7 & $\begin{array}{l}\text { Internal Exposure Incident } \\
\text { Response }\end{array}$ & Yes & Yes & $\begin{array}{l}\text { Addresses roles and responsibilities of } \\
\text { HIDP and clients. Provides criteria for } \\
\text { internal dosimetry response. }\end{array}$ \\
\hline 8 & Quality Assurance & Yes & No & $\begin{array}{l}\text { Description of quality assurance elements } \\
\text { of the HIDP. }\end{array}$ \\
\hline 9 & Documents and Records & Yes & No & $\begin{array}{l}\text { Description of assorted records related to } \\
\text { HIDP but does not specify requirements. }\end{array}$ \\
\hline A & Screening Levels & Yes & Yes & $\begin{array}{l}\text { Provides uniform basis for response and } \\
\text { investigation }\end{array}$ \\
\hline B & $\begin{array}{l}\text { Key to Selected Field Codes } \\
\text { Used in REX Database }\end{array}$ & Yes & No & $\begin{array}{l}\text { Descriptive only. Appendix is provided } \\
\text { for summary convenience only. Full } \\
\text { explanations are provided in REX or } \\
\text { elsewhere (e.g., Section } 6 \text { ) }\end{array}$ \\
\hline $\mathrm{C}$ & Analytical Procedures & Yes & No & $\begin{array}{l}\text { Descriptive only. Summary of analytical } \\
\text { methods used. Changing these is beyond } \\
\text { the scope of HPDAC. }\end{array}$ \\
\hline $\mathrm{D}$ & Sample Kit Instructions & Yes & No & $\begin{array}{l}\text { Descriptive only. These are contractual } \\
\text { between PNNL and subcontracted service } \\
\text { lab. }\end{array}$ \\
\hline $\mathrm{E}$ & $\begin{array}{l}\text { Example Potential Intake } \\
\text { Responses }\end{array}$ & Yes & No & $\begin{array}{l}\text { Information is descriptive, not prescriptive. } \\
\text { ("If some level is observed, then some } \\
\text { given dose may be implied...") }\end{array}$ \\
\hline & Glossary & Yes & Yes & $\begin{array}{l}\text { Information is for convenience and clarity } \\
\text { of description }\end{array}$ \\
\hline
\end{tabular}

\subsection{Document Control}

Controlled document versions of this manual are administered by HIDP. Uncontrolled copies of this manual may be provided for technical or general information, but are not updated and may not reflect the current manual revisions. A copy of this manual is maintained in the HIDP files and available from the HIDP manager or online by searching, PNNL-15613 @ http://www.pnl.gov/publications/. 


\subsection{References}

10 CFR 835. 2007. U.S. Department of Energy, Occupational Radiation Protection. U.S. Code of Federal Regulations. Accessed July 23, 2009 at http://www.gpoaccess.gov/cfr/

Pacific Northwest National Laboratory (PNNL). Methods and Models of the Hanford Internal Dosimetry Program, PNNL-MA-860. Richland, Washington. Internal manual. A copy of this manual is maintained in the HIDP files and available from the HIDP Manager or online by searching, PNNL-15614 @ http://www.pnl.gov/publications/

Pacific Northwest National Laboratory (PNNL). Hanford Internal Dosimetry Procedures Manual, PNLMA-565. Richland, Washington. (Internal manual. Copy maintained in the HIDP files and available from the HIDP Manager.)

U.S. Department of Energy (DOE) - Richland Operations Office. 1993. Hanford Site Services Handbook. RL 1400.1, Richland, Washington.

U.S. Department of Energy (DOE). 2008. Radiation Protection Programs Guide for use with 10 CFR 835. DOE G441.1-1C, Washington, D.C. Accessed July 23, 2009 at http://www.directives.doe.gov

U.S. Department of Energy (DOE) - Richland Operations Office. 2001. Hanford Radiological Health and Safety Document. DOE/RL-2002-12, Richland, Washington. 


\section{HANFORD INTERNAL DOSIMETRY PROGRAM MANUAL PNL-MA-552 \\ SECTION 2.0, PRACTICES OF THE HANFORD INTERNAL DOSIMETRY PROGRAM (HIDP)}

Issued for implementation effective $01 / 01 / 2010$

Supersedes: $12 / 2006$

Use Category: Not applicable

\section{Approval Signatures:}

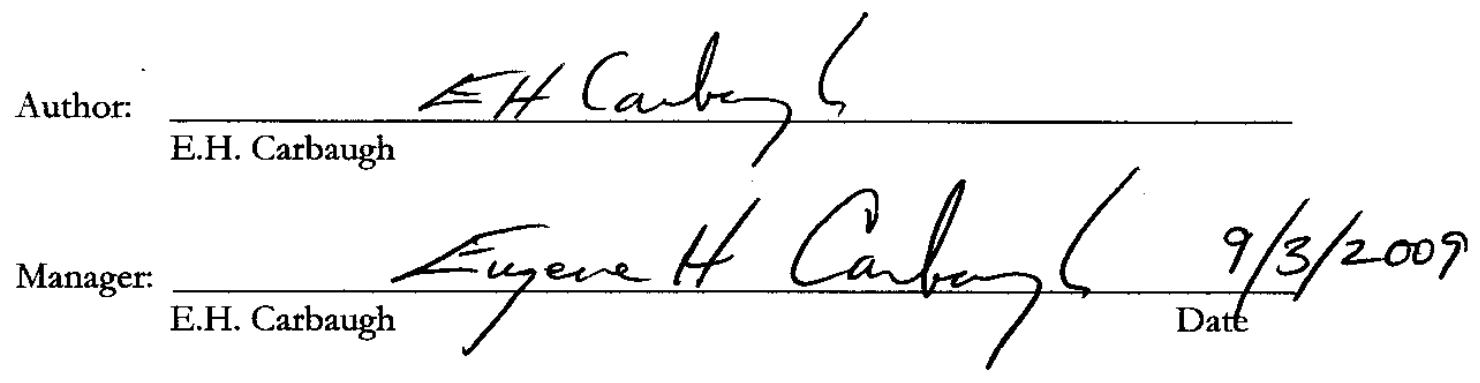

\section{Reviewer Signatures:}

Reviewer \#1:

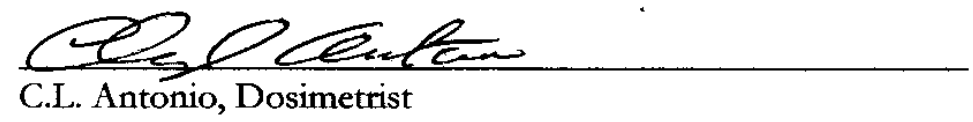

Approved by the Hanford Personnel Dosimetry Advisory Committee on May 12, 2009. 


\section{Contents}

2.0 Practices of the Hanford Internal Dosimetry Program................................................................ 3

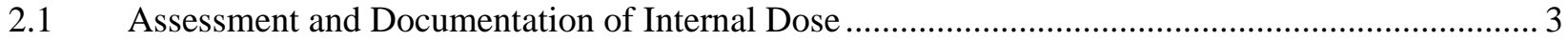

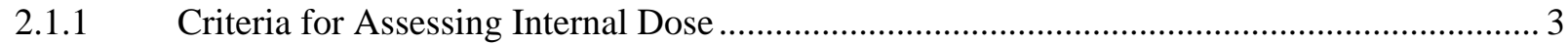

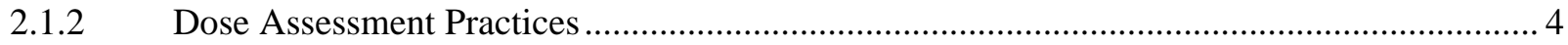

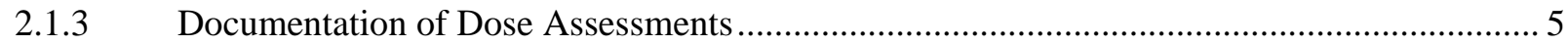

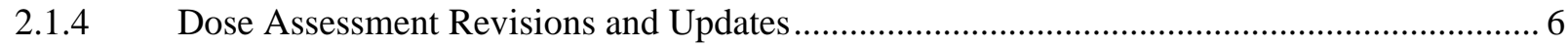

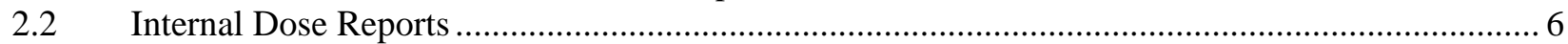

2.2.1 Reports Provided to Contractor Dosimetry Organizations …........................................... 6

2.2.2 Reports Provided to the Hanford Radiation Records Program ......................................... 7

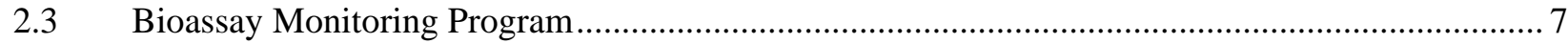

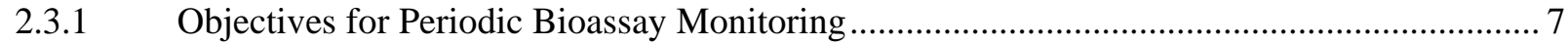

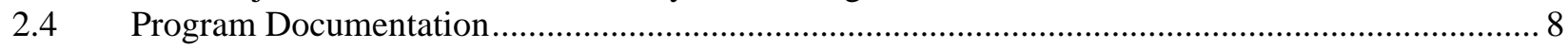

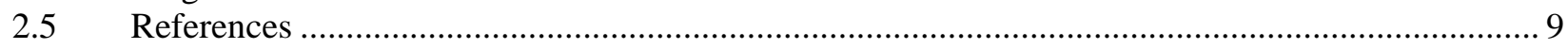




\section{Practices of the Hanford Internal Dosimetry Program}

It is the policy of the Hanford Internal Dosimetry Program (HIDP) to comply with 10 CFR 835 and the Hanford Radiological Health and Safety Document (DOE 2001). Similarly, it is HIDP practice to follow, to the extent practical, the guidance and good practice recommendations issued through the DOE Radiation Protection Programs Guide (2008) and DOE standards, the International Commission on Radiological Protection (ICRP), National Council on Radiation Protection and Measurements (NCRP), U.S. Environmental Protection Agency (EPA), DOE, Health Physics Society (HPS), and American National Standards Institute (ANSI).

This chapter describes the conduct of the HIDP and provides for interpretation of applicable regulations and guidance for use at Hanford. The Hanford Personnel Dosimetry Advisory Committee (HPDAC) has reviewed and concurred with these practices described here. Modifications to these practices require endorsement by the HPDAC.

\subsection{Assessment and Documentation of Internal Dose}

This section presents criteria used to assess, document, and revise internal doses at Hanford.

\subsubsection{Criteria for Assessing Internal Dose}

Assessment of potential internal exposure is conducted for:

- Any potential occupational intake reported to PNNL Internal Dosimetry staff by site radiation protection organizations with a request for dose assessment.

- Any bioassay measurement that indicates a potential occupational intake that has not been evaluated previously, resulting in a committed effective dose greater than $10 \mathrm{mrem}$. This screening level is suitable for occupational workers, as well as minors and members of the public.

- Single or cumulative exposures to airborne radioactivity that result in greater than 10 DAC-hours exposure in a calendar year, after correction for respiratory protection.

- Any "baseline" bioassay measurement indicating a detectable intake that has not been evaluated previously and that is not readily associated with a non-occupational source.

- Any employee, hired by RL, ORP, PNSO or a DOE contractor, who has incurred an occupational intake or internal dose considered significant by the former employer relative to regulatory guidance in place at the time of intake.

The initial assessment generally should include bioassay measurements to confirm the intake. To the extent practicable, measurements should consist of at least:

- One bioassay measurement following a workplace indication of an intake, or

- Two bioassay measurements following a bioassay indication of an intake.

Assessments performed as a result of occupational intakes or assigned doses previous to Hanford employment may not necessarily warrant Hanford measurements. 
A potential intake is considered to be confirmed if:

- A bioassay result exceeding the decision level (and the environmental screening level, if applicable) is associated with a known incident, or

- A bioassay result not associated with a known incident, exceeding the decision level and the screening level, is followed by two consecutive bioassay measurements, one of which exceeds the decision level or screening level.

- An occupational internal dose is assigned.

If follow-up measurements are not obtained following a bioassay result that exceeds the decision and screening levels, an intake will be assumed to have occurred unless there is overriding evidence that one did not. In this circumstance the assumption of an intake is taken as "confirmation" and any appropriate internal doses will be calculated, recorded, and reported. The overriding evidence must be discussed in the evaluation.

Hanford visitors whose baseline bioassay measurements detected radioactivity and whose end-ofassignment measurements are consistent with their baseline measurements will not have their prior occupational dose assessed by Internal Dosimetry unless the site contractor requesting the measurements specifically requests Internal Dosimetry to do so. Instead, the requesting site contractor will be notified of the result and the measurement result(s) will be recorded.

\section{Dose Assessment Practices}

The estimation of internal dose shall be based on bioassay data rather than air concentration values unless bioassay data are unavailable, inadequate, or estimates based on representative air concentration values are demonstrated to be as, or more, accurate. The determination that bioassay data are inadequate, or air concentration values are more accurate will be made on a case-by-case basis by the internal dosimetrist, in consultation with the facility's radiological control organization, and at least one other internal dosimetrist. Generally, air sample data would be used for radionuclides with physical or effective half-lives that are too short to accomplish bioassay measurements, e.g., radon/thoron progeny or when likely low-level intakes are below the bioassay detection capabilities. Prior-to-Hanford exposure expressed in working level months, MPC-hours, or DAC-hours will be converted to internal dose according to methods established in program documentation without consulting Field Dosimetry.

\section{E(50) Less Than 500 mrem}

If the available evidence suggests that the committed effective dose, $E(50)$, from an intake does not exceed 500 mrem and specific information is not readily available, generalized (default) models and assumptions may be used to assess the dose. These general assumptions are as follows:

- $\quad$ The intake occurred by inhalation.

- $\quad$ The intake is acute.

- If the actual intake date is unknown, the intake occurs at the midpoint to the potential exposure period for acute intakes or through the potential exposure period for chronic intakes. 
- For monitored workers, the potential exposure period extends back one monitoring period unless known to be otherwise.

- The radionuclides observed in bioassay measurements, or otherwise known to be present, are included in the assessment. All radionuclides potentially involved in the exposure are considered, including those not specifically identified in the initial bioassay measurements but expected to be present.

- The physiological characteristics of the workers are the same as those of the Reference Man or Woman in ICRP 23 (1974) or ICRP 89 (2002).

- The biokinetic models and parameters described in Methods and Models for Hanford Internal Dosimetry, PNNL-MA-860 are to be used for radionuclides included in that document; otherwise, models and parameters endorsed or prescribed by the NCRP or ICRP are to be used.

- $\quad$ The dose to the embryo/fetus is calculated separately from the dose to the mother.

E(50) Above 500 mrem

At a projected $E(50)$ above 500 mrem, actions are taken as follows:

- Bioassay and exposure characterization data are obtained to enable adjustments to be made to the default assumptions and models, as appropriate.

- Consideration may be given to individual-specific physiological characteristics.

Recording Doses

Doses are recorded as calculated for each assessment, with the following special provisions:

- Quantified doses of less than 10 mrem are rounded to the nearest whole number and doses of 10 mrem or greater may be rounded to two significant figures.

- Organ equivalent doses are recorded for any organ contributing more than $10 \%$ to an $E(50)$ exceeding 100 mrem. This criterion applies to each intake separately, even if a worker has more than one intake a year. (For radionuclides such as tritium and radio-cesium, which provide dose homogeneously to all organs, the dose may be recorded as effective dose; however, it is understood that the same dose applies to all organs.)

- Committed organ and effective doses are assigned to the year of intake.

\subsubsection{Documentation of Dose Assessments}

Assessments of occupational internal doses are documented. The documentation includes or references the methods, assumptions, and data used to make the assessment and lists the assessed doses. A copy of the documented assessment is provided to Hanford Radiation Records Program (HRRP) for placement in the worker's radiation exposure file. For each assessment, a letter is sent either to the worker directly or to the worker's radiation dosimetry organization. The letter summarizes the conclusion of the assessment and updates the worker's current internal dose status. 
Intake assessments are issued within 3 months of obtaining all the necessary data (including bioassay and source-term characterization). Alternative completion times are negotiable with customers considering the priority of specific evaluations and the total evaluation workload. Customers will be notified if lowerpriority evaluations are rescheduled beyond the 3-month target because of other expedited evaluations.

Chronic intakes are assessed on a calendar-year basis for continuing exposures.

\subsubsection{Dose Assessment Revisions and Updates}

The dose assessment for an active worker with a prior intake will be reviewed and updated at the request of the contractor dosimetry organization. In addition, workers maintained on bioassay for radionuclides previously evaluated are reviewed in light of the previous evaluation each time that new measurements are obtained, and a determination is made as to the consistency of the current results with the anticipated results. If results are not consistent, then the reason for the discrepancy is investigated.

Assessments for active workers are revised when information demonstrates a change in the currently assessed committed effective dose of 0.5 rem or a factor of 1.5 of the previously assigned dose for that intake, whichever is higher.

When the revision involves a specific worker's intake, the contractor dosimetry representative is notified, in advance, of the need to issue a revised assessment.

When the revision results from general changes in dosimetry techniques, assumptions, or regulations, and multiple workers are affected, then HIDP presents a discussion of the impacts of the change to the HPDAC.

\subsection{Internal Dose Reports}

HIDP provides reports of internal dose to contractor dosimetry organizations and to HRRP as described in the following subsections.

\subsubsection{Reports Provided to Contractor Dosimetry Organizations}

A final assessment summary letter is provided to the worker and/or contractor dosimetry organization upon completion of the intake evaluation report. Preliminary assessments (verbal or written) are provided upon request. The summary letter contains the following information:

- the identity and magnitude of any confirmed occupational intake

- committed effective dose for a confirmed occupational intake

- committed equivalent doses to significant organs when the committed effective dose exceeds 100 mrem

- date of intake

- facility at which intake occurred

- $\quad$ any long-term follow-up bioassay recommendations. 
The HRRP issues annual dose reports for individual workers showing total effective dose and compliance with regulatory limits. Contractors determine ongoing compliance with administrative control levels and dose limits using the internal dose reports, external dosimetry results, and supplemental work place monitoring.

\subsubsection{Reports Provided to the Hanford Radiation Records Program}

The HIDP provides internal dose information to the HRRP for inclusion in the Radiation Exposure (REX) System and the PNNL Total Records Information Management (TRIM) database.

\subsection{Bioassay Monitoring Program}

The HIDP maintains accreditation for indirect radiobioassay under the Department of Energy Laboratory Accreditation Program (DOELAP), as required by 10 CFR 835.402(d)(1). Accreditation is maintained for DOELAP-proffered radionuclides or categories of radionuclides which are of concern at Hanford. Criteria for accreditation are described in DOE-STD-1112-98 (DOE 1998). The letter and certificate granting accreditation are maintained according to the program File Plan, with copies provided to the HPDAC. The DOELAP accreditation for direct radiobioassay measurements at Hanford is maintained by the In Vivo Monitoring Program.

Internal Dosimetry provides, to the extent that Hanford Site contractors and RL/ORP/PNSO will support and that technical capabilities will allow, a bioassay monitoring program capable of detecting an intake potentially resulting in a committed effective dose of 100 mrem.

Facility-specific radionuclide mixtures and characteristics are considered in the development of the bioassaymonitoring program. Bioassay capabilities are optimized, considering sensitivity requirements, worker inconvenience, and costs.

\subsubsection{Objectives for Periodic Bioassay Monitoring}

The following objectives are established as guidance for cost-effective bioassay monitoring programs which comply with 10 CFR 835.

- The 100-mrem sensitivity does not have to be achieved for all radionuclides measured if workers are not potentially exposed to those radionuclides.

- The 100-mrem sensitivity does not have to be achieved for confirmatory monitoring (i.e., limited surveillance to verify periodic monitoring is not required). Minimum detectable dose (MDD) calculations are not appropriate for confirmatory monitoring.

- For radionuclides or mixtures of radionuclides for which existing bioassay methods and frequencies achieve the 100-mrem sensitivity recommendation, changes should not be allowed that degrade the sensitivity to where the MDD exceeds nominally 100-mrem. This does not preclude the switching of one bioassay method for another to best accomplish Site needs so long as the resulting MDD stays less than 100 mrem.

- For radionuclides or mixtures of radionuclides for which existing bioassay methods and frequencies do not achieve the 100-mrem sensitivity recommendations, changes should be discouraged that significantly degrade the sensitivity. 
For radionuclides or mixtures of radionuclides for which existing bioassay methods and frequencies do not achieve the 100-mrem sensitivity recommendation, the weighting given for cost and inconvenience of the bioassay method decreases as the MDD increases. However, it is recognized that for mixtures composed principally of actinides, the best intake-monitoring program is provided by aggressive workplace monitoring and prompt initiation of special bioassay.

A grace period for all bioassay samples, during which no work restriction is imposed, consists of the calendar month in which the sample is scheduled (the due period) and the immediately following calendar month (the probation period). An excreta sample or in vivo measurement not obtained during the due period is considered late on the first day of the probation period, and delinquent following the end of the grace period. Late bioassays warrant attention to make sure they are obtained during the probation period. Failure to comply with a bioassay request by the end of the grace period should result in a work restriction for the worker until the in vivo measurement is obtained or the excreta sample is provided to the laboratory. The work restriction may be lifted following a receipt of a valid sample. No work restriction should be imposed for a failed analysis, however the grace period will immediately resume with the reporting of the failed analysis.

\subsection{Program Documentation}

The practices and general recommendations of the HIDP are documented in this controlled distribution manual. Copies of the manual and its revisions are maintained in the HIDP files.

Suggestions and recommendations for specific work situations, radiation work permits, or facilities may alternatively be documented in letters, memorandum, or special reports. Such guidance supersedes that contained in this manual. A copy of such guidance will be included in the HIDP files.

Changes in general practices and recommendations presented in this manual are made by Interim Change Notices or manual revisions. Changes are distributed to the controlled distribution for the appropriate document. A copy of the change is maintained in the HIDP files.

The following items are also documented or referenced in the HIDP files (discussed in Section 9):

- $\quad$ operating procedures

- technical bases

- biokinetic models

- computer codes

- Excreta Laboratory Statement of Work

- QA Plan

- DOELAP Accreditations

- Facility - specific internal dosimetry or bioassay design and characterization documents 


\subsection{References}

10 CFR 835. 2007. U.S. Department of Energy, Occupational Radiation Protection. U.S. Code of Federal Regulations. Accessed July 23, 2009 at http://www.gpoaccess.gov/cfr/

International Commission on Radiological Protection (ICRP). 1974. "Report of the Task Group on Reference Man”. (ICRP Publication 23), Pergamon Press, New York.

International Commission on Radiological Protection (ICRP). 2002. "Basic anatomical and Physiological Data for Use in Radiological Protection: Reference Values”. (ICRP Publication 89), Annals of the ICRP, 32:3-4. Pergamon Press, New York.

Pacific Northwest National Laboratory (PNNL). Methods and Models of the Hanford Internal Dosimetry Program, PNNL-MA-860. Richland, Washington. Internal manual. Copy maintained in the HIDP files and available from the HIDP Manager or online by searching, PNNL-15613@

http://www.pnl.gov/publications/

U.S. Department of Energy (DOE). 1998. DOE Standard: The Department of Energy Laboratory Accreditation Program for Radiobioassay. DOE-STD-1112-98, Washington, D.C. Accessed July 23, 2009 at http://www.directives.doe.gov

U.S. Department of Energy (DOE). 2008. Radiation Protection Programs Guide for use with 10 CFR 835. DOE G441.1-1C, Washington, D.C. Accessed July 23, 2009 at http://directives.doc.gov

U.S. Department of Energy (DOE) - Richland Operations Office. 2001. Hanford Radiological Health and Safety Document. DOE/RL-2002-12, Richland, Washington. 


\section{HANFORD INTERNAL DOSIMETRY PROGRAM MANUAL \\ PNL-MA-552}

\section{SECTION 3.0, INTERNAL DOSE ASSESSMENT}

Issued for implementation effective 01/01/2010

Supersedes: $10 / 2003$

Use Category: Not applicable

Approval Signatures:

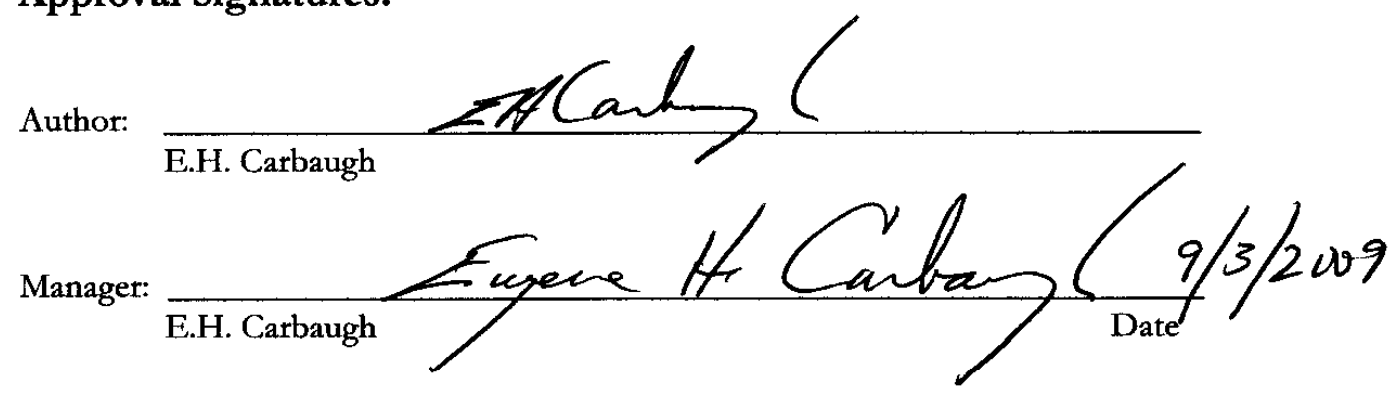

\section{Reviewer Signatures:}

Reviewer \#1:

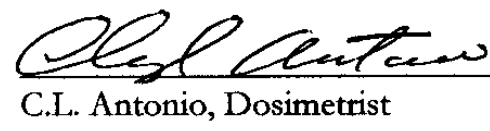

Approved by the Hanford Personnel Dosimetry Advisory Committee on June 1, 2009. 


\section{Contents}

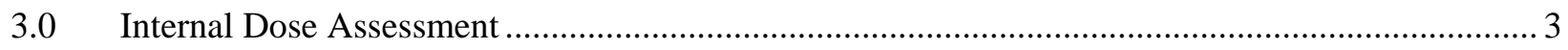

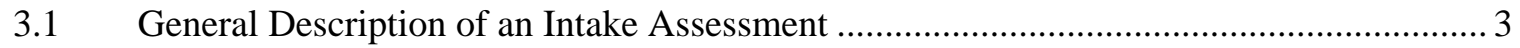

3.1.1 Criteria for Performing an Assessment ........................................................... 3

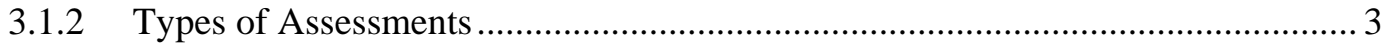

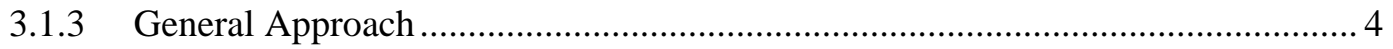

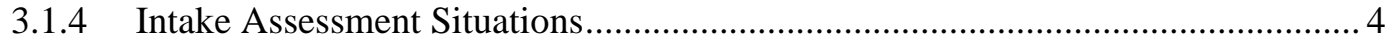

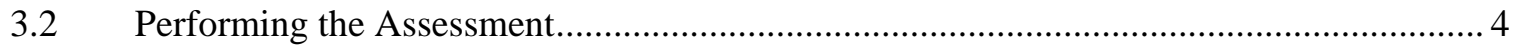

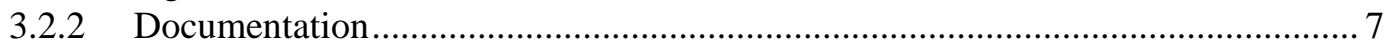

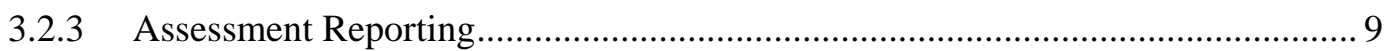

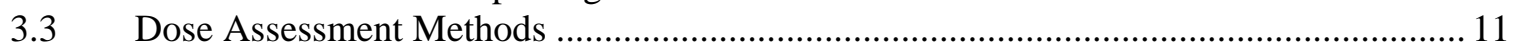

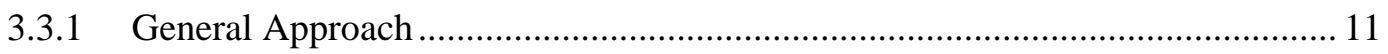

3.3.2 Evaluating Lung Dose for Inhalation Exposures ............................................ 11

3.3.3 Solubility and Particle Size Assumptions ......................................................... 12

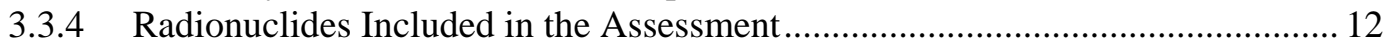

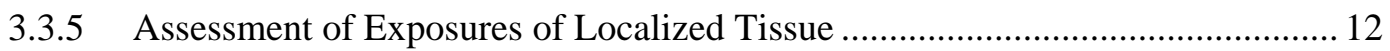

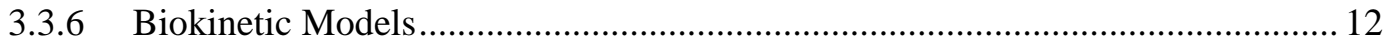

3.3.7 Computer Programs Used for Dose Calculations ............................................... 13

3.3.8 Graded Approach To Dose Assessments .............................................................. 13

3.3.9 Internal Dose Assessment to the Embryo/Fetus ............................................... 14

3.4 Good Practice Recommendations for Field Dosimetry ................................................ 15

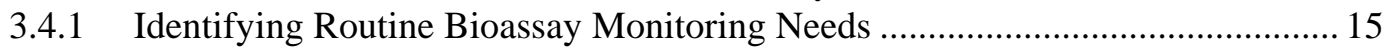

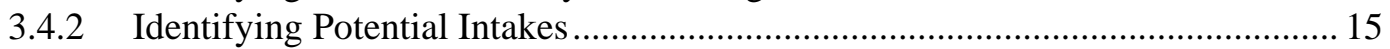

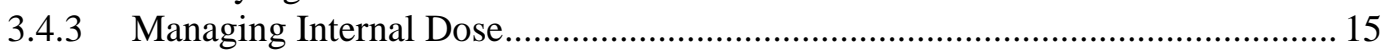

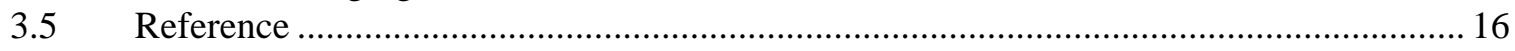




\subsection{Internal Dose Assessment}

The process of assessing internal dose involves collecting and analyzing information concerning a potential intake, and then developing a conclusion regarding the magnitude of the intake in terms that can be related to radiation protection standards. In a broad sense, the dose assessment process consists of three parts:

- Identifying a potential intake.

- Collecting pertinent data.

- Evaluating and documenting intake magnitude and dose.

A successful intake assessment effort at Hanford depends on the support of both the contractor dosimetry organization (i.e., Field Dosimetry) and the Hanford Internal Dosimetry Program (HIDP). Field Dosimetry has the primary responsibility for identifying potential intakes for assessment. HIDP supports this effort by providing guidelines and recommendations for establishing routine bioassay monitoring programs and for identifying situations that warrant intake assessment (see Chapters 5.0, 6.0, and 7.0). The performance of bioassay measurements and the collection of other data and information used in the assessment require the combined efforts and cooperation of Field Dosimetry and HIDP.

Evaluating the data, assessing internal dose, and documenting the assessment are primarily the responsibility of HIDP, as discussed in this chapter.

\subsection{General Description of an Intake Assessment}

Determining when and what kind of an assessment of potential intake is necessary, and how the assessment is conducted for various intake scenarios, is key to the assessment process.

\subsubsection{Criteria for Performing an Assessment}

Program practice statements in Chapter 2.0 establish the criteria for determining when an intake assessment is needed and provide the general guidance used in performing the assessment.

\subsubsection{Types of Assessments}

Assessments of potential intakes generally fall into one of three categories:

- Preliminary evaluation.

- Final evaluation.

- Reevaluation.

Preliminary Evaluation

The purpose of the preliminary evaluation is to provide a prompt or interim assessment of the potential seriousness of an intake prior to obtaining the data required for a final evaluation. Because the preliminary evaluation is performed before completing the investigation, the estimates of intake and dose 
are based on relatively conservative assumptions. Thus, preliminary evaluations tend to result in a higher assessed dose than do final evaluations.

In cases where the significance of the potential intake is obviously small, the conclusions of the preliminary evaluation are reported verbally. For cases with greater significance, Field Dosimetry may request a written preliminary evaluation.

\section{Final Evaluation}

A final evaluation represents the conclusion of the intake assessment process based on the follow-up investigation. (See Exhibit 3.1, Internal Dose Evaluation Report Form, at the end of this chapter.) A report on the final evaluation is generally issued within 3 months of the receipt of the necessary data, with some exceptions as mentioned in Section 2.1.3. Generally, the time period between identifying an intake and issuing a final report ranges from 1 month, for simple cases, to 1 year, for complex cases requiring long-term bioassay data. Final evaluations may be revised by issuing a reevaluation report if additional evidence that affects the conclusion of the previous final evaluation is obtained.

\section{Reevaluation}

A reevaluation is an updated final evaluation report. The criteria for determining when a reevaluation should be performed are provided in Section 2.1.4.

\subsubsection{General Approach}

Intake assessments are conducted by investigating the nature of the exposure and by analyzing bioassay measurement results and other pertinent data. Bioassay measurement data, which provide information on the deposition and retention of radionuclides in the involved individual(s), are the preferred basis for assessing internal dose. In cases where bioassay data are not available, an internal dose assessment can be made using other relevant information that is available, such as air sample data, source terms, and contamination surveys.

\subsubsection{Intake Assessment Situations}

Various situations necessitate an assessment of potential intake. Table 3.1 lists possible situations for which an assessment may be needed and the criteria used to determine whether an assessment should be initiated.

\subsection{Performing the Assessment}

When one of the situations in Table 3.1 occurs and the dose assessment criteria are met, an evaluation of potential intake is performed. The assessment process includes investigating the potential intake, documenting the results, and reporting the conclusions. Figure 3.1 depicts the steps that make up the complete assessment process. (The Internal Dose Evaluation Report is described in Section 3.2.2. See Chapter 4.0 for information on the INTERTRAC and REX databases.) 


\subsubsection{Investigation of a Potential Intake}

The investigation phase of the assessment process involves the performance of special bioassay measurements and the collection of other pertinent data. Special bioassay measurements have three purposes:

1. Identifying (confirming) that an intake occurred.

2. Establishing the material's distribution in and clearance from organs in the body.

3. Assessing dose.

Recommendations for special bioassay measurements are made by HIDP on a case-by-case basis, according to stated practices in Chapter 2.0 and other guidance provided in Section 3.3.8, Chapters 6.0 and 7.0, Appendix E of this manual, and with the concurrence of Field Dosimetry. The type and extent of the measurements depend on the significance and complexity of the case.

Special measurements for assessing dose are based on the need to establish the magnitude of the internal deposition and its clearance rate from the body. Generally, the frequency for performing special bioassay measurements can be decreased with time post-intake, until, for long retained nuclides, the measurements can be continued on an annual monitoring or other appropriate frequency. It is recommended that special bioassay measurements continue until the measurement results are consistently less than detectable or below the screening level established for routine bioassay monitoring. Other information that may be important to the assessment is listed in Table 3.2.

The investigation determines whether an intake occurred. If the conclusion is that an occupational intake did occur, the magnitude of the intake or deposition and the committed effective dose are determined and assigned. If an occupational intake is not confirmed, no dose is assigned. 
Table 3.1. Potential Intake Assessment Situations

\begin{tabular}{ll}
\hline Situation & Criteria for Initiating a Potential Intake Assessment \\
\hline $\begin{array}{l}\text { Field Dosimetry identifies a } \\
\text { potential intake incident. }\end{array}$ & $\begin{array}{l}\text { Field measurement data meet contractor criteria for } \\
\text { potential intake. (Recommendations for these criteria } \\
\text { are provided in Chapter 7.0.) }\end{array}$ \\
$\begin{array}{l}\text { Special (nonroutine) bioassay } \\
\text { measurement shows detectable } \\
\text { activity above natural background. }\end{array}$ & $\begin{array}{l}\text { Measurement results indicate internally deposited } \\
\text { radionuclides. }\end{array}$ \\
$\begin{array}{l}\text { Routine bioassay measurement } \\
\text { shows activity. }\end{array}$ & $\begin{array}{l}\text { Measurement results exceed the screening level for } \\
\text { routine bioassay monitoring. (See Appendix A.) }\end{array}$ \\
$\begin{array}{l}\text { Bioassay result for a worker with a } \\
\text { known internal deposition shows an }\end{array}$ & $\begin{array}{l}\text { When recent and previous bioassay measurements are } \\
\text { compared, it is determined that the recent result } \\
\text { exceeds normally expected fluctuations. }\end{array}$ \\
$\begin{array}{l}\text { Bioassay data collected subsequent } \\
\text { to an evaluated intake suggest that } \\
\text { the assigned dose may be incorrect. }\end{array}$ & $\begin{array}{l}\text { Evidence suggests the assigned committed effective } \\
\text { dose may be in error by 0.5 rem or a factor of } 1.5 \text { of the } \\
\text { previously assigned dose, whichever is higher. }\end{array}$ \\
$\begin{array}{l}\text { Field Dosimetry requests a special } \\
\text { internal dose assessment. }\end{array}$ & $\begin{array}{l}\text { Request by Field Dosimetry. } \\
\begin{array}{l}\text { Prior work history or baseline } \\
\text { bioassay for a newly hired employee } \\
\text { occupational intake. }\end{array}\end{array}$ \\
\hline
\end{tabular}




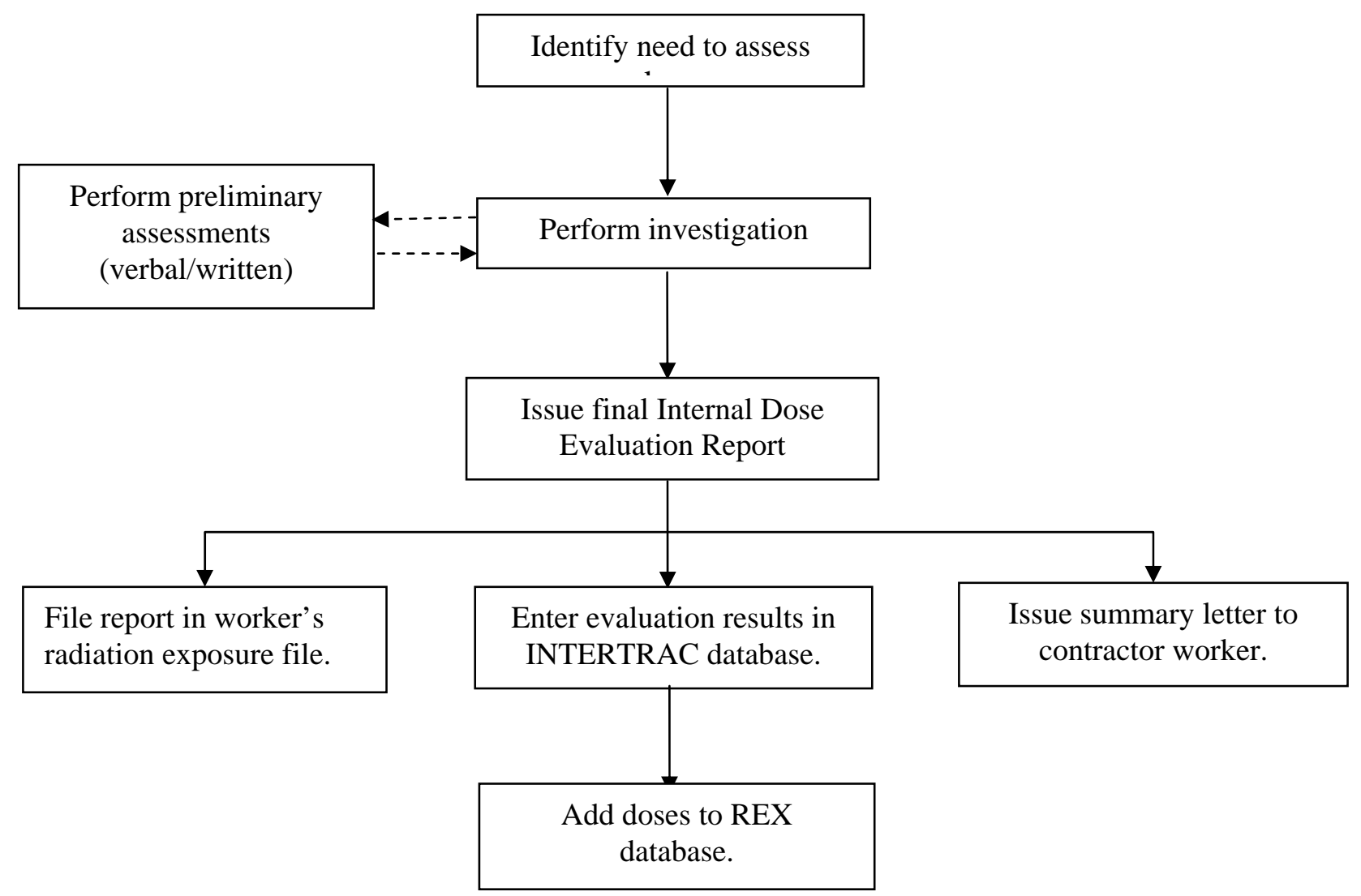

S9310077.1

Figure 3.1. Internal Dose Assessment Process

\subsubsection{Documentation}

\section{Internal Dose Evaluation Report}

Occupational intakes of radionuclides are assessed and formally documented through the internal dose evaluation report. This report describes the methods, assumptions, data, and conclusions of the assessment. All subsequent detailed or summary accounts of internal dose from a particular intake are derived from the report.

Internal dose evaluation reports are prepared by HIDP, using methods and assumptions described in this manual, in the internal manual Methods and Models of the Hanford Internal Dosimetry Program (PNNL-MA-860), and in other resources, as appropriate. Before any report is issued, it is reviewed internally by a peer internal dosimetrist.

Exhibit 3.1 (at the end of this chapter) is an example of the form used to document internal dose evaluation reports. This form is used to identify the assessment, organize the content of the report, summarize the conclusions, and identify the staff that prepared and reviewed the report. When an assessment is complex, special attachments containing the details of the assessment are included with the form. 
Each internal dose evaluation is identified by a unique identification number. Prior to 1987, numbers were assigned sequentially. Beginning on January 1, 1987, the numbering system was revised to include a five-digit event number, followed by a two-digit person designator and a one-digit evaluation revision designator. The first two digits of the event number represent the calendar year during which the evaluation was originally initiated, and the next three digits are assigned sequentially to each event during that year. The sequence character after the two-digit individual worker number indicates that the evaluation report is either the original (A) or a revision (B, C, D, etc). For example, the evaluation number "87005-02A" identifies the evaluation as the original version issued for individual number 2, who was involved in the fifth potential internal exposure event of 1987.

Evaluation numbers are assigned by the HIDP technician upon notification that an assessment will be performed. The evaluation number may also be referred to as the Dose Evaluation Management System (DEMS) number, or the REX database INTERTRAC number.

The following information is provided in the evaluation report:

- The evaluation number.

- The worker's name, payroll or HID number, and social security number.

- The date or period of exposure (actual or assumed).

- $\quad$ The area and building where the exposure occurred or is assumed to have occurred.

- A summary of the exposure scenario, if known.

- Mode of intake (actual or assumed).

- Contractor statement of appropriate source term radionuclides, or a concurrence with the evaluation assumptions. This item is not required for routine tritium oxide assessments, unconfirmed high routine tritium oxide assessments, unconfirmed high routine measurements or for situations with source terms well established in technical basis documentation.

- $\quad$ Radionuclides addressed by the assessment.

- Contractor statement of the measured or calculated determination of air sample representativeness if dose is to be assigned based on air sample results or DAC-hours record. (Not required if assessment is based on records from prior employer.)

The evaluation report also contains:

- A summary of data used in the assessment.

- A description of assessment methods and assumptions.

- Intake magnitude and identity.

- Committed effective dose. 
- The committed equivalent dose to organs or tissues meeting the criteria in Section 2.1.2 references, as required.

- The author's name and signature and the peer reviewer's name and signature.

Table 3.2. Information Supporting the Internal Dose Assessment

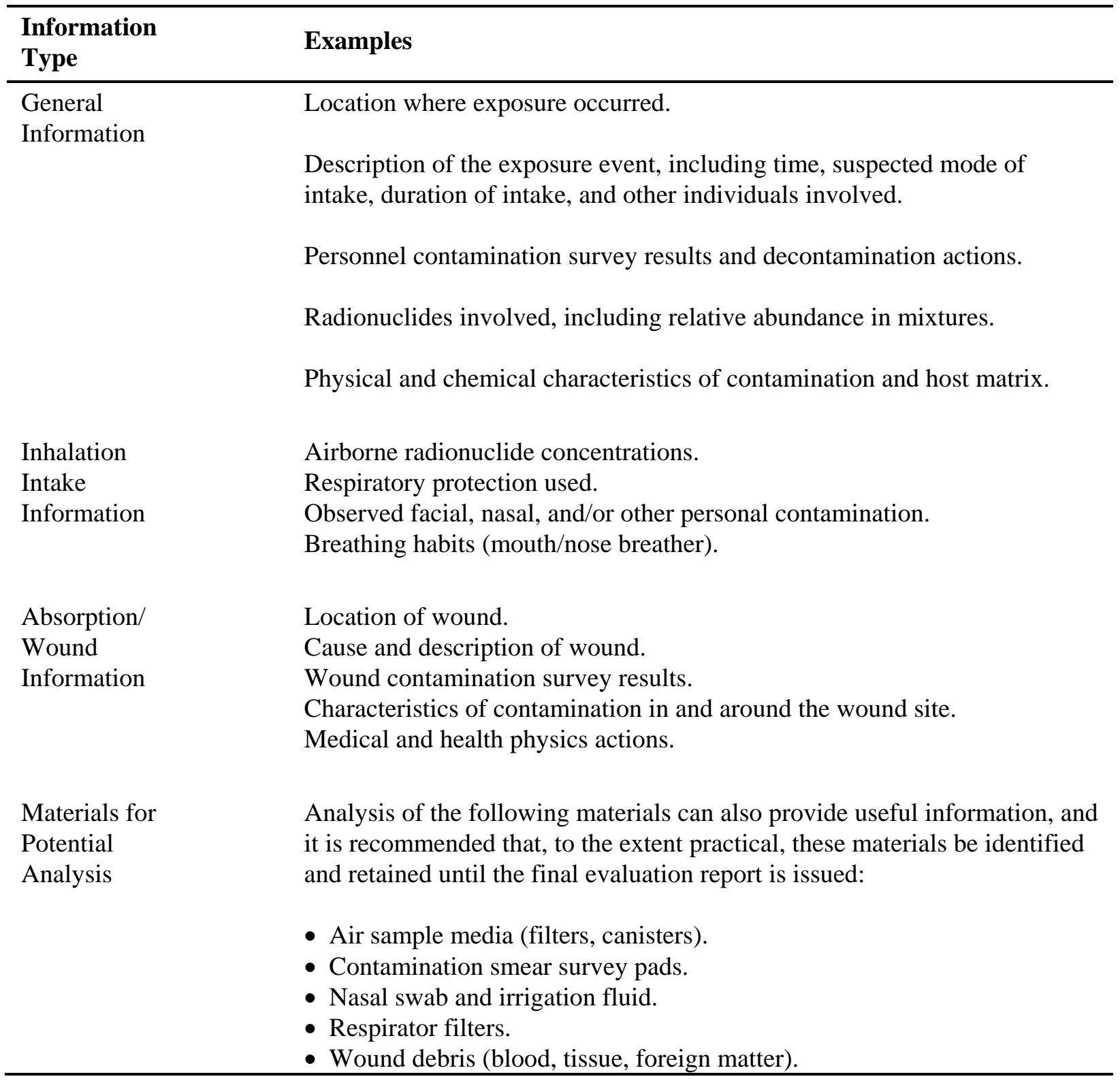

\subsubsection{Assessment Reporting}

Summary Letter

A letter summarizing the conclusions of the evaluation is prepared for each evaluation. Summary letters are sent either directly to the worker or to Field Dosimetry, depending on the circumstances of the evaluations and the conclusion. 


\section{Sent Directly to Worker}

The summary letter is sent by the HIDP directly to the worker, with a copy to Field Dosimetry, when it is considered unlikely that the worker will have questions about the evaluation or conclusion.

Examples of such conditions include the following:

- $\quad$ No occupational dose was assessed.

- The evaluation was a reassessment and Field Dosimetry concurs with addressing the cover letter to the subject.

- Dose was assigned without obtaining confirming bioassay measurements.

- The intake occurred prior to Hanford employment. Field Dosimetry will be notified if the committed effective dose exceeds 50 mrem.

The letter should be sent to the worker's Hanford plant address. If there is no plant address or the worker has terminated Hanford employment, the home address will be used. Field Dosimetry will contact the worker's supervisor if that appears to be necessary. Any worker contacting PNNL HIDP with questions concerning the evaluation will be referred to Field Dosimetry.

Sent to Field Dosimetry for Communication to Worker

The summary letter is sent to Field Dosimetry, for subsequent communication to the worker by Field Dosimetry, when it is considered likely that discussion about the evaluation may be needed or that the worker may have specific questions. Examples of such conditions include the following:

- The evaluation assigns occupational dose associated with Hanford employment.

- The evaluation is for a Hanford visitor.

- Summary letters will be sent to the event contractor field dosimetry organization if the worker's potential intake occurred in a facility not operated by the worker's employer. A copy of the letter will also be provided to the worker's field dosimetry organization.

\section{Summary Letter Contents}

The summary letter contains the following information:

- $\quad$ The worker's name and payroll number.

- The date or period of the intake.

- The area and building where the intake occurred.

- The intake magnitude and identity.

- The assigned committed effective dose and pertinent committed organ doses.

- Recommendations for further follow-up sampling. 
A copy of the evaluation report will be provided to Field Dosimetry upon request. Hanford employees seeking a copy of their evaluation reports should request it through Field Dosimetry. Requests from former Hanford employees are processed by the HRRP staff.

\subsection{Dose Assessment Methods}

Program practices, discussed in Chapter 2.0, provide general statements regarding the operation of the HIDP. Technical considerations for the internal dose assessment process are covered in PNNL-MA-860. The methods and approaches used for investigating, evaluating, and reporting internal dose assessments are summarized in this section. These methods are used unless available information points to a more appropriate method or assumption. If methods and techniques other than those discussed here are used, they are to be documented in the evaluation report.

\subsubsection{General Approach}

Intakes are preferably assessed based on bioassay measurement results. However, if bioassay data are unobtainable, the assessment is performed using any relevant information that is available.

Direct (in vivo) measurements of internal content and retention patterns are preferred to indirect (excreta) methods that require the use of excretion functions and biokinetic models.

Assumptions used in the dose assessment process should be conservative but realistic. Caution should be exercised when multiple conservative assumptions could compound errors and result in an unrealistic estimate. Assumptions should not be made when actual data or information are available.

The expected baseline from any past intake must be factored into evaluations of any new intake.

When the actual intake time or period is not known, it is necessary to identify the probable intake date(s). This may be done by considering available evidence, such as air monitoring results, contamination surveys, operating periods, and previous bioassay measurement results. After the intake time is narrowed to a probable time period, it is assumed that an acute intake occurred at the midpoint of that period. If the evidence suggests that a chronic intake is more reasonable, it is assumed that the chronic intake occurred uniformly throughout the probable exposure period.

If the mode of intake is not known, it is assumed that the intake was by inhalation.

Currently, there is no standardized method for quantifying uncertainties in internal dose assessments. Numerous factors in the internal dose process can result in a change of $50 \%$ or more, e.g., the number of bioassay measurements taken, assumed intake date, particle size, solubility in lung fluid, solubility in blood at the wound site, actual versus reference excreta levels, organ sizes, clearance and retention halftimes, accuracy of corrections for skeletal, liver, or lymph system contents, differences in metabolic behavior between ionic material and material bound in a parent-material matrix, etc. The evaluation philosophy is to weigh the merits of default assumptions versus obtaining additional data on a case-bycase basis. Default assumptions are used when no other data are available.

\subsubsection{Evaluating Lung Dose for Inhalation Exposures}

Potential lung doses from inhalation exposures must be considered, even if direct in vivo measurements do not identify the nuclide in the lung. In such cases, assessments of the lung burden and 
dose should be performed using alternative techniques, such as excreta measurements, air samples, or other available information. However, the assessed activity in the lung should not exceed the reported minimum detectable activity (MDA) level of the chest measurement.

\subsubsection{Solubility and Particle Size Assumptions}

Input terms for biokinetic models should be based on field data and on bioassay measurements that are specific to the intake being evaluated. If the model requires input values that cannot be reasonably obtained, appropriate conservative assumptions should be used. The default particle size for the biokinetic model of the respiratory tract is 5- $\mu \mathrm{m}$ AMAD (activity median aerodynamic diameter for workers). The transportability characteristics should be determined based on the known or probable chemical and physical makeup of the material. The evaluation should include appropriate discussion of the rationale for choosing these parameters.

\subsubsection{Radionuclides Included in the Assessment}

The internal dose assessment should consider all radionuclides that are identified by in vivo or field measurements, as well as additional radionuclides that are reported by Field Dosimetry as being present or that are known to be present from previous experience. If field measurements indicate gross radioactivity levels only (gross beta, gross alpha), appropriate radionuclide representations of these levels should be used, based on a conservative evaluation of radionuclides potentially present. Reference radionuclide mixtures developed in PNNL-MA-860 can be considered applicable in this situation. Field Dosimetry will provide characterization data appropriate for assessing confirmed Hanford intakes, or concur in the characterization used for the assessment. This characterization shall be documented in the evaluation.

\subsubsection{Assessment of Exposures of Localized Tissue}

For long-term radionuclide depositions in localized tissues, such as in regional lymph nodes or at wound sites, the quantity of the radionuclide deposited in the tissue and its projected clearance half- time are assessed and documented. The assessment becomes part of an individual's radiation exposure file, but it is not used for determining compliance with either stochastic or deterministic dose limits. Additional discussion is provided in Section 2.5 of the Methods and Models of the Hanford Internal Dosimetry Program (PNNL-MA-860).

\subsubsection{Biokinetic Models}

Biokinetic models for specific applications are discussed in the Methods and Models of the Hanford Internal Dosimetry Program (PNNL-MA-860). The standardized models summarized below are used for initial evaluation of internal exposure. These models are applied to final evaluations unless a more appropriate model is determined to apply to the specific exposure situation.

Respiratory Tract Model

The Human Respiratory Tract Model presented in ICRP Publication 66 (1994) is used to evaluate retention and elimination of inhaled particulates by the respiratory system. The ICRP 30 respiratory tract model was used prior to January 1, 2010.

Gastrointestinal Tract Model

PNL-MA-552 Section 3.0

Issued for implementation effective 01/01/2010

Page 12 of 20

Supersedes: 10/03 
The model for the gastrointestinal (GI) tract presented in ICRP Publication 30 (1979) and ICRP Publication 78 (1997) is used to evaluate retention and absorption of materials by the stomach and small and large intestines.

\section{Systemic Retention and Excretion Models}

The systemic retention and excretion models used are those described in Methods and Models of the Hanford Internal Dosimetry Program (PNNL-MA-860). Generally, the models used are based on the concepts and models of the ICRP. Deviations from these models can be made if data warrant.

\subsubsection{Computer Programs Used for Dose Calculations}

The computer program codes listed in Table 3.3 are consistent with the biokinetic retention and/or excretion models discussed previously. The codes are used in the assessment process unless another approach is determined to be more appropriate for the specific situation. Each of the computer programs is documented in the HIDP records.

Table 3.3. Computer Programs Used for Dose Calculations

\begin{tabular}{ll}
\hline $\begin{array}{l}\text { Computer } \\
\text { Program } \\
\text { Code Name }\end{array}$ & Purpose \\
\hline IMBA & $\begin{array}{l}\text { IMBA Professional Plus }{ }^{\mathrm{TM}} \text {. A comprehensive internal dosimetry } \\
\text { code implementing ICRP } 60 \text { concepts, the ICRP } 66 \text { respiratory } \\
\text { tract model and advanced recycling biokinetic models of ICRP. }\end{array}$ \\
CINDY & $\begin{array}{l}\text { A dosimetry code specifically developed by DOE for } \\
\text { implementing the ICRP-30 techniques and models. The code was } \\
\text { the primary HIDP internal dosimetry code from } 1992 \text { to } 2010 .\end{array}$ \\
AMERIN & $\begin{array}{l}\text { A code for calculating biological half-life and ingrowth for } \\
\text { mixtures of }{ }^{241} \text { Am and }{ }^{241} \text { Pu. }\end{array}$ \\
Pu.EXE & $\begin{array}{l}\text { Utility for determining isotopic composition of aged plutonium } \\
\text { mixtures }\end{array}$ \\
\hline
\end{tabular}

\subsubsection{Graded Approach To Dose Assessments}

The HIDP uses a graded approach to the data collection and assumptions associated with internal dose assessments. Simple assessments associated with low doses (typically less than $100 \mathrm{mrem}$ ) may be based on limited bioassay data (e.g., one or two measurements) using the standard assumptions described in Methods and Models of the Hanford Internal Dosimetry Program (PNNL-MA-860). As doses increase above 100 mrem committed effective dose, increased data collection effort is warranted to verify the assumptions and models and to choose between alternative parameter values or to select optimum values.

Typically, bioassay measurements are obtained to determine lung, whole body, or wound site retention, systemic excretion (urine samples), and non-systemic excretion (fecal samples). In addition, specific data on material or aerosol characterization may also be sought.

Guidance developed by the IDEAS Project of the European Union (Doerfel, et al 2006) and shown in 
Table 3.4 is informative with regard to the possible extent of measurements warranted for dose assessments. The suggested measurements of Table 3.4 serve as examples; the HIDP and event contractor determine the actual measurements to be obtained for Hanford cases, giving consideration to factors such as the value of the measurement to the assessment, imposition on the worker, and cost.

In addition to bioassay data, the In Vivo Exam Questionnaire (Exhibit 3.2) is obtained from workers showing unusual whole body or lung count results. This questionnaire provides an initial indication from the worker regarding the possible source of detected radioactivity. Additional information from the contractor supplements this questionnaire and guides the decision of whether or not further investigation (i.e., a potential intake evaluation) is required.

Exhibit 3.3 provides flowchart guidance for determining whether or not a bioassay measurement result represents an occupational or nonoccupational intake. An HIDP dosimetrist should be contacted regarding conclusions based on this flow chart.

Table 3.4. European Union Guidance for Number and Type of Data Required for Assessment of Dose for Some Selected Radionuclides and the Respective Monitoring Procedures.

\begin{tabular}{|c|c|c|c|c|c|c|c|}
\hline \multirow[b]{3}{*}{$\begin{array}{l}\text { Radio- } \\
\text { nuclide }\end{array}$} & \multirow[b]{3}{*}{$\begin{array}{c}\text { Type of } \\
\text { Monitoring }\end{array}$} & \multicolumn{6}{|c|}{ Desired Monitoring Data if Facilities Available } \\
\hline & & \multicolumn{2}{|c|}{$E(50)<100$ mrem } & \multicolumn{2}{|c|}{$\begin{array}{l}E(50) \text { range is } \\
100 \text { to } 600 \text { mrem }\end{array}$} & \multicolumn{2}{|c|}{$E(50)>600$ mrem } \\
\hline & & Number & $\begin{array}{c}\text { Time } \\
\text { range } \\
\text { (d) }\end{array}$ & Number & $\begin{array}{c}\text { Time } \\
\text { range } \\
\text { (d) }\end{array}$ & Number & $\begin{array}{c}\text { Time } \\
\text { range } \\
\text { (d) }\end{array}$ \\
\hline${ }^{3} \mathrm{H}$ & Urine & 1 & - & 3 & 14 & 5 & 14 \\
\hline \multirow[t]{2}{*}{${ }^{60} \mathrm{Co}$} & Whole Body & 1 & - & 3 & 30 & 5 & 30 \\
\hline & Urine & - & - & - & - & 3 & 30 \\
\hline \multirow[t]{2}{*}{${ }^{90} \mathrm{Sr}$} & Urine & 1 & - & 3 & 30 & 3 & 30 \\
\hline & Feces & - & - & - & - & 3 & 30 \\
\hline \multirow[t]{2}{*}{${ }^{131} \mathrm{I}$} & Thyroid & 1 & - & 3 & 7 & 3 & 7 \\
\hline & Urine & - & - & - & - & 3 & 7 \\
\hline${ }^{137} \mathrm{Cs}$ & Whole Body & 1 & - & 3 & 90 & 5 & 90 \\
\hline \multirow[t]{3}{*}{${ }^{235} \mathrm{U}$} & Urine & 1 & - & 2 & 30 & 5 & 60 \\
\hline & Feces & - & - & 2 & 30 & 3 & 60 \\
\hline & Lungs & - & - & 2 & 30 & 3 & 60 \\
\hline \multirow[t]{2}{*}{${ }^{239} \mathrm{Pu}$} & Urine & n.a. & - & 3 & 30 & 5 & 60 \\
\hline & Feces & & & 3 & 30 & 5 & 60 \\
\hline \multirow[t]{4}{*}{${ }^{241} \mathrm{Am}$} & Urine & n.a. & - & 2 & 30 & 3 & 60 \\
\hline & Feces & & & 2 & 30 & 3 & 60 \\
\hline & Lungs & & & 2 & 30 & 2 & 180 \\
\hline & Skeleton & & & - & - & 2 & 180 \\
\hline
\end{tabular}

\subsubsection{Internal Dose Assessment to the Embryo/Fetus}

The internal dose to the embryo/fetus considers contributions from radionuclides deposited in the embryo/ fetus and equivalent dose arising from radionuclides deposited in the declared pregnant woman. Unless better information is available, the dose calculation methods described in ICRP Publication 88 (ICRP 2002) shall be used. 


\subsection{Good Practice Recommendations for Field Dosimetry}

Monitoring and assessing intakes at Hanford are accomplished through the mutual effort and cooperation of the HIDP and Field Dosimetry. These activities are complementary; that is, the responsibilities of both the contractor and HIDP must be fulfilled. The following recommendations are suggested by HIDP as general guidance for Field Dosimetry administration of monitoring programs. In addition to this general guidance, HIDP provides specific guidance and technical support as needed.

\subsubsection{Identifying Routine Bioassay Monitoring Needs}

The following good practice recommendations cover activities that are required for a complete internal dosimetry program:

- Identify the routine bioassay monitoring needs of individuals and arrange for a routine bioassay monitoring program that is responsive to these needs. The bioassay monitoring program should be radionuclide-specific; that is, the program should be established by radionuclide and exposure scenario, rather than by measurement type. General guidance on the needs of the bioassay monitoring program is provided in Chapter 5.0 of this manual. HIDP can recommend measurement types to ensure the inclusion of radionuclides of concern.

- Apprise HIDP of the radiological conditions in facilities. Include identification and physical and chemical characteristics of the radionuclides, as well as the potential internal exposure situations that exist.

- Contact HIDP as needed for specific guidance and support in the setup and operation of the routine bioassay monitoring program.

- In cooperation with HIDP, identify the radionuclides for which bioassay monitoring is not performed or is not adequate, and ensure that appropriate monitoring of these radionuclides (using other techniques) is provided. This could apply, for example, to short-lived radionuclides that cannot be reliably detected through routine bioassay monitoring.

- Maintain procedures for collecting workplace and personnel monitoring data, evaluating the data, documenting the results, and maintaining records.

\subsubsection{Identifying Potential Intakes}

Identify potential intake events and report these promptly to HIDP. Assessments of internal dose are more accurate and can be performed with less expense if the intake time is known, if follow-up samples are collected shortly after intake, and if field data are available regarding the nature and characteristics of the exposure. Special bioassay measurements should be obtained if a worker incurs a potential intake of 0.02 ALI in an incident or over a short period of time.

\subsubsection{Managing Internal Dose}

Good practice in managing internal dose includes adhering to the following recommendations:

- Avoid potential intakes to workers until baseline bioassay measurements have been performed and prior exposure history has been reviewed. 
- Consider the impact of intakes on allowable external exposure for workers with internal doses.

- Consider a work restriction if the committed dose from intakes significantly impacts administrative control levels.

- Consider a temporary work restriction to avoid exposure to similar radionuclides if such exposures could adversely affect an ongoing investigation of a potential intake.

- $\quad$ Provide long-term follow-up bioassay measurements for workers with significant internal depositions. These measurements track the retention of the radionuclide and establish a baseline against which to evaluate possible future exposures.

- Inform the worker of the status of the follow-up investigation and dose assessment.

\subsection{Reference}

Doerfel, H., A. Andrasi, M. Bailey, V. Berkovski, E. Blanchardon, C.M. Castellani, C. Hurtgen, B. LeGuen, I. Malatova, J. Marsh, and J. Stather. 2006. “General Guidelines for Estimation of Committed Effective Dose from Incorporation Monitoring Data. Project IDEAS - EU Contract No. FIKR-CT200100160.” FZKA 7243. Forschungszentrum Karlsruhe GmbH, Karlsruhe, Germany.

International Commission on Radiological Protection (ICRP). 1979. "Limits for intakes of radionuclides by workers.” ICRP Publication 30, Part 1.), Annals of the ICRP, 2:3-4, Pergamon Press, New York.

International Commission on Radiological Protection (ICRP). 1994. "Human respiratory tract model for radiological protection.”. (ICRP Publication 66), Annals of the ICRP, 24:1-3, Pergamon Press, New York.

International Commission on Radiological Protection (ICRP). 1997. "Individual Monitoring for Internal Exposure of Workers”. (ICRP Publication 78), Annals of the ICRP, 27:3-4. Pergamon Press New York.

International Commission on Radiological Protection (ICRP). 2002. "Doses to the embryo and fetus from intakes of radionuclides by the mother. Corrected Version, May 2002”. (ICRP Publication 88), Annals of the ICRP, 31:1-3, Pergamon Press, New York.

Pacific Northwest National Laboratory (PNNL). Methods and Models of the Hanford Internal Dosimetry Program, PNNL-MA-860. Richland, Washington. (Internal manual.) Copy maintained in the HIDP files and available from the HIDP Manager or online by searching, PNNL-15613 @

http://www.pnl.gov/publications/. 
Exhibit 3.1. Internal Dose Evaluation Report Form

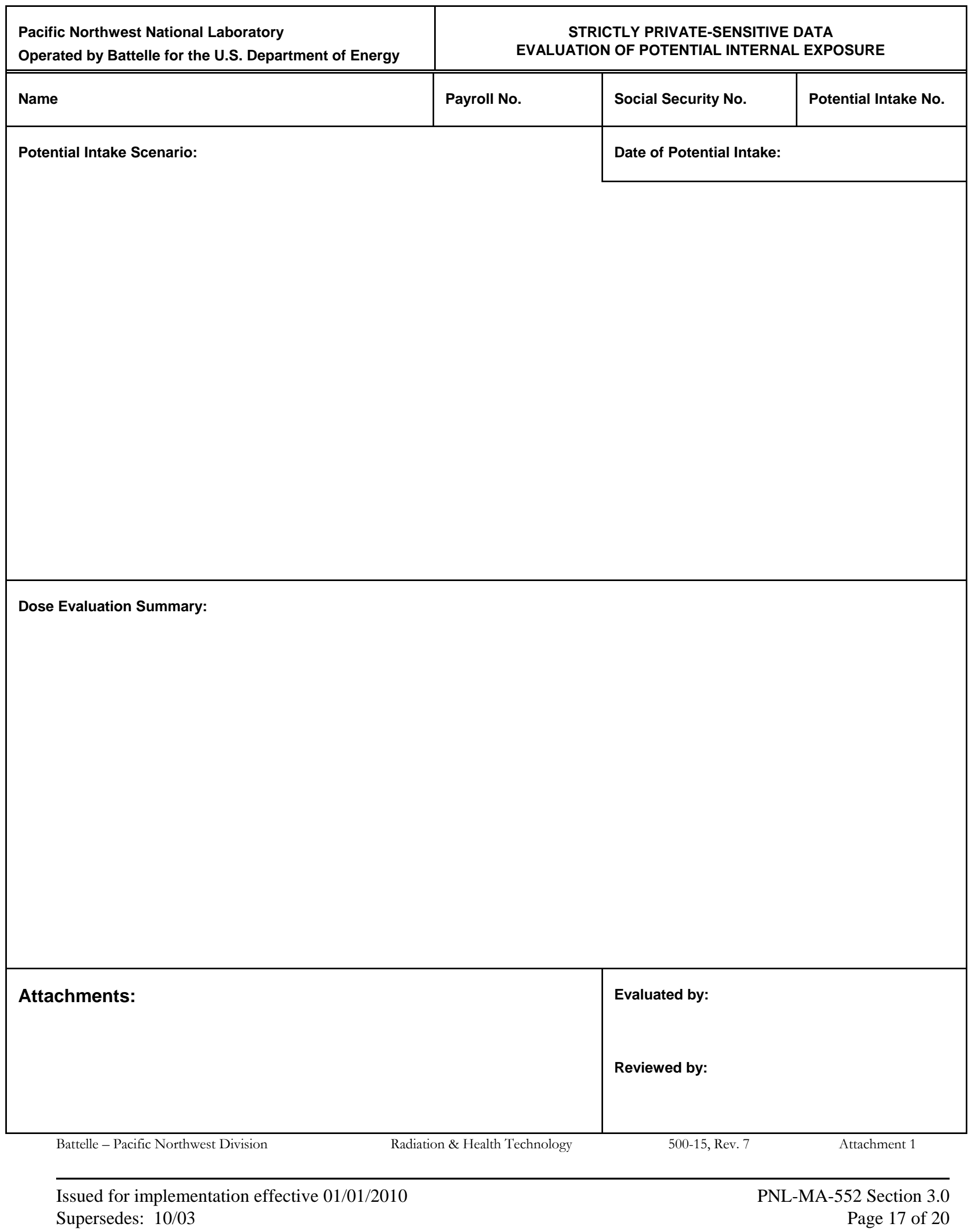


Exhibit 3.2. In Vivo Exam Questionnaire

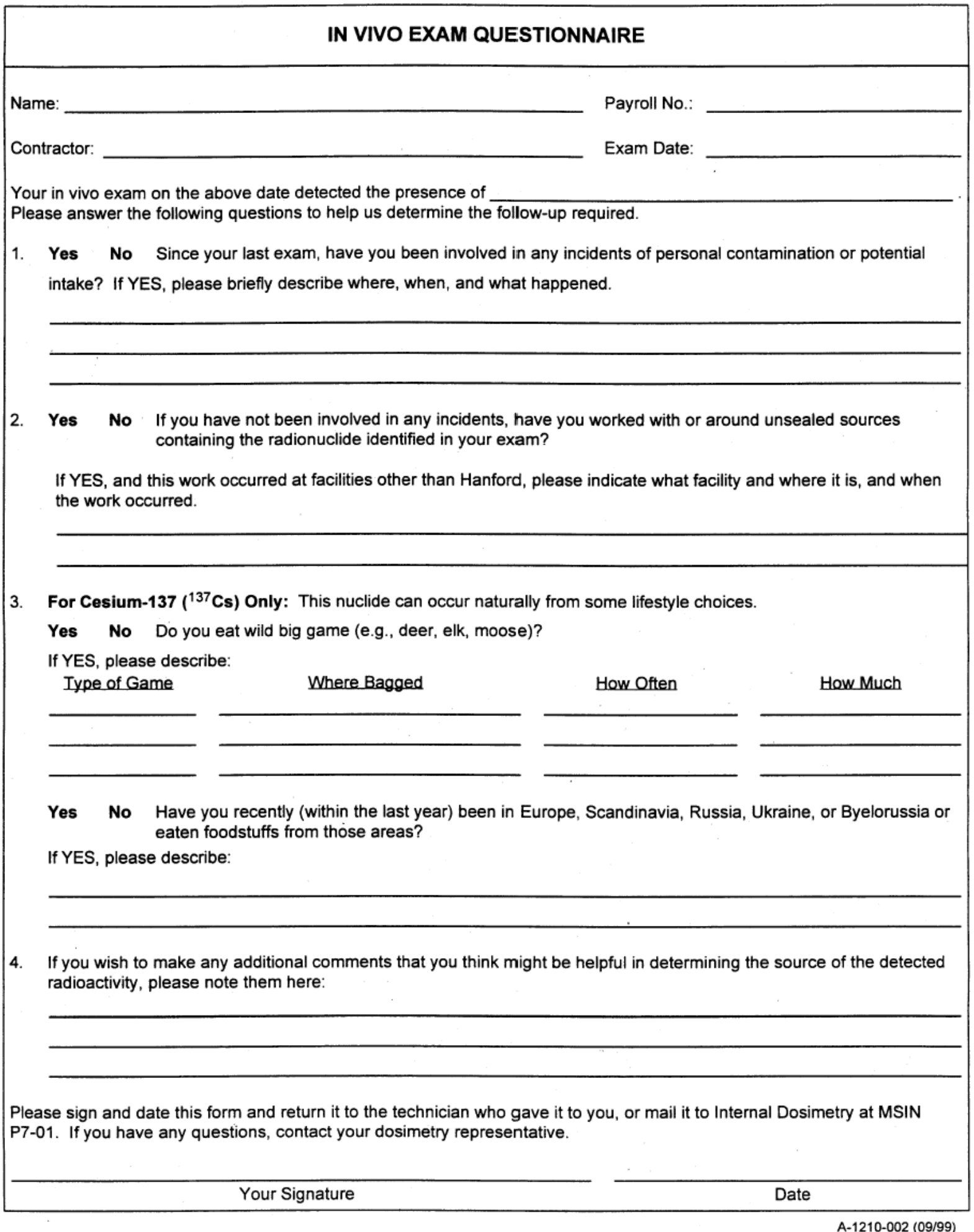

A-1210-002 (09/99) 
Exhibit 3.2. In Vivo Exam Questionnaire (Cont.)

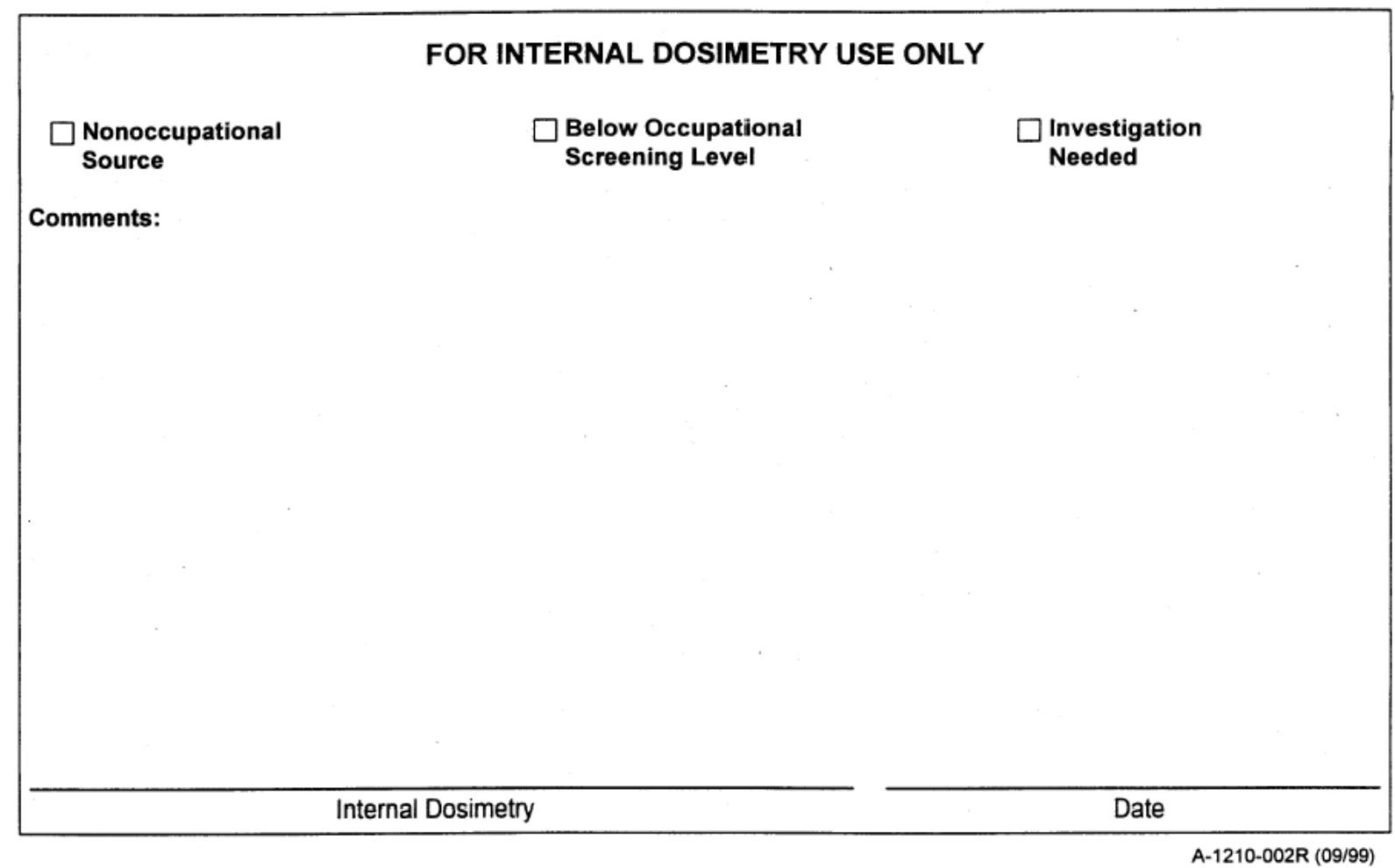


Exhibit 3.3. Determining Occupational and Nonoccupational Intakes*

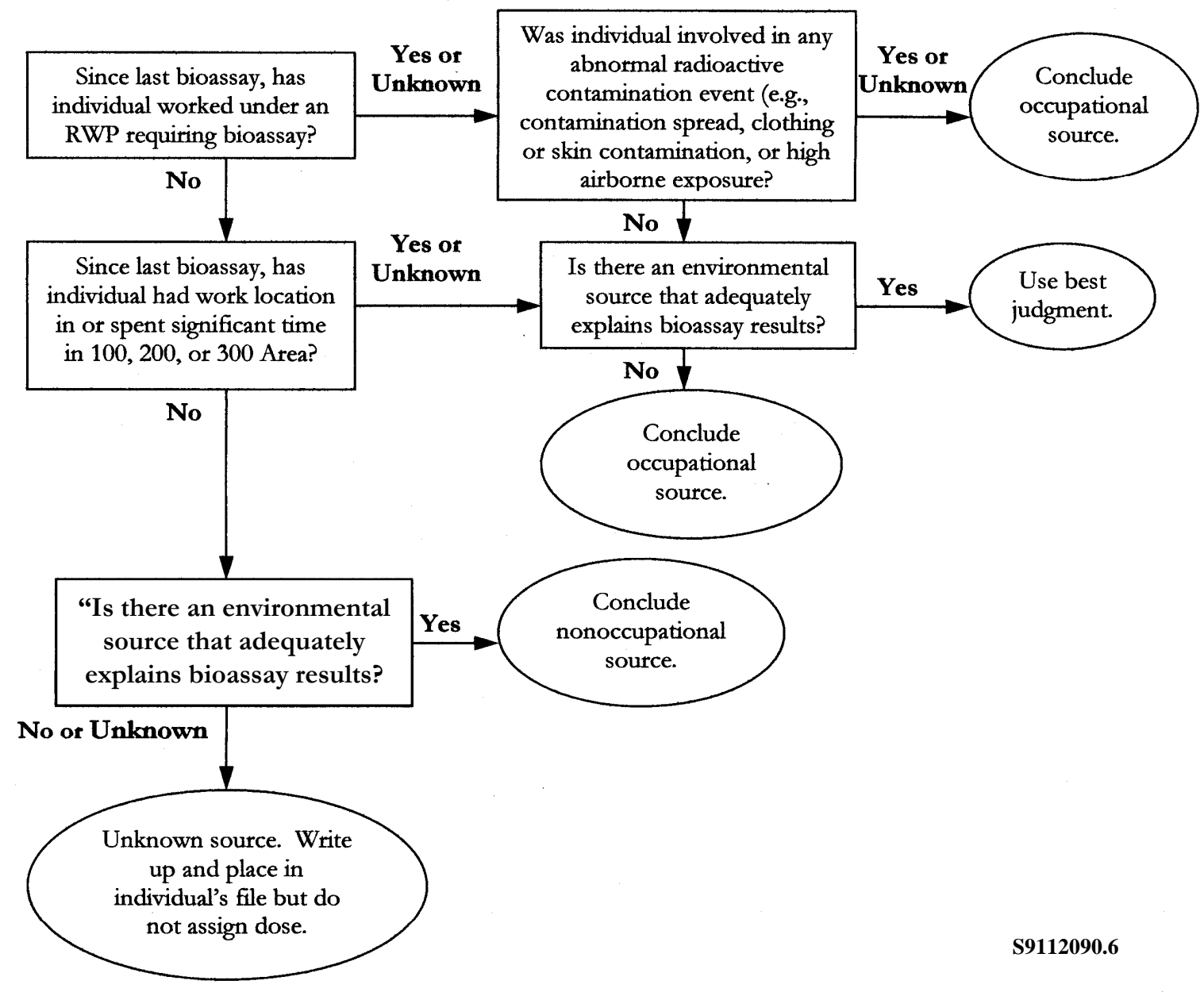

*Does not apply to ${ }^{241} \mathrm{Am}$ or plutonium because of possible increases over long time periods. 


\section{HANFORD INTERNAL DOSIMETRY PROGRAM MANUAL PNL-MA-552}

\section{SECTION 4.0, RECORDING AND REPORTING INTERNAL DOSES}

Issued for implementation on $01 / 01 / 2010$

Supersedes: $12 / 2006$

Use Category: Not applicable

\section{Approval Signatures:}

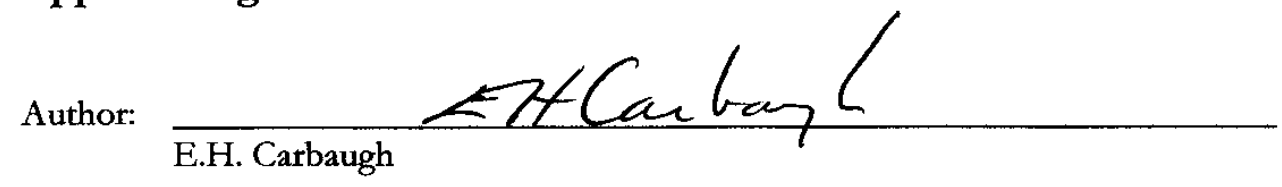

Manager:

\section{Reviewer Signatures:}

Reviewer \# 1:

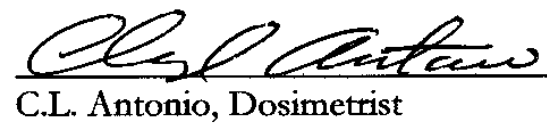

Approved by the Hanford Personnel Dosimetry Advisory Committee on June 4, 2009. 


\section{Contents}

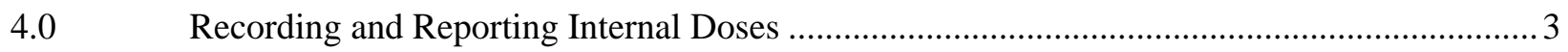

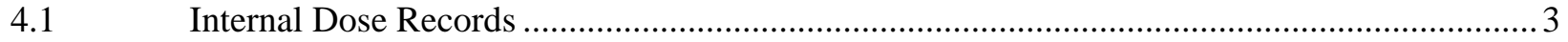

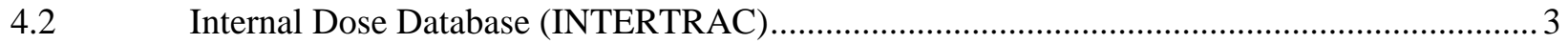

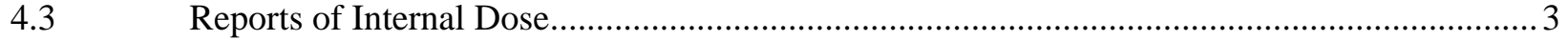

4.4 Requests for Internal Dosimetry Records....................................................................... 4 


\subsection{Recording and Reporting Internal Doses}

Reports of occupational effective dose are required as specified in 10 CFR 835, and in DOE Order 231.1A and Manual 231.1-1A. The occupational effective dose is composed of the dose received from external sources of radiation and the committed effective dose from intakes of radionuclides. This chapter describes the recording and reporting of the internal dose component, as performed by the Hanford Internal Dosimetry Program (HIDP). Assessed internal doses are provided to the Hanford Radiation Records Program (HRRP). After compiling the data, the HRRP prepares the occupational dose reports.

\subsection{Internal Dose Records}

The primary record of internal dose is the internal dose evaluation report. Section 3.2.2 ("Documentation") describes the contents of this report, which is issued for each assessed internal exposure. Completed reports are maintained by the HRRP in the radiation exposure files.

\subsection{Internal Dose Database (INTERTRAC)}

Dose information from Internal Dose Evaluation Reports is maintained by the HRRP in the Internal Dose Tracking System (INTERTRAC) subset of the REX computer database. INTERTRAC contains committed organ and effective dose data, as well as summary intake information from the Internal Dose Evaluation Report for each assessed intake. This information is used to generate dose summaries for tracking and reporting occupational doses to individuals. REX provides online access to recorded internal doses for all active Hanford workers. Each contractor/DOE office has access to files for its own employees.

\subsection{Reports of Internal Dose}

\section{Evaluation Summary}

Summary letters of assessed internal dose are issued upon completion of the Internal Dose Evaluation Report, as discussed in Section 3.2.3.

\section{Dose Summaries}

Annual occupational dose reports (i.e., report cards), reports of occupational dose for terminating employees, and reports to the DOE Radiation Exposure Monitoring System (REMS) are provided by HRRP. Special requests for internal dosimetry information may be made to the HIDP.

\section{Chronic Exposure}

Some Hanford workers may be considered to be chronically exposed to radionuclides during the course of their work. Typically, these are individuals working with tritium or uranium of low or depleted enrichment. Bioassay samples for these workers are collected throughout the year. A final internal dose assessment is issued at the end of each calendar year for those workers having routine bioassay results that suggest a committed effective dose could exceed 10 mrem. 
Throughout the year, the routine bioassay measurements are reviewed and the contractor/DOE office is advised if there is an indication that the committed effective dose from chronic intakes could exceed 100 mrem.

\subsection{Requests for Internal Dosimetry Records}

Occupational radiation exposure records are controlled according to the requirements and provisions of the Privacy Act (1974) and ANSIIHPS N13.6, Practice for Occupational Radiation Exposure Records Systems (HPS, 1999). Access to the records is provided through the HRRP, as follows:

- Current employees may contact their company's radiation protection representative, who will arrange to obtain the requested records.

- Individuals may request their records either in person or by mail. Verbal requests are not honored.

- Employers requesting records of current or former Hanford workers should contact the HRRP.

- Requests by the U.S. Transuranium and Uranium Registries should be made by contacting the HRRP.

- If none of the above apply or are practical, contact the DOE Privacy Act Officer, who will prepare the proper paperwork and submit the request to the HRRP.

In the above cases, the following items are required before records can be released:

- An individual appearing in person must provide a driver's license or other photographic identification and sign a release form that will be provided by the HRRP. This signed release is entered into the individual's record.

- An individual requesting records by mail must provide in a notarized written request his/her name, social security number and/or payroll number, and signature. This written request must define exactly which records are needed and the address to which they should be sent. Verbal requests are not honored.

- Employer and U.S. Transuranium and Uranium Registries requests must be accompanied by a signed radiation exposure release-of-information form.

\subsection{References}

5 USC 552a. 1974. The Privacy Act of 1974, as amended, Public Law 93-579.

10 CFR 835. 2008. U.S. Department of Energy, Occupational Radiation Protection. U.S. Code of Federal Regulations. Accessed 01/23/2009 at http://www.gpoaccess.gov/cfr.

Health Physics Society (HPS). 1999. American National Standard Practice for Occupational Radiation Exposure Records Systems. ANSI $\backslash H P S$ N13.6-1999, McLean, Virginia.

U.S. Department of Energy (DOE). 2004. “Environment, Safety and Health Reporting.” DOE O 231.1A Chg 1. U.S. Department of Energy, Washington, D.C. Accessed 07/23/2009 at http://www.directives.doe.gov. 
U.S. Department of Energy. 2007. “Environment, Safety and Health Reporting Manual.” DOE M 231.11A Chg 2.. U.S. Department of Energy, Washington, D.C. Accessed 07/23/2009 at http://www.directives.doe.gov 


\section{HANFORD INTERNAL DOSIMETRY PROGRAM MANUAL}

PNL-MA-552

\section{SECTION 5.0, BIOASSAY MONITORING}

Issued for implementation on 01/01/2010

Supersedes: 04/2007

\section{Use Category: Not applicable}

\section{Approval Signatures:}

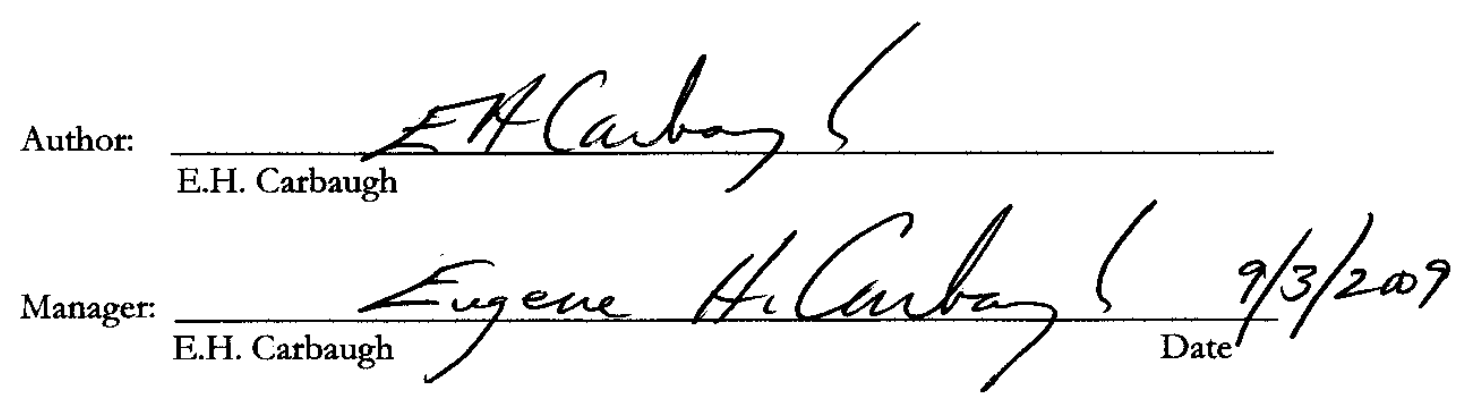

Reviewer Signatures:

Reviewer \#1:

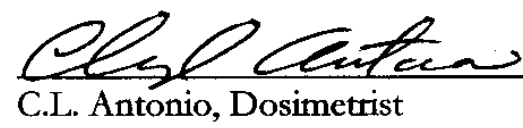

Approved by the Hanford Personnel Dosimetry Advisory Committee on June 25, 2009. 


\section{Contents}

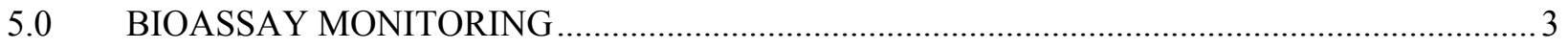

5.1 RECOMMENDED BIOASSAY PROGRAMS FOR TYPICAL APPLICATIONS...................... 3

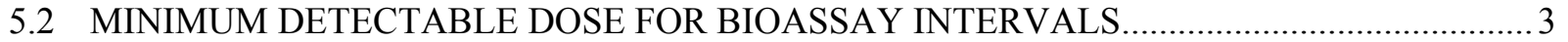

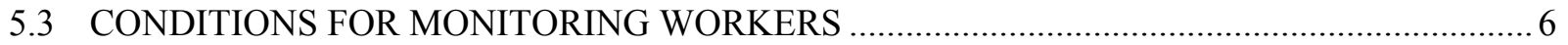

5.3.1 Derived Air Concentration as a Basis for Bioassay ......................................................... 9

5.3.2 Annual Limit on Intake and Material in Process as a Basis for Bioassay Monitoring ..... 10

5.3.3 DAC-hours Exposure as a Basis for Bioassay Monitoring ............................................. 11

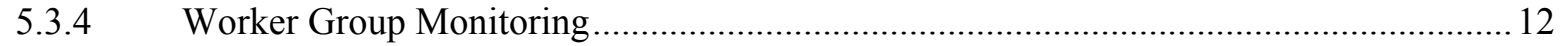

5.3.5 Environmental Restoration and Remediation Activities .............................................. 12

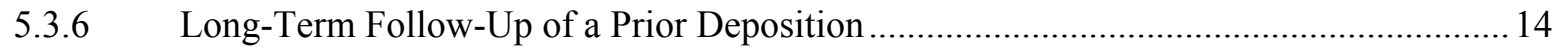

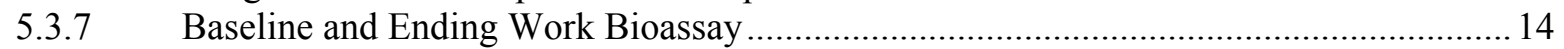

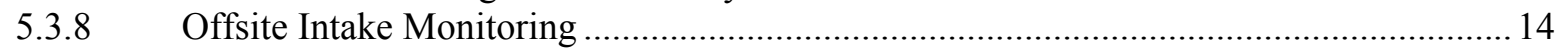

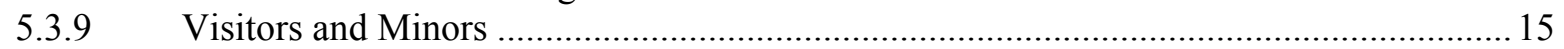

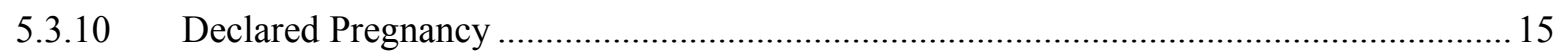

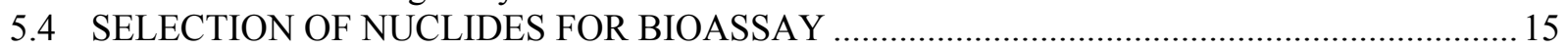

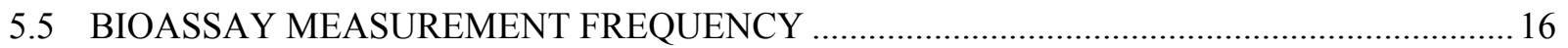

5.6 TECHNICAL DISCUSSION FOR RECOMMENDED PROGRAMS ..................................... 17

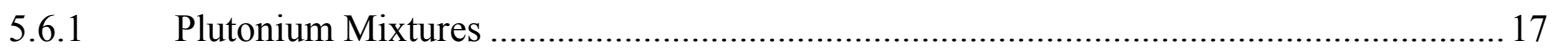

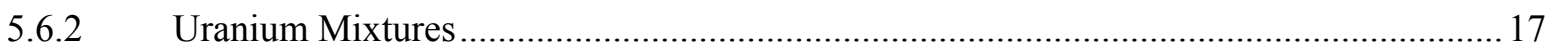

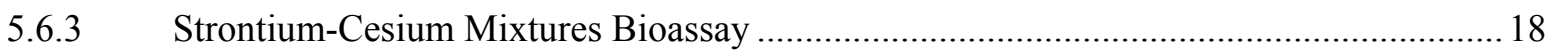

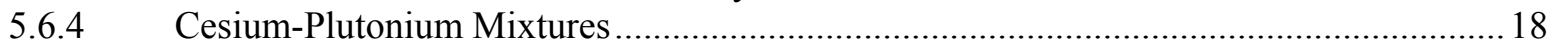

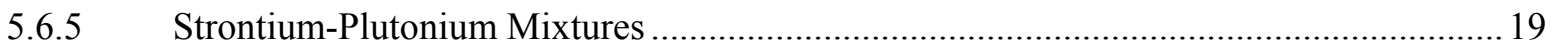

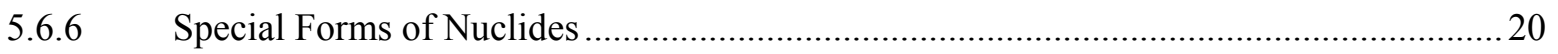

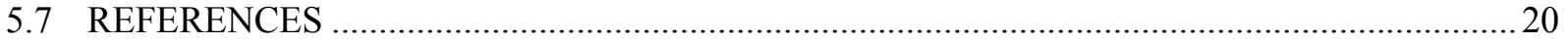




\subsection{BIOASSAY MONITORING}

This chapter recommends bioassay programs for some typical applications. In addition, it discusses who should be included in a routine bioassay monitoring program, what measurements should be performed, and at what frequency.

This chapter provides recommendations and methods to implement the requirements of 10 CFR 835 (2007). Guidance in the DOE Radiation Protection Programs Guide (2008a), the DOE Standard Internal Dosimetry (2008b) and ANSI Standards (HPS 1994, 1997, 2001) has been considered in providing the recommendations for participation in periodic, baseline, termination (or end-of-assignment), and special bioassay monitoring. Elaboration on the technical basis of some of these criteria is provided in the following subsections.

\subsection{RECOMMENDED BIOASSAY PROGRAMS FOR TYPICAL APPLICATIONS}

A summary of recommended combinations of measurements for various nuclides and situations is given in Table 5.1 for single nuclides and for some typical Hanford radionuclide combinations. This tabulation is provided as a convenience for use in a wide range of Hanford facilities, and the recommendations should meet the objectives of Section 2.3. The following sections of this chapter provide guidance and methods for designing task or facility-specific bioassay programs which may be desired as alternatives to those of Table 5.1. Optimum programs can be designed by the Hanford Internal Dosimetry Program (HIDP) based on characterized sources and potential intake patterns.

\subsection{MINIMUM DETECTABLE DOSE FOR BIOASSAY INTERVALS}

Selected minimum detectable doses (MDD) associated with various nuclides, bioassay techniques, and intervals are shown in the exhibits at the end of this chapter. For acute intakes, the analyses assume that an intake occurs on the day following a bioassay measurement and that the bioassay measurement has fallen below the minimum detectable activity (MDA) by the next scheduled measurement. For chronic intakes, a uniform daily intake pattern is assumed to exist for the monitoring interval. Dosimetry methods and factors are those described in the internal manual, Methods and Models of the Hanford Internal Dosimetry Program (PNNL-MA-860), unless otherwise noted. 
TABLE 5.1 Recommended Bioassay Programs for Typical Applications

\section{Application}

High-energy gamma emitters (e.g. ${ }^{137} \mathrm{Cs},{ }^{60} \mathrm{Co}$, $\left.{ }^{154} \mathrm{Eu}\right)$

${ }^{90} \mathrm{Sr}$ and ${ }^{137} \mathrm{Cs}$ mixtures $\left({ }^{137} \mathrm{Cs}\right.$ as an indicator for the mixture)

${ }^{137} \mathrm{Cs}$ and Pu-alpha mixtures $\left({ }^{137} \mathrm{Cs}\right.$ as an indicator for the mixture)

$\mathrm{Cs}: \mathrm{Pu}>40: 1$

Cs:Pu between 10:1 and 40:1

$\mathrm{Cs}: \mathrm{Pu}<10: 1$

$\mathrm{Pu}$ mixtures containing ${ }^{238} \mathrm{Pu},{ }^{239} \mathrm{Pu},{ }^{240} \mathrm{Pu},{ }^{241} \mathrm{Pu}$, and possibly ingrown ${ }^{241} \mathrm{Am}$. Application to either Type $\mathrm{M}$ or unknown type.

Pu mixtures consisting of high-fired Pu oxides

Relatively non-transportable uranium (mixtures of uranium metal or oxides involving predominantly absorption Type $\mathrm{M}$ or $\mathrm{S}$ forms)

Readily transportable (Type F) uranium, infrequent or acute exposure

Readily transportable (Type F) uranium, chronic
Program Description

Annual whole body count. If activity is detected on a stand-up count, a coaxial germanium count is performed. Baseline recommended.

Annual whole body count if the Sr: Cs ratio does not exceed 30:1. Supplement with biennial ${ }^{90} \mathrm{Sr}$ urinalysis at ratios above 30:1. Use of coaxial germanium whole body counter changes ratio to $40: 1$.

Annual whole body count supplemented by $\mathrm{Pu}$ urinalysis based on mixture composition.

Annual whole body count.

Annual whole body count, preferably using coaxial germanium system. Periodic program may not detect 100-mrem committed effective dose.

Consider as a Pu bioassay program supplemented with an annual whole body count. (Annual Pu urinalysis, annual or biennial chest count, and annual whole body count.) Periodic program cannot detect 100-mrem committed effective dose.

Annual Pu urinalysis (IPU code) for all Pu workers. Supplement with annual chest counts for high risk workers. No periodic program is adequate to detect 100-mrem committed effective dose. Baselines optional but strongly recommended for workers with previous potential for $\mathrm{Pu}$ or ${ }^{241} \mathrm{Am}$ exposure.

Annual $\mathrm{Pu}$ urinalysis (IPU analysis code) and annual chest counts.

Annual urine sample and chest count is adequate for acute exposure scenarios. For chronic exposure use a combination of quarterly urine samples and annual or semi-annual chest counts. No periodic program is adequate to detect 100-mrem committed effective dose for Type S uranium. Baseline needed.

Quarterly monitoring or end-of-assignment for short duration work. Mass (U238) or isotopic (IU) analysis, as appropriate for mixture. Baseline needed. 
TABLE 5.1 Recommended Bioassay Programs for Typical Applications

\section{Application}

exposure

Tritium (tritium oxide, tritiated water)

${ }^{90} \mathrm{Sr}$ (pure, i.e., without ${ }^{137} \mathrm{Cs}$ )

${ }^{90} \mathrm{Sr}$ and $\mathrm{Pu}$-alpha mixtures $\left({ }^{90} \mathrm{Sr}\right.$ as an indicator for the mixture)

$\mathrm{Sr}: \mathrm{Pu}>400: 1$

Sr:Pu between 100:1 and 400:1

$\mathrm{Sr}: \mathrm{Pu}<100: 1$

${ }^{131} \mathrm{I}$

${ }^{129} \mathrm{I},{ }^{125} \mathrm{I}$

$\mathrm{Np}$

\section{Program Description}

Biweekly or monthly urine samples obtained after a 2-day absence from workplace (kit code 7). Mass (U238) or isotopic (IU) analysis, as appropriate for mixture.

Baseline needed.

Monthly urine samples for potential chronic or multiple acute exposure, with frequency changed to biweekly if annual tritium dose will likely exceed $100-\mathrm{mrem}$. End-ofassignment sample appropriate for infrequent or shortterm $(<1$-month $)$ exposure periods.

Annual urinalysis. Biennial urinalysis is capable of meeting the 100-mrem bioassay goal but may allow intakes to go undetected for up to two years. Baseline optional.

Annual ${ }^{90} \mathrm{Sr}$ urinalysis supplemented by $\mathrm{Pu}$ urinalysis based on mixture composition.

Annual ${ }^{90} \mathrm{Sr}$ urinalysis

Annual ${ }^{90} \mathrm{Sr}$ urinalysis and consider plutonium urinalysis

Routine program may not be able to detect $100 \mathrm{mrem}$ committed effective dose.

Annual ${ }^{90} \mathrm{Sr}$ urinalysis and plutonium urinalysis.

Consider annual chest count. Routine program cannot detect 100 mrem committed effective dose.

Bimonthly coaxial germanium whole body count or monthly thyroid counts.

Annual thyroid counts for ${ }^{129} \mathrm{I}$. Semiannual thyroid counts for ${ }^{125} \mathrm{I}$. Annual thyroid counts for ${ }^{125} \mathrm{I}$ may be used when supplemented by workplace screening using a portable instrument with $\mathrm{NaI}$ detector.

The chief contributor to dose, even in high-purity $\mathrm{Np}$ situations, may likely be trace quantities of $\mathrm{Pu}$ which can be monitored by Pu bioassay. Np bioassay may not be required. Verify the specific situation with the HIDP staff. Biennial Np urinalysis can detect 100-mrem committed effective dose for pure ${ }^{237} \mathrm{~Np}$.

Use DAC-hours for routine dose assessment. Reliance 
TABLE 5.1 Recommended Bioassay Programs for Typical Applications

Application

Short half-life radionuclides (e.g., ${ }^{90} \mathrm{Y},{ }^{24} \mathrm{Na}$ )

\section{Program Description}

must be placed on workplace indicators as initiators for special bioassay. Reasonable periodic bioassay is not adequate for demonstrating compliance with dose limits. Consult with HIDP staff on specific situations. Baseline recommended.

Bioassay programs may not be feasible, thus reliance must be placed on workplace indicators and air sampling (DAC-hours) for exposure or intake assessment. Consult HIDP staff on specific applications.

\subsection{CONDITIONS FOR MONITORING WORKERS}

Personnel are required by 10 CFR 835 (2007) to participate in an internal dosimetry program, including routine bioassay, if they are likely to receive intakes in a year resulting in a committed effective dose of 100-mrem. In addition, minors and declared pregnant workers are required to participate in such programs if they are likely to receive over 50-mrem committed effective dose from intakes. Monitoring programs are required by $10 \mathrm{CFR} 835.402$.(d) to be adequately sensitive to demonstrate compliance with the dose limits of 10 CFR 835.202 [i.e., 5 rem total effective dose and 50 rem total organ equivalent dose, defined as the sum of equivalent dose to the whole body from external exposures and the committed internal doses from all intakes in a year]. The DOE Radiation Protection Programs Guide (DOE 2008a) suggests that bioassay programs should be capable of verifying doses in excess of 100-mrem committed effective dose. Although the total effective dose includes effective dose from external sources, as well as the committed effective dose, the principle design goal for dose assessment at Hanford is to be able to identify and confirm an intake resulting in a 100-mrem committed effective dose. For some circumstances (e.g., plutonium and Type $\mathrm{S}$ forms of uranium), this goal can be achieved only through special (nonroutine) bioassay monitoring that is promptly initiated by workplace indicators. Other factors must be considered in bioassay program design, and these are addressed in the objectives listed in Section 2.3.1.

\section{Periodic Bioassay}

The HIDP recommends workers to participate in periodic bioassay monitoring if one or more of the following conditions applies:

- Work requires use of a respiratory protection device for radiological protection. For this circumstance, bioassay program participation provides verification that respiratory protection was adequate.

- Work in a High Contamination Area that involves contact with or disturbance of contamination.

- Work with unencapsulated radioactive material at or exceeding $2 \%$ of the annual limit on intake (ALI) values listed in Table 5.2 $2^{(\mathrm{a})}$ or values derived by other methods described in this section. If such work is limited to observing, supervising from a distance, or entering the room without contacting the material, then bioassay is not required unless workplace monitoring indicates that a

(a) These tables provide conservative guidance for meeting the 100-mrem criterion. Improved guidance can be determined in specific cases using case-specific source information and the methods provided in this chapter. 
loss of material control occurred.

- Work with contaminated soil at or exceeding the values listed in Table $5.3^{(\text {a) }}$.

- Exposure to low-level airborne activity (below posting requirements) such that the total exposure for a year would exceed 40 DAC-hours.

End-of-assignment monitoring can be used in lieu of periodic monitoring if the work period is shorter than the periodic interval.

Additional consideration for periodic bioassay programs should be given to the following:

- Knowledge of or prior experience with the work performed or the facility involved.

- Workers who are subjected to a wide range of potential internal exposure conditions.

\section{Baseline and Termination Bioassay}

The HIDP also identifies the following specific circumstances under which baseline and termination bioassay monitoring are recommended:

- Baseline bioassay evaluation of personnel likely to receive intakes resulting in a committed effective dose greater than 100 mrem shall be conducted before they begin work that may expose them to occupational intakes. The evaluation may be limited to review of the worker's exposure history or may include baseline measurements.

- Termination or end-of-assignment bioassay monitoring is required for any worker who participated in or qualified for participation in bioassay monitoring, unless it is documented in the worker's radiation exposure file that the worker was not potentially exposed to unencapsulated material in the workplace.

- If the worker has had previous intakes which might affect interpretation of current bioassay measurements.

- Regardless of prior exposure, if there is potential for occupational intakes of material that may be present in bioassay measurements from naturally-occurring or non-occupational radioactive sources (e.g., uranium in urine).

\section{Special Bioassay}

Special bioassay is recommended by the HIDP under any of the following conditions, unless it was caused by radon progeny (also see Table 7.1):

- Facial contamination that indicates a potential for intake.

- Nasal contamination is present.

- Air monitoring indicates the potential for intakes resulting in a committed effective dose exceeding

(a) These tables provide conservative guidance for meeting the 100-mrem criterion. Improved guidance can be determined in specific cases using case-specific source information and the methods provided in this chapter. 
100 mrem.

- An unplanned intake is suspected for any other reason.

- Periodic or ending work results indicate an unexpected intake resulting in a committed effective dose of 100 mrem or more.

Special bioassay is also recommended by the HIDP if skin contamination can result in an intake. The levels of skin contamination requiring special bioassay are listed in Chapter 7 (see Table 7.1).

\section{Contractor Request}

Supplemental bioassay obtained at the discretion of the contractor and for which special review or evaluation is not required. The reason for a contractor request bioassay should be documented to the worker's personal radiation history file. Exhibit 6.2 provides an example form for documenting a contractor request bioassay. Analytical results below the screening level receive a normal result form letter. Results exceeding the screening level are subject to the potential intake evaluation process.

\section{General Recommendation Based on Committed Dose}

The HIDP recommends placing workers on a routine bioassay monitoring program if the committed effective dose from a single intake or multiple intakes in a single calendar year may exceed 100 mrem for all radionuclides.

The derived air concentration (DAC), annual limit intake (ALI), and DAC-hour concepts, as well as the nature of the work and the exposure, may be used to determine who should be included in a bioassay monitoring program. Where the DAC, ALI, and DAC-hours values are based on stochastic dose limits (i.e., stochastic DAC, SALI), the committed effective dose associated with two percent (0.02) of the DAC or SALI should be 100 mrem. If the deterministic limit-based DAC or DALI is more limiting than the stochastic limit-based value, then the corresponding committed effective dose associated with two percent of the deterministic DAC or DALI will be something less than 100 mrem. Under such circumstances, use of the deterministic DAC or DALI in lieu of the stochastic DAC or SALI provides a conservative basis for bioassay monitoring actions.

Values of stochastic and deterministic ALIs for selected nuclides of common interest at Hanford are shown in Table 5.2, along with the DACs tabulated in 10 CFR 835 Appendix A. ALIs for other nuclides can be derived by dividing the 5-rem effective dose limit or the 50-rem single organ or tissue dose limit by the appropriate dose coefficient. The following subsections provide guidance for applying these concepts and conditions to bioassay monitoring. 
TABLE 5.2. Stochastic and Deterministic Annual Limits on Intake (ALI) and Derived Air Concentrations (DAC) for Selected Radionuclides of Concern at Hanford, Based on Inhalation of 5- $\mu \mathrm{m}$ AMAD Particles.

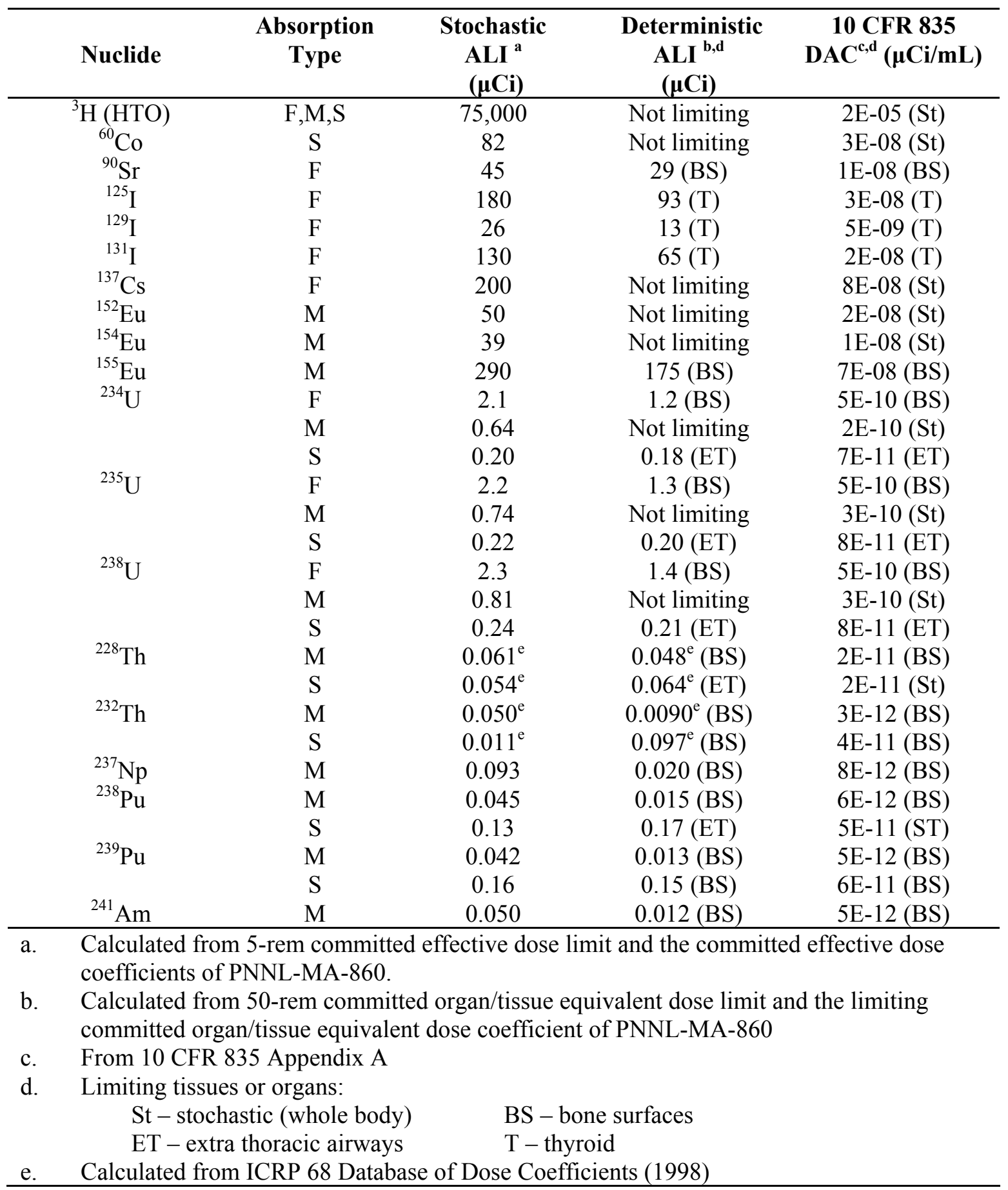

\subsubsection{Derived Air Concentration as a Basis for Bioassay}

Long-Term Chronic Exposure

A worker should be placed on a routine bioassay program if the worker will be chronically exposed to 
airborne radioactivity with an average concentration exceeding $2 \%$ of the DAC. For exposures to multiple nuclides, the contribution from each significant nuclide should be considered using a sum-of-thefractions approach. The DACs referred to in this manual are those contained in Appendix A of 10 CFR 835.

\section{Short-Term Chronic Exposures}

Workers exposed to short-term chronic exposures should participate in a routine bioassay monitoring program for each radionuclide to which they are exposed when the average air concentration exceeds that determined by the following formula:

$$
\text { Air Concentration Implying Bioassay Monitoring }=\frac{0.02 * \mathrm{DAC}}{\mathrm{f}_{\mathrm{w}}}
$$

where DAC is the derived air concentration listed in 10 CFR 835, and $f_{w}$ is the occupancy factor determined by

$$
\mathrm{f}_{\mathrm{w}}=\frac{\text { number of hours per year in airborne area }}{2000 \text { working hours per year }}
$$

\subsubsection{Annual Limit on Intake and Material in Process as a Basis for Bioassay Monitoring}

The ALI is a useful concept for bioassay planning when acute intakes are considered or exposure may be limited to readily identifiable quantities or sources, e.g., well-defined sources in a laboratory environment, as opposed to general contamination in a waste management facility. A routine bioassay program should be considered if an acute or chronic intake of activity corresponding to $2 \%$ of the stochastic ALI (SALI) might be possible. Use of a more restrictive deterministic ALI (DALI) over the SALI is a conservative practice that may be preferred for some applications. Table 5.2 provides a tabulation of SALIs and DALIs for selected nuclides of typical interest at Hanford, derived from the 5rem committed effective dose limit and 50-rem committed organ/tissue dose limit and the limiting dose coefficients of PNNL-MA-860. ALI values for other nuclides can be calculated using the appropriate dose limit and the limiting dose coefficient from ICRP-68 (ICRP 1994, ICRP 1998) or by contacting HIDP.

If the source of material to which a worker might be exposed is below $2 \%$ of the SALI, bioassay program participation is not required.

If the source of material in process exceeds $2 \%$ of the ALI, factors such as physical and chemical form of the material, containment barriers, handling or processing to be performed, frequency of work, and past experience with similar facilities or operations all may affect the determination that bioassay is warranted. Various methods for calculating a quantity of material in process that warrants bioassay program participation have been proposed (e.g., HPS 2001, IAEA 1999, Carbaugh et al 1994, Brodsky 1980 and 1983, NRC 1988). The HIDP does not recommend any single method as preferred, but notes that each method has its own advantages and disadvantages, and should be exercised with good professional judgment. The use of any of these methods to determine bioassay program participation (or non-participation) should be clearly documented by the worker's radiation protection organization. 


\subsubsection{DAC-hours Exposure as a Basis for Bioassay Monitoring}

DAC-hours of airborne exposure are an indication of potential intake. Worker exposure (in terms of DAC-hours) should be expressed after appropriate correction for respiratory protection. The dose to an individual can be determined based on airborne radioactivity data according to the direction of items (a) through $(\mathrm{g})$ below, but these actions are not necessary if routine bioassay monitoring can detect exposures less than 40 DAC-hours, and a policy of performing special bioassays is implemented for potential intakes resulting from unplanned incidents. For conversion to dose, DAC-hours should be first converted to a potential intake. The following actions are recommended for purposes of dosimetry:

a) A DAC-hours tracking log should be initiated for single intakes in excess of 1 DAC-hour. Single intakes below 1 DAC-hour are considered insignificant and do not require tracking.

b) Acute exposures $>40$ DAC-hours should be investigated by special bioassay with a subsequent evaluation issued by the HIDP.

c) Acute exposures between 10 and 40 DAC-hours should be considered for special bioassay and undergo an internal dose evaluation based on the data most appropriate for the individual, factoring in considerations for sensitivity and representativeness.

NOTE: For ${ }^{239}$ Pu using the Hanford models, 1 DAC-hour (Type M) will correspond to approximately $0.72 \mathrm{mrem}$ committed effective dose for $5-\mu \mathrm{m}$ particles. Thus, the implied dose of 10 - 40 DAC-hours is nominally 7 to 30 mrem.)

d) Acute exposures below 10 DAC-hours need not be confirmed by bioassay for dose evaluation. At such low levels, the determination of whether bioassay or DAC-hours is most representative is highly subjective and the decision should be made by the contractor in consultation with HIDP, based on the circumstances of each case. Bioassay is useful to provide a possible upper bound on the individual's intake and dose, although actual assessment of that upper bound is not required. However, doses may be assigned directly from DAC-hours exposure, without bioassay, if it is concluded that the DAChours exposure is a reasonable estimate of the worker's intake.

e) For multiple small acute exposures or chronic low-level exposures, where the cumulative exposure does not exceed 40 DAC-hours in a calendar year, doses may be assigned directly from DAC-hours estimates.

f) Cumulative DAC-hours exposures $>10$ DAC-hours in a calendar year should undergo dose assessment and be included in the worker's exposure history.

g) Cumulative DAC-hours exposures $\leq 10$ DAC-hours in a calendar year may be dispositioned at the contractor's discretion. They may be permanently recorded in the worker's files, but individual dose assessment and recording is not required. It is highly unlikely that committed effective doses in excess of $10 \mathrm{mrem}(\mathrm{Pu})$ would go unreported. The upper bound of a committed effective dose for ${ }^{90} \mathrm{Sr}$ or ${ }^{137} \mathrm{Cs}$ using this scheme would be $25 \mathrm{mrem}$, however workers at such levels are typically subject to more sensitive periodic bioassay measurements.

Documentation by Field Dosimetry of the air sample representativeness is required for inclusion in a dose assignment based on DAC-hours. Facility air samples are not always representative of air breathed. Lapel sample data may generally be considered representative or conservative. General room or facility 
air sample data from fixed heads must be interpreted for representativeness based on investigation of the unique aspects of the potential exposure.

\subsubsection{Worker Group Monitoring}

Worker group monitoring can be a suitable alternative to individual worker monitoring for working situations in which the potential for intakes is very low or doses from any intakes would be quite small. The approach is to monitor only a representative portion of the workers on a rotating basis. With this program design, it is assumed that all workers have the same risk for exposure in any period, and that a bioassay result for one worker can be taken as characteristic for the entire group.

Worker group monitoring can be used in one of two ways. First, it can be used as an expedient method of confirmatory monitoring to verify that workers do not require an individual-specific bioassay program. Secondly, it can be used to provide data for low-level chronic exposure situations in which a combined set of bioassay data from many workers is used to assign doses to individual workers.

For confirmatory monitoring, not all workers in the group need to receive bioassay. Consistent with recommendations of the National Council on Radiation Protection and Measurements (NCRP 1987), the following guidance is offered for establishing the scope of a bioassay monitoring program for a group:

Worker Population
$\geq 120$
12 to 120

$<12$
Number Monitored $10 \%$

12

All

If a screening level applied to a worker group is exceeded and an intake is confirmed, then all members of the group should be placed on individual bioassay programs, unless an investigation shows that just the one worker was exposed due to unusual circumstances.

\subsubsection{Environmental Restoration and Remediation Activities}

Special criteria have been developed for application to environmental restoration and remediation (ER) work at Hanford. This work may involve short-term soil sampling activities, excavation of dirt, transport of contaminated soil, or sample well or monitoring borehole drilling operations. The soil involved may range from essentially uncontaminated overburden at burial grounds to soil contaminated with a wide range and magnitude of radionuclides at liquid effluent disposal sites, such as cribs or ponds.

Criteria for two types of exposure conditions have been addressed: the single job involving acute exposure to very high dust loadings in air (i.e., near the worker tolerance level for dust), and the longterm job involving chronic exposure to moderately high dust loadings. The acute exposure assumed a 360 -mg inhalation intake (e.g., 2 hours exposure to $150-\mathrm{mg} / \mathrm{m}^{3}$ dust loading) of $5-\mu \mathrm{m}$-AMAD dust. The chronic exposure assumed an inhalation intake rate of $48 \mathrm{mg} /$ day of 5- $\mu \mathrm{m}$-AMAD dust for 250 working days/year (e.g., 2-h/day exposure to a $20-\mathrm{mg} / \mathrm{m}^{3}$ dust loading). The chronic exposure scenario is comparable to the OSHA $5-\mathrm{mg} / \mathrm{m}^{3}$ respirable particle fugitive dust standard.

Soil contamination criteria are shown in Table 5.3. As long as the geometric mean soil concentrations do not exceed those listed, intakes are not likely to exceed 0.02 ALI and worker bioassay measurements are not required. Use of the arithmetic mean soil concentration (as a convenient substitute for the geometric mean) is acceptable, and will result in conservative determinations of the need for bioassay. The soil concentration values shown are for the most restrictive absorption type considered likely to be encountered. 
TABLE 5.3 Bioassay Monitoring Criteria for Work Involving Exposure to Contaminated Soil ${ }^{(\mathrm{a})}$ Based on Potential Inhalation of 0.02 ALI

\begin{tabular}{lcc}
\hline & \multicolumn{2}{c}{ Soil Contamination $\mathbf{( p C i / g )}$} \\
\cline { 2 - 3 }${\text { Nuclide, } \text { Form }^{(\mathbf{c})}}^{(\mathbf{b})}$ & $\frac{\text { Acute }^{(\mathbf{d})}}{40,000}$ & $\frac{\text { Chronic }^{(\mathbf{e})}}{1,000}$ \\
Uranium - Total $^{(\mathrm{f})}$ & 10,000 & 400 \\
$\quad$ Type M & & \\
Type S & 2,000 & 70 \\
Pu- $\alpha \quad$ Type M & 9,000 & 300 \\
$\quad$ Type S & 500 & 15 \\
Th-232 Type M & 2,700 & 80 \\
Th-228 Type M & $2,000,000$ & 70,000 \\
Sr-90 Type F & $11,000,000$ & 300,000 \\
Cs-137 Type F & $4,000,000$ & 100,000 \\
Co-60 Type S & $6,000 \mu \mathrm{Ci} / \mathrm{L}$ & $24 \mu \mathrm{Ci} / \mathrm{L}$ \\
Tritium in groundwater & $(\mathrm{g})$
\end{tabular}

(a) Criteria are established for two potential scenarios. "Acute" implies normally not exposed to contamination but potential exists for a single, heavy exposure. "Chronic" implies frequent exposure to less dusty conditions. Bioassay would be required if either scenario applied to a worker.

(b) For other nuclides or chemical forms, consult with HIDP for guidance.

(c) Units apply to uniform concentrations representative of the soil being disturbed, and not to small, spotty contamination.

(d) Assumes a 360-mg inhalation intake of 5- $\mu \mathrm{m}$ AMAD soil dust in a single exposure.

(e) Assumes a 48-mg/day inhalation intake rate of 5- $\mu \mathrm{m}$ AMAD soil dust particles for 250 working days/year, $(12 \mathrm{~g} / \mathrm{y})$. Exposure is comparable to OSHA $5-\mathrm{mg} / \mathrm{m}^{3}$ respirable particle fugitive dust standard on a 8-h time-weighted average basis.

(f) U-natural, ${ }^{234} \mathrm{U},{ }^{235} \mathrm{U}$, or ${ }^{238} \mathrm{U}$ in any combination. Based on recycled uranium common at Hanford. Same numbers apply for uranium in units of $\mathrm{ppm}$ or $\mu \mathrm{g} / \mathrm{g}$ soil.

(g) Assumes acute consumption of one cup $(0.25 \mathrm{~L})$ or chronic consumption of one cup $(0.25 \mathrm{~L})$ per day of groundwater at the indicated contamination.

In addition, based on the highest measured tritium contamination levels in Hanford groundwater (nominally $1.2 \mu \mathrm{Ci} / \mathrm{L}$ in the 200 -West Area as noted by Hartman, et al. 2009), there is no need for workers to be on a tritium bioassay program. Tritium bioassay for ER work need not be considered unless concentrations in water exceed $24 \mu \mathrm{Ci} / \mathrm{L}$.

Exposure to multiple radionuclides must address the additive impact of all nuclides. The need for bioassay can then be established by calculating an "index for bioassay" value as the sum of the ratios of each nuclide to its respective criterion value, as shown below:

$$
\text { Index for Bioassay }=\frac{\text { conc. } 1}{\text { criteria } 1}+\frac{\text { conc } .2}{\text { criteria } 2}+\text { etc. }
$$

If the index value exceeds one, a bioassay program should be established. The issue of what type of bioassay to perform remains. Where sources consist of a single nuclide, the choice is generally obvious. If multiple nuclides are involved, the predominant nuclide may be the best choice. However, some bioassay procedures are substantially more sensitive than others, and if one nuclide can be used as an indicator for 
another (because of known source inter-relationships), then a more sensitive bioassay procedure for a less predominant radionuclide may be adequate. HIDP staff can be consulted for advice on specific situations. Details on these criteria are provided in the original supporting report. ${ }^{(a)}$

\subsubsection{Long-Term Follow-Up of a Prior Deposition}

A worker who has been assessed as having a long-term internal deposition of radioactive material may be recommended by HIDP for a specialized follow-up bioassay monitoring program to verify the accuracy of the assessment and identify any potential need for revision. This provision results from the need to update long-term body burdens and associated doses from well-retained radionuclides, and should apply regardless of present work assignment or origin of the occupational exposure.

Better understanding of the biokinetic behavior of retained material and improved estimates of dose can be obtained from long-term follow-up bioassay measurements. For example, a small, very long-term component of material in the lung may be masked for several years by short-term components until the short-term components are removed. However, the long-term component may add significantly to the 50-year committed dose.

Long-term follow-up monitoring is most likely to be associated with depositions of plutonium and americium, although other nuclides may also warrant it.

\subsubsection{Baseline and Ending Work Bioassay}

Baseline (or contractor request) and end-of-assignment samples or measurements should be obtained for a worker whose work assignments will require, or have required, routine bioassay monitoring (NCRP 1987; HPS 1997). Such samples should provide a better estimate of the time and nature of an intake, prevent the improper assignment of a prior intake to the present task, and provide accurate feedback on the effectiveness of radiation protection measures for specific work assignments.

Baseline and end-of-assignment measurements may be a suitable alternative to the routine bioassay monitoring associated with work assignments of limited duration. Consult with HIDP to determine whether this option is appropriate.

End-of-assignment measurements may be performed in lieu of and at the scheduled time of routine measurements. This option does not apply to visitors and terminating employees who should have specially scheduled measurements.

\subsubsection{Offsite Intake Monitoring}

Bioassay programs designed for monitoring intakes and work at Hanford may not necessarily be adequate for monitoring at offsite facilities. HIDP should be contacted to determine the appropriate bioassay if offsite intake is a possibility.

(a) Letter report to T. J. Kelly (WHC) from Eugene H. Carbaugh (PNL) dated December 3, 1991, "Bioassay Criteria for Environmental Restoration Workers." A copy is maintained in the permanent files of the Hanford Radiological Records Program. 


\subsubsection{Visitors and Minors}

Routine bioassay programs for plutonium, thorium, and insoluble uranium are not capable of demonstrating compliance with the 100-mrem committed effective dose limit for minors and visitors. Therefore, it is recommended that radiation work permits prohibit minors and visitors from being exposed to these materials such that they would be at risk for an intake which could exceed the 100 -mrem committed effective dose limit. If there is potential for external dose as well, then the potential intake must be at a level less than 100 mrem to assure that the total effective dose doesn't exceed $100 \mathrm{mrem}$. If necessary, fecal sampling performed immediately after an acute or short-term exposure can demonstrate compliance with the limit.

Bioassay monitoring is required by 10 CFR 835 if it is likely that visitors or minors will receive over 50-mrem committed effective dose from an intake. Although monitoring may be required, as noted in the preceding paragraph, there are nuclides for which routine monitoring is not capable of demonstrating compliance with the dose limits.

Special bioassays will be performed if conditions encountered while at Hanford require them. If measurements are performed at the beginning or end of the visit, any abnormal results will be reported to the responsible Hanford contractor. Internal doses for detectable baseline results will be assessed only if a specific request is made by the contractor.

\subsubsection{Declared Pregnancy}

The 10 CFR 835 dose limit for declared pregnant women is substantially more restrictive than for occupational workers.

When a worker on a routine bioassay schedule declares her pregnancy, HIDP should be notified and supplemental bioassay obtained as soon as possible. This is necessary to determine the possible internal dose to the fetus from conception to the date of declaration. These supplemental measurements should be scheduled as Contractor Requests (CR) with priority processing and include a note or comment that the measurement is pregnancy-related.

If the worker continues to be exposed to possible intakes, the contractor must schedule another bioassay measurement at the conclusion of the pregnancy. The same scheduling protocol should be used. The minimum detectable doses for embryo-fetus bioassay programs are shown in Exhibit 5.8. Doses to the embryo-fetus are based on the gestation period dose and not the committed effective dose.

The 10-mrem screening levels of Appendix A will be used as a basis for determining the need for evaluation.

\subsection{SELECTION OF NUCLIDES FOR BIOASSAY}

Any radionuclide or mixture of radionuclides that may contribute more than $25 \%$ to the 100 -mrem committed effective dose criterion should be included in the bioassay monitoring program.

As a rule of thumb, it may be assumed that workers are not likely to be exposed to more than four reference mixtures of radionuclides. Radionuclides do not require specific bioassay monitoring if they are adequately monitored by indicator nuclides for a reference mixture. 
In some cases, it is possible to use indicator radionuclides for established mixtures to optimize the number of bioassay measurements performed. For example, mixtures containing ${ }^{90} \mathrm{Sr}$ and ${ }^{137} \mathrm{Cs}$ may be sufficiently monitored by using whole body measurements of ${ }^{137} \mathrm{Cs}$ as an indicator of exposure. (See Table 5.1 for guidance.)

Once a worker is placed on a routine program, that program should be reviewed on a regular basis to ensure that potentially significant nuclides are adequately addressed.

A "broad-base" bioassay program involving multiple analyses may be appropriate for workers who rotate between facilities on occasional or routinely have short-notice assignments. Such a program is intended to satisfy current baseline requirements for many facilities, rather than imply a worker is likely to incur intakes individually or collectively totaling 100-mrem committed effective dose.

\subsection{BIOASSAY MEASUREMENT FREQUENCY}

The frequency of bioassay measurements is dictated by two objectives. The first is to assure that significant acute intakes are detected for dose evaluation and appropriate corrections to the working conditions (NCRP 1987). The second is to monitor the accumulation of radioactive material in the body from low-level chronic intakes.

In general, significant acute intakes are discovered by workplace monitoring (e.g., air monitoring, and clothing and body surveys) and are investigated according to the protocol discussed in Chapter 7.0. Nevertheless, a properly chosen bioassay frequency is important both to account for undetected, acute intakes and to monitor the effectiveness of workplace monitoring.

The choice of frequency depends on the following:

- The purpose of the measurement (i.e., to monitor for accumulation from chronic intakes, for potential acute intakes undetected by first-line monitoring methods, or for acute intakes that occur simultaneously with a known chronic intake).

- The ability to meet the 100-mrem committed effective dose objective stated in Section 2.3.

- MDAs for various radionuclides and bioassay measurements.

- The likelihood and ratios of combinations of radionuclides associated with an intake for a particular facility or task.

- The cost of bioassay measurements and,

- The cost of lost productive time while workers are participating in the bioassay program.

\section{Longest Interval Between Bioassays}

Generally, annual measurements are suggested as a convenient minimum frequency to match annual reporting requirements for worker doses. Routine bioassay measurement periods longer than five effective half-lives are also generally not recommended, because the potential deviation of individuals from assumed retention or excretion patterns can substantially affect doses associated with the program design. 
For mixtures of nuclides (e.g., ${ }^{90} \mathrm{Sr}$ and ${ }^{137} \mathrm{Cs}$ ), an annual individual bioassay measurement (e.g., whole body count) may be used in combination with a less frequent radionuclide-specific measurement (e.g., biennial ${ }^{90} \mathrm{Sr}$ urine sample analysis).

\subsection{TECHNICAL DISCUSSION FOR RECOMMENDED PROGRAMS}

The recommended bioassay programs of Table 5.1 were established based on considerations discussed below and in the exhibits at the end of this section. Additional discussion of capabilities is contained in the internal manual, Methods and Models of the Hanford Internal Dosimetry Program, (PNNL-MA-860).

\subsubsection{Plutonium Mixtures}

Baseline urine and chest measurements for plutonium and americium are not considered essential for routine monitoring of previously unexposed workers because background levels in people are far below the routine measurement detection capability. However, baselines are strongly recommended when the person has previously worked in a plutonium facility or has had a known intake of plutonium or americium.

Periodic programs are not capable of meeting the 100-mrem committed effective dose bioassay goal. Annual urine sampling is recommended for all Pu workers. Workers with the highest risk for Pu intake should also receive annual chest counts. Legacy dry Pu contamination in facilities should be considered Type $\mathrm{S}$ regardless of original form.

Prompt detection of an intake by use of workplace indicators is essential to provide capability to detect 100 mrem committed effective dose by timely initiation of special bioassay monitoring. Special monitoring should emphasize early fecal samples analyzed for isotopic $\mathrm{Pu}$ or $\mathrm{Pu}$ and ${ }^{241} \mathrm{Am}$ to provide maximum sensitivity to detection of intakes. Special Pu urinalysis, though less sensitive to intake detection than fecal sampling, is very important to help discriminate between Type $\mathrm{M}$ and Type $\mathrm{S}$ forms of $\mathrm{Pu}$.

Very high sensitivity mass measurements of plutonium in urine can be obtained by special arrangement with other national laboratories. These methods include thermal ionization mass spectrometry (TIMS) at Los Alamos National Laboratory and accelerator mass spectrometry (AMS) at Lawrence Livermore National Laboratory. These methods are substantially more sensitive than standard alpha spectrometry, but require special interlab arrangements and would probably involve lengthy turnaround times. They are best suited as supplemental measurements for investigations of suspected highly insoluble forms of plutonium.

\subsubsection{Uranium Mixtures}

Monitoring for uranium poses special problems for the following reasons:

- Uranium presents both chemical and radiological toxicity risks, the relative importance of which depends on its absorption type.

- Uranium can exist in mixed absorption type.

- Small, recent intakes easily mask larger, older intakes because nearly $50 \%$ of the uranium going to blood is cleared immediately through the urine. 
- An intake of Type $S$ material potentially resulting in a committed effective dose of 100 mrem generally cannot be detected by routine bioassay monitoring. Monitoring of the workplace to document the working environment and to provide immediate indication of an intake is essential.

- Low-level chronic intakes are possible for certain types of work, so the bioassay program may need to monitor for long-term buildup as well as for potentially significant acute intakes.

- Individual and temporal variability in the environmental background of uranium complicates interpretation of urinalysis results.

- Baseline urine bioassay is needed because of the highly variable nature of background excretion from individuals.

Consequently, the proper bioassay monitoring program for uranium workers is best determined on a case-by-case basis in consultation with HIDP.

\subsubsection{Strontium-Cesium Mixtures Bioassay}

Mixtures of ${ }^{90} \mathrm{Sr}$ and ${ }^{137} \mathrm{Cs}$ are not uncommon at Hanford and may be found in facilities associated with fission product waste management. The composition of these mixtures can vary from essentially pure ${ }^{90} \mathrm{Sr}$ to essentially pure ${ }^{137} \mathrm{Cs}$. Where the composition can be well-characterized, e.g., a potential intake identified at the time by field indicators, then whole body counting of ${ }^{137} \mathrm{Cs}$ may be adequate for intake assessment if a smear sample can be analyzed for the ${ }^{90} \mathrm{Sr}:{ }^{137} \mathrm{Cs}$ ratio.

In other circumstances, notably a high-routine whole body exam, there may not be any obvious specific material to which the worker might have been exposed. For many years a 1:1 ratio was assumed based on the typical fission product yields. However, the wide range of waste management practices which have occurred at Hanford do not provide assurance that the 1:1 ratio is valid. Thus, for highroutine whole body exams, a recommended follow-up practice is to include a ${ }^{90} \mathrm{Sr}$ urinalysis unless it is clear that the worker could only have been exposed to pure ${ }^{137} \mathrm{Cs}$ or the dose consequences are quite small. The ${ }^{90} \mathrm{Sr}$ urinalysis can also help distinguish between environmental and occupational exposures of ${ }^{137} \mathrm{Cs}$.

The issue of when to place a worker on both a whole body exam and ${ }^{90} \mathrm{Sr}$ urinalysis is slightly more complex. The minimum detectable doses associated with ${ }^{137} \mathrm{Cs}$ and ${ }^{90} \mathrm{Sr}$ urinalysis bioassay minimum detectable activities for several ${ }^{90} \mathrm{Sr}:{ }^{137} \mathrm{Cs}$ ratios are shown in Exhibit 5.6. Based on this table, an annual whole body exam using the stand-up counter is capable of meeting the 100-mrem committed effective dose bioassay goal for minimum detectable dose for mixtures up to about a $30: 1{ }^{90} \mathrm{Sr}:{ }^{137} \mathrm{Cs}$ ratio. Supplemental ${ }^{90} \mathrm{Sr}$ urinalysis is recommended when the ${ }^{90} \mathrm{Sr}:{ }^{137} \mathrm{Cs}$ ratio exceeds $30: 1$.

\subsubsection{Cesium-Plutonium Mixtures}

Mixtures of ${ }^{137} \mathrm{Cs}$ and $\mathrm{Pu}$ may be found at Hanford in facilities associated with fuel irradiation, storage or handling of irradiated fuel, and wastes associated with such facilities. Examples include spent fuel basins, fuel processing hot cells, and waste tank sludges. By radioactivity, these mixtures are likely to be mostly ${ }^{137} \mathrm{Cs}$, with Cs:Pu ratios ranging from perhaps 1000:1 to 1:1. Until the mid-1990s, little attention was given to trace amounts of $\mathrm{Pu}$ in predominantly $\mathrm{Cs}$ contamination. However, a recognition of the dosimetric importance of the trace Pu developed with the implementation of the committed dose system and as more detailed facility contamination characterization data became available.

Where the composition can be well-characterized, e.g., a potential intake identified at the time by 
field indicators, then whole body counting of ${ }^{137} \mathrm{Cs}$ may be adequate for intake assessment if a representative

sample can be analyzed for the ${ }^{137} \mathrm{Cs}: \mathrm{Pu}$ ratio. Such a sample might be a nasal smear or surface wipe of the contamination.

In other circumstances, notably a high-routine whole body exam, there may not be any obvious specific material to which the worker might have been exposed. The assumption of any kind of default $\mathrm{Cs}: \mathrm{Pu}$ ratio is premature at this time, and this renders difficult the investigation of high routine ${ }^{137} \mathrm{Cs}$ whole body counts for workers in those facilities.

To help determine appropriate bioassay monitoring for workers in facilities with Cs-Pu mixtures, the information in Exhibit 5.7 led to the guidelines below. For convenience, it is considered irrelevant as to whether the $\mathrm{Pu}$ is ${ }^{239} \mathrm{Pu},{ }^{238} \mathrm{Pu}$, or Pu-alpha: the isotopic differences are relatively small compared to the issue of Type $\mathrm{M}$ or $\mathrm{S}$ forms and the general uncertainty of Cs:Pu ratio.

Cs:Pu $>40: 1$

Annual ${ }^{137} \mathrm{Cs}$ whole body counting using either the stand-up counter or the coax counter is capable of meeting the 100-mrem committed effective dose bioassay goal. This applies to either Type M or Type S forms of $\mathrm{Pu}$.

\section{Between 40:1 and 10:1}

Between Cs:Pu ratios of 10:1 and about $40: 1$, annual ${ }^{137} \mathrm{Cs}$ whole body counting using the coaxial germanium detector system is preferred over the stand-up counter. Both easily demonstrate compliance with the 10 CFR 835 dose limits. However, as the ratio decreases below 40:1, a technical shortfall exists in the ability to meet the 100 -mrem goal.

Cs:Pu $<10: 1$

Below 10:1 the ability of whole body counting to provide adequate bioassay is weak, and the worker should be placed on a plutonium bioassay program supplemented by an annual whole body count.

\section{High Routines}

Investigation of high routine whole body counts that detect ${ }^{137} \mathrm{Cs}$ should consider the possibility of plutonium if the worker is associated with facilities having Cs-Pu mixtures. For such workers, investigation should include plutonium urinalysis as a minimum. Assuming a Pu intake had occurred within approximately the past year, the urine sample can be used to demonstrate regulatory compliance with 10 CFR 835 dose limits. Fecal samples can demonstrate compliance for Type S material (MDD of 200 to 400 mrem committed effective dose). If neither the urine nor fecal sample detect $\mathrm{Pu}$, a dose assessment can be performed assuming ${ }^{137} \mathrm{Cs}$ alone, with the recognition that the worker has been evaluated against the MDDs for routine Pu bioassay, and has demonstrated a margin of safety comparable to plutonium workers with regard to the dose limits.

\subsubsection{Strontium-Plutonium Mixtures}

Strontium and plutonium mixtures can be found in such waste sources as tank farm or spent fuel storage basin sludges. Exhibit 5.7 provides additional details on the capability of screening measurements. 
$\mathrm{Sr}: \mathrm{Pu}>400: 1$

Annual ${ }^{90} \mathrm{Sr}$ urinalysis provides capability of detecting committed effective dose of 100 mrem or less. Sr:Pu between 100:1 and 400:1

Annual ${ }^{90} \mathrm{Sr}$ urinalysis provides nominal minimum detectable committed effective dose of 100 to 300 mrem. Consider annual $\mathrm{Pu}$ urinalysis as a supplement.

And Sr:Pu $<100: 1$

The ability to use ${ }^{90} \mathrm{Sr}$ as an indicator for Pu is weak. The worker should be placed on a Pu bioassay program supplemented with annual ${ }^{90} \mathrm{Sr}$ urinalysis.

\subsubsection{Special Forms of Nuclides}

Special forms of radionuclides (e.g., tritium or ${ }^{14} \mathrm{C}$-labeled materials) can behave much differently than the normal compounds for which routine bioassay programs are designed. Case-specific bioassay monitoring programs for situations such as these should be established through consultation with HIDP.

\subsection{REFERENCES}

10 CFR 835. 2007. Department of Energy, Occupational Radiation Protection. U.S. Code of Federal Regulations. Accessed on 4/18/2009 at http://www.access.gpo.gov/.

Brodsky, A. 1980. "Resuspension factors and probabilities of intake for Material in Process, or Is $10^{-6}$ a Magic Number in Health Physics?" Health Physics 39(6):992-1000.

Brodsky, Alan. 1983. Information for Establishing Bioassay Measurements and Evaluations of Tritium Exposure. NUREG-0938. U.S. Nuclear Regulatory Commission. Washington, D. C.

Carbaugh, E.H., D.E. Bihl, J.A. MacLellan, M.P. Long, 1994. Hanford Internal Dosimetry Program Manual, PNL-7001 Rev 1. Pacific Northwest National Laboratory, Richland, Washington.

Hartman, M.J., V.S. Richie, and J.A. Rediker. 2009. "Hanford Site Groundwater Monitoring for Fiscal Year 2009." DOE/RL-2008-66 Rev 0. CHSM Hill, Richland Washington. Accessed on 4/20/2009 at http://www.hanford.gov/cp/gpp/library/govrp08/start08.htm.

Health Physics Society (HPS). 1994. Internal Dosimetry Programs for Tritium Exposure - Minimum Requirements. HPS N13.14-1994. An American National Standard approved by American National Standards Institute, Health Physics Society, McLean, Virginia.

Health Physics Society (HPS). 1997. Internal Dosimetry for Mixed Fission and Activation Products. HPS N 13.42-1997. Standard approved by American National Standards Institute, Health Physics Society, McLean, Virginia.

Health Physics Society (HPS). 2001. Design of Internal Dosimetry Programs. ANSI/HPS N13.39-2001. An American National Standard approved by American National Standards Institute, Health Physics Society, McLean, Virginia.

International Atomic Energy Agency (IAEA). 1999. Assessment of Occupational Exposure Due to 
Intakes of Radionuclides. IAEA Safety Standards Series No. RS-G-1.2. International Atomic Energy Agency, Vienna. Accessed on 4/13/2009 at http://www-pub.iaea.org/MTCD/publications/ResultsPageSSS.asp?p=6\#name90.

International Commission on Radiological Protection (ICRP). 1994. Dose Coefficients for Intakes of Radionuclides by Workers. ICRP Publication 68. Annals of the ICRP, Vol 24 No. 4. Pergamon Press.

International Commission on Radiological Protection (ICRP). 1998. The ICRP Database of Dose Coefficients: Workers and Members of the Public. Version 2.01 for Windows 95/98/Me/NT/2000 available as compact disk. Pergamon.

National Council on Radiation Protection and Measurements (NCRP). 1987. Use of Bioassay Procedures for Assessment of Internal Radionuclide Deposition. NCRP Report No. 87. Bethesda, Maryland.

Pacific Northwest National Laboratory (PNNL). Methods and Models of the Hanford Internal Dosimetry Program, PNNL-MA-860. Richland, Washington. Internal manual. A copy of this manual is maintained in the HIDP files and available from the HIDP Manager or online by searching, PNNL-15614 @ http://www.pnl.gov/publications/.

U.S. Department of Energy (DOE). 2008a. Radiation Protection Programs Guide for Use with Title 10, Code of Federal Regulations, Part 835, Occupational Radiation Protection. DOE G 441.1.-1c. Washington, D.C. Accessed on 5/19/2009 at http://www.directives.doe.gov.

U.S. Department of Energy (DOE). 2008b. DOE Standard Internal Dosimetry. DOE-STD-1121-2008. Washington, D.C. Accessed on 5/19/2009 at http://www.directives.doe.gov.

U.S. Nuclear Regulatory Commission (NRC). 1988. Criteria for Establishing a Tritium Bioassay Program. Regulatory Guide 8.32. Washington, D.C. Accessed on 4/16/2009 at http://www.nrc.gov/reading-rm/doc-collections/reg-guides/occupational-health/active/. 


\section{EXHIBIT 5.1}

\section{BIOASSAY CAPABILITY FOR TRITIUM}

$\underline{\text { Urine Bioassay Analysis }}$

Tritium (H3)

MDA: $20 \mathrm{dpm} / \mathrm{mL}$

The tritium monitoring program is based on liquid scintillation analysis for tritium oxide in urine.

Because only $1 \mathrm{~mL}$ is analyzed, virtually any volume of sample can be used. For convenience, single void or simulated 12-hr samples are generally collected and a small aliquot analyzed. Program capability is shown below.

Minimum Detectable Committed Effective Dose for Acute and Chronic ( $365 \mathrm{~d} / \mathrm{y}$ ) Exposures to Tritium Oxide

\begin{tabular}{cccc}
\hline $\begin{array}{c}\text { Days Post-Intake } \\
\text { or Interval } \\
\text { Length }\end{array}$ & $\begin{array}{c}\text { Single } \\
\text { Acute Exposure } \\
(\text { mrem })\end{array}$ & $\begin{array}{c}\text { Multiple }^{(\mathbf{a})} \\
\text { Acute Exposure }_{\text {(mrem) }}\end{array}$ & $\begin{array}{c}\text { Chronic }_{\text {Exposure }^{(\mathbf{b})}} \\
\text { (mrem) }\end{array}$ \\
\hline 1 & 0.027 & NA & 0.64 \\
2 & 0.029 & NA & 0.64 \\
7 & 0.040 & 2.1 & 0.64 \\
14 & 0.064 & 1.7 & 0.64 \\
30 & 0.18 & 2.2 & 0.64 \\
60 & 0.98 & 5.9 & 0.64 \\
180 & 3.1 & 12 & 0.64 \\
365 & 19 & 38 & 0.64 \\
\hline
\end{tabular}

(a) Assuming one intake per interval.

(b) Assumed constant equilibrium in body water at $20 \mathrm{dpm} / \mathrm{mL}$. $\mathrm{NA}=$ Not Applicable 


\section{EXHIBIT 5.2}

\section{IN VIVO BIOASSAY CAPABILITY FOR HIGH-ENERGY GAMMA EMITTERS}

Whole Body Counting

Bioassay measurements for high-energy gamma-emitting radionuclides are performed using the IVRRF preview counter or the coaxial germanium whole body counter. The minimum detectable doses for single nuclides are shown below for the chemical forms commonly encountered at Hanford.

Minimum Detectable Committed Effective Dose, E(50), for Single Acute 5- $\mu$ m AMAD Inhalation Intake Based on MDA Detection in a Whole Body Count at the Indicated Day Post-Intake

\begin{tabular}{|c|c|c|c|c|c|}
\hline Nuclide & Type & $\begin{array}{c}\operatorname{MDA}^{(\mathbf{a})} \\
(\mathbf{n C i})\end{array}$ & $\begin{array}{c}\text { Day } \\
\text { Post } \\
\text { Intake }\end{array}$ & $\begin{array}{l}\text { Measurement } \\
\text { Interval }\end{array}$ & E(50) (mrem) \\
\hline \multicolumn{6}{|c|}{ Preview Counter } \\
\hline${ }^{6 \mathrm{O}} \mathrm{Co}$ & S & 1.2 & $\begin{array}{l}365 \\
730\end{array}$ & $\begin{array}{l}\text { Annual } \\
\text { Biennial }\end{array}$ & $\begin{array}{l}2.9 \\
4.6\end{array}$ \\
\hline${ }^{137} \mathrm{Cs}$ & $\mathrm{F}$ & 1.3 & $\begin{array}{l}365 \\
730\end{array}$ & $\begin{array}{l}\text { Annual } \\
\text { Biennial }\end{array}$ & $\begin{array}{l}0.76 \\
7.7\end{array}$ \\
\hline${ }^{154} \mathrm{Eu}$ & M & 7.0 & $\begin{array}{l}365 \\
730 \\
\end{array}$ & $\begin{array}{c}\text { Annual } \\
\text { Biennial } \\
\end{array}$ & $\begin{array}{l}20 \\
24 \\
\end{array}$ \\
\hline Nuclide & Type & $\begin{array}{c}\operatorname{MDA}^{(\mathbf{a})} \\
(\mathbf{n C i})\end{array}$ & $\begin{array}{c}\text { Day } \\
\text { Post } \\
\text { Intake }\end{array}$ & $\begin{array}{l}\text { Measurement } \\
\text { Interval }\end{array}$ & E(50) (mrem) \\
\hline \multicolumn{6}{|c|}{ Coax Germanium System } \\
\hline${ }^{6 \mathrm{O}} \mathrm{Co}$ & S & 0.8 & $\begin{array}{l}365 \\
730\end{array}$ & $\begin{array}{l}\text { Annual } \\
\text { Biennial }\end{array}$ & $\begin{array}{l}1.9 \\
3.1\end{array}$ \\
\hline${ }^{137} \mathrm{Cs}$ & $\mathrm{F}$ & 1.0 & $\begin{array}{l}365 \\
730\end{array}$ & $\begin{array}{l}\text { Annual } \\
\text { Biennial }\end{array}$ & $\begin{array}{c}0.58 \\
5.9\end{array}$ \\
\hline${ }^{154} \mathrm{Eu}$ & M & 2.0 & $\begin{array}{l}365 \\
730\end{array}$ & $\begin{array}{l}\text { Annual } \\
\text { Biennial }\end{array}$ & $\begin{array}{l}6 \\
7\end{array}$ \\
\hline
\end{tabular}




\section{EXHIBIT 5.2}

\section{IN VIVO BIOASSAY CAPABILITY FOR HIGH-ENERGY GAMMA EMITTERS (contd)}

\section{Thyroid Counting for Radioiodine}

Thyroid counting for ${ }^{125} \mathrm{I}$ and ${ }^{129} \mathrm{I}$ is the recommended bioassay over urine sample analysis for those nuclides. Thyroid counting for ${ }^{131} \mathrm{I}$ is significantly more sensitive than whole body counting for that nuclide. Thyroid counts are performed with planar germanium detectors. The program capability for thyroid counting is shown below:

Minimum Detectable Committed Effective Dose, E(50), for Single Acute 5- $\mu$ m AMAD Inhalation Type F Intake Based on MDA Detection in Thyroid Counter at the Indicated Day Post-Intake

\begin{tabular}{|c|c|c|c|c|}
\hline Nuclide & $\operatorname{MDA}(\mathrm{nCi})$ & $\begin{array}{l}\text { Day Post- } \\
\text { Intake }\end{array}$ & $\begin{array}{c}\text { Measurement } \\
\text { Interval }\end{array}$ & $\mathbf{E}(50)$ (mrem) \\
\hline${ }^{125} \mathrm{I}$ & 0.1 & $\begin{array}{r}30 \\
90 \\
180 \\
365\end{array}$ & $\begin{array}{l}\text { Monthly } \\
\text { Quarterly } \\
\text { Semiannual }^{\text {(a) }} \\
\text { Annual }^{(a)}\end{array}$ & $\begin{array}{r}0.27 \\
0.78 \\
3.9 \\
110\end{array}$ \\
\hline${ }^{129} \mathrm{I}$ & 0.2 & $\begin{array}{r}30 \\
90 \\
180 \\
365\end{array}$ & $\begin{array}{l}\text { Monthly } \\
\text { Quarterly } \\
\text { Semiannual } \\
\text { Annual }^{(a)}\end{array}$ & $\begin{array}{r}1.3 \\
1.9 \\
3.4 \\
11\end{array}$ \\
\hline${ }^{131} \mathrm{I}$ & 0.26 & $\begin{array}{l}30 \\
60 \\
90\end{array}$ & $\begin{array}{l}\text { Monthly } \\
\text { Bimonthly } \\
\text { Quarterly }\end{array}$ & $\begin{array}{r}0.45 \\
7.2 \\
120\end{array}$ \\
\hline
\end{tabular}

(a) Recommended frequency supplemented by workplace screening using portable survey meter with $\mathrm{NaI}$ detector. 


\section{EXHIBIT 5.3}

\section{BIOASSAY CAPABILITY FOR STRONTIUM}

\section{$\underline{\text { Strontium-90 Bioassay Monitoring }}$}

Urine sample analysis is the preferred method for ${ }^{90} \mathrm{Sr}$ bioassay monitoring. For low-risk potential exposure situations, it may be convenient to use an annual whole body exam to monitor for ${ }^{137} \mathrm{Cs}$ as an indicator for the presence of ${ }^{90} \mathrm{Sr}$. Program capabilities are shown below for pure ${ }^{90} \mathrm{Sr}$. See Exhibit 5.6 for mixtures of ${ }^{90} \mathrm{Sr}$ and ${ }^{137} \mathrm{Cs}$.

Minimum Detectable Committed Effective Dose, E(50), for Single Acute 5- $\mu$ m AMAD Inhalation Type F Intake Based on MDA Detection $(10 \mathrm{dpm} / \mathrm{d})$ in Urine at the Indicated Day Post-Intake

\begin{tabular}{ccc}
\hline $\begin{array}{c}\text { Day Post- } \\
\text { Intake }\end{array}$ & $\begin{array}{c}\text { Measurement } \\
\text { Interval }\end{array}$ & E(50) (mrem) \\
\hline & Special & 0.007 \\
1 & Special & 0.08 \\
7 & Monthly & 0.53 \\
30 & Quarterly & 4.6 \\
90 & Semiannual & 9.0 \\
180 & Annual & 24 \\
365 & Biennial $^{(2)}$ & 63 \\
& & \\
\hline & Recommended frequency. \\
\hline
\end{tabular}




\section{EXHIBIT 5.4}

\section{BIOASSAY CAPABILITY FOR URANIUM}

$\underline{\text { Urine Bioassay Analyses }}$

Mass Uranium (U238) MDA: $0.06 \mu \mathrm{g}$

Used for natural, depleted, or recycled uranium mixtures, in any chemical form. Simulated 24-hour sample collected. A screening level of $0.2 \mu \mathrm{g} / \mathrm{d}$ is used as an upper range of the normal expected excretion rate, implying an occupationally attributable excretion rate of $0.18 \mu \mathrm{g} / \mathrm{d}$ may exist above the geometric mean environmental level of $0.02 \mu \mathrm{g} / \mathrm{d}$, established for the Hanford work force. Minimum detectable dose analyses for natural uranium mixtures and various intake scenarios are shown in Tables 5.4.1 through 5.4.3.

Isotopic Uranium (IU) MDA: $0.02 \mathrm{dpm}$

Used for single isotopes of uranium or mixtures enriched to greater than $5 \%$ (by weight) of ${ }^{235} \mathrm{U}$. Simulated 24-hour sample collected. Screening levels of 0.16 and $0.15 \mathrm{dpm}$ are used for ${ }^{233+234} \mathrm{U}$ and ${ }^{238} \mathrm{U}$, respectively and $0.007 \mathrm{dpm}$ for ${ }^{235} \mathrm{U}$, corresponding to $0.2 \mu \mathrm{g} / \mathrm{d}$ for natural uranium; thus, the minimum detectable dose analyses for uranium mixtures are comparable to those for the elemental uranium procedure.

\section{$\underline{\text { In Vivo Measurements }}$}

\begin{tabular}{|c|c|c|c|c|}
\hline \multirow[b]{2}{*}{ Isotope } & \multirow{2}{*}{$\begin{array}{l}\text { Chest Count (3000 s) } \\
\qquad \begin{array}{l}\text { MDA } \\
\end{array}\end{array}$} & \multicolumn{3}{|c|}{$\begin{array}{l}\text { Implied Uranium Present } \\
\text { (nCi of uranium mixture) }\end{array}$} \\
\hline & & Natural U & Depleted U & Recycled U \\
\hline${ }^{235} \mathrm{U}$ & $0.09 \mathrm{nCi}$ & 4.0 & 8.4 & 3.9 \\
\hline${ }^{34} \mathrm{Th}$ & $1.5 \mathrm{nCi}$ & 3.1 & 1.8 & 4.1 \\
\hline
\end{tabular}

Detection of uranium in the lungs is generally used only for relatively insoluble (Type $\mathrm{M}$ or $\mathrm{S}$ ) forms. The ${ }^{235} \mathrm{U}$ and ${ }^{234} \mathrm{Th}$ measurements can be used as independent checks on potentially positive results. The ${ }^{234} \mathrm{Th}$ (assumed to be in secular equilibrium with ${ }^{238} \mathrm{U}$ ) is slightly more sensitive in terms of total uranium than ${ }^{235} \mathrm{U}$ detection for most Hanford mixtures, and is the basis for the minimum detectable dose analyses. 
TABLE 5.4.1 Minimum Detectable Committed Effective Dose for 5- $\mu$ m AMAD Type M Acute Inhalation Intakes of Recycled Uranium ${ }^{(a)}$ Detected by Uranium Urinalysis or Chest Counting.

\begin{tabular}{|c|c|c|c|}
\hline \multirow[b]{2}{*}{ Day Post-Intake } & \multirow[b]{2}{*}{$\begin{array}{c}\text { Measurement } \\
\text { Interval }\end{array}$} & \multicolumn{2}{|c|}{ Committed Effective Dose (mrem) } \\
\hline & & Urinalysis $^{(\mathbf{b})}$ & $\begin{array}{c}{ }^{234} \text { Th by Chest } \\
\text { Count }^{(c)}\end{array}$ \\
\hline 1 & Special & 0.05 & 510 \\
\hline 2 & Special & 1.0 & 520 \\
\hline 7 & Special & 1.8 & 570 \\
\hline 14 & Special & 2.6 & 620 \\
\hline 30 & Monthly & 4.4 & 760 \\
\hline 90 & Quarterly & 9.4 & 1300 \\
\hline 180 & Semiannual & 18 & 2500 \\
\hline 365 & Annual & 54 & NA \\
\hline 730 & Biennial & 370 & NA \\
\hline
\end{tabular}

(a) Multiply doses by 0.73 for natural uranium and by 0.40 for depleted uranium.

(b) Based on screening level of $0.2 \mu \mathrm{g} / \mathrm{d}$ urine excretion, implying an occupationally attributed $0.18 \mu \mathrm{g} / \mathrm{d}$ above the environmental geometric mean level of $0.02 \mu \mathrm{g} / \mathrm{d}$.

(c) Based on detection of $1.5 \mathrm{nCi}$ of ${ }^{234} \mathrm{Th}$ by chest counting, implying the presence of $4.1 \mathrm{nCi}$ recycled uranium in the lungs.

$\mathrm{NA}=$ Not Applicable 
TABLE 5.4.2 Minimum Detectable Committed Effective Dose for 5- $\mu$ m AMAD Type S Acute Inhalation Intakes of Recycled Uranium Mixture, ${ }^{(a)}$ Detected by Uranium Urinalysis or Chest Counting.

\begin{tabular}{|c|c|c|c|}
\hline \multirow[b]{2}{*}{$\begin{array}{l}\text { Day Post- } \\
\text { Intake }\end{array}$} & \multirow[b]{2}{*}{$\begin{array}{c}\text { Measurement } \\
\text { Interval }\end{array}$} & \multicolumn{2}{|c|}{ Committed Effective Dose (mrem) } \\
\hline & & Uranium Urinalysis $^{(\mathbf{b})}$ & $\begin{array}{c}{ }^{234} \text { Th by Chest } \\
\text { Count }^{(\mathrm{c})}\end{array}$ \\
\hline 1 & Special & 5.5 & 1500 \\
\hline 2 & Special & 88 & 1600 \\
\hline 7 & Special & 200 & 1600 \\
\hline 14 & Special & 300 & 1700 \\
\hline 30 & Monthly & 500 & 2000 \\
\hline 90 & Quarterly & 900 & 2600 \\
\hline 180 & Semiannual & 1200 & 3000 \\
\hline 365 & Annual & 1500 & 3700 \\
\hline 730 & Biennial & 2000 & 5100 \\
\hline
\end{tabular}

(a) Multiply doses by 0.74 for natural uranium and 0.41 for depleted uranium.

(b) Based on screening level of $0.2 \mu \mathrm{g} / \mathrm{d}$ urine excretion, implying an occupationally attributed 0.18 $\mu \mathrm{g} / \mathrm{d}$ above the environmental geometric mean level of $0.02 \mu \mathrm{g} / \mathrm{d}$.

(c) Based on detection of $1.5 \mathrm{nCi}$ of ${ }^{234} \mathrm{Th}$ by chest counting, implying the presence of $4.1 \mathrm{nCi}$ recycled uranium mixture in the lungs. 
TABLE 5.4.3 Minimum Detectable Committed Effective Dose for 5- $\mu$ m AMAD Type F Acute Inhalation Intakes of Recycled Uranium ${ }^{(a)}$ Detected by Uranium Urinalysis ${ }^{(\text {b) }}$.

\begin{tabular}{clcc}
\hline $\begin{array}{c}\text { Day Post- } \\
\text { Intake }\end{array}$ & \multicolumn{1}{c}{$\begin{array}{c}\text { Measurement } \\
\text { Interval }\end{array}$} & Intake (mg) & $\begin{array}{c}\text { Committed Effective } \\
\text { Dose (mrem) }\end{array}$ \\
\hline & & & \\
1 & Special & 0.00098 & 0.002 \\
2 & Special & 0.028 & 0.062 \\
7 & Special & 0.052 & 0.11 \\
14 & Special & 0.093 & 0.20 \\
30 & Monthly ${ }^{(\mathrm{c})}$ & 0.26 & 0.58 \\
90 & Quarterly & 1.5 & 3.3 \\
180 & Semiannual & 5.8 & 13 \\
365 & Annual & 33 & 71 \\
730 & Biennial & 69 & 150 \\
\hline
\end{tabular}

(a) Multiply doses by 0.72 for natural uranium and 0.41 for depleted uranium.

(b) Based on screening level of $0.2 \mu \mathrm{g} / \mathrm{d}$ urine excretion, implying an occupationally attributed 0.18 $\mu \mathrm{g} / \mathrm{d}$ above the environmental geometric mean level of $0.02 \mu \mathrm{g} / \mathrm{d}$.

(c) Recommended frequency based on potential chemical toxicity of intakes using a screening level of $7 \mu \mathrm{g} / \mathrm{d}$ for chemical toxicity and $3 \mu \mathrm{g} / \mathrm{d}$ for dose assessment.

(d) Recommended frequency based on a screening level of $0.5 \mu \mathrm{g} / \mathrm{d}$ for dose assessment and $1 \mu \mathrm{g} / \mathrm{d}$ for chemical toxicity. 


\section{EXHIBIT 5.5}

\section{BIOASSAY CAPABILITY FOR PLUTONIUM}

$\underline{\text { In Vivo Lung Counting }}$

$\underline{\text { Urine Bioassay Analyses }}$

Plutonium in Urine (IPU)

$\begin{aligned} \mathrm{MDA}= & 0.02 \mathrm{dpm} / \mathrm{sample}^{239+24 \mathrm{O}} \mathrm{Pu} \\ & (\text { assumed } 0.02 \mathrm{dpm} / \mathrm{d})\end{aligned}$

Isotopic plutonium is normally analyzed in a simulated 24-hr urine sample. The MDA is assumed to apply to a daily excretion rate. The minimum detectable doses for fresh and aged plutonium mixtures are shown in Table 5.5.3. 
TABLE 5.5.1 Minimum Detectable Committed Effective Dose for Acute 5- $\mu$ m AMAD Inhalation Intakes of Type S Plutonium Mixtures Based on MDA Chest Count of ${ }^{241} \mathrm{Am}(0.16 \mathrm{nCi})$ at Indicated Day Post-Intake.

\begin{tabular}{|c|c|c|c|}
\hline \multirow[b]{2}{*}{$\begin{array}{l}\text { Day Post- } \\
\text { Intake }\end{array}$} & \multirow[b]{2}{*}{$\begin{array}{l}\text { Measurement } \\
\text { Interval }\end{array}$} & \multicolumn{2}{|c|}{$\begin{array}{c}\text { Committed Effective Dose } \\
\text { (rem) }\end{array}$} \\
\hline & & $\begin{array}{c}\text { 20-Y } \\
\text { Aged } \\
\text { Weapons- } \\
\text { Grade Pu }\end{array}$ & $\begin{array}{c}20-Y \\
\text { Aged } \\
\text { Fuel-Grade } \\
\text { Pu }\end{array}$ \\
\hline 1 & Special & 0.47 & 0.22 \\
\hline 2 & Special & 0.48 & 0.22 \\
\hline 7 & Special & 0.51 & 0.23 \\
\hline 14 & Special & 0.54 & 0.25 \\
\hline 30 & Monthly & 0.61 & 0.28 \\
\hline 60 & Bimonthly & 0.72 & 0.33 \\
\hline 90 & Quarterly & 0.79 & 0.36 \\
\hline 180 & Semiannual & 0.93 & 0.43 \\
\hline 365 & Annual $^{(a)}$ & 1.1 & 0.51 \\
\hline 730 & Biennial & 1.5 & 0.69 \\
\hline Reco & equency. & & \\
\hline
\end{tabular}

TABLE 5.5.2 Minimum Detectable Committed Effective Dose for Acute 5- $\mu$ m AMAD Inhalation Intakes of Type M Plutonium Mixtures Based on MDA Chest Count of ${ }^{241} \mathrm{Am}(0.16 \mathrm{nCi})$ at the Indicated Day Post Intake.

\begin{tabular}{|c|c|c|c|}
\hline \multirow[b]{2}{*}{$\begin{array}{l}\text { Day Post- } \\
\text { Intake }\end{array}$} & \multirow[b]{2}{*}{$\begin{array}{c}\text { Measurement } \\
\text { Interval }\end{array}$} & \multicolumn{2}{|c|}{$\begin{array}{c}\text { Committed Effective Dose } \\
\text { (rem) }\end{array}$} \\
\hline & & $\begin{array}{c}\text { 20-Y } \\
\text { Aged } \\
\text { Weapons- } \\
\text { Grade Pu }\end{array}$ & $\begin{array}{c}\text { 20-Y } \\
\text { Aged } \\
\text { Fuel-Grade } \\
\text { Pu }\end{array}$ \\
\hline 1 & Special & 2.0 & 0.89 \\
\hline 2 & Special & 2.0 & 0.91 \\
\hline 7 & Special & 2.2 & 0.99 \\
\hline 14 & Special & 2.4 & 1.1 \\
\hline 30 & Monthly & 2.9 & 1.3 \\
\hline 60 & Bimonthly & 4.0 & 1.8 \\
\hline 90 & Quarterly & 5.1 & 2.3 \\
\hline 180 & Semiannual & 9.3 & 4.2 \\
\hline 365 & Annual & 28 & 13 \\
\hline 730 & Biennial & 160 & 100 \\
\hline
\end{tabular}


TABLE 5.5.3 Minimum Detectable Committed Effective Dose for 5- $\mu$ m AMAD 20-year Aged Weapons-Grade Pu Mixtures ${ }^{(\mathrm{a})}$ Based on MDA Detection $(0.02 \mathrm{dpm} / \mathrm{d})$ of ${ }^{239} \mathrm{Pu}$ in Urine by Isotopic Plutonium Analysis (IPU).

\begin{tabular}{|c|c|c|c|c|}
\hline \multirow{2}{*}{\multicolumn{2}{|c|}{$\begin{array}{l}\text { Day Post- } \\
\text { Intake }\end{array}$}} & \multirow[b]{2}{*}{$\begin{array}{l}\text { Measurement } \\
\text { Interval }\end{array}$} & \multicolumn{2}{|c|}{ Committed Effective Dose (rem) } \\
\hline & & & $\begin{array}{c}\text { Type M } \\
\text { Inhalation }\end{array}$ & $\begin{array}{c}\text { Type } S \\
\text { Inhalation }\end{array}$ \\
\hline & 1 & Special & 0.0064 & 0.17 \\
\hline & 2 & Special & 0.011 & 0.29 \\
\hline & 7 & Special & 0.061 & 1.3 \\
\hline & 14 & Special & 0.13 & 2.1 \\
\hline & 30 & Monthly & 0.16 & 2.3 \\
\hline & 60 & Bimonthly & 0.18 & 2.4 \\
\hline & 90 & Quarterly & 0.21 & 2.5 \\
\hline & 180 & Semiannual & 0.28 & 2.5 \\
\hline & 365 & Annual $^{(\mathrm{b})}$ & 0.38 & 2.4 \\
\hline & 730 & Biennial & 0.53 & 2.2 \\
\hline (a) & \multicolumn{4}{|c|}{$\begin{array}{l}\text { For } 20 \text {-y aged Fuel Grade Pu mixtures, the associated committed effective doses } \\
\text { are only } 3 \text { to } 5 \% \text { higher than for } 20 \text {-y aged Weapons Grade Pu mixtures. Contact } \\
\text { the HIDP staff for unusual mixtures. } \\
\text { Recommended frequency. }\end{array}$} \\
\hline
\end{tabular}


EXHIBIT 5.6

BIOASSAY CAPABILITY FOR STRONTIUM-CESIUM MIXTURES

Bioassay for mixtures of ${ }^{90} \mathrm{Sr}$ and ${ }^{137} \mathrm{Cs}$ may include whole body counting for ${ }^{137} \mathrm{Cs}$, urinalysis for ${ }^{90} \mathrm{Sr}$, or a combination of both. The minimum detectable committed effective doses (mrem) shown below assume acute intakes of 5- $\mu \mathrm{m}$ AMAD Type F forms of these materials.

\begin{tabular}{|c|c|c|c|c|c|c|}
\hline \multirow[b]{2}{*}{$\begin{array}{c}\text { Days Post } \\
\text { Intake }\end{array}$} & \multicolumn{4}{|c|}{$\mathrm{Sr}^{90}$ to $\mathrm{Cs}^{137}$ Ratio } & \multirow[b]{2}{*}{ 100:1 } & \multirow[b]{2}{*}{ 1000:1 } \\
\hline & $\begin{array}{c}\text { Bioassay } \\
\text { Type }\end{array}$ & 1:1 & 10:1 & $30: 1$ & & \\
\hline 1 & $\begin{array}{l}\text { WBC }^{(a)} \\
\text { Urine }^{(b)}\end{array}$ & $\begin{array}{l}0.30 \\
0.01\end{array}$ & $\begin{array}{c}2.5 \\
0.01\end{array}$ & $\begin{array}{c}7.4 \\
0.01\end{array}$ & $\begin{array}{c}24 \\
0.01\end{array}$ & $\begin{array}{l}240 \\
0.01\end{array}$ \\
\hline 2 & $\begin{array}{l}\text { WBC }^{(a)} \\
\text { Urine }^{(b)}\end{array}$ & $\begin{array}{l}0.35 \\
0.03\end{array}$ & $\begin{array}{c}2.9 \\
0.02\end{array}$ & $\begin{array}{c}8.7 \\
0.02\end{array}$ & $\begin{array}{c}29 \\
0.02\end{array}$ & $\begin{array}{l}290 \\
0.02\end{array}$ \\
\hline 7 & $\begin{array}{l}\text { WBC }^{(a)} \\
\text { Urine }^{(b)}\end{array}$ & $\begin{array}{l}0.42 \\
0.10\end{array}$ & $\begin{array}{c}3.5 \\
0.08\end{array}$ & $\begin{array}{c}10 \\
0.08\end{array}$ & $\begin{array}{c}35 \\
0.08\end{array}$ & $\begin{array}{l}350 \\
0.08\end{array}$ \\
\hline 14 & $\begin{array}{l}\text { WBC }^{(a)} \\
\text { Urine }^{(b)}\end{array}$ & $\begin{array}{l}0.45 \\
0.22\end{array}$ & $\begin{array}{c}3.7 \\
0.18\end{array}$ & $\begin{array}{c}11 \\
0.18\end{array}$ & $\begin{array}{c}37 \\
0.18\end{array}$ & $\begin{array}{c}370 \\
0.18\end{array}$ \\
\hline 30 & $\begin{array}{l}\text { WBC }^{(a)} \\
\text { Urine }^{(b)}\end{array}$ & $\begin{array}{l}0.50 \\
0.64\end{array}$ & $\begin{array}{c}4.2 \\
0.54\end{array}$ & $\begin{array}{c}12 \\
0.53\end{array}$ & $\begin{array}{c}41 \\
0.53\end{array}$ & $\begin{array}{l}410 \\
0.53\end{array}$ \\
\hline 90 & $\begin{array}{l}\text { WBC }^{(a)} \\
\text { Urine }^{(\mathrm{b})}\end{array}$ & $\begin{array}{c}0.73 \\
5.6\end{array}$ & $\begin{array}{l}6.1 \\
4.7\end{array}$ & $\begin{array}{l}18 \\
4.6\end{array}$ & $\begin{array}{l}60 \\
4.6\end{array}$ & $\begin{array}{l}600 \\
4.6\end{array}$ \\
\hline 180 & $\begin{array}{l}\text { WBC }^{(a)} \\
\text { Urine }^{(b)}\end{array}$ & $\begin{array}{l}1.3 \\
11\end{array}$ & $\begin{array}{l}11 \\
9.2\end{array}$ & $\begin{array}{l}32 \\
9.1\end{array}$ & $\begin{array}{l}110 \\
9.0\end{array}$ & $\begin{array}{c}1100 \\
9.0\end{array}$ \\
\hline 365 & $\begin{array}{l}\text { WBC }^{(\mathrm{a})} \\
\text { Urine }^{(\mathrm{b})}\end{array}$ & $\begin{array}{l}4.2 \\
29\end{array}$ & $\begin{array}{l}35 \\
25\end{array}$ & $\begin{array}{c}100 \\
24\end{array}$ & $\begin{array}{c}340 \\
24\end{array}$ & $\begin{array}{c}3400 \\
24\end{array}$ \\
\hline 730 & $\begin{array}{l}\text { WBC }^{(a)} \\
\text { Urine }^{(b)}\end{array}$ & $\begin{array}{l}43 \\
77\end{array}$ & $\begin{array}{c}360 \\
64\end{array}$ & $\begin{array}{c}1100 \\
63\end{array}$ & $\begin{array}{c}3500 \\
63\end{array}$ & $\begin{array}{c}35000 \\
63\end{array}$ \\
\hline
\end{tabular}

(a) Based on $1.3 \mathrm{nCi}^{137} \mathrm{Cs}$ MDA for the NaI preview counter. Values for the coaxial Ge system are 0.77 times the values shown.

(b) Based on $10 \mathrm{dpm}$ MDA for ${ }^{90} \mathrm{Sr}$ urinalysis. 


\section{EXHIBIT 5.7}

\section{BIOASSAY CAPABILITY FOR CESIUM-PLUTONIUM MIXTURES AND STRONTIUM-PLUTONIUM MIXTURES}

Waste mixtures such as are found in tank farm facilities or storage basins often contain relatively large quantities of fission product activity $\left({ }^{137} \mathrm{Cs}\right.$ and/or $\left.{ }^{90} \mathrm{Sr}\right)$ and trace quantities of plutonium. Because periodic bioassay for plutonium is relatively insensitive, cost-effective bioassay programs can sometimes make use of ${ }^{137} \mathrm{Cs}$ and $/$ or ${ }^{90} \mathrm{Sr}$ as an indicator radionuclide for the possible presence of plutonium. The indicator bioassay concept involves a screening measurement for the indicator nuclide. If the indicator nuclide is present, inference is made that plutonium may also be present, initiating an investigation which may include special follow-up bioassay measurements. The capability and adequacy of indictor bioassay programs for the mixture depends on the activity ratio of the indicator relative to plutonium.

Tabulations are provided in this exhibit for ${ }^{137} \mathrm{Cs}+{ }^{239} \mathrm{Pu}$ mixtures and ${ }^{90} \mathrm{Sr}+{ }^{239} \mathrm{Pu}$ mixtures. Various activity ratios for the mixtures at intake are addressed. In both sets of tabulations, the indicator nuclide $\left({ }^{137} \mathrm{Cs}\right.$ or $\left.{ }^{90} \mathrm{Sr}\right)$ is assumed to be inhalation Type $\mathrm{F}$ form and ${ }^{239} \mathrm{Pu}$ is assumed to be Type M. These assumptions are considered reasonable because the mixtures involved typically are of an aqueous or semi-aqueous nature (waste tank contents, storage basin sludges, etc). The minimum detectable doses for Type $\mathrm{S}$ plutonium would be substantially lower than those tabulated for Type M. It was also assumed that all intakes were by inhalation of $5-\mu \mathrm{m}$ AMAD aerosols. The activity ratios of the indicator relative to ${ }^{239} \mathrm{Pu}$ are suitable for gross alpha activity smear or air sample results and can also be extended to pure isotopes (including ${ }^{241} \mathrm{Am}$ ) for the purposes of bioassay program design. Minimum detectable doses would vary slightly between plutonium isotopes but would generally be less than a 10 percent variation.

Bioassay for mixtures of ${ }^{137} \mathrm{Cs}$ and alpha-emitting isotopes of $\mathrm{Pu}$ can be accomplished by using whole body counting as a screening tool for many mixtures, if there is reasonable assurance about the likely or worst-case activity ratios. If nothing is detected by the screening whole body count, no additional bioassay need be performed. If ${ }^{137} \mathrm{Cs}$ is detected, then at least one supplemental urinalysis should be performed to provide monitoring capability approximately comparable to those workers on periodic plutonium bioassays. More in-depth evaluation may include plutonium fecal samples, as might be performed for suspected plutonium intakes.

In a similar approach, screening bioassay for mixtures of ${ }^{90} \mathrm{Sr}$ and plutonium can be accomplished by a ${ }^{90} \mathrm{Sr}$ urinalysis. This screening technique may be particularly suitable for waste tank sludges that tend to be rich in ${ }^{90} \mathrm{Sr}$ and plutonium but somewhat reduced in ${ }^{137} \mathrm{Cs}$. 


\section{EXHIBIT 5.7}

\section{BIOASSAY CAPABILITY FOR CESIUM-PLUTONIUM MIXTURES AND STRONTIUM-PLUTONIUM MIXTURES (contd)}

\begin{tabular}{|c|c|c|c|c|c|}
\hline \multicolumn{6}{|c|}{${ }^{137} \mathrm{Cs}$ and Pu Mixtures } \\
\hline \multirow{2}{*}{$\begin{array}{l}\text { Days Post } \\
\text { Intake }\end{array}$} & \multicolumn{5}{|c|}{$\begin{array}{l}\text { Minimum detectable committed effective dose } \\
\text { for }{ }^{137} \mathrm{Cs}:{ }^{239} \mathrm{Pu} \text { ratios at intake (mrem) }{ }^{(\mathrm{a})}\end{array}$} \\
\hline & $\underline{1: 1}$ & $\underline{10: 1}$ & $\underline{40: 1}$ & $\underline{100: 1}$ & $\underline{1000: 1}$ \\
\hline 1 & 260 & 26 & 6.6 & 2.7 & 0.32 \\
\hline 2 & 310 & 31 & 7.8 & 3.2 & 0.37 \\
\hline 7 & 370 & 37 & 9.4 & 3.8 & 0.45 \\
\hline 14 & 390 & 39 & 10 & 4.0 & 0.47 \\
\hline 30 & 440 & 44 & 11 & 4.4 & 0.53 \\
\hline 90 & 640 & 64 & 16 & 6.5 & 0.77 \\
\hline 180 & 1,100 & 110 & 29 & 12 & 1.4 \\
\hline 365 & 3,700 & 370 & 93 & 40 & 4.4 \\
\hline 730 & 38,000 & 3,800 & 950 & 380 & 45 \\
\hline
\end{tabular}

(a) Based on $1.3 \mathrm{nCi}^{137} \mathrm{Cs}$ MDA for whole body counter, assuming 5- $\mu \mathrm{m}$ AMAD aerosol, Type $\mathrm{F}$ Cs and Type M Pu. Values for the coaxial Ge detector system are 0.77 times the values shown.

\begin{tabular}{|c|c|c|c|c|}
\hline \multicolumn{5}{|c|}{${ }^{90} \mathrm{Sr}$ and Pu Mixtures } \\
\hline \multirow{2}{*}{$\begin{array}{l}\text { Days Post } \\
\text { Intake }\end{array}$} & \multicolumn{4}{|c|}{$\begin{array}{l}\text { Minimum detectable committed effective dose for } \\
{ }^{90} \mathrm{Sr}:{ }^{239} \mathrm{Pu} \text { ratios at intake }(\mathrm{mrem}){ }^{(\mathrm{b})}\end{array}$} \\
\hline & 1000:1 & $340: 1$ & $100: 1$ & $\underline{10: 1}$ \\
\hline 1 & 0.02 & 0.03 & 0.09 & 0.80 \\
\hline 2 & 0.04 & 0.09 & 0.25 & 2.3 \\
\hline 7 & 0.17 & 0.33 & 0.94 & 8.6 \\
\hline 14 & 0.37 & 0.75 & 2.1 & 19 \\
\hline 30 & 1.1 & 2.2 & 6.2 & 57 \\
\hline 90 & 9.4 & 19 & 53 & 490 \\
\hline 180 & 19 & 37 & 100 & 970 \\
\hline 365 & 50 & 100 & 280 & 2,600 \\
\hline 730 & 130 & 260 & 730 & 6,800 \\
\hline
\end{tabular}

(b) Based on $10 \mathrm{dpm}{ }^{90} \mathrm{Sr}$ MDA for one-day urine sample, assuming 5- $\mu \mathrm{m}$ AMAD aerosol, Type F Sr and Type M Pu. 


\section{EXHIBIT 5.8}

\section{PRENATAL BIOASSAY PROGRAM}

For most radionuclides the dose to embryo/fetus will be similar to or less than the dose to the corresponding maternal tissues, but current guidance requires the dose to the embryo/fetus to be calculated separately. Bioassay results from shortly after the date the pregnancy was declared and following the end of the pregnancy are adequate to demonstrate compliance with dose limits. The following table shows the maximum dose received by the embryo/fetus following an inhalation intake by the mother that results in an excretion or retention of radioactive material at the end of pregnancy equal to the minimum detectable activity for the bioassay analysis used.

\section{Minimum Detectable Dose for Prenatal Bioassay Program}

\begin{tabular}{|c|c|c|c|c|c|}
\hline \multicolumn{4}{|c|}{ Maternal Inhalation $(5-\mu \mathrm{m}$ AMAD) } & \multicolumn{2}{|c|}{ Minimum Detectable Dose $^{(\mathrm{a})}$, mrem } \\
\hline Nuclide & Type & $\begin{array}{c}\text { Analysis }^{(b)} \text { and } \\
\text { MDA }\end{array}$ & Intake & Acute Intake & Chronic Intake \\
\hline${ }^{238} \mathrm{Pu}$ or ${ }^{239} \mathrm{Pu}$ & M & Urine, $0.02 \mathrm{dpm}$ & 2.33 & 0.1 & $1 \mathrm{E}-4$ \\
\hline${ }^{238} \mathrm{Pu}$ or ${ }^{239} \mathrm{Pu}$ & $\mathrm{S}$ & Urine, $0.02 \mathrm{dpm}$ & 53.6 & 0.7 & $3 \mathrm{E}-4$ \\
\hline $\mathrm{U}$ (recycled) & $\mathrm{F}$ & Urine, $0.2 \mu \mathrm{g}$ & $32.5 \mathrm{mg}$ & 0.001 & $2 \mathrm{E}-7$ \\
\hline $\mathrm{U}$ (recycled) & $\mathrm{S}$ & Urine, $0.2 \mu \mathrm{g}$ & $68.2 \mathrm{mg}$ & 0.2 & $4 \mathrm{E}-5$ \\
\hline${ }^{90} \mathrm{Sr}$ & $\mathrm{F}$ & Urine, $10 \mathrm{dpm}$ & $220 \mathrm{nCi}$ & 0.001 & $1 \mathrm{E}-6$ \\
\hline${ }^{90} \mathrm{Sr}$ & $\mathrm{S}$ & Urine, $10 \mathrm{dpm}$ & $2000 \mathrm{nCi}$ & 3.3 & $2 \mathrm{E}-3$ \\
\hline${ }^{137} \mathrm{Cs}$ & $\mathrm{F}$ & $\begin{array}{l}\text { In Vivo, } 1.3 \\
\mathrm{nCi}\end{array}$ & $31 \mathrm{nCi}$ & 0.6 & $2 \mathrm{E}-4$ \\
\hline
\end{tabular}

(a) Effective dose to the embryo/fetus for the 9-month gestation period and assuming intake occurred at time of conception based on ICRP-88 (2001) dose coefficients.

(b) All urinalyses assumed to represent total 24-hour excretion at 1 year (365-d) post intake. 


\section{EXHIBIT 5.9}

\section{GRACE PERIOD TECHNICAL JUSTIFICATION}

The adoption of a grace period for routine bioassay measurements, consisting of the scheduled month and the next month following, implies that as much as two months may pass beyond the scheduled date of a measurement and the date that it is actually obtained. The impact of this potential delay on the minimum detectable dose (MDD) in terms of committed effective dose as an indication of bioassay program sensitivity for various circumstances is discussed below. All inhalation intakes were based on $5-\mu \mathrm{m}$ AMAD particle size.

\section{Annual Bioassays}

Type S Pu Urinalysis:

Type M Pu Urinalysis:

Type S U Urinalysis:

Type M U Urinalysis:

Type F Sr Urinalysis:

Acute Type S Pu

Chest Counts

Acute Type S Uranium Chest Counts
No significant change in MDD from semi-annual to biennial (MDD goes from 2.5 rem semi-annual to 2.2 rem biennial). Thus, choice of grace period date for this case is independent of technical considerations about MDD.

Change from annual to biennial results in a nominal $40 \%$ increase of MDD (0.38 to $0.53 \mathrm{rem}$ ). A grace period of even a year would still provide an adequate safety net with regard to compliance with the dose limit.

Change from annual to biennial results in a nominal $33 \%$ increase in MDD (1.5 rem to 2.0 rem for recycled uranium). Grace period choice is independent of technical MDD considerations.

Change from annual (54 mrem) to biennial (370 mrem) is a significant impact on the MDD, but still provides a good safety net with regard to the dose limit. A lengthy grace period (e.g., several months for an annual sample) can still be acceptable.

Change from annual (24 mrem) to biennial (63 mrem) has no significant impact on MDD. Thus, choice of grace period for this case is independent of technical considerations about MDD.

Shifting from annual to biennial chest counts changes the MDD from $1.1 \mathrm{rem}$ to $1.5 \mathrm{rem}$ for 20 -y aged weapons grade $\mathrm{Pu}$ and $0.51 \mathrm{rem}$ to $0.69 \mathrm{rem}$ for $20-\mathrm{y}$ aged fuel grade $\mathrm{Pu}$. Thus, choice of grace period for this case is independent of technical considerations about MDD.

Shifting from annual chest counts (3.7 rem) to biennial (5.1 rem) shifts MDD from being able to show compliance with dose limit to not being able to show such compliance. A two month grace Chest Counts period date for this case has no significant technical impact on MDD. 


\section{EXHIBIT 5.9}

\section{GRACE PERIOD TECHNICAL JUSTIFICATION (contd)}

10:1 Cs to Pu Mixtures

Whole Body Count
(For ratios $<10: 1, \mathrm{Pu}$ bioassay is recommended)

Shifting from annual WBC (MDD of 370 mrem) to 14 months

(MDD of $540 \mathrm{mrem}$ ) has modest impact but does not affect the ability to show compliance with the dose limit. A two-month grace period date for this case would seem acceptable from a technical standpoint.

\section{Semi-Annual Bioassays}

No present bioassay programs are recommended with semi-annual urinalyses.

\section{Quarterly Bioassays}

Infrequent / acute

Type M U Urinalysis:

Chronic / multiple acute Type S U Urinalysis:

\section{Monthly Bioassays}

Tritium

Soluble U Urinalysis:

Post Job
Quarterly (9.4 mrem) to semi-annual (18 mrem) has no significant impact on MDD. Thus, choice of grace period date for this case is independent of technical considerations about MDD.

Quarterly (900 mrem) to semi-annual (1,200 mrem) has modest impact on MDD but does not affect the ability to show compliance with the dose limit. Thus, choice of grace period date for this case is independent of technical considerations about MDD.
Shift from biweekly (0.064 mrem) to bimonthly ( $0.98 \mathrm{mrem})$ has no significant impact on MDD. Thus, choice of grace period date for this case is independent of technical considerations about MDD. If a biweekly or monthly sample is missed, there is no problem with waiting until the next one comes up. Missing two in a row is reasonable grounds for work restriction.

None of these are currently being performed, and chemical toxicity, not internal dose, is the driving technical factor for the measurements. Changing from monthly ( $7 \mathrm{ug} / \mathrm{d}$ screening level for chemical toxicity) to a quarterly sample $(1 \mathrm{ug} / \mathrm{d}$ for chemical toxicity) is not likely to have a major impact.

The selection of a sampling time following completion of a job is not a significant technical issue for $\mathrm{Pu}, \mathrm{U},{ }^{90} \mathrm{Sr}$, or even ${ }^{3} \mathrm{H}$. Because routine monitoring programs are typically at much longer frequencies, a suggested sample late date is one-month following completion of the work. 


\section{HANFORD INTERNAL DOSIMETRY PROGRAM MANUAL PNL-MA-552}

\section{SECTION 6.0, BIOASSAY SERVICES}

Issued: For implementation effective 01/01/2010

Supersedes: 04/2007

Use Category: Not applicable

\section{Approval Signatures:}

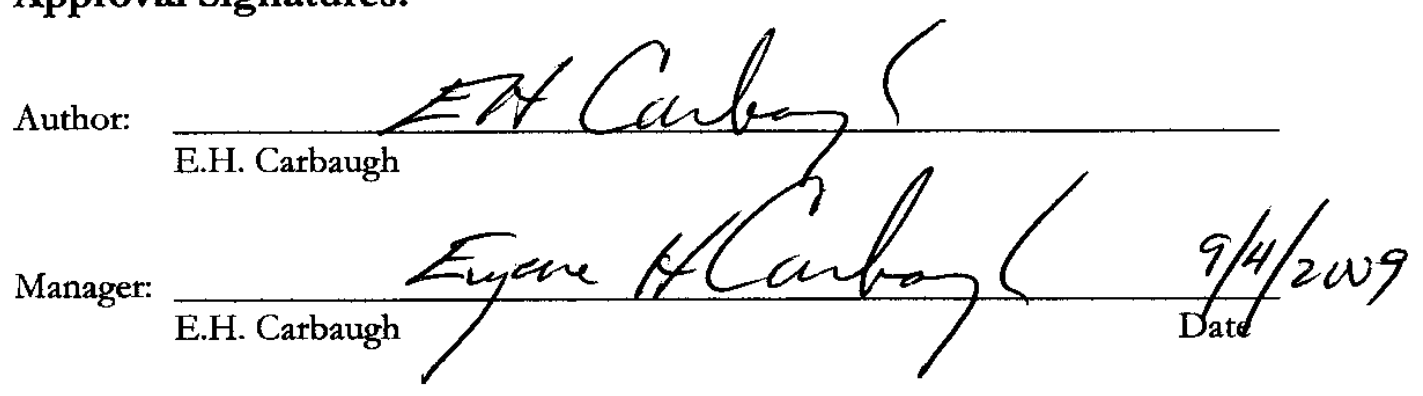

Reviewer Signatures:

Reviewer \#1

Approved by the Hanford Personnel Dosimetry Advisory Committee is not required for this section per Section 1.0 of this manual. 


\section{Contents}

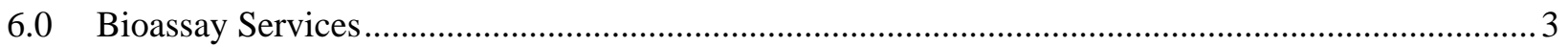

6.1 Indirect Bioassay Measurement Services..................................................................................... 3

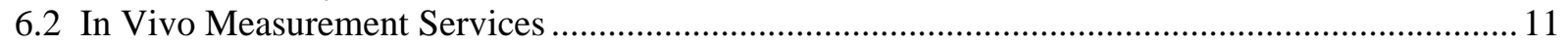

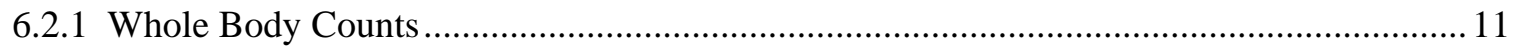

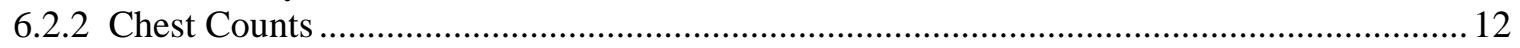

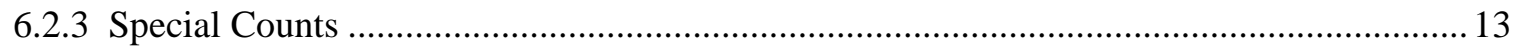

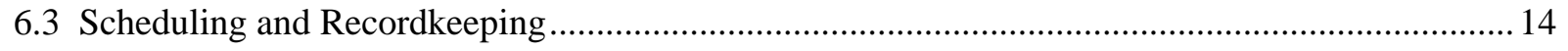

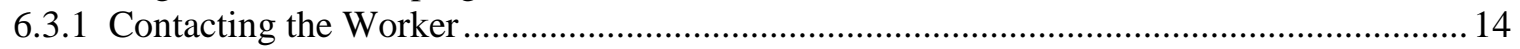

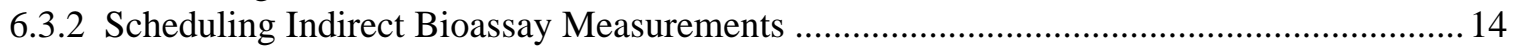

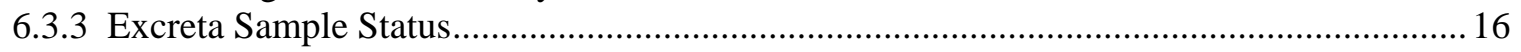

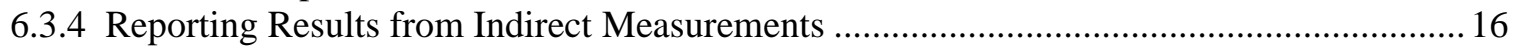

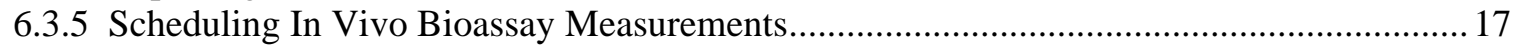

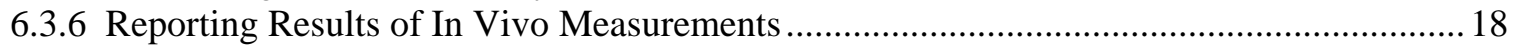

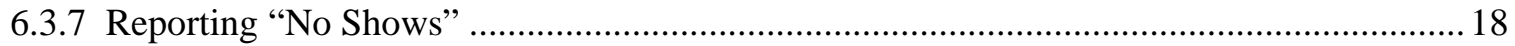

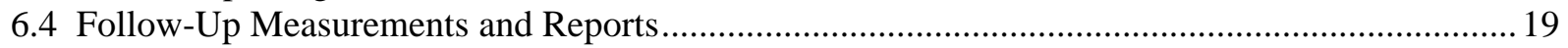

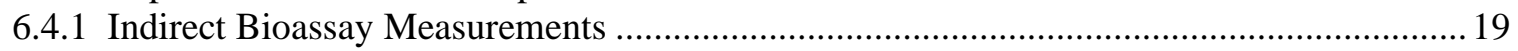

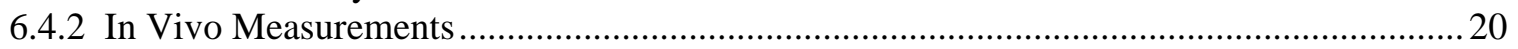

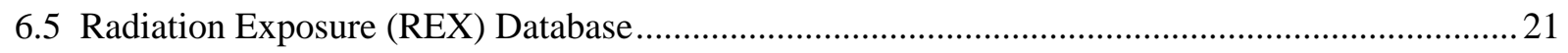

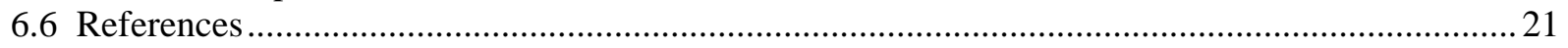




\subsection{Bioassay Services}

After a bioassay monitoring need has been identified and the appropriate types of measurements have been determined, the measurements need to be scheduled and performed. This chapter describes the normal bioassay services provided through the Hanford Internal Dosimetry Program (HIDP), the scheduling of bioassay samples, and the generation, reporting, and follow-up of data. Special services not included here may be obtainable by contacting HIDP.

Frequently used telephone numbers and mail stops for bioassay services are:

- $\quad$ HIDP Office, 376-7245, B1-60

- $\quad$ IVRRF, 376-6102, B1-60

- $\quad$ Dosimetry Operations, 373-1322, P7-01

- $\quad$ General Engineering Laboratories, Richland, 943-2121.

\subsection{Indirect Bioassay Measurement Services}

The indirect bioassay analyses are performed by the Analytical Services Laboratory (Lab). The Lab is responsible for the following activities:

- Providing sample kits, including kit delivery and pickup at designated locations (usually worker residences) within a 75-mile radius of Richland. (Field Dosimetry is responsible for kit delivery and pickup outside this range unless a mailer kit is used.) Delivery and pickup of routine and priority samples are usually available on business days only.

- Attempting a second pickup of a "container not out" sample on a day specified by Field Dosimetry or the worker, within 10 days after the originally scheduled pickup.

- Analyzing urine and fecal samples in four processing categories: routine, priority, expedite, and emergency.

- Analyzing miscellaneous samples, such as air filters, smears, blood, tissue specimens, or cloth, by emergency or priority processing.

Provisions have been made for obtaining bioassay samples from workers outside the 75-mile service area through the use of mail and private carrier. HIDP should be contacted if this method of bioassay sampling is to be done.

Kit Codes

Lab Capability
The sample type and collection method are identified by the sample kit code. Kit codes that are available are described in Appendix B, Table B.4. Instructions for kit use are provided in Appendix D.

The analytical and reporting requirements for the four processing categories as of FY 2009 are detailed in Tables 6.1 through 6.6. Changes in these requirements may occur from year to year. Therefore, HIDP should be contacted if the most current information is needed. 
Note that the contract detection levels (CL) listed are extracted from the contract statement of work (SOW) for the Lab and are considered the upper limit for acceptable performance. The minimal detectable activities (MDA) calculated for comparison with the CLs are based on the equations developed in the Multi-Agency Radiological Laboratory analytical Protocols Manual (MARLAP 2004).

Minimum Sample Size Minimum volumes for valid samples are specified in the Lab's statement of work. They generally depend on the same kit code and processing category. Unless otherwise noted, the numeric kit code represents both sample delivery and pick-up and the letter kit code designation "other than A or B" represents sample pick-up only. Values are shown below:

\begin{tabular}{cllc}
\hline Kit Code & \multicolumn{1}{c}{ Application } & Routine Processing & Other Processing \\
\cline { 3 - 4 } 1,P & Approximate 24 hr & $500 \mathrm{~mL}$ & \\
2,Q & 12-hr Termination & $20 \mathrm{~mL}$ & $20 \mathrm{~mL}$ \\
3,R & Total 24-hr & $500 \mathrm{~mL}$ & $20 \mathrm{~mL}$ \\
4,S & Single Void Urine & $20 \mathrm{~mL}$ & $20 \mathrm{~mL}$ \\
5,T & Feces & not applicable & $20 \mathrm{gL}$ \\
6,U & Approximate 12-hr. & $250 \mathrm{~mL}$ & $20 \mathrm{~mL}$ \\
7,V & 12-hr weekend & $250 \mathrm{~mL}$ & $20 \mathrm{~mL}$ \\
8,W & Single Void Fecal & $20 \mathrm{~g}$ & not applicable \\
9,X & Mailer Kit & $20 \mathrm{~mL}$ & $20 \mathrm{~mL}$ \\
A,Y & Approximate 48-hr & $1000 \mathrm{~mL}$ & not applicable \\
B,Not & 12-hr Term Sample & $20 \mathrm{~mL}$ & $20 \mathrm{~mL}$ \\
Applicable & "Delivery Only” & & \\
\hline
\end{tabular}

Tritium is an exception to these values. The minimum volume for tritium analysis is $20 \mathrm{~mL}$, regardless of kit code. For other analyses, samples with less than the listed volumes shall be reported as insufficient volume (IS) and shall not be processed unless specifically directed otherwise by HIDP. 


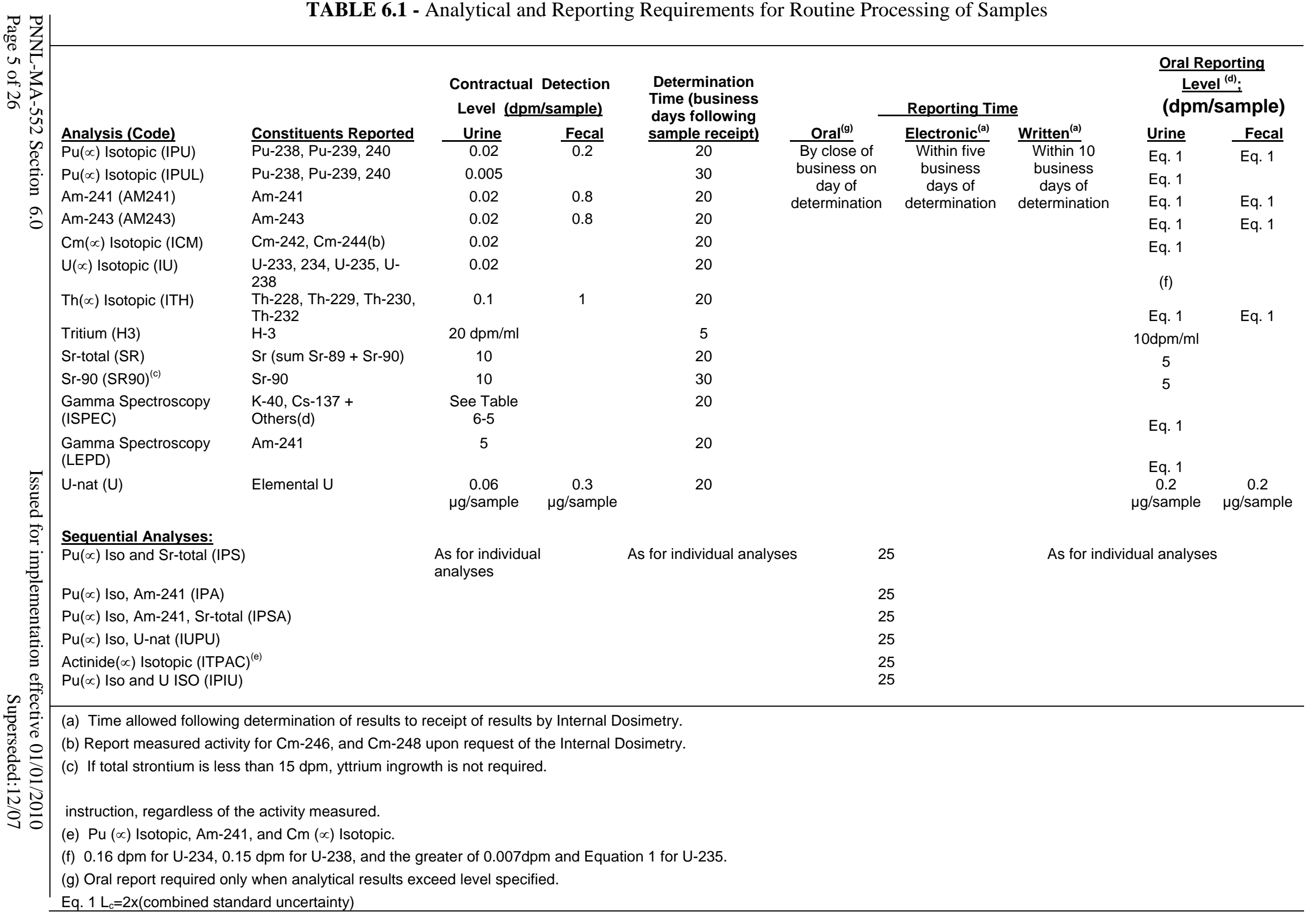

PNL-MA-552 Section 6.0

Page 5 of 26
Issued for implementation effective 01/01/2010

Supersedes: $12 / 07$ 
TABLE 6.2 - Analytical and Reporting Requirements for Priority Processing of Samples

\begin{tabular}{|c|c|c|c|c|c|c|c|}
\hline \multirow[b]{2}{*}{ Analysis (Code) } & \multirow[b]{2}{*}{ Constituents Reported } & \multicolumn{2}{|c|}{$\begin{array}{l}\text { Contractual Detections } \\
\text { Level(a) (dpm/sample) }\end{array}$} & $\begin{array}{c}\text { Determination } \\
\text { Time (business } \\
\text { days following }\end{array}$ & \multirow{4}{*}{$\begin{array}{c}\text { Oral(b) } \\
\begin{array}{c}\text { By close of } \\
\text { business on } \\
\text { day of }\end{array} \\
\text { determination }\end{array}$} & \multirow{3}{*}{$\begin{array}{l}\frac{\text { Reporting Time }}{\text { Electronic(b) }} \\
\text { Within five } \\
\text { business days }\end{array}$} & \multirow{3}{*}{$\begin{array}{c}\frac{\text { Written }(\mathbf{b})}{\text { Within } 10} \\
\text { business day }\end{array}$} \\
\hline & & Urine & Feces & sample receipt) & & & \\
\hline $\mathrm{Pu}(\propto)$ Isotopic (IPU) & Pu-238, Pu-239, 240 & 0.02 & 0.2 & 8 & & & \\
\hline $\mathrm{U}(\propto)$ Isotopic (IU) & $\mathrm{U}-233,234, \mathrm{U}-235, \mathrm{U}-238$ & 0.02 & 0.3 & 8 & & & \\
\hline $\mathrm{Ra}(\propto)$ Isotopic (IRA) & $\mathrm{Ra}-224, \mathrm{Ra}-226$ & 0.3 & 1.5 & 8 & & & \\
\hline Np-237 (NP237) & Np-237 & 0.02 & 0.1 & 8 & & & \\
\hline Am-241 (AM241) & Am-241 & 0.02 & 0.8 & 8 & & & \\
\hline Am-243 (AM243) & $\begin{array}{l}\text { Am-243 } \\
\text { Th-228, Th-229, Th-230, Th- }\end{array}$ & 0.02 & 0.8 & 8 & & & \\
\hline Th( $\propto$ ) Isotopic $(\mathrm{ITH})$ & 232 & $\begin{array}{c}0.1 \\
0.06\end{array}$ & 1 & 8 & & & \\
\hline U-nat $(U)$ & Elemental U & $\mu \mathrm{g} / \mathrm{sample}$ & $0.3 \mu \mathrm{g} / \mathrm{sample}$ & 8 & & & \\
\hline Tritium (H3) & $\mathrm{H}-3$ & $20 \mathrm{dpm} / \mathrm{ml}$ & & 3 & & & \\
\hline $\mathrm{C}-14$ (C14) & $\mathrm{C}-14$ & $10 \mathrm{dpm} / \mathrm{ml}$ & 200 & 3 & & & \\
\hline Sr-total (SR) & Sr (sum Sr-89 + Sr-90) & 10 & 30 & 7 & & & \\
\hline Sr-Isotopic (ISR) & Sr-89, Sr-90 & $\begin{array}{l}30,30 \\
\text { respectively }\end{array}$ & $\begin{array}{l}45,30 \\
\text { respectively }\end{array}$ & $15(e)$ & & & \\
\hline Sr-90 (SR90) & Sr-90 & 10 & 30 & $15(e)$ & & & \\
\hline Pu-241 (PU241) & Pu-241 & 10 & 10 & 9 & & & \\
\hline & K-40, Cs-137 + Others(d) & See Table 6-5 & See Table 6-5 & 3 & & & \\
\hline $\begin{array}{l}\text { Gamma Spectroscopy } \\
\text { (LEPD) } \\
\text { Sequential Analyses: }\end{array}$ & Am-241 & 5 & 5 & 8 & & & \\
\hline $\mathrm{Pu}(\propto)$ Iso and Sr-total (IPS) & As for individual analyses & As for indiv & ual analyses & 9 & & & \\
\hline $\mathrm{Pu}(\propto)$ Iso, Am-241 (IPA) & & & & 9 & & & \\
\hline $\mathrm{Pu}(\propto)$ Iso, Am-241, Sr-total(I & & & & 9 & & & \\
\hline $\mathrm{Pu}(\propto)$ Iso, $\mathrm{Pu}-241$ (IPUB) & & & & $9(f)$ & & & \\
\hline $\mathrm{Pu}(\propto)$ Iso, $\mathrm{Pu}-241, \mathrm{Am}-241$ & UBA) & & & $9(f)$ & & & \\
\hline $\mathrm{Pu}(\propto)$ Iso, U-nat (IUPU) & & & & $9(g)$ & & & \\
\hline $\mathrm{Pu}(\propto)$ Iso and UISO (IPIU) & & & & 9 & & & \\
\hline
\end{tabular}

(a) CL is stated in terms of dpm/sample for fecal samples of 20 to $500 \mathrm{~g}$.

(b) Time allowed following determination of results to receipt of results by Internal Dosimetry.

(c) Report measured activity for $\mathrm{Cm}-246$, and $\mathrm{Cm}-248$ upon request of the Internal Dosimetry.

(d) Report all isotopes present at levels exceeding one-half the appropriate CL listed in Table 6-5. If ordered by the Internal Dosimetry, report results for radionuclides in

Table 6-5 specified in the processing instructions, regardless of the activity measured.

(e) Sr-90 to be determined within 15 business days. Total Strontium to be determined within 7 business days and reported orally upon determination. If total strontium is

less than $15 \mathrm{dpm}$, yttrium in-growth is not required.

(f) Pu-241 to be determined within 16 business days.

(g) U-nat to be determined within 12 business days. 
TABLE 6.3 - Analytical and Reporting Requirements for Expedite Processing of Samples

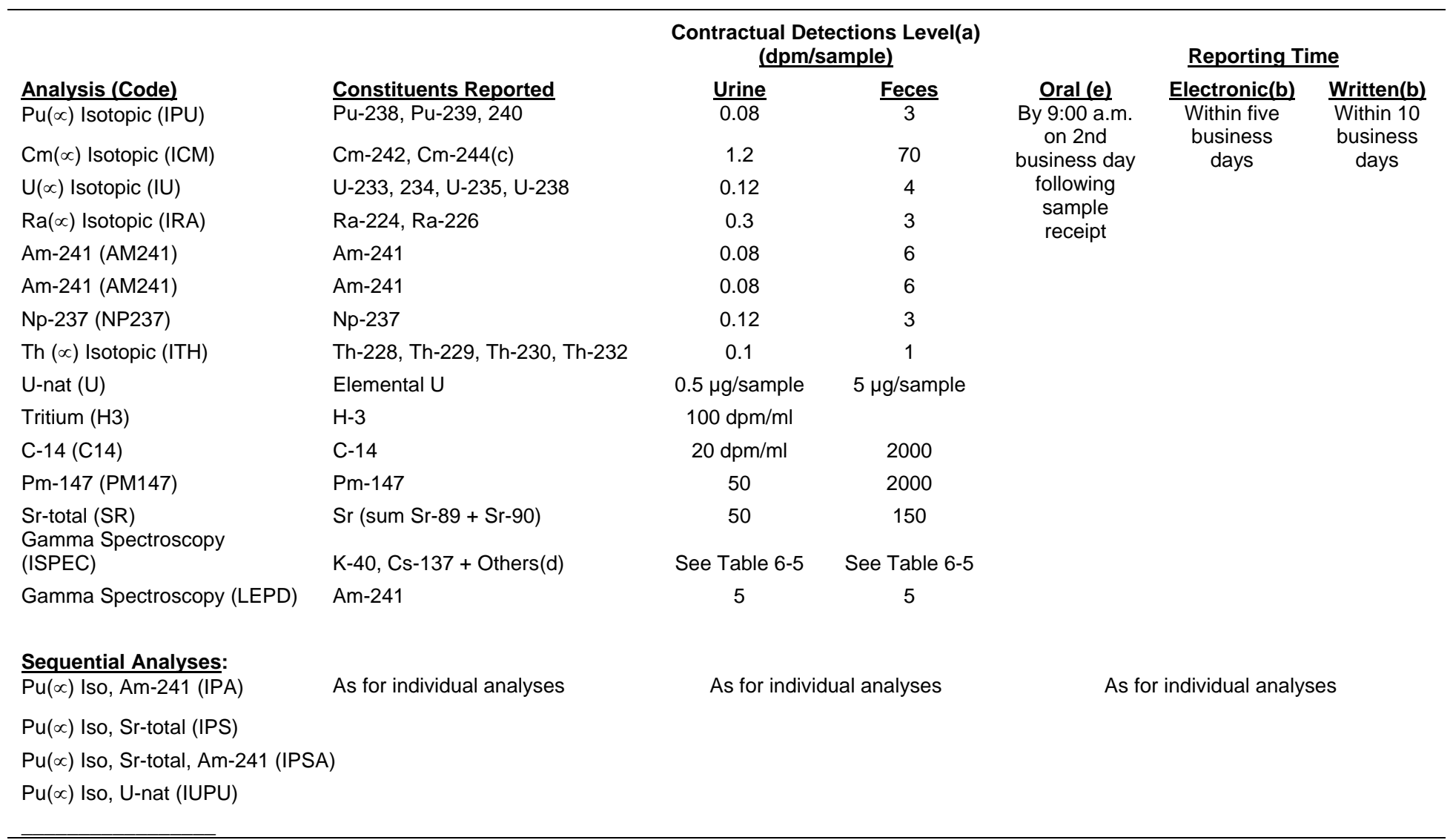

(a) Detection level in terms of dpm/300 ml for urine samples in excess of $300 \mathrm{ml}$. CL is stated in terms of dpm/sample for fecal samples of 20 to $500 \mathrm{~g}$.

(b) Time allowed following oral report to delivery of results to the Internal Dosimetry.

(c) Report measured activity for $\mathrm{Cm}-246$, and $\mathrm{Cm}-248$ upon request of the Internal Dosimetry.

(d) Report all isotopes present at levels exceeding one-half the appropriate CL listed in Table 6-5. If ordered by the Internal Dosimetry, report results for radionuclides in Table 6-5 specified in the processing instructions, regardless of the activity measured.

(e) Oral report required for all analytical results. 
TABLE 6.4 - Analytical and Reporting Requirements for Emergency Processing of Samples

\begin{tabular}{|c|c|c|c|c|c|c|}
\hline \multirow[b]{2}{*}{ Analysis (Code) } & & \multicolumn{2}{|c|}{$\begin{array}{l}\text { Contractual Detections Level(a) } \\
\text { (dpm/sample) }\end{array}$} & \multicolumn{3}{|c|}{$\underline{\text { Reporting Time }}$} \\
\hline & $\frac{\text { Constituents Reported }}{\text { Pu-238, Pu-239, } 240}$ & $\frac{\text { Urine }}{0.5}$ & $\frac{\text { Feces }}{9}$ & $\frac{\text { Oral (b) }}{24}$ & \multirow{13}{*}{$\begin{array}{l}\frac{\text { Electronic(e) }}{\text { Within five }} \\
\text { business days. }\end{array}$} & \multirow{3}{*}{$\begin{array}{c}\text { Written(c) } \\
\text { Within ten } \\
\text { business } \\
\text { days. }\end{array}$} \\
\hline $\mathrm{Cm}(\propto)$ Isotopic (ICM) & $\mathrm{Cm}-242,244+$ Others(d) & 10 & 240 & 24 & & \\
\hline $\mathrm{U}(\propto)$ Isotopic (IU) & U-233, 234, U-235, U-238 & 1 & 12 & 24 & & \\
\hline $\mathrm{Ra}(\propto)$ Isotopic (IRA) & $\begin{array}{l}\text { Ra-224, Ra-226 } \\
\text { Th-228, Th-229, Th-230, Th- }\end{array}$ & 2 & 10 & 24 & & \\
\hline Th( $\propto$ ) Isotopic (ITH) & 232 & 0.5 & 2 & 24 & & \\
\hline Am-241 (AM241) & $A m-241$ & 1 & 20 & 24 & & \\
\hline Am-241 (AM241) & Am-241 & 1 & 20 & 24 & & \\
\hline Np-237 (NP237) & Np-237 & 1 & 10 & 24 & & \\
\hline U-nat (U) & Elemental U & $7 \mu \mathrm{g} / \mathrm{sample}$ & $8 \mu \mathrm{g} / \mathrm{sample}$ & 24 & & \\
\hline Tritium (H3) & $\mathrm{H}-3$ & $100 \mathrm{dpm} / \mathrm{ml}$ & - & 24 & & \\
\hline C-14 (C14) & C-14 & $100 \mathrm{dpm} / \mathrm{ml}$ & 10,000 & 24 & & \\
\hline Pm-147 (PM147) & Pm-147 & 80 & 8,000 & 24 & & \\
\hline $\begin{array}{l}\text { Sr-total (SR) } \\
\text { Gamma Spectroscopy } \\
\text { (ISPEC) } \\
\text { Gamma Spectroscopy (LEPD) }\end{array}$ & $\begin{array}{l}\text { Sr }(\mathrm{Sr}-89+\mathrm{Sr}-90) \\
\mathrm{K}-40, \mathrm{Cs}-137,+ \text { Others }(\mathrm{e}) \\
\text { Am-241 }\end{array}$ & $\begin{array}{c}80 \\
\text { See Table 6-6 } \\
20\end{array}$ & $\begin{array}{c}450 \\
\text { See Table 6-6 } \\
20\end{array}$ & $\begin{array}{l}24 \\
24 \\
24\end{array}$ & & \\
\hline \multicolumn{7}{|l|}{ Sequential Analyses: } \\
\hline $\begin{array}{l}\mathrm{Pu}(\propto) \text { Iso, Sr-total (IPS) } \\
\mathrm{Pu}(\propto) \text { Iso, Sr-total, Am-241 (IP } \\
\mathrm{Pu}(\propto) \text { Iso, U-nat (IUPU) }\end{array}$ & & analyses & analyses & $\begin{array}{l}24 \\
24 \\
24\end{array}$ & & \\
\hline \multicolumn{7}{|c|}{$\begin{array}{l}\text { (a) Detection level in terms of } \mathrm{dpm} / 300 \mathrm{ml} \text { for urine samples in excess of } 300 \mathrm{ml} \text {. CL is stated in terms of dpm/sample for fecal samples of } 20 \text { to } 500 \mathrm{~g} \text {. } \\
\text { (b) Hours following sample receipt. Oral report required for all analytical results. These time requirements apply for up to } 25 \text { ( } 20 \text { for LEPD) samples submitted at any } \\
\text { one time. }\end{array}$} \\
\hline \multicolumn{7}{|c|}{ (c) Time allowed following oral report to delivery of results to the Internal Dosimetry. } \\
\hline \multicolumn{7}{|c|}{ (d) Report measured activity for $\mathrm{Cm}-246$, and $\mathrm{Cm}-248$ upon request of the Internal Dosimetry. } \\
\hline \multicolumn{7}{|c|}{$\begin{array}{l}\text { (e) Report all isotopes present at levels exceeding one-half the appropriate CL listed in Table 6-6. If ordered by the Internal Dosimetry, report results for radionuclides in } \\
\text { Table 6-6 specified in the processing instructions, regardless of the activity measured. }\end{array}$} \\
\hline
\end{tabular}


Table 6.5 - Contractual Detection Levels for Routine, Priority, and Expedite Processing of Gamma Spectroscopy Analysis ${ }^{(a)}$

\begin{tabular}{ccc}
\hline Isotope & $\begin{array}{c}\text { CL, Urine } \\
\text { (dpm/sample) }{ }^{(\mathbf{b})}\end{array}$ & $\begin{array}{c}\text { CL, Feces } \\
\text { (dpm/sample) }\end{array}$ \\
${ }^{60} \mathrm{Co}$ & 15 & 15 \\
${ }^{59} \mathrm{Fe}$ & 15 & 15 \\
${ }^{54} \mathrm{Mn}$ & 10 & 10 \\
${ }^{106} \mathrm{Ru}$ & 60 & 75 \\
${ }^{141} \mathrm{Ce}$ & 15 & 20 \\
${ }^{144} \mathrm{Ce}$ & 40 & 50 \\
${ }^{134} \mathrm{Cs}$ & 10 & 10 \\
${ }^{137} \mathrm{Cs}$ & 15 & 15 \\
${ }^{95} \mathrm{Zr}$ & 15 & 20 \\
${ }^{140} \mathrm{Ba}$ & 35 & 35 \\
${ }^{131} \mathrm{I}$ & 10 & 20 \\
${ }^{24} \mathrm{Na}$ & 15 & 15 \\
${ }^{22} \mathrm{Na}$ & 15 & 15 \\
${ }^{65} \mathrm{Zn}$ & 20 & 20 \\
${ }^{239} \mathrm{~Np}$ & 25 & 30 \\
${ }^{241} \mathrm{Am}$ & 70 & 65 \\
${ }^{140}$ & &
\end{tabular}

(a) The lab shall resolve and quantify unknown mixtures of gamma-emitting radionuclides. The nuclides and CLs listed shall be interpreted as a minimum requirement; the lab shall detect and quantify all other gamma emitters present at a nominal detection level of $20 \mathrm{dpm}$ for each unspecified nuclide with $E_{\tau}>100 \mathrm{keV}$ as relative to the energy and photon abundance ${ }^{137} \mathrm{Cs}$.

(b) CL is in units of $d p m / L$, for samples greater than or equal to $1 \mathrm{~L}$. 
Table 6.6 - Contractual Detection Levels for Emergency Processing of Gamma Spectroscopy Analyses ${ }^{(a)}$

\begin{tabular}{ccc}
\hline Isotope & $\begin{array}{c}\text { CL, Urine } \\
\text { (dpm/sample) })^{(\mathbf{b})}\end{array}$ & $\begin{array}{c}\text { CL, Feces } \\
\text { (dpm/sample) }\end{array}$ \\
${ }^{60} \mathrm{Co}$ & 35 & 35 \\
${ }^{59} \mathrm{Fe}$ & 35 & 55 \\
${ }^{54} \mathrm{Mn}$ & 20 & 35 \\
${ }^{106} \mathrm{Ru}$ & 115 & 220 \\
${ }^{141} \mathrm{Ce}$ & 20 & 35 \\
${ }^{144} \mathrm{Ce}$ & 75 & 145 \\
${ }^{134} \mathrm{Cs}$ & 20 & 30 \\
${ }^{137} \mathrm{Cs}$ & 20 & 35 \\
${ }^{95} \mathrm{Zr}$ & 30 & 50 \\
${ }^{140} \mathrm{Ba}$ & 60 & 115 \\
${ }^{131} \mathrm{I}$ & 15 & 25 \\
${ }^{24} \mathrm{Na}$ & 25 & 25 \\
${ }^{22} \mathrm{Na}$ & 25 & 25 \\
${ }^{65} \mathrm{Zn}$ & 40 & 65 \\
${ }^{239} \mathrm{~Np}$ & 40 & 70 \\
${ }^{241} \mathrm{Am}$ & 100 & 180 \\
\hline
\end{tabular}

(a) The lab shall resolve and quantify unknown mixtures of gamma-emitting radionuclides. The nuclides and CLs listed shall be interpreted as minimum requirements; the lab shall detect and quantify all other gamma emitters detectable using the same conditions as for the CLs listed.

(b) $\mathrm{CL}$ is in units of $d p m / L$, for samples greater than or equal to $10 \mathrm{~mL}$. 


\subsection{In Vivo Measurement Services}

Routine in vivo measurements are performed at the 747A Building (805 Goethals, Richland). In vivo measurement services are summarized below and details are provided in the In-Vivo Monitoring Program Manual (PNL-MA-574). The type of measurement performed depends on the radionuclide(s) being tested for and the expected location of the radionuclide(s) in the body.

\subsubsection{Whole Body Counts}

Most gamma-emitting radionuclides can be easily detected by a standard whole body count. This measurement is normally scheduled as a periodic routine measurement or when an employee is newly hired, terminated, or beginning or ending a special project. Whole body counts are scheduled by Field Dosimetry through the REX System. A limited number of walk-ins can also be accommodated.

Routine whole body measurements are performed using two systems, the NaI or the HPGe (Coax Counter). The contractor/DOE office has the option of requesting a screening count on the Preview Counter, using the NaI stand-up detector system, or a 10-min whole body count using the HPGe co-axial counting system. If the Preview Counter indicates the presence of an occupationally related radionuclide, or if there are interferences that limit the usefulness of NaI spectrometry, the Coax Counter is also used. The Coax Counter uses an array of coaxial germanium detectors to better resolve and quantify radionuclides, especially in the presence of interfering radionuclides, such as radon progeny. Routine 10minute coax counts are performed on workers for whom more sensitive measurements are required because of radionuclide mixture or potential interferences on the NaI system. A 20-minute follow-up measurement is performed using the co-axial counting system.

A mobile whole body counter is available which has technology and sensitivities comparable to the Preview Counter. This system is contained in a trailer and requires substantial lead-time for assembly and relocation.

Table 6.7 lists the detection capabilities for radionuclides routinely quantified by the whole body exam. The Coax Counter provides sensitivity equal to or better than that of the Preview Counter for all listed radionuclides. A peak search analysis is performed on each spectrum to look for peaks from nuclides that are not normally expected to be present. The peak search is less sensitive than the library directed analysis. 
Table 6.7 - Nominal Minimum Detectable Amount (MDA) Values for Whole Body Exams

\begin{tabular}{ccc}
\hline Nuclide & $\begin{array}{c}\text { Preview Counter } \\
\text { MDA (nCi) }\end{array}$ & $\begin{array}{c}\text { Coax Counter } \\
\text { MDA (nCi) }\end{array}$ \\
$\left.{ }^{40} \mathrm{~K}\right)$ & 10 & 7 \\
${ }^{60} \mathrm{Co}$ & 1.2 & 0.8 \\
${ }^{137} \mathrm{Cs}$ & 1.3 & 1.0 \\
${ }^{154} \mathrm{Eu}$ & 7.0 & 2.0 \\
\end{tabular}

(a) The MDA values are for routine 200-s measurements with the Preview Counter (five cylindrical sodium-iodide detectors in a vertical array). The corresponding values for 200-s measurements with the mobile counter are comparable.

(b) The MDA values are for 600-s variable velocity scans with the coaxial germanium detector system positioned posteriorly to the supine subject. The corresponding values for 1200 -s measurements will be decreased by a factor of approximately 1.4 .

\subsubsection{Chest Counts}

Chest counting is performed when there is concern about the presence in the lung of radionuclides that emit photons with energies of less than $200 \mathrm{keV}$. A chest count must be scheduled in advance with the IVRRF staff. When possible, annual chest counts are scheduled to coincide with a worker's whole body measurement. The typical chest count lasts 50-min (code $\mathrm{C}$ ). If a result from the initial chest count exceeds the decision level, a follow-up 60-min chest count (code C2) is performed. To improve sensitivity, in most cases, the spectrum from a 50-min and 60-min chest count is summed. Detection capabilities for chest counts are listed in Table 6.8. In addition chest counts may be scheduled to provide only americium-241 results (code CA), only uranium-235 and thorium-234 results (code CU), or the combination of all three results (code CC). 
Table 6.8 - Nominal Minimum Detectable Activity (MDA) Values for Planar Germanium Detector In Vivo Measurements

\begin{tabular}{|c|c|}
\hline Measurement and Radionuclide & MDA (nCi) \\
\hline \multicolumn{2}{|l|}{ Normal Chest Count ${ }^{(\mathrm{a})}$} \\
\hline${ }^{241} \mathrm{Am}$ & 0.16 \\
\hline${ }^{235} \mathrm{U}$ & 0.09 \\
\hline${ }^{234} \mathrm{Th}$ & 1.5 \\
\hline \multicolumn{2}{|l|}{ Skeleton Burden by Head Count ${ }^{(\mathrm{b})}$} \\
\hline${ }^{241} \mathrm{Am}$ & 0.5 \\
\hline \multicolumn{2}{|l|}{ Liver Count ${ }^{(\mathrm{c})}$} \\
\hline${ }^{241} \mathrm{Am}$ & 0.17 \\
\hline \multicolumn{2}{|l|}{ Thyroid Count $^{(\mathrm{d})}$} \\
\hline${ }^{125} \mathrm{I}$ & 0.1 \\
\hline${ }^{131} \mathrm{I}$ & 0.26 \\
\hline \multicolumn{2}{|l|}{$\begin{array}{l}\text { Transuranic Wound Count } \\
\text { (600-s count time) }\end{array}$} \\
\hline${ }^{241}$ Am (59.5 keV x-ray) & Determined as needed \\
\hline${ }^{239} \mathrm{Pu}$ (17.0 and $20.4 \mathrm{keV}$ x-rays) & Determined as needed \\
\hline \multicolumn{2}{|l|}{ (a) } \\
\hline \multicolumn{2}{|l|}{ (b) Value is based on 3000-s measureme } \\
\hline $\begin{array}{l}\text { (c) Value is based on } 3000 \text {-s measurem } \\
\text { positioned over the liver for average }\end{array}$ & $\begin{array}{l}\text { three detectors } \\
\text { bject. }\end{array}$ \\
\hline \multicolumn{2}{|c|}{$\begin{array}{l}\text { (d) Values are based on } 600 \text {-s measurements with one } 38 \mathrm{~cm}^{2} \text { detector } \\
\text { positioned } 10 \mathrm{~cm} \text { above the thyroid. }\end{array}$} \\
\hline
\end{tabular}

If activity is confirmed in a chest count, a measurement of chest wall thickness, a liver count, and a head count may also be needed to make appropriate corrections to the chest count data. These measurements may be performed on the same day or rescheduled for a later date. Ultrasound measurements are routinely scheduled on a two-year interval for workers with long-term detectable chest count activity.

\subsubsection{Special Counts}

Other counts performed by special request include liver counts (for low-energy photons), head counts (to determine skeletal content of low-energy photons), thyroid counts (for radioiodines), wound counts, and selected lymph node counts. These counts are normally performed as part of special investigations or as a long-term follow-up of known depositions. These counts are arranged through Internal Dosimetry.

Table 6.8 lists the detection capabilities for radionuclides emitting low-energy photons, which are analyzed using germanium detectors, assuming normal count times. Slightly lower MDAs can be achieved if longer count times can be arranged. The MDA values for wound counts or other tissues (e.g., lymph nodes) are highly variable depending on the circumstances of the measurement. Contact Internal Dosimetry if additional information is required.

Issued for implementation effective 01/01/2010

PNL-MA-552 Section 6.0 


\subsection{Scheduling and Recordkeeping}

This section discusses scheduling of bioassay measurements, reporting of routine results to Field Dosimetry, and record keeping. Follow-up of detected activity is discussed in Section 6.4. Assessment of confirmed intakes is covered in Chapter 3.0, and response to incidents is described in Chapter 7.0.

\subsubsection{Contacting the Worker}

Contacts with the worker concerning the scheduling and results of bioassay measurements are usually conducted by Field Dosimetry. (During a response to an incident, both Field Dosimetry and Internal Dosimetry usually work directly with the worker.) Internal Dosimetry also consults with a worker at other times at the request of Field Dosimetry.

\subsubsection{Scheduling Indirect Bioassay Measurements}

Summary

Baseline, Termination, End of Assignment
Internal Dosimetry coordinates all bioassay measurement requests to the Lab, either through the HIDP or the HRRP, using the REX database.

The details of scheduling depend on the reason the sample is needed. Currently used sample-reason codes are described in Table 6.9, and scheduling details categorized by reason type are discussed below.

To schedule a worker for a baseline, termination, or end-of-assignment sample, Field Dosimetry must

1. Complete a Dosimetry Change Request form (Exhibit 6.1 or a document containing similar information) and enter the information into the REX database. This deletes the old schedule (if there is one) and establishes the new schedule. The completed form is submitted to the HRRP for inclusion in the worker's radiation exposure file. (A Dosimetry Change Request form is not needed for beginning and end-of-assignment samples for planned offsite exposures.)

2. HIDP staff are responsible for reviewing special requests and the transmittal to the Lab. 
Table 6.9 - Bioassay Measurement Reason Codes for the REX System

\begin{tabular}{|c|c|c|}
\hline Code & Name & Description \\
\hline BL & Baseline & $\begin{array}{l}\text { Measurement is performed to establish a reference level against which } \\
\text { subsequent measurements will be compared. This may be for new or } \\
\text { established employees prior to commencing work with radioactive } \\
\text { materials, beginning a specific type of radiation zone work, or making an } \\
\text { offsite trip where potential internal exposure could occur. }\end{array}$ \\
\hline CR & Contractor Request & $\begin{array}{l}\text { Measurement is requested by employer for reasons other than periodic, } \\
\text { baseline, end-of-assignment, or special investigation. }\end{array}$ \\
\hline EA & End of Assignment & $\begin{array}{l}\text { Measurement is performed following completion of a specific work } \\
\text { assignment, but not end of employment. }\end{array}$ \\
\hline HL & Pick up and Hold & Collect sample but hold for analysis pending instruction from IDP. \\
\hline PR & Periodic & Measurement is performed at a regularly scheduled interval. \\
\hline QR & Quality and Research & $\begin{array}{l}\text { Measurement is performed as part of quality control, quality assurance, or } \\
\text { research work. }\end{array}$ \\
\hline RA & Reanalysis A & $\begin{array}{l}\text { First reanalysis of sample, by taking another aliquot and repeating the } \\
\text { same radiochemical or chemical analysis. }\end{array}$ \\
\hline $\mathrm{RB}$ & Reanalysis B & $\begin{array}{l}\text { Second reanalysis of sample, by taking another aliquot and repeating the } \\
\text { same radiochemical or chemical analysis. }\end{array}$ \\
\hline $\mathrm{R} 1$ & Recount 1 & First recount of original excreta sample or repeat in vivo exam. \\
\hline $\mathrm{R} 2$ & Recount 2 & Second recount of original excreta sample or repeat in vivo exam. \\
\hline SP & Special & $\begin{array}{l}\text { Measurement is performed as part of a specific investigation of potential } \\
\text { internal dose. May include response to off-normal work conditions, or } \\
\text { follow-up of abnormal periodic measurements. }\end{array}$ \\
\hline $\mathrm{TM}$ & Termination & Final bioassay at termination of employment. \\
\hline 12 & Contract Work & $\begin{array}{l}\text { In vivo measurement performed under contract to customers rather than } \\
\text { Hanford employees. }\end{array}$ \\
\hline 20 & Source Count & $\begin{array}{l}\text { In vivo source count is made for system calibration or as a function } \\
\text { check, usually using a known check source. }\end{array}$ \\
\hline 30 & Background Count & $\begin{array}{l}\text { In vivo system background measurement is performed for system } \\
\text { calibration or as a functional check. }\end{array}$ \\
\hline
\end{tabular}

\section{Periodic}

Field Dosimetry initiates the request for a periodic bioassay measurement schedule by completing the Dosimetry Change Request form (Exhibit 6.1), and entering the information into the REX database. The completed form is sent to the HRRP for verification and filing in the worker's radiation exposure file.

Approximately one month before the scheduled sample time, a list of scheduled periodic samples is sent to Field Dosimetry for review. The reviewed list is then electronically transmitted to the Lab one week before the scheduled sample month. This pattern is repeated until another Dosimetry Change Request form is received. 
Contractor Request

Special,

Reanalysis, Recounts
If the periodic sample is not collected, is of insufficient volume, or is a failed analysis, the Lab notifies HIDP, who then notifies Field Dosimetry. Field Dosimetry reschedules the sample request through the REX System. HIDP transmits the request electronically to the Lab.

Contractor-requested measurements are made by Field Dosimetry or the Internal Dosimetrist. An Explanation for Supplemental "Contractor Request” Bioassay Form (Exhibit 6.2 or equivalent) should be completed to explain the reason for the measurement and sent to HRRP.

Special measurement requests, reanalysis, and recount requests are made by an Internal Dosimetrist after consultation with Field Dosimetry. During incident response, the Internal Dosimetrist often gives sample kits directly to the worker. The "special" measurement code is used while data are being collected for an evaluation. After a final evaluation has been made, samples collected for long-term surveillance of the intake are usually scheduled as periodic samples.

\subsubsection{Excreta Sample Status}

Once an excreta sample request has been submitted to the lab, it is assigned a status code that describes where that sample is in the process. Sample status codes are shown in the Administrative Tables/Excreta/Status Codes screen (KU12) of REX.

\subsubsection{Reporting Results from Indirect Measurements}

Valid Results

Invalid or

No Results

Failed Analyses (FA)
A result from a routinely processed sample is verbally or electronically reported or faxed to Internal Dosimetry by the Lab if the result exceeds the reporting level. Analytical and contractual reporting requirements for indirect bioassay measurements are included in Tables 6.1 through 6.6. All bioassay sample results are transferred electronically from the Lab to the REX database, as specified contractually. Results below the reporting level for samples other than reason code Special are sent a REX-generated letter (Exhibit 6.3).

There are a number of reasons that a sample may not be obtained or a result not be provided. When such circumstances occur, the Lab notifies Internal Dosimetry to take appropriate follow-up action. These circumstances and appropriate actions are as follows:

An FA code indicates that a valid sample was provided by the worker but a valid analytical result could not be obtained. The majority of FA are a result of insufficient tracer recovery. Acceptable recovery levels are detailed in the statement of work. However, if a FA is a result of a laboratory error, then the lab should notify Internal Dosimetry by phone or by email and submits a nonconforming data report to the contract administrator, with a copy to Internal Dosimetry. Examples of these problems include spillage, crosscontamination, analytical procedure errors, inadequate yield, or out-ofspecification quality control samples. Generally, a worker whose result is a failed analysis should be rescheduled for another sample and analysis. 
Insufficient

Volume Sample (IS)

Container-Not-Out (CN)

Lost Container (LC)

Not Delivered (ND)

Not Evaluated (NE)

No Sample (NS)

Cancelled Sample (CS)
If a urine sample does not meet the minimum volume requirement specified for the sample type (see Section 6.1), the sample is not analyzed and the IS code is noted in the REX database. A worker who provides an insufficient volume sample should be contacted to ensure that the sample kit instructions will be followed, and then the sample and analysis should be rescheduled.

If the kit was not out at the time of the scheduled pickup, a CN interim status code is assigned. The Lab will advise Internal Dosimetry of the attempted pickup and will make one more attempt to retrieve the container when notified of a revised pickup date. Samples not retrieved or scheduled for later retrieval within 10 business days of the scheduled pickup are assigned a "lost container" designation and should be rescheduled.

The LC code means that the Lab delivered a sample kit but was unsuccessful in retrieving it. The sample should be rescheduled.

The ND code indicates that a scheduled sample kit was not delivered by the Lab. The sample should be rescheduled.

The NE code shows a sample was obtained but a decision was made not to analyze the sample usually because the sample was redundant to other measurements or determined to be unnecessary.

The NS code means that a sample kit was delivered to the designated residence; however, it was not used and remained outside at the residence on the scheduled pickup date. The Lab notifies Internal Dosimetry of no samples. Internal Dosimetry then contacts Field Dosimetry. The sample should be rescheduled.

The CS code means that a scheduled sample was subsequently cancelled.

\subsubsection{Scheduling In Vivo Bioassay Measurements}

Summary

Typical Measurements
In vivo measurements with reason codes of baseline, end-of-assignment, termination, periodic, and contractor-request are scheduled by Field Dosimetry using REX. The IVRRF has allocated to each contractor specific blocks of time for counting workers, and Field Dosimetry schedules their workers into those blocks. Whole body counts are scheduled by the day; chest and other counts are scheduled by the day and hour. Counts with the reason code "Special" may be scheduled directly with IVRRF, if necessary, although it is preferred to use REX if possible. Special counts may take precedence over other scheduled measurements.

Field Dosimetry initiates the request for periodic in vivo measurements by completing the Dosimetry Change Request form (Exhibit 6.1 or a document containing similar information) and entering the information into the REX database.

The REX in vivo scheduling program identifies workers who are specified for a periodic in vivo exam in the coming month. Field Dosimetry then schedules whole body exams for individual workers using the contractor 
Contractor Request

Recounts

Special allocations of count times provided by the IVRRF. Each night REX sends an electronic file to the IVRRF containing the names of workers scheduled for exams the next day.

Unscheduled workers will also be accepted, although some rescheduling might be required.

Contractor-requested measurements are made by Field Dosimetry or the Internal Dosimetrist. An Explanation for Supplemental "Contractor Request” Bioassay Form (Exhibit 6.2 or equivalent) should be completed to explain the reason for the measurement and sent to HRRP.

Recounts are measurements performed on the same day as a positive count to confirm the initial measurement. Measurements performed at a later date as follow-up or because a same-day recount could not be performed are assigned the "special" code.

Special in vivo measurements are performed in response to an identified potential intake or as follow-up to a periodic measurement that exceeds a screening level. These measurements may be requested by the Internal Dosimetrist or the event contractor/DOE office. Timely completion of special measurements is a high priority and may preempt a scheduled measurement for a worker.

\subsubsection{Reporting Results of In Vivo Measurements}

Valid Results

HIDP is verbally notified if a measurement result exceeds the reporting level and is provided a copy of the measurement results. The reporting levels for routinely scheduled in vivo measurements are shown in Appendix A. In addition, results from special measurements are provided to HIDP, along with a verbal notification, regardless of the level of the results. Internal Dosimetry, in turn, relays the results to Field Dosimetry with recommendations for follow-up, if necessary. Results are electronically transmitted to the REX database, usually within one week of the measurements.

No Results

Invalid results or no results may be obtained for an in vivo measurement for a variety of reasons, such as a preliminary count that was followed by a record count on the same day, radon daughter interference, equipment problems, or interference from medically administered radioactivity. A comprehensive list of no-result codes is provided in Appendix B, Table B.14.

\subsubsection{Reporting "No Shows"}

Whether or not a worker reported for an in vivo measurement can be determined from the REX System. Following each day's measurements, IVRRF staff send an electronic "show" file to REX, listing workers who reported to IVRRF for exams, including unscheduled walk-ins. Walk-ins are scheduled at the time they show up at IVRRF. The actual measurement results are not part of this file. 
REX generates a report by retrieving the "show" file and matching it with the day's schedule file. Matches and walk-ins appear as "shows." Workers scheduled but not listed in the "show" file are identified as "no-shows."

\subsection{Follow-Up Measurements and Reports}

Follow-up measurements and their associated documentation are handled as described in the following subsections.

\subsubsection{Indirect Bioassay Measurements}

The need for follow-up indirect bioassay measurements depends on the initial measurement result and its relationship to the screening levels of Appendix A.

$\leq$ Screening Level

$>$ Screening Level

Recounts
If the indirect bioassay measurement result is at or below the screening levels of Appendix A, no follow-up is performed by HIDP and a computergenerated letter similar to Exhibit 6.3, is completed and sent to Field Dosimetry to be forwarded to the worker or the worker's manager.

If the result is above the screening levels of Appendix A, different actions are taken, depending on the reason for the sample, according to the practices discussed in Chapter 2.0. If the reason code is for a baseline or special measurement, any result above the reporting level is investigated. If the reason code is for a periodic, contractor-request, end-of-assignment, or termination measurement, the result is compared with 1) the expected result because of any prior assessed intakes, and 2) a level that would possibly indicate an intake resulting in a committed effective dose greater than 10 mrem (see Appendix A). If the result is greater than expected or implies that an intake greater than the 10-mrem dose criterion has occurred, the result is investigated. Otherwise, a letter similar to Exhibit 6.3 is completed and sent to the worker and a copy to the HRRP for inclusion in the worker's radiation exposure file. A notification is also provided to Field Dosimetry. For Fluor Hanford, Plateau Remediation contractor, Tank Operations contractor, and DOE workers, the letter is sent directly to the worker and a notification is sent to Field Dosimetry. No follow-up is performed by Internal Dosimetry.

If a routine- or priority-processed urinalysis for alpha-emitting nuclides exceeds the screening level but not the contractual detection level, HIDP commonly requests two recounts. This step reduces random false-positive results that ensue from counting statistics alone. If both recounts are less than the screening level, a letter similar to Exhibit 6.3 is sent to the worker and a copy to the HRRP for inclusion in the worker's radiation exposure file. A notification is also provided to Field Dosimetry. For Fluor Hanford, Plateau Remediation contractor, Tank Operations contractor, and DOE workers, the letter is sent directly to the worker and a notification is sent to Field Dosimetry. If at least one recount is at or above the screening level, then HIDP notifies Field Dosimetry and initiates a formal assessment of possible internal dose. Details about the assessment of internal dose are discussed in Chapter 3.0. 
Recounts may be ordered under other circumstances at the discretion of the Internal Dosimetrist. Such recounts are appropriate to verify an unexpectedly high measurement.

If a result exceeds the screening level for an analysis that required only an aliquot of the original sample, HIDP may request reanalysis of that sample, provided that sufficient sample remains. If two reanalyses are below the screening level, the initial result is considered unconfirmed. If one reanalysis is also at or above the screening level, Internal Dosimetry notifies Field Dosimetry and initiates a formal assessment of possible internal dose. Details about the assessment of internal dose are discussed in Chapter 3.0.

\subsubsection{In Vivo Measurements}

The need for follow-up in vivo measurements depends on the measurement result and its relation to the screening levels listed in Appendix A. For in vivo measurements, the reporting levels are equal to the decision levels for the nuclides measured, except for naturally occurring ${ }^{40} \mathrm{~K}$, ${ }^{208} \mathrm{Tl}$, and ${ }^{214} \mathrm{Bi}$. IVRRF staff attempt to recount all unexpected positive results on the same day, if possible. If a recount or summed counts result exceeds the screening level, IVRRF staff report results of both initial and recount measurements to HIDP. HIDP then reviews the reported results against the applicable screening levels (see Appendix A) before determining the final disposition.

Preliminary Report

Final Report $\leq$ Screening Level
The worker receives a preliminary report on the results of in vivo measurements at the end of each visit to the IVRRF (see Exhibit 6.4). The preliminary report places the results of the measurements into one of four categories, and one of the four alternatives is selected in the body of the letter as appropriate:

- less than the decision level (results do not exceed criteria for follow-up)

- false-positive initial indication (for chest counts only)

- not immediately available (e.g., final calculations by computer are delayed or calculation/evaluation by hand is required)

- $\quad$ exceeded the decision level.

Where several screening levels may exist, depending on whether the measurement is a baseline or routine periodic assay, HIDP determines the applicable screening level for each case. When a result is finalized, and if the result is at or below the screening level and is not associated with an incident, no follow-up is performed by HIDP. If the information in the preliminary report needs no change, no further correspondence is necessary. If the final result differs from the preliminary report but no evaluation is necessary, the letter shown in Exhibit 6.5 is completed and sent to the worker. A copy of the letter is placed in the worker's radiation exposure file and a notification is provided to Field Dosimetry. 
Final Report

Screening Level
If the result is above the screening level, different actions are taken $\geq$ depending on $\geq$ the reason for the measurement, according to the practices discussed in Chapter 2.0. If the reason code is for a baseline, any result above the reporting level is investigated. If the reason code is for a periodic, contractor-request, end-of assignment, or termination measurement, the result is compared with 1) the expected result because of prior assessed intakes, and 2) a level that might indicate an intake resulting in a committed effective dose greater than 10 mrem (see Appendix A). If the result is greater than expected or implies that an intake greater than the 10-mrem dose criterion has occurred, the result is investigated. Otherwise, the letter shown in Exhibit 6.5, with the appropriate box checked, is sent to the worker. A copy is placed in the worker's radiation exposure file, and Field Dosimetry is notified. No follow-up is performed by HIDP.

\subsection{Radiation Exposure (REX) Database}

The results of all bioassay measurements are permanently retained in the REX database. The staff of Field Dosimetry, Internal Dosimetry, the IVRRF, and the Lab have access to only those parts of the REX database that are essential to their task responsibilities.

\subsection{References}

Health Physics Society (HPS). 1996. Performance Criteria for Radiobioassay. HPS N13.30-1996, McLean, Virginia.

MARLAP 2004. Multi-Agency Radiological Laboratory Analytical Protocols Manual (MARLAP). U.S. Environmental Protection Agency.

Pacific Northwest National Laboratory (PNNL). In Vivo Monitoring Program Manual, PNL-MA-574. Richland, Washington. (Internal manual.) 
Exhibit 6.1 - Dosimetry Change Request

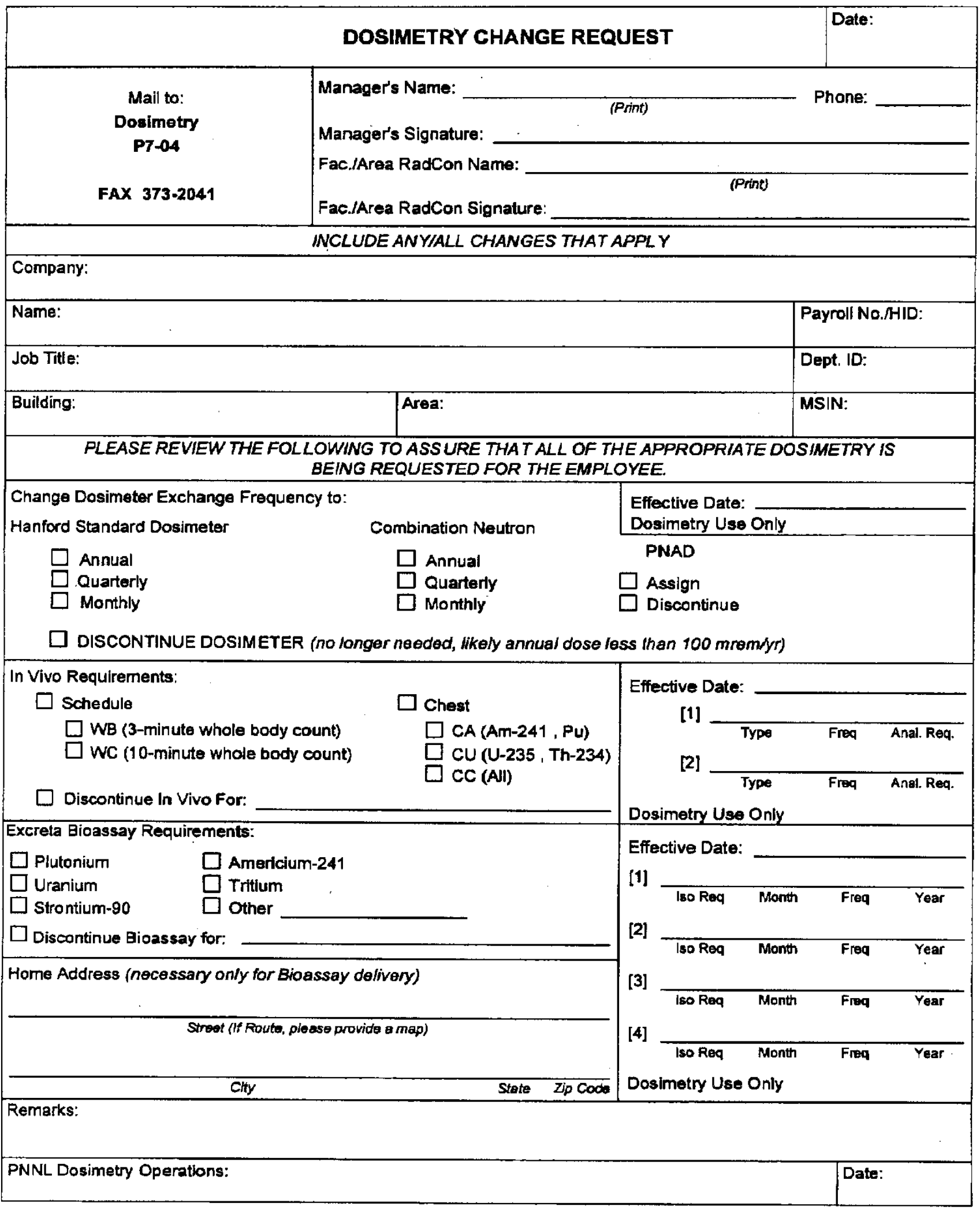




\section{Exhibit 6.2}

\section{Explanation For Supplemental "Contractor Request" Bioassay}

\section{Worker's Name:}

\section{Payroll No. or Hanford ID No:}

The following measurement(s) is requested under the Contractor Request reason code as a one-time supplement to the worker's normal routine (periodic) bioassay monitoring program, or as a standalone request for a worker not normally on a routine program. The reason for this supplemental bioassay does not meet the criteria for "Special" bioassay, as defined in the Hanford Internal Dosimetry Program Manual, PNL-MA-552.

\section{$\underline{\text { Bioassay Analysis }}$}

Reason for Contractor Request supplementary bioassay:

\section{Bioassay Date}


Exhibit 6.3 - Sample Form - Bioassay Urine Sample Results

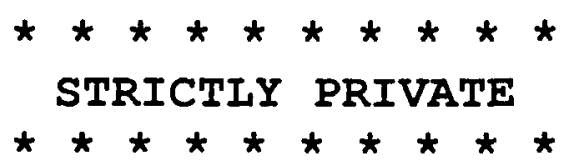

Date: $07 / 18 / 2003$

HID :

Name:

Org Cd: D9TRP

Dept Id: 118004

Bioassay Examination Report

The analysis of your excreta sample collected on $06 / 19 / 2003$ has been completed for the following tests: U ISOTOPIC (IU)

Results do not exceed the criteria for follow-up measurement nor do they change previous assessments of internal dose or current bioassay measurement schedules.

Records of this and your other bioassay examinations are maintained in your personal exposure file. Contact your company's radiation protection or radiation dosimetry office on 376-1707 if you have any questions regarding your occupational radiation exposure status.

This statement was prepared by Hanford Internal Dosimetry.

REX-GR1O 
Exhibit 6.4

\section{PRELIMINARY ANALYSIS OF IN VIVO EXAMINATION}

\section{NAME: \\ PAYROLL: \\ REASON CODE: \\ EXAM DATE:}

Preliminary analysis of your in vivo examination(s) indicates:

(1) Your in vivo measurements are completed, and the results do not exceed the criteria for follow-up.

(2) Your first in vivo measurement indicated the possible presence of internal radioactivity from occupational sources. However, the results from your second count, usually longer and more sensitive did not indicate the presence of radioactive material from occupational sources. Your first count may have been a false positive result, expected to occur about 5 percent of the time, or caused by other factors including the presence of naturally occurring radon progeny.

(3) Final analysis of the examination data is not immediately available. This may be due to a temporary suspension of the analysis portion of the computer software or a need to review the quality of the detection system performance. The results of this examination will be provided to your company's radiation protection organization when available.

(4) Your measurement exceeds a screening level. This can result from a random, statistical fluctuation in the background measured by the detector, very lowlevel skin contamination, an intake of naturally occurring or medical-related radioactive material not related to your work, or an occupational intake. A further review of the examination will be performed and your radiation protection organization will be notified of the results. Follow-up measurements may be required.

If you have any questions, please contact your radiation protection representative listed below.

Contractor Name:

Contact Name:

Contact Phone:

Please note: This report is based on a preliminary evaluation of your measurement by computer and is subject to change based upon additional review. If there is a change from the above reported results, Personnel Dosimetry will notify your company's radiation protection organization. 
Exhibit 6.5 - Sample Letter - In Vivo Measurements Results

\section{STRICTLY PRIVATE}

Date: $\quad 09 / 27 / 2003$

Name: IM ATEST

PR No: 12345

\section{IN VIVO EXAMINATION REPORT}

The preliminary analysis or subsequent review of your 09/26/03, whole body exam indicated the possible presence of radioactivity, and the possibility of additional measurements may have been discussed with you. A detailed review of the measurement spectrum has since been performed, with the conclusion indicated by the box(es) checked below:

FALSE POSITIVE - Your result does not truly reflect the presence of radioactivity and has been identified as a "false positive" result. The extreme sensitivity of our measurements makes the slight variation in background levels from one person to another sometimes appear as a detected result when analyzed by the computer. An in-depth technical review of the measurement showed interference that the computer interpreted as radioactivity. These false-positive results are a fact-of-life associated with highly sensitive measurements, and are expected in as many as five percent of our measurements.

MEDICAL - The detected radioactivity is associated with medical applications. It could result from a nuclear medicine procedure you had recently, or if you were recently in close contact with someone who had such a procedure. Typical radionuclides in this category include thallium-201, thallium-202, iodine-131, and technetium-99m.

ENVIRONMENTAL - The detected radioactivity is attributed to non-occupational sources.

CONSISTENT WITH PRIOR EVALUATION - The detected radioactivity is consistent with a previously evaluated intake and does not require a new investigation.

BELOW OCCUPATIONAL SCREENING LEVELS - The detected radioactivity could be attributable to occupational intake, but is below the screening levels used for investigation and dose assessment. Any implied doses are below 10 mrem committed effective dose.

Based on this determination, no further measurements are required and no additional investigation will be performed. Records of this and your other bioassay examinations are maintained in your personal exposure file. If you have questions concerning this, please contact Robert Jones at 376-1707.

Hanford Internal Dosimetry

cc: Radiation Exposure File 


\title{
HANFORD INTERNAL DOSIMETRY PROGRAM MANUAL PNL-MA-552 \\ SECTION 7.0, POTENTIAL INTAKE INCIDENT RESPONSE
}

\author{
Issued for implementation effective 01/01/2010
}

Supersedes: 04/2007

Use Category: Not applicable

Approval Signatures:

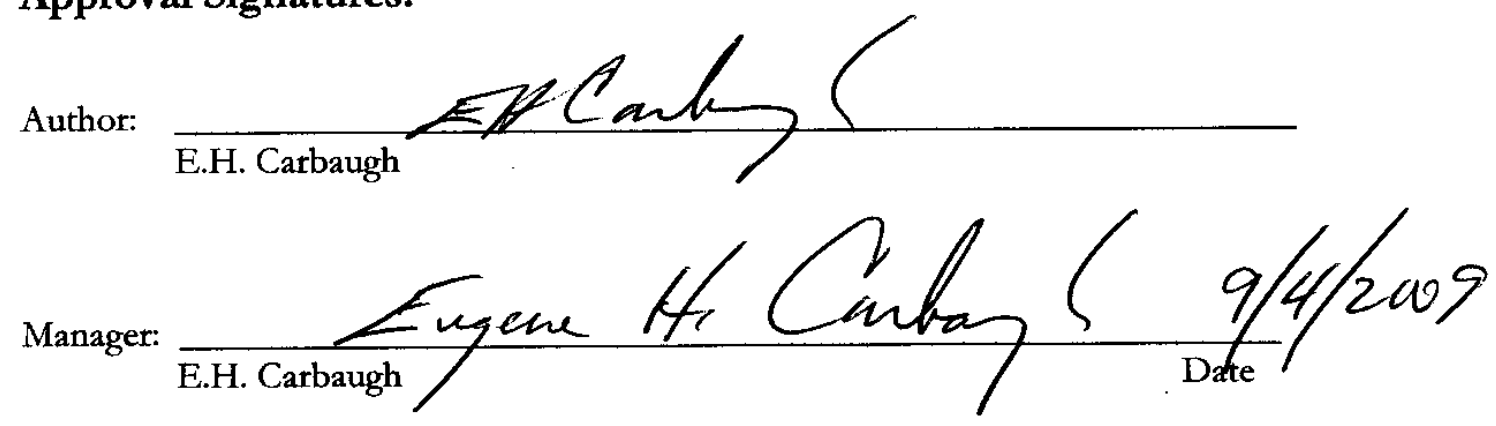

Reviewer Signatures:

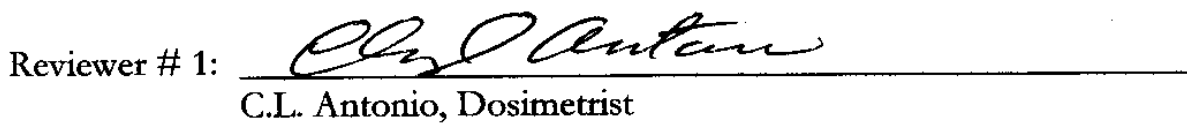

Approved by the Hanford Personnel Dosimetry Advisory Committee on June 4, 2009. 


\section{Contents}

7.0 Potential Intake Incident Response .................................................................................. 3

7.1 Incident Response Objectives of the Hanford Internal Dosimetry Program............................... 3

7.2 Incident Response Services Provided By the Hanford Internal Dosimetry Program................... 3

7.3 Determining the Need for Internal Dosimetry Support..........................................................

7.3.1 Notifications for Prompt Intake Assessment and Dose Reduction Therapy ........................ 5

7.3.2 Information to Provide when Notifying the Exposure Evaluator ....................................... 6

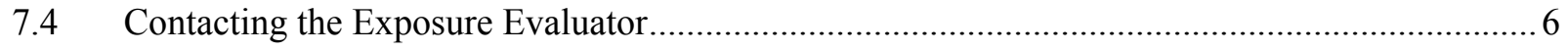

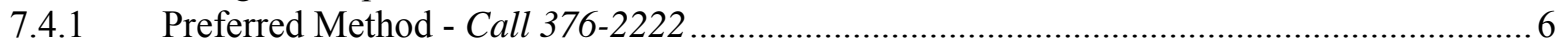

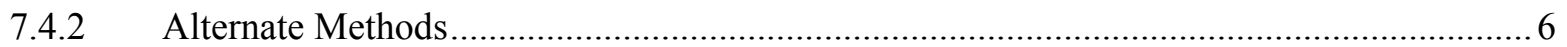

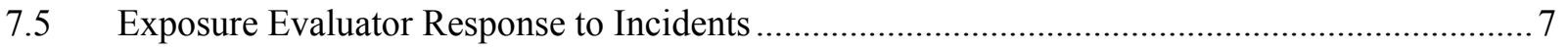

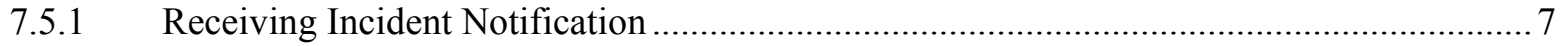

7.5.2 Scheduling and Performing Bioassay Measurements .............................................. 7

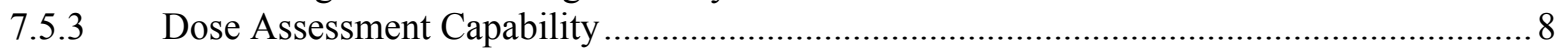

7.6 Guidance for Exposure Evaluator Response to Incidents ...................................................... 9

7.6.1 Managing Uninjured Workers Who Are Externally Contaminated.................................. 9

7.6.2 Managing Injured Workers Who Are Externally Contaminated ....................................... 9

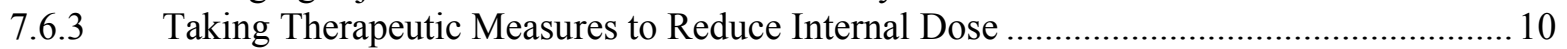

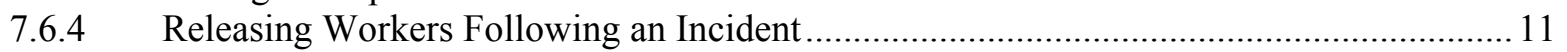

7.6.5 Assisting in External Radiation Exposure Situations..................................................... 11

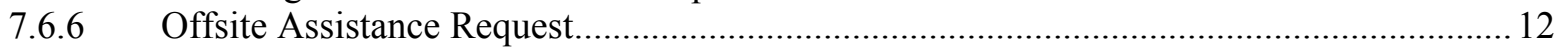

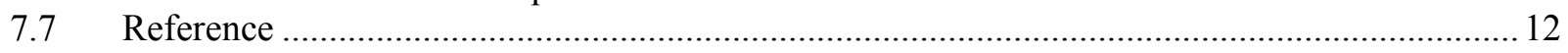




\subsection{Potential Intake Incident Response}

This chapter provides guidance for recommended dosimetry response to incidents of potential radionuclide intake. The roles of the contractor, DOE office, Hanford Internal Dosimetry Program (HIDP) via the Exposure Evaluator (EE), and other support groups in obtaining dosimetry data and in performing early assessments of intake are discussed. Also addressed are some EE tasks that are performed under the auspices of the HIDP but are not directly related to Internal Dosimetry.

For the purposes of this chapter, a potential intake incident is defined as any circumstance involving loss of containment or administrative control that may result in a worker incurring an intake requiring an internal dose assessment. However, the majority of the material in this chapter is directed toward the circumstance where knowledge of a potential intake is recent (i.e., within one to three days).

\subsection{Incident Response Objectives of the Hanford Internal Dosimetry Program}

In responding to a potential intake incident, the HIDP's principal objective is to perform initial and follow-up assessments of the seriousness of the exposure. Such assessments support the DOE office/contractors' reporting and investigating requirements, and address the medical considerations regarding the effectiveness of dose-reduction therapy. In addition to the role in responding to potential intake incidents, the EE provides notification services for other types of incidents at Hanford.

\subsection{Incident Response Services Provided By the Hanford Internal Dosimetry Program}

The HIDP provides incident response by means of its EE function. The EE is a sitewide 24-hour oncall contact for dosimetry and notification assistance.

\section{Internal Dosimetry Services}

The following intake assessment services are available through the EE:

- Consultation regarding the need for and priority of special bioassay measurements.

- Arrangements for bioassay measurements and samples.

- Identification of supplemental measurements and samples to aid in the performance of internal exposure evaluations (e.g., measurement of air filters and smears).

- Arrangement with PNNL Radiological Control for Radiological Control Technicians (RCT) support for the In Vivo Radiobioassay and Research Facility (IVRRF) and offsite medical support facilities.

- Initial assessment of the potential severity of intakes based on early data.

- Discussion with workers about the results of specific measurements (done in conjunction with Field Dosimetry and contractor/DOE office representative).

- Arrangement for appropriate follow-up bioassay measurements. 


\section{Services Not Related To Internal Dosimetry}

The following services, not related to internal dosimetry, are also available through the EE:

- Dosimetry assistance for unusual external exposure situations.

- Request for assistance from PNNL Radiological Control for monitoring potentially contaminated Hanford patients who report to Kadlec Medical Center, other local hospitals or medical facilities, Hanford first aid stations, or the IVRRF.

\subsection{Determining the Need for Internal Dosimetry Support}

\section{Notification Criteria for EE}

HIDP should be contacted whenever an intake of radioactivity is suspected, or when the dosimetric significance of an observation or event is in doubt.

The following are examples of circumstances that could warrant contacting HIDP:

- Abnormal radioactivity detected on nasal smears.

- Suspected intake of radioactive material with the potential for a committed effective dose of 100 mrem.

- Single or cumulative airborne exposures totaling more than 10 DAC-hours in a calendar year, after correction for respiratory protection worn at the time of exposure.

- Extended or extensive personal skin contamination.

- Loss of containment or exposure control, such as failure of a ventilation system or respiratory protection, resulting in exposure to high concentrations of radioactivity in the air.

- Spread of contamination that results in levels of radionuclides at or exceeding the levels given in Table 7.1. The tabulated levels are based on empirical experience and not modeled calculations.

- Unplanned releases of radioactive material to the environment that may have affected workers.

It is also recommended that HIDP be included on the distribution list for radiation occurrence reports. 
Table 7.1. Contamination Levels for Notifying Internal Dosimetry

\begin{tabular}{|c|c|c|}
\hline Indicator & Alpha-Emitters, dpm & Beta-/Gamma-Emitters, dpm \\
\hline Nasal or mouth smears & Above background & Above background \\
\hline Facial contamination & 200 & 4,000 \\
\hline Skin breaks & $\begin{array}{l}\text { Any skin break while } \\
\text { handling alpha-emitters } \\
\text { other than sealed sources. }\end{array}$ & $\begin{array}{l}\text { Any detectable activity around or } \\
\text { on a skin break; or detectable } \\
\text { activity on a blood smear. }\end{array}$ \\
\hline Head, neck contamination & 2,000 & 40,000 \\
\hline $\begin{array}{l}\text { Contamination inside } \\
\text { respirator }\end{array}$ & \multicolumn{2}{|c|}{ Detectable activity inside respirator after use. } \\
\hline $\begin{array}{l}\text { Hands, forearms, clothing }{ }^{(a)} \\
\text { (spotty, loose) }\end{array}$ & 10,000 & 200,000 \\
\hline $\begin{array}{l}\text { Airborne contamination after } \\
\text { incorporating respiratory } \\
\text { protection factor }\end{array}$ & \multicolumn{2}{|c|}{$\begin{array}{l}\text { Acute exposure exceeding } 40 \text { DAC-hours }{ }^{(\mathrm{b})} \text { should undergo } \\
\text { special bioassay. Acute or cumulative exposures exceeding } 10 \\
\text { DAC-hours in a calendar year should undergo dose assessment; } \\
\text { use DAC-hours or special bioassay as appropriate. }\end{array}$} \\
\hline $\begin{array}{l}\text { Clothing contamination } \\
\text { contamination levels on }\end{array}$ & $\begin{array}{l}\text { Is apply to exposure with } \\
\text { sonal clothing or inner cor }\end{array}$ & $\begin{array}{l}\text { respiratory protection, such as } \\
\text { alls while undressing. }\end{array}$ \\
\hline (b) DAC-hours = time-integra & ted exposure to airborne con & mination. \\
\hline
\end{tabular}

\section{Criteria for Notifying Occupational Medicine}

HIDP recommends that Occupational Medicine be promptly alerted to potential intakes when the criteria of Table 7.2 are exceeded. The primary purpose of this notification is to alert Occupational Medicine to the possibility that dose reduction therapy may be warranted. At the request of the contractor/DOE office, the EE may make this notification. The EE may also informally notify Occupational Medicine if there seems to be a possibility that therapy is warranted.

Table 7.2. Contamination Levels for Notifying Occupational Medicine

\begin{tabular}{lcc}
\hline \multicolumn{1}{c}{ Indicator } & Alpha-Emitters, dpm & Beta-/Gamma-Emitters, dpm \\
\hline Nasal or mouth smears & 1,000 & 100,000 \\
Facial contamination & 25,000 & 500,000 \\
Skin Breaks & 100 & 20,000 \\
\hline
\end{tabular}

\subsubsection{Notifications for Prompt Intake Assessment and Dose Reduction Therapy}

\section{When to Notify the EE}

The EE should be notified immediately when prompt actions may be required to evaluate internal exposure. The criteria recommended for immediate notification and request for support are shown in Table 7.1. These criteria are based primarily on Hanford experience, which may be taken as indicators that the committed effective dose may exceed 100 mrem.

The EE should be notified the same day that intakes or potential intakes occur or are identified to ensure that adequate provision is made to obtain bioassay measurements for dose assessment.

When the criteria of Table 7.1 are not met, it is unlikely that therapeutic actions would be taken based on early bioassay measurements. Bioassay measurements are still needed for dose assessment purposes. 
In some cases the measurements may not need to be immediate (i.e., same day), but may be scheduled on a priority basis a few days after the potential intake. Under these circumstances, the EE may suggest a delayed measurement protocol in consideration of convenience and cost.

\subsubsection{Information to Provide when Notifying the Exposure Evaluator}

What Information To Provide

Exhibit 7.1 (at the end of this chapter) provides a summary checklist of information that may be useful to the EE for dosimetry evaluation. The EE Office maintains a telephone log for each separate incident notification, using a form similar to the one shown in Exhibit 7.2.

\subsection{Contacting the Exposure Evaluator}

How to Contact the EE

Contacting the on-call EE may be done using several methods which are described here. During normal working hours, it should be possible to contact the EE within a few minutes by one phone call. After-hours procedures have been established with the intent that the maximum response time for obtaining EE support should not exceed 40 minutes.

\subsubsection{Preferred Method - Call 376-2222}

The preferred method of contacting the EE is to call the EE Office on 376-2222. During working hours, HIDP staff usually answers the phone. After working hours, the phone is forwarded to the on-call EE's residence. If no answer is obtained, wait 5 minutes and try again. Make at least two attempts, waiting at least 5 minutes between each call. If contact cannot be made by this method, use one of the alternate methods described below.

\subsubsection{Alternate Methods}

Radio Pager: Onsite: 85-9901, Offsite: 376-4190 (9901)

The on-call EE carries a pager that can be activated from a Hanford Site telephone by dialing 859901. From an offsite phone, the pager can be activated by dialing 376-4190 and then entering " 9901 " at the tone. At the cue from the recorded message, enter the phone number for the EE to call. This method is particularly useful after hours if the EE is not at home to answer the EE office number (376-2222). Expect some delay in response to allow the EE to reach a telephone.

If no response is received within 15 minutes, contact the Hanford Patrol Operations Center (POC) or the PNNL Single-Point Contact at the numbers below and request an alternate EE.

\section{Patrol Operations Center or PNNL Single Point Contact}

Both the Hanford Patrol Operations Center (POC) and the PNNL Single Point Contact have emergency procedures for contacting the EE, including a radio pager and alternate contacts.

Patrol Operations Center: 373-3800

PNNL Single-Point Contact: 375-2400 


\subsection{Exposure Evaluator Response to Incidents}

This section briefly describes the general EE response to a potential intake incident. Details and some example incident response protocols are provided in Appendix E.

\subsubsection{Receiving Incident Notification}

Upon notification of an incident, the EE initiates an incident telephone log similar to Exhibit 7.2. The initial priority of the EE is to obtain the identification of the workers and the circumstances surrounding the exposure, and to determine the appropriate bioassay measurements. Based on the information provided by the contractor/DOE office and the specific services requested, the EE makes appropriate emergency notifications and arranges for bioassay measurements. The EE then makes a preliminary assessment of the potential effectiveness of therapeutic measures, and identifies additional information that might assist in assessing the significance of the exposure.

The EE Office does not normally report contractor incidents to DOE or Occupational Medicine. The decision to report incidents to DOE or Occupational Medicine is the responsibility of the contractor, unless other arrangements have been made with the EE Office. However, if the probability of intake is considered serious enough to possibly warrant therapy, Occupational Medicine may be informally advised by the EE Office.

NOTE: These statements should not be construed as restricting the EE Office in any way from responding to requests from DOE or Occupational Medicine regarding the dosimetry associated with an incident.

\subsubsection{Scheduling and Performing Bioassay Measurements}

\section{Initial Bioassay Measurements}

A variety of bioassay measurements may be requested. Some of the typical reasons for requesting particular bioassay measurements are described in Table 7.3.

The EE arranges to obtain suitable bioassay measurements. The EE also establishes priorities for measurement types and, if necessary, for individuals needing measurements.

In addition to direct in vivo counts, which can be performed within a few hours of the incident, the EE may arrange for rapid processing of excreta samples, which can provide an analytical result within approximately 24 hours of sample receipt. With rapid sample processing, analytical sensitivity is sacrificed for quick turn-around time. The purpose of rapid processing is to obtain immediate results to assess the potential need for, or effectiveness of, dose reduction therapy. The EE should determine if trading analytical sensitivity for quick results is appropriate for dosimetry. Circumstances may also warrant rapid processing to provide the contractor with preliminary information.

\section{Follow-Up Bioassay Measurements}

Based on initial measurements, the EE determines the need for follow-up bioassay measurements and advises Field Dosimetry of the needed measurements. In some cases, it may be appropriate for the EE to arrange follow-up measurements directly with the worker at the time of the initial measurements. As information becomes available, the EE advises contractor/DOE office and discusses results with workers, 
if requested. The intent of EE function is to work through Field Dosimetry for all but the most pressing worker communications.

Table 7.3. Typical Incident-Response Bioassay Measurements and Their Purposes

\begin{tabular}{|c|c|}
\hline Measurement & Purpose \\
\hline Whole body counts and lung counts & $\begin{array}{l}\text { Measure activity present in a person at a specific } \\
\text { post-intake time. Multiple measurements are used to } \\
\text { establish the specific retention pattern in the person. }\end{array}$ \\
\hline Head counts & $\begin{array}{l}\text { Estimate skeleton burden of bone-seeking } \\
\text { radionuclides. This estimate is used to confirm } \\
\text { skeleton deposition and to convert chest count results } \\
\text { to lung content by correcting for interference from } \\
\text { skeleton activity. }\end{array}$ \\
\hline Organ counts or wound count & $\begin{array}{l}\text { Measure activity present in a specific organ or tissue } \\
\text { at a specific post-intake time. Used to estimate the } \\
\text { retention pattern of the individual. }\end{array}$ \\
\hline $\begin{array}{l}\text { Urine samples } \\
\text { approximate } 12 \mathrm{~h} \\
\text { approximate } 24 \mathrm{~h} \\
\text { total }\end{array}$ & $\begin{array}{l}\text { Estimate excretion rate of radionuclides not readily } \\
\text { detectable by direct in vivo counting. Internal } \\
\text { deposition of such nuclides is estimated based on } \\
\text { standard models. Multiple samples may be required } \\
\text { to determine the individual excretion patterns and } \\
\text { appropriate excretion model. }\end{array}$ \\
\hline $\begin{array}{l}\text { Urine samples } \\
\text { (single voiding or "spot") }\end{array}$ & $\begin{array}{l}\text { Provide initial order-of-magnitude estimate of } \\
\text { exposure based on excretion model. This } \\
\text { measurement is also suitable for routine and } \\
\text { nonroutine tritium dosimetry. }\end{array}$ \\
\hline Fecal samples & $\begin{array}{l}\text { Confirm intake. Provide isotope identification and } \\
\text { ratio information. Estimate dose based on early } \\
\text { clearance (may require multiple samples). } \\
\text { Differentiate soluble from insoluble materials. }\end{array}$ \\
\hline
\end{tabular}

Measurement Protocols

The EE determines measurement protocols for incidents. Some example protocols are included in Appendix E.

\subsubsection{Dose Assessment Capability}

The dose assessment and reporting practices are described in Chapters 3.0 and 4.0 of this manual. Summary statements are provided here because they are related to incident response.

\section{Dose Sensitivity}

The HIDP has the capability to assess a committed effective dose of 100 mrem for all radionuclides of concern at Hanford. In some cases, however, the ability to do so is contingent upon obtaining appropriate bioassay measurements (fecal samples, urine samples, in vivo measurements) within the first few days post-exposure. For most nuclides, if early data are obtained within the first few days following exposure, the dose assessment capability is 10 mrem or less. The exhibits in Chapter 5.0 and Appendix E of this manual describe the capability of bioassay measurements with regard to minimum detectable dose. 
Methods and Models of the Hanford Internal Dosimetry Program (PNNL-MA-860) provides additional discussion on the methods of determining the sensitivity.

\section{Preliminary Dose Assessment}

An initial assessment of the magnitude of a potential intake and internal dose is made as soon as the data permit. Because the circumstances of each intake are different, initial estimates may be inaccurate. In general, when bioassay measurements confirm an intake, follow-up measurements are required to estimate an internal dose accurately. Early estimates of internal dose should be considered as order-ofmagnitude estimates only.

Initial assessments are normally communicated directly to Field Dosimetry without a formal evaluation and transmittal letter. If requested by the contractor/DOE office, a preliminary dose assessment letter is provided.

\section{Final Dose Assessment}

Final dose assessments are issued when sufficient data have been obtained to confidently estimate the doses required to be reported to DOE. These dose assessments become part of the worker's radiation exposure file.

\subsection{Guidance for Exposure Evaluator Response to Incidents}

This section provides general guidance for EE responses to some anticipated situations. It is not intended to be an all-encompassing statement of EE response, nor is it intended to replace other contractor, DOE or EE policies, procedures, or requirements.

\subsubsection{Managing Uninjured Workers Who Are Externally Contaminated}

The incident contractor/DOE office is responsible for the management of externally contaminated uninjured workers. Normally, workers should be decontaminated before being released from the facility. If external contamination is detected on workers at the IVRRF, the EE, RCT, contractor/DOE office, and IVRRF staff must determine the action to be taken. The IVRRF is not used as a decontamination center, and workers with removable contamination should not be counted until such contamination has been removed.

Clothing or personal items discovered to be contaminated in surveys made at the IVRRF are bagged and dispositioned according to the contractor/DOE office instructions. Normally, the contractor/DOE office radiological controls organization deals with these items.

\subsubsection{Managing Injured Workers Who Are Externally Contaminated}

The primary responsibility for management of all injured workers, whether contaminated or not, lies with the responding medical authority. This authority may be Occupational Medicine, Kadlec Medical Center, another hospital or the Hanford Fire Department ambulance operating under the direction of the Mid-Columbia Emergency Medical Service.

When dealing with contaminated workers, the EE supports medical staff by providing advice in matters of dosimetry for the patients and attending staff. The decontamination of an injured worker is a 
medical staff responsibility, although the EE or RCT may be requested to assist in the decontamination efforts. Medical staff also determine the priority of medical treatment versus decontamination.

If decontamination efforts fail to completely remove personal contamination, it may be appropriate to release a worker with residual skin contamination. This decision must be made by the contractor/DOE office representative. Under such circumstances, the worker should be advised of appropriate techniques to limit the potential spread of contamination after release.

Such techniques might include the use of shower caps, gloves, or bandages, to provide a barrier against contamination spread. In addition, it is suggested that the worker be advised when spread of contamination would not be a significant concern upon release. Home surveys may be appropriate in some cases, and are the responsibility of the event contractor/DOE office and the worker's employer.

\subsubsection{Taking Therapeutic Measures to Reduce Internal Dose}

Therapeutic measures to reduce dose are the responsibility of Occupational Medicine or the medical care provider. These methods may include the use of various drugs (e.g., diethylenetriamine pentaacetic acid [DTPA], potassium iodide, alginates, or diuretics) and surgical techniques (e.g., minor tissue excision, wound debridement). The EE advises Occupational Medicine of the potential effectiveness of various treatment alternatives to reduce dose, and informs Occupational Medicine of the potential dose to patients as subsequent bioassay data become available. General levels of intake or dose and appropriate considerations for dose intervention therapy are shown in Table 7.4, based on the guidance of Bhattacharyya, et al.(1992). Specific guidance on therapeutic actions and associated intervention levels for bioassay measurements is contained in Appendix E. 
Table 7.4. General Recommendations for Dose Reduction Therapy Adapted from Bhattarchayya et al. (1992).

\begin{tabular}{|c|c|}
\hline Intake or Dose Magnitude $^{\text {a }}$ & Therapy Consideration \\
\hline \multicolumn{2}{|l|}{ Intake of transportable forms } \\
\hline $\begin{array}{l}\text { Below } 0.5 \text { stochastic ALI }(<2 \text { rem } \\
\text { committed effective dose) }\end{array}$ & Therapy not a consideration \\
\hline $\begin{array}{l}0.5 \text { to } 5 \text { times the stochastic ALI, or } 2 \\
\text { to } 20 \text { rem committed effective dose }\end{array}$ & $\begin{array}{l}\text { Consider therapy. Clinical consequences from } \\
\text { the intake are unlikely. }\end{array}$ \\
\hline $\begin{array}{l}\text { Greater than } 10 \text { times the stochastic } \\
\text { ALI ( }>20 \text { rem committed effective } \\
\text { dose) }\end{array}$ & $\begin{array}{l}\text { Therapy is warranted. Implement extended or } \\
\text { protracted treatment depending on severity of } \\
\text { exposure. }\end{array}$ \\
\hline \multicolumn{2}{|l|}{$\begin{array}{l}\text { Inhalation intake of poorly transportable } \\
\text { forms }\end{array}$} \\
\hline $\begin{array}{l}\text { Greater than } 100 \text { times the stochastic } \\
\text { ALI ( }>200 \text { rem committed effective } \\
\text { dose) }\end{array}$ & Consider lung lavage. \\
\hline Wound contamination guidance & $\begin{array}{l}\text { Remove by debridement or surgical excision if } \\
\text { no risk of functional impairment exists. }\end{array}$ \\
\hline
\end{tabular}

a. Stochastic Annual Limit on Intake based on 5 rem committed effective dose.

\subsubsection{Releasing Workers Following an Incident}

The initial bioassay measurements that are necessary following an incident should be performed before the worker is released. The personal comfort of a worker is considered if extensive hold-over following a workday has already occurred or if discomfort occurs because of injury or extensive counting times. Actual measurements for the initial worker assessment should not normally require more than about 2 hours at the IVRRF. If more than one worker is involved in an incident, this time could be extended, or workers may be requested to return for additional counts at a later time.

When workers involved in an incident are initially counted or treated, a contractor/DOE office representative should be present. This representative bears the responsibility for release of the workers and for dealing with their questions regarding such items as overtime compensation or when to return. The EE addresses, to the extent that the available data allow, questions about potential internal dose and arranges for necessary excreta samples.

\subsubsection{Assisting in External Radiation Exposure Situations}

If the contractor/DOE office requests special assistance regarding an external radiation exposure incident or concern, the EE arranges for the Hanford External Dosimetry Program to provide this assistance. 


\subsubsection{Offsite Assistance Request}

If the EE receives a request for assistance from a non-Hanford source, the EE attempts to determine the nature of the requested assistance and to direct the inquiry to the appropriate authority. Specific requests for Hanford services are directed to RL.

\subsection{Reference}

Bhattacharyya, M.H., B.D. Breitenstein, H. Metivier, B.A. Muggenburg, G.N. Stradling, and V. Volf. 1992. "Guidebook for the Treatment of Accidental Internal Radionuclide Contamination of Workers." Radiat. Prot. Dosim., 41:1.

Pacific Northwest National Laboratory (PNNL). Methods and Models of the Hanford Internal Dosimetry Program, PNNL-MA-860. Richland, Washington. A copy of this manual is maintained in the HIDP files and available from the HIDP Manager or online by searching, PNNL-15613 @ http://www.pnl.gov/publications/. 
Exhibit 7.1 Checklist for Incident Data

\section{General Information}

- Description of incident — one or two sentences and date and time of incident

- Location of incident (area, building, room)

- Personnel involved (name, payroll number, job title, and address for each person).

\section{Internal Exposure-Related Information}

- Retain any object causing contamination for possible investigation

- Radionuclides

- Form of material (wet/dry, chemical form, soluble/insoluble)

- Mode of intake

- Respiratory protection (type, evidence of leakage)

- Nasal, mouth, or blood smear results (dpm)

- Facial contamination level (dpm)

- Other skin contamination (dpm)

- Clothing contamination (dpm)

- Area contamination (dpm)

- Airborne activity concentration $(\mu \mathrm{Ci} / \mathrm{cc})$

- Correlation of contamination levels to potential exposure of worker.

\section{External Exposure-Related Information}

- Radionuclides (or type and energy of emission)

- Source activity

- Source geometry

- Estimated dose rate (type of instrument and distance)

- Supplemental dosimetry

- Duration of exposure

- Worker position relative to source

- Shielding around worker

- Shielding around source

- Anticipated delivery of dosimeters for processing.

\section{Criticality Exposure-Related Information}

- How detected?

- Number of workers exposed?

- Quick sort performed? Results of gut readings?

- Readings on worker personal effects

- Item, reading

- Instrument used, efficiency and background

- Elapsed time between criticality and reading

- Orientation and distance of worker to critical assembly

- Any immediate symptoms? (describe)

- Fissile material

- Shielding material and thickness

- Current status of area; any chance for recurrence?

- Environmental release?

- Have nuclear accident dosimeters (NADs or "candles") been collected?

- Have worker dosimeters been collected? 
Exhibit 7.2 Incident Telephone Log

\section{RADIATION INCIDENT - TELEPHONE REPORT}
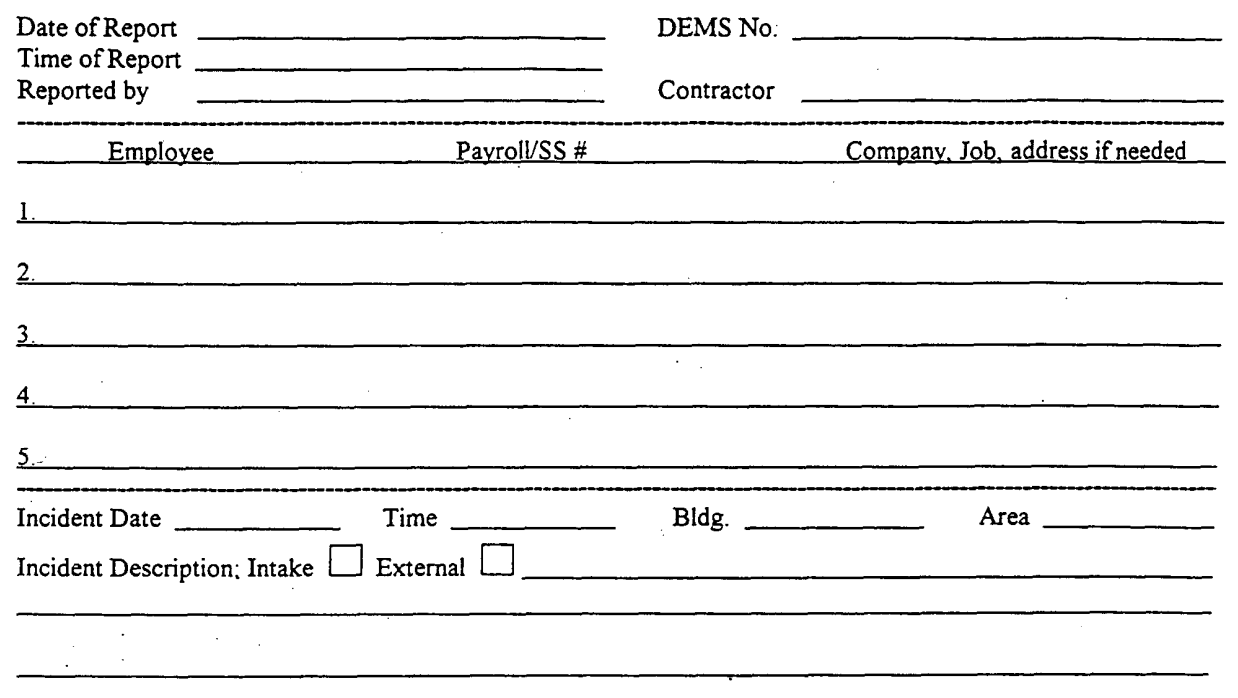

Prin. Isotope(s)

Mode of Intake

\begin{tabular}{|c|c|c|c|}
\hline $\begin{array}{l}\text { Employ. } \\
\text { No. }\end{array}$ & & $\begin{array}{l}\text { Nasal Contaminat } \\
\text { Alpha }\end{array}$ & $\begin{array}{l}\text { tion } \\
\text { Beta }\end{array}$ \\
\hline 1. & Rt & $\mathrm{dpm}_{\mathrm{cpm}}$ & 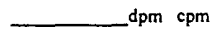 \\
\hline
\end{tabular}

2. $\mathrm{Rt} \longrightarrow \mathrm{dpm} \mathrm{cpm} \longrightarrow \mathrm{dpm} \mathrm{cpm}$

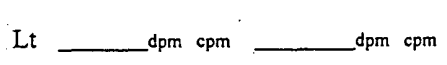

3. Rt $\_\mathrm{dpm} \mathrm{cpm} \longrightarrow \mathrm{dpm} \mathrm{cpm}$

Lt __ dpm $\mathrm{cpm} \_\mathrm{dpm} \mathrm{cpm}$

Skin. Other Personal Contamination

4. $\mathrm{Rt} \longrightarrow \mathrm{dpm} \mathrm{cpm} \longrightarrow \mathrm{dpm} \mathrm{cpm}$

$\mathrm{Lt} \_\mathrm{dpm} \mathrm{cpm} \_\mathrm{dpm} \mathrm{cpm}$

5. Rt $\longrightarrow \mathrm{dpm} \mathrm{cpm} \longrightarrow \mathrm{dpm} \mathrm{cpm}$

$\mathrm{Lt} \longrightarrow \mathrm{dpm} \mathrm{cpm} \_\mathrm{dpm} \mathrm{cpm}$ 
Exhibit 7.2 Incident Telephone Log (contd)

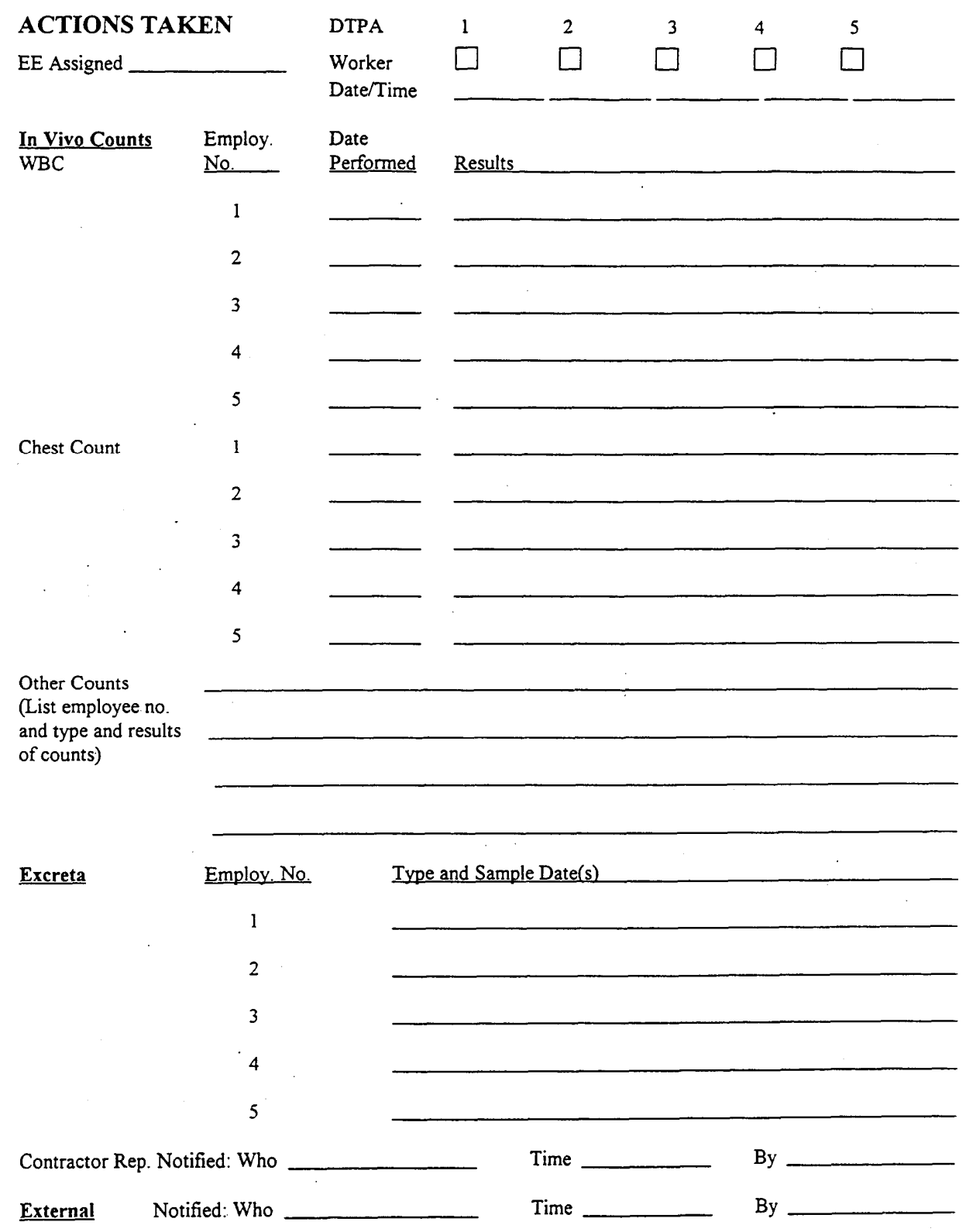




\section{HANFORD INTERNAL DOSIMETRY PROGRAM MANUAL PNL-MA-552}

\section{SECTION 8.0, QUALITY ASSURANCE}

Issued for implementation effective 01/01/2010

Supersedes: 04/2007

\section{Use Category: Not applicable}

\section{Approval Signatures:}

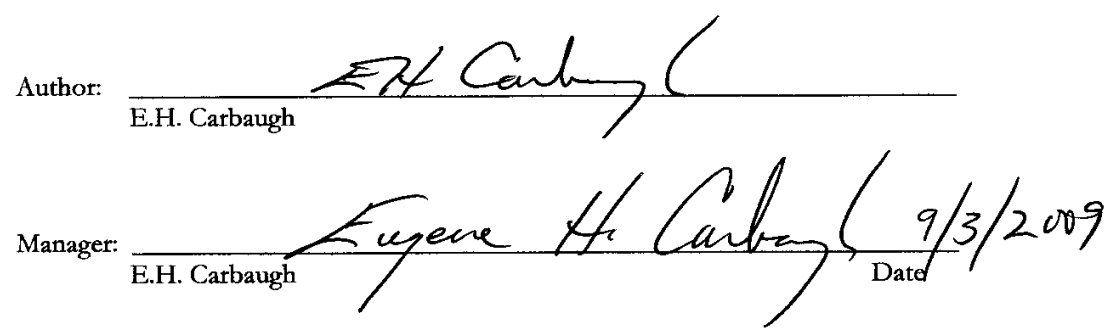

Reviewer Signatures:

Reviewer \# 1:

Approved by the Hanford Personnel Dosimetry Advisory Committee is not required per Section 1.0 of this manual. 


\section{Contents}

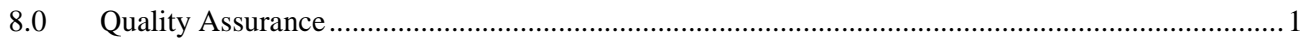

8.1 Quality Assurance and Quality Control for Bioassay Analyses ................................................

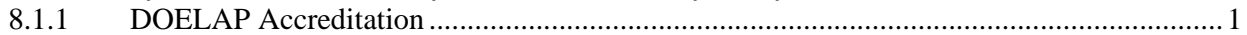

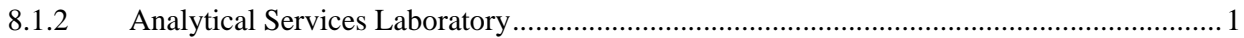

8.1.3 Internal Dosimetry Oversight of the Lab’s Quality Control Program ................................ 2

8.1.4 Quality Assurance of In Vivo Measurements ....................................................................

8.2 Quality Assurance and Quality Control for Dose Assessments ...............................................

8.3 Internal Dosimetry Program Records......................................................................................... 3

8.4 Assessments of the Internal Dosimetry Program ................................................................. 3

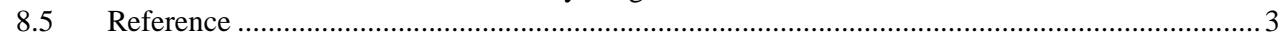

PNL-MA-552 Section 8.0

Page 2 of 8
Issued for implementation effective 01/01/2010

Supersedes: 04/07 


\subsection{Quality Assurance}

The quality assurance (QA) and quality control (QC) features of the Hanford Internal Dosimetry Program (HIDP) are summarized in this chapter. The overall quality assurance plan for the HIDP is described in the Radiation and Health Technology (R\&HT) Quality Assurance Program Plan (QAPP), with Appendix B of that plan detailing items specific to the HIDP.

\subsection{Quality Assurance and Quality Control for Bioassay Analyses}

The quality of analytical results is monitored by the QA and QC programs of the Analytical Services Laboratory (Lab) and the laboratory oversight program of HIDP, the In Vivo Monitoring Program (IVMP), and the Department of Energy (DOE) through its Laboratory Accreditation Program (DOELAP).

\subsubsection{DOELAP Accreditation}

The HIDP maintains accreditation for indirect radiobioassay analyses through the Department of Energy Laboratory Accreditation Program (DOELAP). The accreditation involves submittal of documentation to DOELAP, triennial performance testing of the analytical laboratory, and an onsite assessment by DOELAP technical assessors. A copy of the accreditation letter and certificate is shown in Exhibits 8.1.

Separate accreditation for direct radiobioassay measurements is maintained by the In Vivo Monitoring Program.

\subsubsection{Analytical Services Laboratory}

The Lab analyzes essentially all indirect bioassay samples and is required by contract to maintain rigorous, extensive, well-documented QA and QC programs.

The Lab is required to maintain a QA manual that outlines responsibilities and provides requirements for data control, document control, calibration and checks of maintenance and test equipment, procedures, training, corrective action in the event of noncompliance, and traceability to standardizing bodies such as the National Institute of Standards and Technology (NIST).

The QC program involves analyzing blanks and spiked samples with each batch of real samples, constantly reviewing data, and publishing quarterly and annual QC reports. No less than $15 \%$ of all samples processed are blanks and spikes.

The QC samples are used to demonstrate compliance with requirements specified in the contract between the Lab and Battelle Memorial Institute. The requirements in the contract are at least as restrictive as, and in some areas more restrictive than, the recommendations for performance criteria for radiobioassay testing in American National Standard HPS N13.30-1996 (HPS 1996) and DOE Standard DOE-STD-1112-98 (DOE 1998). These requirements determine minimum detection levels (MDAs) for each analysis and matrix, as well as the allowable bias and required precision of the results. The Lab must demonstrate that actual MDAs are no greater than the levels specified in the contract and that bias and precision are within specified limits.

An annual audit of the Lab is performed by Pacific Northwest National Laboratory (PNNL) QA and HIDP staff. All routine analyses (i.e., not research and procedure development work) must be done

PNL-MA-552 Section 8.0

Page 1 of 8
Issued for implementation effective 01/01/2010

Supersedes: $04 / 07$ 
according to written and approved procedures. In addition, all analysts must be trained and certified in each procedure before they can routinely perform the applicable analysis.

\subsubsection{Internal Dosimetry Oversight of the Lab's Quality Control Program}

HIDP conducts an independent oversight program as a check on the validity of the Lab’s QC results. The program consists of a combination of blank and spiked samples, which may be submitted for analysis as known audit samples (single blind audits), masked for analysis as authentic worker samples (double blind audits), or split with another laboratory for simultaneous analytical intercomparison (split samples). The results of the audit samples are used to track Lab performance relative to the contractual detection levels in essentially the same manner as the Lab's own QC program. This process serves as an additional check on the Lab's ability to meet HPS N13.30 (HPS 1996) recommendations and contract requirements.

The results of HIDP's oversight program are documented quarterly by means of a letter report. Any discrepancies between the results of the Lab's and HIDP's QC data are investigated, and corrective actions are taken as necessary.

\subsubsection{Quality Assurance of In Vivo Measurements}

The QA of in vivo measurements is detailed in the In Vivo Monitoring Program Manual (PNL-MA574), and in the R\&HT QAPP. In brief, the program consists of daily equipment calibration and background checks using secondary reference sources and periodic calibrations using primary sources (i.e., NIST-traceable sources) in phantoms. In addition, the IVMP participates in laboratory intercomparison studies, in which spiked phantoms are sent to national and international facilities and the results are compared.

The results of workers' counts are tracked on computer by payroll number and name and are transmitted to the REX database weekly. The QA data are temporarily stored in hard-copy form at the In Vivo Radioassay and Research Facility and ultimately transferred to the records management archives. Computer codes are validated and verified according to software test plans.

\subsection{Quality Assurance and Quality Control for Dose Assessments}

The intention of the HIDP is for internal dose assessments to meet the DOE requirements as stipulated in 10 CFR 835, and the Radiation Protection Programs Guide (DOE 2008). The methods used to assess internal dose are described briefly in Chapter 3.0 of this manual and are addressed more completely in the Methods \& Models of the Hanford Internal Dosimetry Program (PNNL-MA-860). Generally, the methods are consistent with those recommended by national and international authorities, such as the ICRP and the NCRP.

All internal dose assessments are performed by the HIDP technical-professional staff and include or reference all methods and data used in the evaluation. Documentation of the assessment should be sufficient to enable a technically qualified health physicist to reconstruct the assumptions, methods, and conclusions of the assessment. To demonstrate compliance with Department of Energy software QA requirements, computer codes used for dose assessment are verified and validated according to codespecific software test plans.

Before an internal dose evaluation is issued, it undergoes peer review by a second HIDP technicalprofessional staff member to verify the technical accuracy and completeness. In addition, the evaluation and summary letter must be approved by the HIDP Manager before they are issued. HIDP staff 
responsible for dose assessments have basic knowledge of ionizing radiation and ICRP and NCRP guidance on internal dosimetry through either education or training. In addition, they have been trained in methods described in this manual and on the specific computer codes germane to each dose assessment that they perform. Before new dosimetrists are determined ready to perform dose assessments by the HIDP Manager, they undergo a period of apprenticeship commensurate with their experience and education.

\subsection{Internal Dosimetry Program Records}

The records generated by the HIDP are maintained in files within the R\&HT organization. The HIDP manager is responsible for the designation and maintenance of these records. Additional information is provided in Chapter 9.0.

\subsection{Assessments of the Internal Dosimetry Program}

Quality assurance assessments and management self-assessments are part of the HIDP and are planned and performed as required by the R\&HT QAPP. These assessments are intended to fulfill the requirements of 10 CFR.830.122 (i), but are not intended to fulfill the requirements of 10 CFR 835.102.

The HIDP is also subject to quality verification assessments by outside organizations in support of their own quality assurance programs and regulatory compliance efforts, such as the 10 CFR 835.102 requirement for contractor radiation program assessments. The responsibility for planning and conducting such assessments is beyond the scope of the HIDP, lying with the contractor organization governed by its specific radiation protection program. The HIDP will be responsive to contractor auditing requirements.

\subsection{Reference}

10 CFR 835. 2009. Department of Energy, Occupational Radiation Protection. U.S. Code of Federal Regulations. Accessed on 5/19/2009 http://www.gpoacess.gov/cfr/index.html.

Health Physics Society (HPS). 1996. Performance Criteria for Radiobioassay. HPS N13.30-1996, McLean, Virginia.

Pacific Northwest National Laboratory (PNNL). In Vivo Monitoring Program Manual, PNL-MA-574. Richland, Washington. (Internal manual.)

Pacific Northwest National Laboratory (PNNL). Methods and Models of the Hanford Internal Dosimetry Program, PNNL-MA-860. Richland, Washington. A copy of this manual is maintained in the HIDP files and available from the HIDP Manager or online by searching, PNNL-15614 @ http://www.pnl.gov/publications/.

Pacific Northwest National Laboratory (PNNL). “R\&HT Quality Assurance Program Plan.” Richland, Washington. Internal Manual. Copy maintained in the HIDP files and available by contacting the HIDP Manager.

U.S. Department of Energy (DOE). 1998. DOE Standard Department of Energy Laboratory Accreditation Program for Radiobioassay. DOE-STD-1112-98, Washington, D.C. 
U.S. Department of Energy (DOE). 1998. DOE Standard Department of Energy Laboratory

Accreditation Program for Radiobioassay. DOE-STD-1112-98, Washington, D.C.

U.S. Department of Energy (DOE). 2008. Radiation Protection Programs Guide for use with Title 10,

Code of Federal Regulations, Part 835, Occupational Radiation Protection. DOE G441.1-1C,

Washington, D.C. Accessed on 5/19/2009 at http://www.directives.doe.gov.

PNL-MA-552 Section 8.0

Page 4 of 8
Issued for implementation effective 01/01/2010

Supersedes: $04 / 07$ 
Exhibit 8.1 Certificate of DOELAP Accreditation for Hanford Indirect Radiobioassay

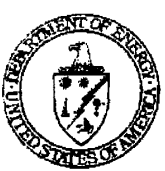

\author{
Department of Energy \\ Washington, DC 20585
}

March 13, 2008

MEMORANDUM FOR WAYNE M. GLINES RICHLAND OPERATIONS OFFICE

FROM:

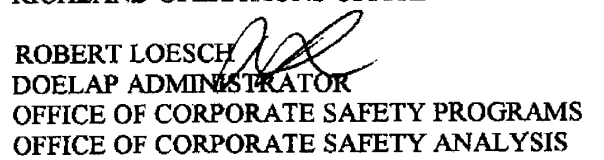

SUBJECT:

Laboratory Accreditation of the Hanford Site Radiobioassay Program

I have received information provided by the Performance Evaluation Program Administrator and the Oversight Board with regard to participation by the Pacific Northwest National Laboratory (PNNL) in the Department of Energy Laboratory Accreditation Program (DOELAP). They have recommended that accreditation be granted.

1 concur with this recommendation and, accordingly, grant accreditation in accordance with the Conditions of Accreditation accompanying this certificate.

Continuing accreditation is contingent upon maintaining radiobioassay practices consistent with the methodologies used during DOELAP performance testing and the site assessment. Changes in these practices, as described in DOELAP Technical Standard, DOE-STD-1112-98, The Department of Energy Laboratory Accreditation Program for

Radiobioassay, should be brought to the attention of the DOELAP

Performance Evaluation Program Administrator for Radiobioassay.

PNNL is to be congratulated for their successful participation in DOELAP. We also appreciate the support of the DOE Richland Operations Office in this important program. Attached are the official DOELAP Certificate of Accreditation and the Conditions of Accreditation. Please see that they are presented to PNNL in an appropriate manner as soon as possible. If you have any questions, I can be reached at (301) 903-4443.

Attachments: DOELAP Certificate of Accreditation Conditions of DOELAP Accreditation

cc: Anita Bhatt, DOE/ID

Eugene Carbaugh, PNNL

Timothy Lynch, PNNL 


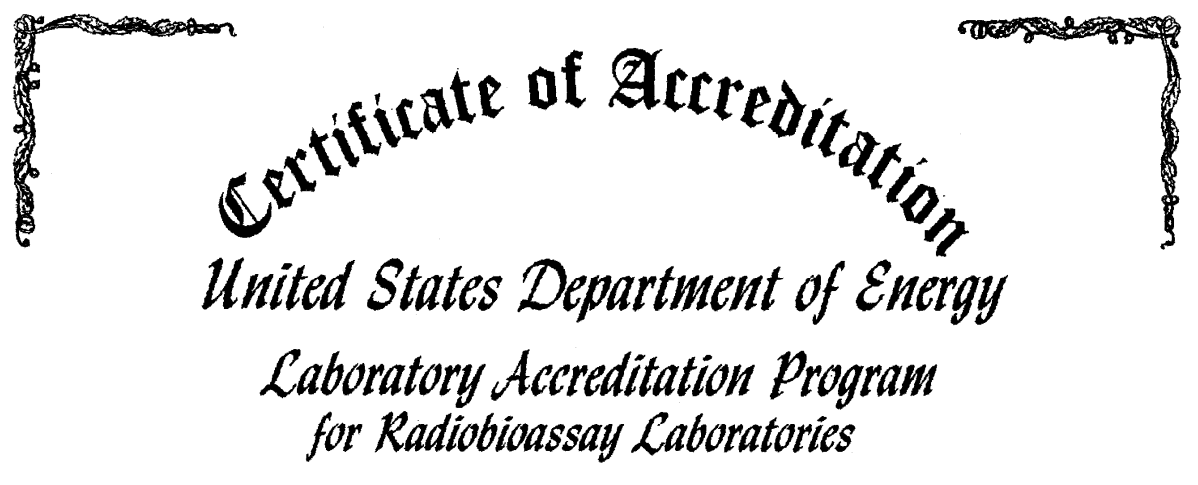

\section{Hanford Site}

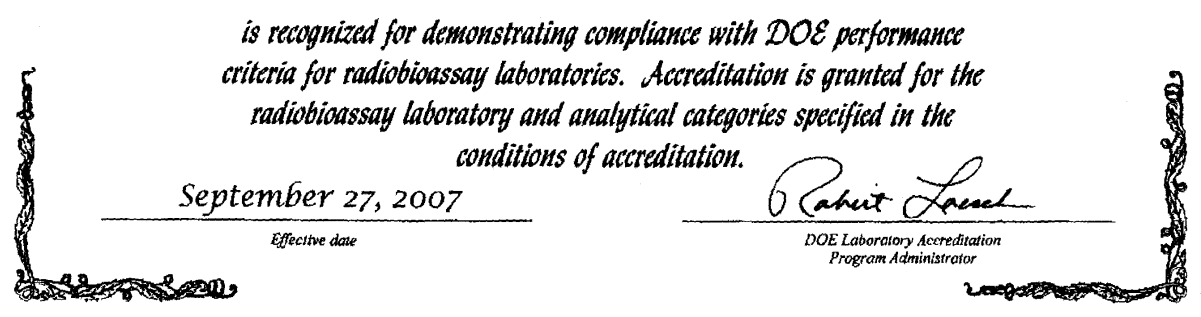




\section{CONDITIONS OF DOELAP ACCREDITATION}

\section{Hanford Site}

Effective until September 27, 2010, the in-direct (in-vitro) and direct (in-vivo) radiobioassay systems described below, used at the Hanford Site, are hereby granted DOELAP accreditation:

DOELAP In-Direct Categaries: Beta Activity: Avg. Energy $<100 \mathrm{keV}$

Hydrogen-3

Carbor-14

Sulfur-35

Radium-228

II Beta Activity: Avg. Energy $\geq 100 \mathrm{keV}$

Phosphorus-32

Strontiun-89/90

or Strontium-90

II Alpha activity, isotopic analysis

Thorium-228/230

or Thorium-232

Uranium-234/235

or Uranium-238

Neptunium-237

Plutonium-238

or Plutonium-239/240

Americium-241

IV Elemental (mass/volume)

Uranium by KPA

V Gamma (photon) activity

Cesium-137

Cobalt-60

lodine-125

$\begin{array}{cc}\text { Urine } & \text { Fecal } \\ \square & \square \\ \square & \square \\ \square & \square \\ \square & \square \\ \square & \square \\ \square & \square \\ \square & \square \\ \square & \square \\ \square & \square \\ \square & \square \\ \square & \square \\ \square & \square \\ \square & \square \\ \square & \square \\ \square & \square \\ \square & \square \\ \square & \square \\ \square & \square \\ \square & \square\end{array}$

$\begin{array}{ll} & \text { DOELAP Direct Categories: } \\ \text { I Transuranium elements via } L \text { x-rays } \\ \text { Plutonium-238 } \\ \text { II Americium-241 } \\ \text { II. Thorium-234 } \\ \text { IV Uranium-235 } \\ \text { V Fission and activation products } \\ \text { Manganese-54 } \\ \text { Cobait-58 } \\ \text { Cobalt-60 } \\ \text { Cerium-144 } \\ \text { Fission and activation products } \\ \text { Cesium-134 } \\ \text { Cesium-137 } \\ \\ \text { VII Radionuclides in the thyroid } \\ \text { lodine } 131 \\ \text { or lodine-125 }\end{array}$

$\begin{array}{lccccc}\text { Type } & \begin{array}{c}\text { Iron } \\ \text { Room }\end{array} & \begin{array}{c}\text { SS } \\ \text { Room }\end{array} & \begin{array}{c}\text { Palmer } \\ \text { Room }\end{array} & \begin{array}{c}\text { Lead } \\ \text { Room }\end{array} & \begin{array}{c}\text { Stand } \\ \text { Up }\end{array} \\ \text { Lung } & \square & \square & \square & \square & \square \\ \text { Lung } & \square & \square & \square & \square & \square \\ \text { Lung } & \square & \square & \square & \square & \square \\ \text { Lung } & \square & \square & \square & \square & \square \\ \text { Lung } & \square & \square & \square & \square & \square \\ & \square & \square & \square & \square & \square \\ & \square & \square & \square & \square & \square\end{array}$

Total body

Thyroid

$\begin{array}{ll}\square & \square \\ \square & \square \\ \square & \square \\ \square & \square \\ \square & \square\end{array}$

$\begin{array}{ll}\square & \square \\ \square & \square \\ \square & \square \\ \square & \square \\ \square & \square\end{array}$

$\square$
$\square$
$\square$
0
$\square$ 


\section{Conditions of Accreditation \\ Hanford Site \\ Page 2}

Accreditation is for these radiobioassay systems only, and is contingent upon maintaining radiobioassay practices that are consistent with the methodologies used during DOELAP

performance testing and the onsite assessment. Accreditation of your radiobioassay system will be necessary every three years as required by 10 CFR 835.402(b) and as discussed in the DOE

Technical Standard, DOE STD-1112-98, Laboratory Accreditation Program for Radiobioassay.

PNL-MA-552 Section 8.0

Page 8 of 8
Issued for implementation effective 01/01/2010 Supersedes: $04 / 07$ 


\section{HANFORD INTERNAL DOSIMETRY PROGRAM MANUAL}

PNL-MA-552

\section{SECTION 9.0, DOCUMENTS AND RECORDS}

Issued for implementation effective $01 / 01 / 2010$

Supersedes: 04/2007

Use Category: Not applicable

\section{Approval Signatures:}

Author:

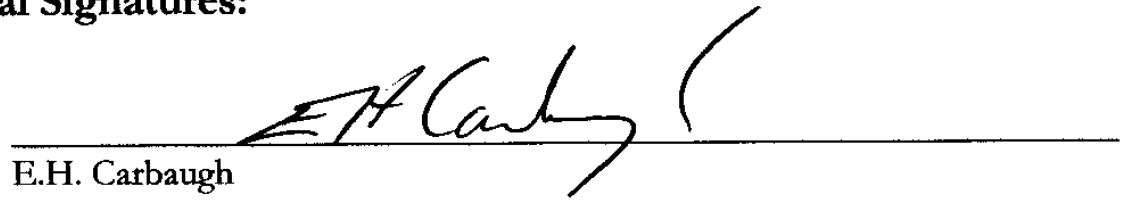

Manager:

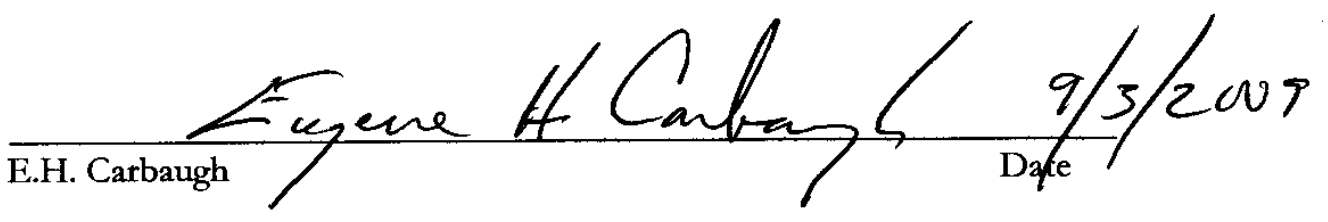

Reviewer Signatures:

Reviewer \# 1:

C.I. Antonio, Dosimetrist

Approval by the Hanford Personnel Dosimetry Advisory Committee is not required per Section 1.0 of this manual. 


\section{Contents}

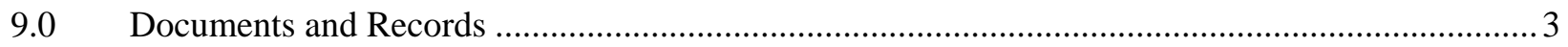

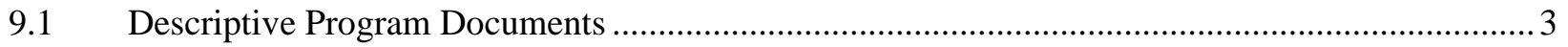

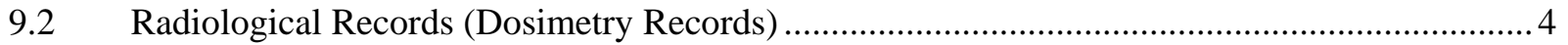

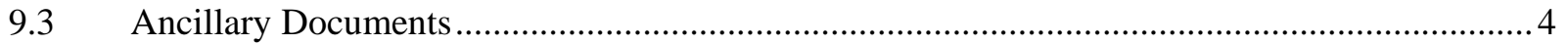

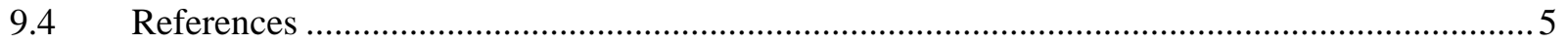




\subsection{Documents and Records}

The Hanford Internal Dosimetry Program (HIDP) is described by and operated in accordance with numerous documents. A variety of records are created and managed by the operation of the HIDP. Many of those records are subject to provisions of the Privacy Act (1979). This section provides a brief description of the types of documents and records important to the program. The Program File Plan (formerly known as Records Inventory and Disposition System (RIDS) index), maintained by the Program Manager, provides the details on record identification, storage, custodianship, retention periods, and disposition. Repositories for these documents include the program records files, the Hanford Radiation Records Program (HRRP), the Hanford Historical File (maintained by the HRRP), worker personal radiation exposure files (maintained by HRRP), the Pacific Northwest National Laboratory (PNNL) Total Records Information Management (TRIM) electronic records management system, and the Department of Energy Holding Area. Information concerning these documents and records is available from the HIDP Manager.

A moratorium on the destruction of all records generated under the PNNL 1830 contract is in effect. Due to pending litigation the Department of Energy has directed Battelle-PNNL to cease the destruction of 1830 contract records. This includes records that have met their retention requirements, whether they are maintained in offices or have been sent to storage.

\subsection{Descriptive Program Documents}

Descriptive program documents provide the technical and administrative basis on which the HIDP is founded, and the implementing procedures by which it is run. Examples of these documents include manuals, quality assurance plans, program management documents, reports, correspondence, computer codes and their manuals, procedures, and similar implementing instructions, guidance, and reports. The following documents are of particular importance:

- Methods and Models of the Hanford Internal Dosimetry Program, PNNL-MA-860. This manual describes the science and assumptions used by the HIDP. It includes technical methods, supporting evidence, and reference information. The target audience for this document is the technical staff directly supporting the program.

- Hanford Internal Dosimetry Program Manual, PNL-MA-552. This manual describes the services and capabilities provided by the HIDP, including its operating practices, recommendations for good practice, general guidance to users, and statements of bioassay capabilities. The target audience for this document are the clients of the HIDP.

- Hanford Internal Dosimetry Procedures Manual, PNL-MA-565. This manual is a compilation of the procedures for the day-to-day operations of the HIDP, including data reviews, communications, evaluation documentation, and records management.

- Radiation and Health Technology Quality Assurance Program Plan. This is the quality assurance manual under which the HIDP operates. The numbered sections of the manual apply to all activities within the PNNL Radiation and Health Technology group. Appendix B to this plan describes those quality provisions specific to the HIDP.

- Analytical Laboratory Contract and Statement of Work (SOW). The SOW provides the technical requirements for contractual performance by the excreta bioassay analytical support laboratory. The 
contract is between Battelle Memorial Institute and the supporting laboratory, and is technically administered through the HIDP.

- In Vivo Monitoring Program Manual (PNL-MA-574). This document provides the technical basis for the In Vivo Monitoring Program (IVMP) that performs all in vivo measurements at Hanford. The IVMP is managed independently of the HIDP. It is included here for completeness in identification of program documents directly relevant to internal dosimetry at Hanford.

- On-Call Exposure Evaluator Manual (PNL-MA-857). This manual is a compilation of technical information, forms, and call lists that can be used in combination with professional judgment when an on-call exposure evaluator responds to requests for assistance. Its distribution is generally limited to those specifically trained as on-call exposure evaluators.

\subsection{Radiological Records (Dosimetry Records)}

Radiological records, as used in this discussion, are those data that are maintained in a worker's personal radiation history file or in the electronic database (i.e., REX) supporting such records. These records typically (but not always) contain data subject to the Privacy Act and are routinely marked "Strictly Private" in accordance with PNNL policy or "Strictly Private - Sensitive" in response to some contractor requirements. Some examples of these records include:

- Final bioassay results for excreta or in vivo measurements

- Bioassay notification letters

- Internal dose evaluations for specific workers

- Contractor Supplemental Bioassay Requests

- In Vivo Exam Questionnaires

\subsection{Ancillary Documents}

A variety of ancillary documents are generated as part of the routine program operations. These documents include record and nonrecord material, both with and without Privacy Act implications. These documents may be contractually required reports, documents created for routine process monitoring, quality problem reports, management or quality assessments, analytical laboratory vendor documents (e.g., procedures, incident reports), quality oversight or technical reports, or measurement data leading to final results (e.g., measurement spectra, sample process sheets, data reduction calculations, QA/QC/management reviews).

These documents also include the minutes of the Hanford Personnel Dosimetry Advisory Committee, which provides a forum for addressing site-wide dosimetry issues and documenting conclusions. The record copy of these minutes is maintained by the HRRP. The HIDP maintains convenience copies for reference.

Where documents are required as records, the disposition of them is specified in the Program File Plan. Documents generated for convenience are disposed of at the discretion of the staff generating them. 


\subsection{References}

Pacific Northwest National Laboratory (PNNL). Hanford Internal Dosimetry Program Manual, PNLMA-552. Richland, Washington. A copy of this manual is maintained in the HIDP files and available from the HIDP Manager or online by searching, PNNL-15613 @ http://www.pnl.gov/publications/.

Pacific Northwest National Laboratory (PNNL). Hanford Internal Dosimetry Procedures Manual, PNLMA-565. Richland, Washington. Internal Manual. Copy maintained in the HIDP files and available by contacting the HIDP Manager.

Pacific Northwest National Laboratory (PNNL). In Vivo Monitoring Program Manual (PNL-MA-574). Richland, Washington. Internal Manual. Copy maintained in the HIDP files and available by contacting the HIDP Manager.

Pacific Northwest National Laboratory (PNNL). On-Call Exposure Evaluator Manual (PNL-MA-857). Richland, Washington. Internal Manual. Copy maintained in the HIDP files and available by contacting the HIDP Manager.

Pacific Northwest National Laboratory (PNNL). Methods and Models of the Hanford Internal Dosimetry Program, PNNL-MA-860. Richland, Washington. A copy of this manual is maintained in the HIDP files and available from the HIDP Manager or online by searching, PNNL-15614 @ http://www.pnl.gov/publications/.

Pacific Northwest National Laboratory (PNNL). Radiation and Health Technology Quality Assurance Program Plan. Richland, Washington. (Internal manual)

Privacy Act. 44 Federal Register, 510772 (1979). 


\section{HANFORD INTERNAL DOSIMETRY PROGRAM MANUAL}

PNL-MA-552

\section{APPENDIX A - ORAL REPORTING AND SCREENING \\ LEVELS FOR BIOASSAY MEASUREMENTS}

Issued for implementation effective 01/01/2010

Supersedes: $10 / 2003$

Use Category: Not applicable

Approval Signatures:

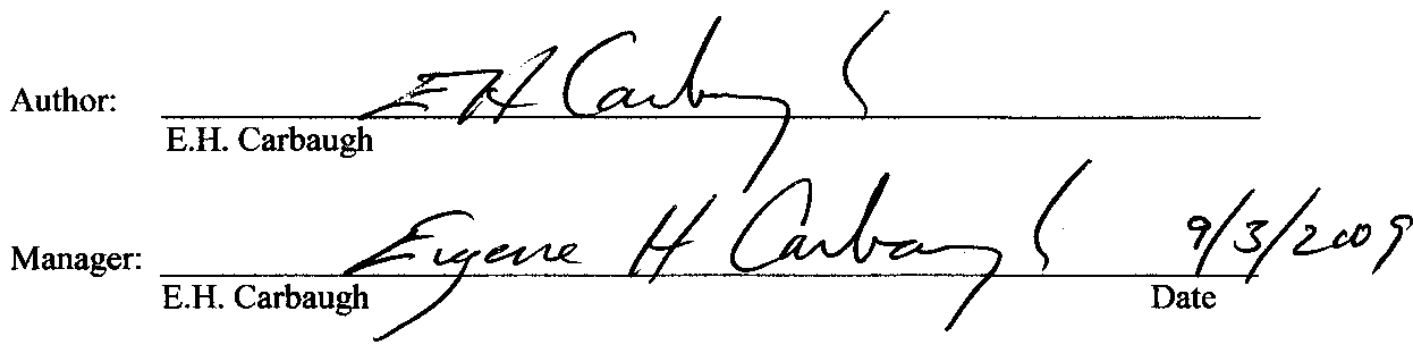

Reviewer Signatures:

Reviewer \# 1:

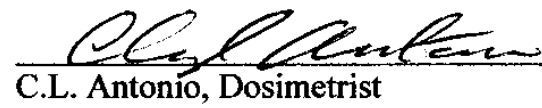

Approved by the Hanford Personnel Dosimetry Advisory Committee on June 5, 2009. 


\section{Contents}

Appendix A - Oral Reporting and Screening Levels for Bioassay Measurements ..................................... 3 


\section{Appendix A - Oral Reporting and Screening Levels for Bioassay Measurements}

This appendix lists the levels of routine bioassay measurement results that initiate response by the Hanford Internal Dosimetry Program (HIDP), according to practices discussed in Chapter 2.0. The bioassay measurement laboratories provide prompt notification to HIDP for any results that exceed the oral reporting level (ORL). Results reported to HIDP are compared with the screening levels in Tables A.1 through A.4 to determine if additional investigation or initiation of the dose assessment process is required.

Oral reporting levels are specified in the bioassay laboratory statement of work. For excreta samples processed using routine processing codes, the ORL is a numerical value determined as specified in Tables A.1 through A.3. All excreta samples processed using priority, expedite, or emergency processing codes are reported verbally or electronically to HIDP. The ORL for any in vivo measurement is the detection of any radionuclide other than ${ }^{40} \mathrm{~K},{ }^{208} \mathrm{Tl}$, or ${ }^{214} \mathrm{Bi}$.

Individual-specific screening levels may be established for workers with unusual background levels due to environmental sources or long-term detectable levels resulting from an assessed intake. Such levels are established by the dose assessment process and documented in the resulting evaluations.

Screening levels for bioassay measurements are listed as follows:

Table A.1 Transuranics and ${ }^{90} \mathrm{Sr}$ Urinalysis

Table A.2 Tritium Urinalysis

Table A.3 Uranium Urinalysis

Table A.4 In Vivo Measurements

Table A.1. Transuranic and ${ }^{90} \mathrm{Sr}$ Urinalysis Oral Reporting and Screening Levels and Their Basis

\begin{tabular}{|c|c|c|c|}
\hline $\begin{array}{c}\text { Bioassay } \\
\text { Measurement }\end{array}$ & $\begin{array}{l}\text { Oral Report } \\
\text { Level, dpm }\end{array}$ & $\begin{array}{c}\text { Screening } \\
\text { Level, dpm }\end{array}$ & $\begin{array}{c}\text { Basis for } \\
\text { Screening Level }\end{array}$ \\
\hline \multicolumn{4}{|c|}{ Routine urine analysis results } \\
\hline (IPU) & $>\mathrm{L}_{\mathrm{C}}^{(\mathrm{a})}$ & $>$ ORL & Detected activity $^{(\mathrm{b})}$ \\
\hline${ }^{239+240} \mathrm{Pu}$ (IPU) & $>\mathrm{L}_{\mathrm{c}}{ }^{(\mathrm{a})}$ & $>$ ORL & Detected activity $^{(b)}$ \\
\hline${ }^{239+240} \mathrm{Pu} \quad$ (IPUL) & $>\mathrm{L}_{\mathrm{c}}{ }^{\text {(a) }}$ & $>$ ORL & Detected activity $^{(b)}$ \\
\hline${ }^{241} \mathrm{Am}$ & $>\mathrm{L}_{\mathrm{c}}^{(\mathrm{a})}$ & $>$ ORL & Detected activity $^{(\mathrm{b})}$ \\
\hline${ }^{242} \mathrm{Cm}$ & $>\mathrm{L}_{\mathrm{c}}{ }^{\text {(a) }}$ & $>$ ORL & Detected activity $^{(b)}$ \\
\hline${ }^{243+244} \mathrm{Cm}$ & $>\mathrm{L}_{\mathrm{c}}{ }^{\text {(a) }}$ & $>$ ORL & Detected activity $^{(\mathrm{b})}$ \\
\hline${ }^{90} \mathrm{Sr}$ or $\mathrm{Sr}$ & 4 & $>$ ORL & Detected activity $^{(b)}$ \\
\hline
\end{tabular}

(a) For alpha spectroscopy procedures, the oral reporting level is determined according to the following formula: $\mathrm{L}_{\mathrm{c}}=2 * \mathrm{CSU}$, where CSU (combined standard uncertainty) $=$ the sample specified estimate of the overall uncertainty associated with the analytical result.

(b) Any result greater than the oral reporting level (> ORL) indicates that a committed effective dose could potentially exceed 10 mrem. 
Table A.2. Tritium Urinalysis Oral Reporting and Screening Levels and Their Basis

\begin{tabular}{|c|c|c|c|}
\hline Tritium Measurement & $\begin{array}{l}\text { Oral Reporting } \\
\text { Level, dpm/ml }\end{array}$ & $\begin{array}{c}\text { Screening } \\
\text { Level, } \\
\text { dpm/ml }\end{array}$ & Basis for Screening Level \\
\hline Baseline & 10 & $>$ ORL & Detected activity $^{(\mathrm{a})}$ \\
\hline 400-Area Baseline & 10 & 40 & $\begin{array}{c}\text { Elevated } 400 \text { Area } \\
\text { background }\end{array}$ \\
\hline \multicolumn{4}{|l|}{ Multiple Acute Scenario } \\
\hline Biweekly Routine & 10 & 120 & 10 mrem $E(50)^{(b)}$ \\
\hline Monthly Routine & 10 & 90 & 10 mrem $E(50)^{(c)}$ \\
\hline Supplemental Monthly & 10 & 900 & 100 mrem $E(50)^{(\mathrm{d})}$ \\
\hline Quarterly & 10 & 16 & 10 mrem $E(50)^{(e)}$ \\
\hline Chronic Equilibrium & & 310 & 10 mrem $E(50)$ \\
\hline Single Acute Scenario, Days Post-Intake: & & & 10 mrem/intake \\
\hline 1 & 10 & 7,400 & \\
\hline 2 & 10 & 6,900 & \\
\hline 3 & 10 & 6,500 & \\
\hline 7 & 10 & 5,000 & \\
\hline 14 & 10 & 3,100 & \\
\hline 30 & 10 & 1,100 & \\
\hline
\end{tabular}

(a) Indicates past tritium exposure. The potential source and dose need to be considered for possible inclusion in the lifetime dose estimate.

(b) Assumes 26 equally spaced intakes per year to give 10 mrem committed effective dose. No consideration is given to buildup of tritium levels in urine.

(c) Assumes 12 equally spaced intakes per year to give 10 mrem committed effective dose. No consideration is given to buildup of tritium levels in urine.

(d) Dose could potentially exceed 100 mrem; therefore, a change to biweekly sampling is recommended for closer monitoring until results fall below the biweekly screening level.

(e) Assumes 4 equally spaced intakes per year to give 10-mrem. No consideration is given to buildup of tritium levels in urine. 
Table A.3. Uranium Urinalysis Oral Reporting and Screening Levels and Their Basis

\begin{tabular}{|c|c|c|c|}
\hline Uranium Measurement & $\begin{array}{l}\text { Oral Reporting } \\
\text { Level }\end{array}$ & $\begin{array}{c}\text { Screening } \\
\text { Level }\end{array}$ & $\begin{array}{c}\text { Basis for } \\
\text { Screening Level } \\
\end{array}$ \\
\hline \multicolumn{4}{|l|}{$\begin{array}{l}\text { Isotopic Uranium (IU) } \\
\text { (approximate } 24 \text {-h sample) }\end{array}$} \\
\hline${ }^{238} \mathrm{U}$ & $0.15 \mathrm{dpm}$ & $0.15 \mathrm{dpm}$ & Background level \\
\hline${ }^{233+234} \mathrm{U}$ & $0.15 \mathrm{dpm}$ & $0.15 \mathrm{dpm}$ & Background level \\
\hline${ }^{235} \mathrm{U}$ & $0.007 \mathrm{dpm}$ & $0.007 \mathrm{dpm}$ & Background level \\
\hline \multicolumn{4}{|l|}{ Insoluble Uranium } \\
\hline approximate $24-\mathrm{h}$ & $0.2 \mu \mathrm{g}$ & $0.2 \mu \mathrm{g}$ & Background level \\
\hline approximate $12-\mathrm{h}$ & $0.2 \mu \mathrm{g}$ & $0.2 \mu \mathrm{g}$ & Oral reporting level ${ }^{(a)}$ \\
\hline \multicolumn{4}{|c|}{$\begin{array}{l}\text { Infrequent (single acute) Exposure Potential, } \\
\text { (approximate 24-h sample) }\end{array}$} \\
\hline Quarterly - Elemental Uranium Mass & $0.2 \mu \mathrm{g}$ & $0.4 \mu g^{(\mathrm{c})}$ & 10-mrem $E(50)$ \\
\hline \multicolumn{4}{|l|}{ Quarterly - Isotopic Uranium } \\
\hline${ }^{238} \mathrm{U}$ & $0.15 \mathrm{dpm}$ & $0.30 \mathrm{dpm}$ & 10-mrem $E(50)$ \\
\hline${ }^{233+234} U$ & $0.15 \mathrm{dpm}$ & $0.30 \mathrm{dpm}$ & for mixture ${ }^{(c)}$ \\
\hline${ }^{235} \mathrm{U}$ & $0.007 \mathrm{dpm}$ & $0.014 \mathrm{dpm}$ & \\
\hline Quarterly Supplemental & $0.2 \mu \mathrm{g}$ & $1.3 \mu \mathrm{g}$ & Chemical toxicity $^{(\mathrm{d})}$ \\
\hline ICP MS Analysis for ${ }^{236} \mathrm{U}$ & $7 \mathrm{E}-04 \mu \mathrm{g}$ & $>$ ORL & Detected activity ${ }^{(\mathrm{e})}$ \\
\hline \multicolumn{4}{|c|}{$\begin{array}{l}\text { (a) The oral reporting level is contractually the same as for approximate 24-hour samples. The screening } \\
\text { level for } 12 \text {-hour samples is numerically the same as for } 24 \text {-hour samples, but extrapolation to a daily } \\
\text { excretion implies a less sensitive daily screening level of } 0.4 \mu \mathrm{g} / \mathrm{d} \text {. }\end{array}$} \\
\hline \multicolumn{4}{|c|}{ (b) Based on background level of $0.2 \mu \mathrm{g} / \mathrm{d}$ divided by Reference Man daily urine excretion rate of $1.6 \mathrm{~L} / \mathrm{d}$. } \\
\hline \multicolumn{4}{|c|}{$\begin{array}{l}\text { (c) Assumes } 0.2 \mu \mathrm{g} \text { from a } 1.5 \mathrm{mg} \text { Type } \mathrm{M}, 5-\mu \mathrm{m} \text { inhalation plus } 0.2 \mu \mathrm{g} \text { from environmental background, } \\
\text { interpreted as natural uranium. }\end{array}$} \\
\hline \multicolumn{4}{|c|}{$\begin{array}{l}\text { (d) Levels shown indicate a potential acute intake at one-third of the assumed threshold for acute chemical } \\
\text { toxicity for inhalation of } 5-\mu \mathrm{m} \text { Type F uranium. }\end{array}$} \\
\hline \multicolumn{4}{|c|}{ (e) Based on detection of ${ }^{236} \mathrm{U}$ which is reactor produced and not present in natural uranium. } \\
\hline
\end{tabular}

Issued: Issued for implementation effective 01/01/20010

PNL-MA-552 Appendix A

Supersedes: 10/03

Page 5 of 6 
Table A.4. Oral Reporting and Screening Levels for Routine In Vivo Bioassay Measurements and Their Basis

\begin{tabular}{|c|c|c|c|}
\hline Bioassay Measurement & $\begin{array}{c}\text { Oral } \\
\text { Reporting } \\
\text { Level }\end{array}$ & $\begin{array}{c}\text { Screening } \\
\text { Level }\end{array}$ & $\begin{array}{l}\text { Basis for } \\
\text { Screening Level }\end{array}$ \\
\hline \multicolumn{4}{|l|}{ Baseline and Annual Whole Body Exam } \\
\hline${ }^{40} \mathrm{~K}$ & $200 \mathrm{nCi}$ & $200 \mathrm{nCi}$ & Environmental $^{(a)}$ \\
\hline${ }^{60}$ Co (as Type S) & $>\mathrm{L}_{\mathrm{c}}$ & $4 \mathrm{nCi}$ & 10 mrem $E(50)^{(b)}$ \\
\hline${ }^{137}$ Cs (as mixture indicator) & $>\mathrm{L}_{\mathrm{c}}$ & $>$ ORL & Detected activity $^{(\mathrm{c})}$ \\
\hline${ }^{137}$ Cs (pure nuclide) & $>\mathrm{L}_{\mathrm{c}}$ & $20 \mathrm{nCi}$ & 10 mrem $E(50){ }^{(b)}$ \\
\hline${ }^{152} \mathrm{Eu}$ & $>\mathrm{L}_{\mathrm{c}}$ & $4 \mathrm{nCi}$ & 10 mrem $E(50)^{(\mathrm{b})}$ \\
\hline${ }^{154} \mathrm{Eu}$ & $>\mathrm{L}_{\mathrm{c}}$ & $3 \mathrm{nCi}$ & 10 mrem $E(50)^{(b)}$ \\
\hline Other Radionuclides $^{(\mathrm{d})}$ & $>\mathrm{L}_{\mathrm{c}}$ & $>$ ORL & Unknown source \\
\hline \multicolumn{4}{|l|}{ Chest Count } \\
\hline Any Radionuclide ${ }^{(d)}$ & $>\mathrm{L}_{\mathrm{c}}$ & $>$ ORL & Unknown source \\
\hline \multicolumn{4}{|l|}{$\begin{array}{l}\text { Thyroid Count } \\
\text { (semiannual, germanium detector) }\end{array}$} \\
\hline${ }^{125} \mathrm{I}$ & $>\mathrm{L}_{\mathrm{c}}$ & $1 \mathrm{nCi}$ & 10 mrem $E(50)^{(\mathrm{e})}$ \\
\hline \multicolumn{4}{|c|}{ (a) Potassium-40 in the general public normally ranges up to about $200 \mathrm{nCi}$. } \\
\hline \multicolumn{4}{|l|}{ (b) Assumes one year post intake. } \\
\hline \multirow{2}{*}{\multicolumn{4}{|c|}{$\begin{array}{l}\text { (c) Any result > ORL indicates a committed effective dose could potentially exceed } 10 \text { mrem. } \\
\text { (d) Excluding known medical administrations. }\end{array}$}} \\
\hline & & & \\
\hline \multicolumn{4}{|c|}{ (e) Based on potential semiannual exposure with a possible dose of 5 mrem each interval. } \\
\hline
\end{tabular}




\title{
HANFORD INTERNAL DOSIMETRY PROGRAM MANUAL PNL-MA-552
}

\section{APPENDIX B - KEY TO SELECTED FIELD CODES USED IN THE RADIATION EXPOSURE (REX) DATABASE}

\author{
Issued for implementation effective 01/01/2010
}

Supersedes: $10 / 2003$

Use Category: Not applicable

\section{Approval Signatures:}

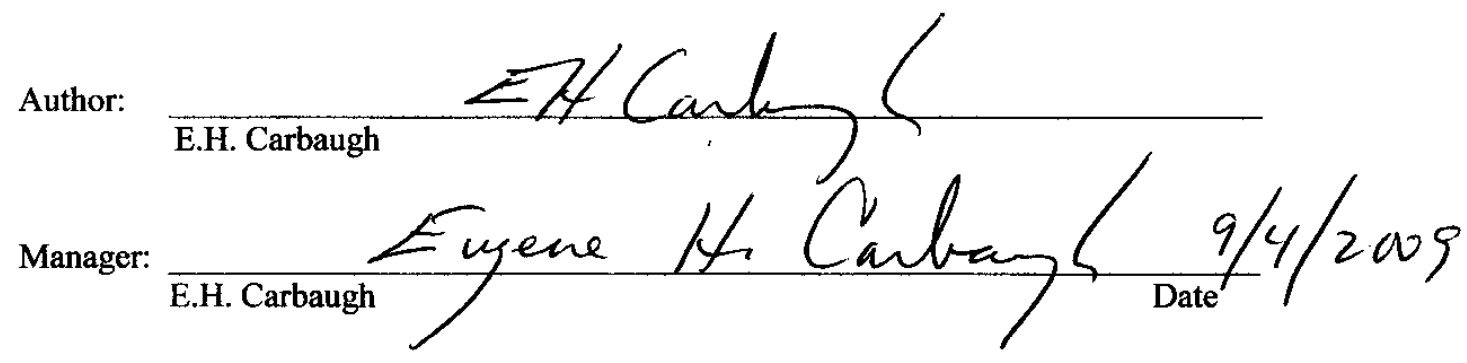

Reviewer Signatures:

Reviewer \# 1:

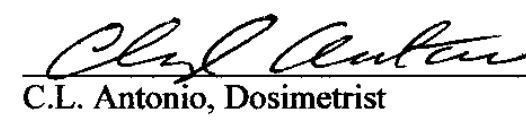

Approval by the Hanford Personnel Dosimetry Advisory Committee is not required per Section 1.0 of this manual. 


\section{Contents}

Appendix B - Key to Selected Field Codes Used in the Radiation Exposure (REX) Database .................. 1 


\section{Appendix B - Key to Selected Field Codes Used in the Radiation Exposure (REX) Database}

This appendix provides an explanation of selected data field codes used in the Radiation Exposure (REX) database that are pertinent to the Hanford Internal Dosimetry Program. The REX database includes online helps which provide an interpretive key to the fields. The listings in this appendix are not necessarily complete or current; they are provided for use when computer access may not be readily available, such as when reviewing hardcopy printouts or reports. The most current listings can be obtained directly from REX, or by contacting the Hanford Radiation Records Program database administrator.

\begin{tabular}{cl}
\hline Table & Title \\
\hline B.1 & Contractor Codes \\
B.2 & Sample Type Codes \\
B.3 & Bioassay Measurement Reason Codes for the REX System \\
B.4 & Excreta Sample Kit Codes \\
B.5 & Sample Status Codes \\
B.6 & Excreta Processing and No-Sample Codes \\
B.7 & Codes for Units \\
B.8 & Isotope Codes \\
B.9 & Excreta Analysis Type and Multiple Result Codes for Excreta Samples \\
B.10 & Bioassay Frequency Codes \\
B.11 & In-Vivo Body Location Codes \\
B.12 & In-Vivo Detector Codes \\
B.13 & In-Vivo Schedule-Type Codes \\
B.14 & In Vivo Analysis Request Codes \\
B.15 & In-Vivo No-Results Codes \\
B.16 & INTERTRAC Mode-of-Intake Codes \\
B.17 & INTERTRAC Evaluation Reason Codes \\
B.18 & INTERTRAC Source-of-Intake Codes \\
B.19 & INTERTRAC Miscellaneous Codes \\
B.20 & Person Codes \\
B.21 & Excreta Laboratory Codes \\
\hline
\end{tabular}


Table B.1. Contractor Codes

\begin{tabular}{cl}
\hline Code & \multicolumn{1}{c}{ Contractor } \\
\hline AA & DuPont, General Electric, ITT Support Services \\
BB & Isochem, Atlantic Richfield, and Rockwell Hanford Operations \\
BE & Bechtel Hanford \\
BN & Bechtel National Corporation \\
BP & Babcock and Wilcox Protec, Inc. \\
BW & Babcock and Wilcox Hanford Company \\
CH & CH2M-Hill Hanford Group \\
DE & DOE (Early service crew, FBI, Army, BPA, AEC, ERDA, etc.) \\
DN & Duke Engineering \& Services Northwest \\
DS & Duke Engineering \& Services Hanford \\
DY & Dyncorp Hanford \\
FD & Fluor Hanford \\
FH & DuPont, General Electric, ITT Support Services \\
FL & Fluor Daniel Northwest Services \\
FN & Fluor Federal Services \\
HF & Hanford Environmental Health Foundation \\
HH & Douglas United Nuclear, United Nuclear Industries, UNC Nuclear Industries \\
LM & Lockheed Martin Hanford Company \\
LS & Lockheed Martin Services, Inc. \\
NH & Numatec Hanford, Inc. \\
PN & Battelle - PNNL \\
PP & Energy Northwest \\
PR & Plateau Remediation Contractor \\
PS & Protection Technology Hanford \\
QC & Quality Control \\
RF & Duratek Federal Services Northwest \\
RR & Kaiser \\
RS & Duratek Federal Services of Hanford \\
SU & Cogema Engineering Corporation \\
TO & Tank Farm Operations Contractor \\
TT & JA Jones Construction, George A. Grant, Combustion Engineering, \\
& subcontractors \\
VV & Westinghouse Hanford Company (WADCO/HEDL) \\
W & Multiple Hanford Contractors \\
\hline &
\end{tabular}

Table B.2. Sample Type Codes

\begin{tabular}{cc}
\hline Code & Type of Sample \\
\hline B & Blood \\
F & Feces \\
S & Sputum \\
T & Tissue \\
U & Urine \\
\hline
\end{tabular}


Table B.3. Bioassay Measurement Reason Codes for the REX System

\begin{tabular}{|c|c|c|}
\hline Code & Name & Description \\
\hline BL & Baseline & $\begin{array}{l}\text { Measurement is performed to establish a } \\
\text { reference level against which subsequent } \\
\text { measurements will be compared. Generally, this } \\
\text { may be for new employees, or for established } \\
\text { employees, prior to commencing work with } \\
\text { radioactive materials, beginning a specific type } \\
\text { of radiation zone work, or making an offsite trip } \\
\text { where potential intakes could occur. }\end{array}$ \\
\hline PR & Periodic & $\begin{array}{l}\text { Measurement is performed at a regularly } \\
\text { scheduled interval. }\end{array}$ \\
\hline EA & $\begin{array}{l}\text { End of } \\
\text { Assignment }\end{array}$ & $\begin{array}{l}\text { Measurement is performed following completion } \\
\text { of specific work assignment, but not end of } \\
\text { employment. }\end{array}$ \\
\hline SP & Special & $\begin{array}{l}\text { Measurement is performed as part of a specific } \\
\text { investigation of potential internal dose. May } \\
\text { include response to off-normal work conditions, } \\
\text { or follow-up of abnormal periodic measurements. }\end{array}$ \\
\hline CR & $\begin{array}{l}\text { Contractor } \\
\text { Request }\end{array}$ & $\begin{array}{l}\text { Measurement requested by employer for reasons } \\
\text { other than periodic, baseline, end of assignment, } \\
\text { or special investigation. }\end{array}$ \\
\hline RA & Reanalysis A & $\begin{array}{l}\text { First repeat in vivo measurement or second } \\
\text { aliquot analysis of an excreta sample. }\end{array}$ \\
\hline $\mathrm{RB}$ & Reanalysis B & $\begin{array}{l}\text { Second repeat in vivo measurement or third } \\
\text { aliquot analysis of an excreta sample. }\end{array}$ \\
\hline $\mathrm{RC}$ & Reanalysis C & $\begin{array}{l}\text { Third repeat aliquot analysis of an excreta } \\
\text { sample. }\end{array}$ \\
\hline R1 & Recount 1 & $\begin{array}{l}\text { First recount of original excreta sample or repeat } \\
\text { in vivo exam. }\end{array}$ \\
\hline $\mathrm{R} 2$ & Recount 2 & $\begin{array}{l}\text { Second recount of original excreta sample or } \\
\text { repeat in vivo exam. }\end{array}$ \\
\hline QR & $\begin{array}{l}\text { Quality and } \\
\text { Research }\end{array}$ & $\begin{array}{l}\text { Measurement performed as part of quality } \\
\text { control, quality assurance, or research work. }\end{array}$ \\
\hline TM & Termination & Final bioassay at termination of employment. \\
\hline 12 & Contract Work & $\begin{array}{l}\text { In vivo measurement performed under contract to } \\
\text { customers rather than for Hanford employees. }\end{array}$ \\
\hline 20 & Source Count & $\begin{array}{l}\text { In vivo source count made for system calibration } \\
\text { or as a function check, usually using a known } \\
\text { check source. }\end{array}$ \\
\hline 30 & $\begin{array}{l}\text { Background } \\
\text { Count }\end{array}$ & $\begin{array}{l}\text { In vivo system background measurement } \\
\text { performed for system calibration or as a } \\
\text { functional check. }\end{array}$ \\
\hline
\end{tabular}


Table B.4. Excreta Sample Kit Codes

\begin{tabular}{|c|c|c|c|}
\hline \multicolumn{2}{|c|}{ Kit Code* } & \multirow[b]{2}{*}{ Media } & \multirow[b]{2}{*}{ Sample Description } \\
\hline $\mathbf{D} / \mathbf{R}$ & $\mathbf{P} / \mathbf{U}$ & & \\
\hline 1 & $\mathrm{P}$ & Urine & $\begin{array}{l}\text { Approximate 24-hour urine collection. Collected at home over a 2-day } \\
\text { period. Used for routine sampling and when a larger volume sample is } \\
\text { desired. Designated sample date is the day after kit delivery to the } \\
\text { employee. }\end{array}$ \\
\hline 2 & $\mathrm{Q}$ & Urine & $\begin{array}{l}\text { Approximate 12-hour urine collection for termination sampling only. } \\
\text { Collected at home overnight. Designated sample date is the day after } \\
\text { the date of kit delivery to the employee. }\end{array}$ \\
\hline 3 & $\mathrm{R}$ & Urine & $\begin{array}{l}\text { Total 24-hour urine collection. Collected at home and at work (if } \\
\text { necessary) to collect all urine voided during a 24-hour period. } \\
\text { Generally used for sampling immediately following an occurrence or } \\
\text { for work restriction sampling. Designated sample date is the day after } \\
\text { delivery or the date on which the sample collection began. }\end{array}$ \\
\hline 4 & $\mathrm{~S}$ & Urine & $\begin{array}{l}\text { Single void (spot urine) collection. Collection in a single bottle, used } \\
\text { for initial indications of an intake or when small sample volumes are } \\
\text { adequate. Designated sample date is the date of voiding. }\end{array}$ \\
\hline 5 & $\mathrm{~T}$ & Feces & $\begin{array}{l}\text { Collection of a single fecal voiding usually for investigation of a } \\
\text { potential intake. Sample date is the day after kit delivery or date on } \\
\text { which the sample was voided. }\end{array}$ \\
\hline 6 & $\mathrm{U}$ & Urine & $\begin{array}{l}\text { Partial day or approximate } 12 \text {-hour collection. Usually collected at } \\
\text { home overnight. Used for collection following an occurrence or when } \\
\text { a large volume urine sample is not necessary. Designated sample date } \\
\text { is the date of delivery to the employee. }\end{array}$ \\
\hline 7 & $\mathrm{~V}$ & Urine & $\begin{array}{l}\text { Approximate 12-hour collection Sunday-Monday sample (Friday } \\
\text { delivery only). Generally used for workers chronically exposed to } \\
\text { soluble uranium. Designated sample date is the Sunday in the } \\
\text { sampling period. }\end{array}$ \\
\hline 8 & W & Feces & $\begin{array}{l}\text { Collection of a single fecal voiding used for a special program for } \\
\text { plutonium oxide workers. Designated sample date for shift workers is } \\
\text { the Tuesday of long shift change, and for day workers is the } \\
\text { appropriate Sunday. }\end{array}$ \\
\hline 9 & $X$ & Urine & $\begin{array}{l}\text { Kit designed for collection of urine outside the local service area. } \\
\text { Transportation is handled by private carrier. Generally used for } \\
\text { termination samples not collected locally. }\end{array}$ \\
\hline A & $\mathrm{Y}$ & Urine & $\begin{array}{l}\text { Simulated 48-hour urine collection. Collected at home over a 4-day } \\
\text { period. Used for IPUL sampling. Designated sample date is two days } \\
\text { after kit delivery to the employee. }\end{array}$ \\
\hline B & $\begin{array}{c}\text { Not } \\
\text { Applicable }\end{array}$ & Urine & $\begin{array}{l}\text { 12-hour urine collection for termination sampling only. Collected at } \\
\text { home overnight. Kit delivered in normal manner, but brought to a } \\
\text { designated on-site location by worker for pick-up by Contractor. } \\
\text { Designated sample date is the day after the date of kit delivery to the } \\
\text { employee. Delivery Only, no home pick-up required. }\end{array}$ \\
\hline & envery & & \\
\hline
\end{tabular}

Issued for implementation effective 01/01/2010

PNL-MA-552 Appendix B

Supersedes: 10/03

Page 4 of 12 
Table B.5. Sample Status Codes

\begin{tabular}{cl}
\hline Code & \multicolumn{1}{c}{ Description } \\
\hline CN & CONTAINER NOT OUT \\
\hline DL & KIT DELIVERED \\
FA & FAILED ANALYSIS \\
IS & INSUFFICIENT VOLUME \\
LC & LOST CONTAINER \\
ND & KIT NOT DELIVERED \\
NE & NOT EVALUATED \\
NS & NO SAMPLE \\
OR & ORDER RECEIVED BY LAB \\
PE & PENDING (AFTER 3/31/05) \\
& $\quad$ (awaiting instructions for analysis) \\
PN & PENDING (BEFORE 4/1/05) \\
RV & VALID SAMPLE RECEIVED \\
\hline
\end{tabular}

Table B.6. Excreta Processing Codes and No-Sample Codes

\begin{tabular}{|c|c|c|}
\hline $\begin{array}{l}\text { Processing } \\
\text { Code }\end{array}$ & $\begin{array}{l}\text { No-Sample } \\
\text { Code }\end{array}$ & Description \\
\hline $\mathrm{R}$ & & Routine processing \\
\hline $\mathrm{P}$ & & Priority processing \\
\hline $\mathrm{X}$ & & Expedite processing \\
\hline \multirow[t]{10}{*}{ E } & & Emergency processing \\
\hline & CS & Cancelled sample/analysis \\
\hline & CT & $\begin{array}{l}\text { Sample lost due to bioassay analysis contract } \\
\text { termination }\end{array}$ \\
\hline & FA & $\begin{array}{l}\text { Failed Analysis. A valid analytical result could } \\
\text { not be obtained }\end{array}$ \\
\hline & IS & $\begin{array}{l}\text { Insufficient sample. Sample provided by worker } \\
\text { but volume insufficient to meet contractual } \\
\text { requirements }\end{array}$ \\
\hline & $\mathrm{LC}$ & Lost container. Sample kit not retrieved \\
\hline & ND & $\begin{array}{l}\text { Not delivered. Sample scheduled but kit never } \\
\text { delivered }\end{array}$ \\
\hline & NE & $\begin{array}{l}\text { Not evaluated - Sample was collected but not } \\
\text { analyzed. Typically used when a backup sample } \\
\text { was obtained but analysis was determined to be } \\
\text { unnecessary and the sample discarded. }\end{array}$ \\
\hline & NS & $\begin{array}{l}\text { No sample. Kit retrieved but no sample provided } \\
\text { by worker }\end{array}$ \\
\hline & WW & Waived excreta exam \\
\hline
\end{tabular}


Table B.7. Codes for Units

\begin{tabular}{cl}
\hline Code & \multicolumn{1}{c}{ Description of Units } \\
\hline 01 & $\mathrm{dpm} /$ sample \\
02 & $\mathrm{dpm} /$ volume analyzed \\
03 & $\mu \mathrm{g} / \mathrm{l}$ until 07-01-82 \\
& $\mu \mathrm{g} / \mathrm{sample}$ after 07-01-82 \\
& $\mu \mathrm{g} / \mathrm{gram}$ until 07-01-82 \\
04 & $\mu \mathrm{g} /$ sample after 07-01-82 \\
05 & $\mu \mathrm{Ci} / \mathrm{l}$ \\
06 & $\mu \mathrm{Ci} / \mathrm{l}$ \\
07 & $\mathrm{nCi}$ (nanocuries) \\
08 & $\mu \mathrm{Ci}$ (microcuries) \\
09 & $\mathrm{dpm} / \mathrm{ml}$ \\
\hline
\end{tabular}

Issued for implementation effective 01/01/2010

PNL-MA-552 Appendix B

Supersedes: 10/03

Page 6 of 12 
Table B.8. Isotope Codes

Note: This listing is substantially abbreviated. Check the on-line REX help feature for a complete listing. List includes both request and result codes.

\begin{tabular}{|c|c|c|c|}
\hline $\begin{array}{c}\text { Isotope } \\
\text { Code } \\
\end{array}$ & $\begin{array}{c}\text { Multiple } \\
\text { Result Code }\end{array}$ & Isotope & $\begin{array}{c}\text { Multiple } \\
\text { Result Code }\end{array}$ \\
\hline AM241 & & MN 54 & \\
\hline C 14 & & NP237 & \\
\hline CE144 & & PB210 & \\
\hline CM242 & & PM147 & \\
\hline CM244 & & PO210 & \\
\hline CS137 & & PU & Plutonium - Alpha \\
\hline CO 60 & & PUMIX & Plutonium - Mixture \\
\hline EU154 & & PU238 & \\
\hline EU155 & & PU239 & \\
\hline EU156 & & PU240 & \\
\hline GS & & PU241 & \\
\hline H 3 & & PU242 & \\
\hline I 131 & & QUS & \\
\hline IAM & A & RA224 & \\
\hline IPIU & $\mathrm{B}$ & RA226 & \\
\hline ACS & $\mathrm{C}$ & RA228 & \\
\hline ICM & $\mathrm{D}$ & RND & Radon \& Daughters \\
\hline UMS & $\mathrm{E}$ & RU106 & \\
\hline IEU & $\mathrm{F}$ & SR & \\
\hline IPA & $\mathrm{J}$ & S 35 & \\
\hline IPS & $\mathrm{P}$ & SR 89 & \\
\hline IPSA & $\mathrm{L}$ & SR 90 & \\
\hline IPSR & M & TAC & \\
\hline IPU & $\mathrm{Q}$ & TC 99 & \\
\hline IPUB & $\mathrm{N}$ & TH227 & \\
\hline IPUBA & $\mathrm{Z}$ & TH228 & \\
\hline IRA & $\mathrm{R}$ & TH230 & \\
\hline IR192 & & TH232 & \\
\hline ISCP & $\mathrm{S}$ & TH234 & \\
\hline ISPEC & $\mathrm{W}$ & $\mathrm{U}$ & \\
\hline ISR & $\mathrm{Y}$ & U DEP & \\
\hline ITH & $\mathrm{T}$ & U NAT & \\
\hline ITPAC & $\mathrm{K}$ & U 233 & \\
\hline IU & $\mathrm{U}$ & U 235 & \\
\hline IPUL & G & U 238 & \\
\hline IUPU & $\mathrm{O}$ & U MIX & \\
\hline K 40 & & US & \\
\hline LEPD & $*$ & ZN 65 & \\
\hline MFP & & ZR95 & \\
\hline \multicolumn{4}{|c|}{$\begin{array}{l}\text { Note: This listing is substantially abbreviated. Check the on-line REX } \\
\text { help feature for a complete listing. List includes both request and result } \\
\text { codes. }\end{array}$} \\
\hline
\end{tabular}


Table B.9. Excreta Analysis Type and Multiple Result Codes for Excreta Samples

\begin{tabular}{|c|c|c|c|}
\hline Analysis Type & $\begin{array}{c}\text { Multiple } \\
\text { Result } \\
\text { Code }\end{array}$ & $\begin{array}{l}\text { Analysis } \\
\text { Code }\end{array}$ & Results Reported \\
\hline Pu isotopic & Q & IPU & ${ }^{238} \mathrm{Pu},{ }^{239,240} \mathrm{Pu}$ \\
\hline Gamma Spectroscopy & $\mathrm{W}$ & ISPEC & ${ }^{40} \mathrm{~K},{ }^{137} \mathrm{Cs}$, and others \\
\hline Gamma Spectroscopy & $*$ & LEPD & ${ }^{241} \mathrm{Am}$ \\
\hline $\begin{array}{l}\text { Sequential Pu Isotopic, } \\
\text { Am Isotopic, Cm }\end{array}$ & K & ITPAC & $\begin{array}{c}{ }^{238} \mathrm{Pu},{ }^{244}{ }^{239,240} \mathrm{Pu},{ }^{241} \mathrm{Am}, \\
{ }^{242} \mathrm{Cm}\end{array}$ \\
\hline Sequential ${ }^{90} \mathrm{Sr}, \mathrm{Ce}, \mathrm{Pm}$ & S & ISCP & ${ }^{90} \mathrm{Sr},{ }^{144} \mathrm{Ce},{ }^{147} \mathrm{Pm}$ \\
\hline $\begin{array}{l}\text { Sequential Sr-Total, } \\
\text { Ce, Pm }\end{array}$ & $\mathrm{I}$ & SCP & $\mathrm{Sr},{ }^{144} \mathrm{C},{ }^{147} \mathrm{Pm}$ \\
\hline Cm Isotopic & $\mathrm{D}$ & ICM & ${ }^{244} \mathrm{Cm},{ }^{242} \mathrm{Cm}$, and others \\
\hline Eu Isotopic & $\mathrm{F}$ & IEU & ${ }^{152} \mathrm{Eu},{ }^{154} \mathrm{Eu},{ }^{155} \mathrm{Eu}$ \\
\hline U Isotopic & $\mathrm{U}$ & IU & ${ }^{233,234} \mathrm{U},{ }^{235} \mathrm{U},{ }^{238} \mathrm{U}$ \\
\hline Sequential Pu, ${ }^{90} \mathrm{Sr}$ & $\mathrm{P}$ & IPS & ${ }^{238} \mathrm{Pu},{ }^{239,240} \mathrm{Pu},{ }^{90} \mathrm{Sr}$ \\
\hline $\begin{array}{l}\text { Sequential Pu Isotopic, } \\
{ }^{241} \mathrm{Am}\end{array}$ & $\mathrm{J}$ & IPA & ${ }^{238} \mathrm{Pu},{ }^{239,240} \mathrm{Pu},{ }^{241} \mathrm{Am}$ \\
\hline $\begin{array}{l}\text { Sequential Pu Isotopic, } \\
\text { Sr-Total }\end{array}$ & M & IPSR & ${ }^{238} \mathrm{Pu},{ }^{239,240} \mathrm{Pu}, \mathrm{Sr}$ \\
\hline $\begin{array}{l}\text { Sequential Pu Isotopic, } \\
\text { Sr-Total, }{ }^{241} \mathrm{Am}\end{array}$ & $\mathrm{L}$ & IPSA & ${ }^{238} \mathrm{Pu},{ }^{239,240} \mathrm{Pu}, \mathrm{Sr},{ }^{241} \mathrm{Am}$ \\
\hline Sr Isotopic & $\mathrm{Y}$ & ISR & ${ }^{89} \mathrm{Sr},{ }^{90} \mathrm{Sr}$ \\
\hline $\mathrm{Pu}$ Isotopic, ${ }^{241} \mathrm{Pu}$ & $\mathrm{N}$ & IPUB & ${ }^{238} \mathrm{Pu},{ }^{239,240} \mathrm{Pu},{ }^{241} \mathrm{Pu}$ \\
\hline Pu Isotopic, ${ }^{241} \mathrm{Pu},{ }^{241} \mathrm{Am}$ & Z & IPUBA & ${ }^{238} \mathrm{Pu},{ }^{239,240} \mathrm{Pu},{ }^{241} \mathrm{Pm}$ \\
\hline Pu Isotopic/U-Natural & $\mathrm{O}$ & IUPU & ${ }^{238} \mathrm{Pu},{ }^{239,240} \mathrm{Pu}, \mathrm{U}$ \\
\hline Pu Isotopic/U-Isotopic & B & IPIU & ${ }^{238} \mathrm{Pu},{ }^{239,240} \mathrm{Pu},{ }^{238} \mathrm{U}{ }^{234} \mathrm{U},{ }^{235} \mathrm{U}$, \\
\hline U-Natural (soluble) & $\mathrm{H}$ & QUS & $\mathrm{U}$ \\
\hline Th Isotopic & $\mathrm{T}$ & ITH & ${ }^{228} \mathrm{Th},{ }^{230} \mathrm{Th},{ }^{232} \mathrm{Th}$ \\
\hline Ra Isotopic & $\mathrm{R}$ & IRA & ${ }^{224} \mathrm{Ra},{ }^{226} \mathrm{Ra}$ \\
\hline $\begin{array}{l}\text { Sequential Am and Cm } \\
\text { Isotopic }\end{array}$ & & $\mathrm{ACM}$ & ${ }^{241} \mathrm{Am},{ }^{242} \mathrm{Cm},{ }^{243,244} \mathrm{Cm}$ \\
\hline Low-level Isotopic Pu & G & IPUL & ${ }^{238} \mathrm{Pu}^{, 239,240} \mathrm{Pu}$ \\
\hline Sequential Ac and Th & $\mathrm{C}$ & ACS & ${ }^{227} \mathrm{Ac},{ }^{227} \mathrm{Th}$ \\
\hline
\end{tabular}


Table B.10. Bioassay Frequency Codes

\begin{tabular}{cc}
\hline Code & Frequency of Bioassay \\
\hline A & Annual \\
B & Biennial (every 2 years) \\
D & Special Day \\
F & Five years \\
Q & Quarterly \\
S & Semiannual \\
M & Monthly \\
W & Weekly \\
X & Biweekly (every 2 weeks) \\
\hline
\end{tabular}

Table B.11. In Vivo Body Location Codes

\begin{tabular}{cl}
\hline Code & \\
\hline ABD & Abdomen \\
CA1 & Chest - Am \\
CA2 & Chest - Am corrected by ultrasound \\
CC1 & Chest - combination (Am, Uranium) \\
CC2 & Chest - combination (Am, Uranium) Corrected by ultrasound \\
CHT & Chest result \\
CH1 & Chest result \\
CH2 & Chest result corrected by ultrasound measurement of chest wall \\
CU1 & thickness \\
CU2 & Chest - ultrasound \\
HND & Hand \\
KNE & Knee \\
LG1 & Lung result. (Chest result corrected for skeleton burden \\
& interference) \\
LG2 & Lung result. (Chest result corrected for skeleton and liver \\
LV1 & burden interference) \\
LV2 & Liver \\
LV3 & Liver result corrected for skeleton burden interference \\
LYM & Lymph nodes \\
SK1 & Skeleton result based on a head count \\
SK2 & Skeleton result based on something other than a head count \\
SPL & Special \\
THX & Thorax \\
THY & Thyroid \\
TRY & Throat \\
WBD & Whole body \\
WND & Wound \\
\hline
\end{tabular}


Table B.12. In Vivo Detector Codes ${ }^{(a)}$

\begin{tabular}{ll}
\hline Code & \multicolumn{1}{c}{ Type of Detector or Counting Cell } \\
\hline & \multicolumn{1}{c}{ Codes Typically in Use as of August 2003 } \\
CC & Coax GE counter for high resolution whole body counts \\
DS & Stainless steel room with digital signal processing \\
LD & Lead Room for special counting geometry \\
CH & Lead Room special counts \\
SU & Stand-up whole body count for screening \\
SS & Stainless Steel Room Lung Count \\
IR & Iron Room Counter for Lung Count \\
\hline (a) & The current and historical listing of in vivo detector codes is \\
& maintained by the InVivo Monitoring Program. The listing provided \\
& in this manual is not necessarily current or complete. For the most \\
& current information, contact the InVivo Monitoring Program \\
& Manager. \\
(b) & IG = Intrinsic germanium.
\end{tabular}

Table B.13. In Vivo Schedule-Type Codes

\begin{tabular}{cl}
\hline Code & \multicolumn{1}{c}{ Type of Measurement } \\
\hline C & Chest count \\
C2 & Extended chest count \\
HC & Head and chest count \\
HD & Head count \\
H2 & Head and extended chest count \\
LC & Liver and chest count \\
LV & Liver count \\
LY & Lymph node count \\
TC & Thyroid and chest count \\
TH & Thyroid count \\
WB & Whole body count \\
WC & Coaxial germanium whole body count \\
WD & Wound count \\
\hline
\end{tabular}

Table B.14. In Vivo Analysis Request Codes

\begin{tabular}{cl}
\hline Code & \multicolumn{1}{c}{ Analysis Performed } \\
\hline CA & Chest count for ${ }^{241} \mathrm{Am}$ only \\
CC & Chest count for combination of ${ }^{241} \mathrm{Am}^{235} \mathrm{U}$, and ${ }^{234} \mathrm{Th}$. \\
CU & Chest count for uranium ${ }^{235} \mathrm{U}$ and ${ }^{234} \mathrm{Th}$ \\
\hline
\end{tabular}


Table B.15. In Vivo No-Result Codes

\begin{tabular}{|c|c|}
\hline Code & Reason For No Results \\
\hline $\mathrm{C}$ & $\begin{array}{l}\text { External contamination other than radon detected on the subject. } \\
\text { Measurement invalid; no results obtained. }\end{array}$ \\
\hline $\mathrm{F}$ & $\begin{array}{l}\text { Failure of equipment or faulty setup of equipment. Measurement invalid; no } \\
\text { results obtained. }\end{array}$ \\
\hline I & $\begin{array}{l}\text { Interference from localized activity in another part of the subject's body. } \\
\text { Measurement invalid; no results obtained. }\end{array}$ \\
\hline $\mathrm{L}$ & $\begin{array}{l}\text { Location of internal or external activity was qualitatively determined by } \\
\text { mapping, masking, or collimating. May include one or more measurement } \\
\text { counts. These measurements are qualitative for identifying location of } \\
\text { activity and do not yield quantifiable estimates of activity. }\end{array}$ \\
\hline M & $\begin{array}{l}\text { Medically administered radioactivity interfered with measurement. } \\
\text { Measurement invalid; no results obtained. }\end{array}$ \\
\hline $\mathrm{N}$ & No show. Worker did not meet appointment. \\
\hline $\mathrm{P}$ & $\begin{array}{l}\text { Preliminary count, when followed by a more quantitative record count. Used } \\
\text { to indicate measurement taken, but not a record count. }\end{array}$ \\
\hline $\mathrm{R}$ & $\begin{array}{l}\text { Radon interference from subject's clothing, hair, or skin. Measurement } \\
\text { invalid; no results obtained. }\end{array}$ \\
\hline$S$ & $\begin{array}{l}\text { The subject's actions interrupted completion of the count. Measurement } \\
\text { invalid; no results obtained. }\end{array}$ \\
\hline $\mathrm{W}$ & Waived. Scheduled exam was waived based on needs review. \\
\hline $\mathrm{X}$ & $\begin{array}{l}\text { Measurement invalid; no results obtained. Other no-result codes do not } \\
\text { apply. See comment field for a brief description. }\end{array}$ \\
\hline $\mathrm{Z}$ & Test case. \\
\hline otes: & $\begin{array}{l}\text { 1. The comment field may have a brief explanation in addition to the codes } \\
\text { listed above. }\end{array}$ \\
\hline
\end{tabular}

Table B.16. INTERTRAC Mode-of-Intake Codes

\begin{tabular}{ll}
\hline Code & \multicolumn{1}{c}{ Mode of Intake } \\
\hline ABS & Absorption \\
ING & Ingestion \\
INH & Inhalation \\
NON & None (no intake) \\
UNK & Unknown \\
WND & Wound \\
\hline
\end{tabular}

Table B.17. INTERTRAC Evaluation Reason Codes

\begin{tabular}{cl}
\hline Code & \multicolumn{1}{c}{ Reason for Evaluation } \\
\hline A & Annual chronic intake evaluation \\
C & Contractor requested evaluation \\
D & DAC-hours evaluation \\
H & High routine bioassay evaluation \\
I & Incident evaluation \\
N & New hire measurement or previous employment record indicated \\
R & exposure prior to Hanford employment \\
\hline
\end{tabular}


Table B.18. INTERTRAC Source-of-Intake Codes

\begin{tabular}{ll}
\hline Code & \multicolumn{1}{c}{ Source of Intake } \\
\hline DHE & Intake at DOE site while employed at Hanford \\
HAN & Intake at Hanford \\
NHE & Intake at non-DOE site while employed at Hanford \\
NOC & Nonoccupational intake \\
PTH & Intake occurred prior to Hanford employment \\
\hline
\end{tabular}

Table B.19. INTERTRAC Miscellaneous Codes

\begin{tabular}{lcl}
\hline \multicolumn{1}{c}{ Code Type } & Code & \multicolumn{1}{c}{ Description } \\
\hline Intake & Y & Yes (occupational intake) \\
Confirmed & N & No \\
Nature of & A & Acute \\
Intake & C & Chronic \\
Recorded & Y & Yes (occupational intake) \\
Dose & N & No \\
& O & Undetermined - (old evaluation assessing body \\
& & burden rather than dose, or an evaluation in \\
& & process) \\
Source & Y & Recorded dose is zero mrem \\
Known & N & Yes \\
Type of & P & Preliminary \\
Evaluation & F & Final \\
\hline
\end{tabular}

Table B.20. Person Codes

\begin{tabular}{cl}
\hline Code & \multicolumn{1}{c}{ Description } \\
\hline E & Employee \\
F & Fetus \\
N & Non-resident \\
S & Subcontractor (inactive code) \\
V & Visitor \\
\hline
\end{tabular}

Table B.21. Excreta Laboratory Codes

\begin{tabular}{cl}
\hline Code & \multicolumn{1}{c}{ Analytical Laboratory } \\
\hline GL & General Engineering Laboratories \\
\hline IT & IT Analytical Services - Richland \\
LA & Los Alamos National Laboratory \\
OR & Oak Ridge National Laboratory \\
PL & PNNL Analytical Chemistry Laboratory \\
QN & Quanterra \\
RE & REECO (Reynolds Electric Company, Nevada Test Site) \\
ST & Severn Trent Laboratories-Richland \\
TA & TMA/Norcal, Richmond, California \\
WH & Westinghouse Hanford Company, 222-S Lab \\
\hline
\end{tabular}




\section{HANFORD INTERNAL DOSIMETRY PROGRAM MANUAL PNL-MA-552}

\section{APPENDIX C - ANALYTICAL PROCEDURES}

Issued for implementation effective $01 / 01 / 2010$

Supersedes: 12/2006

Use Category: Not applicable

\section{Approval Signatures:}

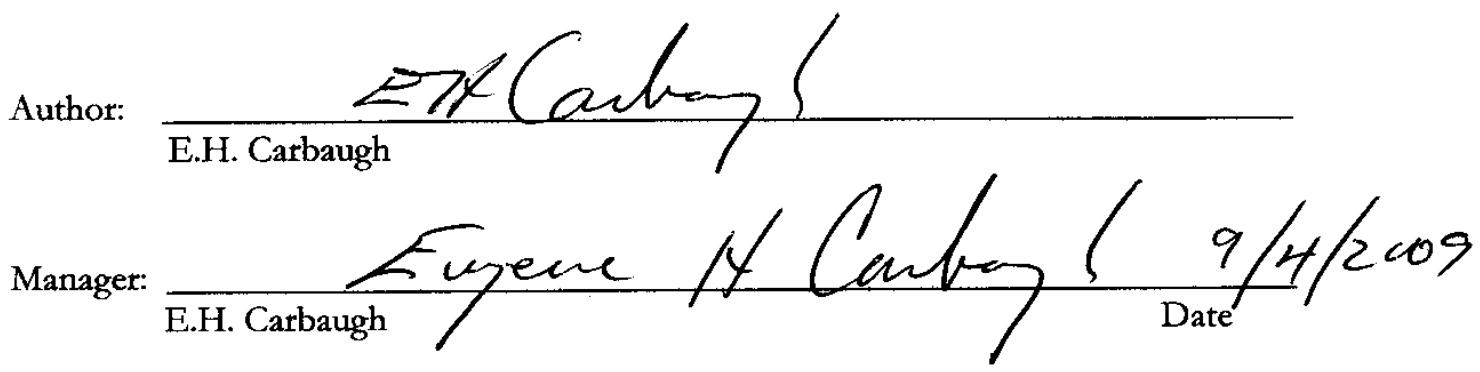

Reviewer Signatures:

Reviewer \# 1:

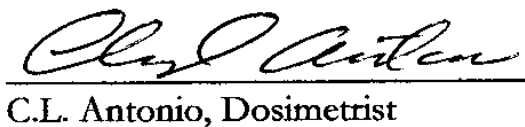

C.L. Antonio, Dosimetrist

Approval by the Hanford Personnel Dosimetry Advisory Committee is not required per Section 1.0 of this manual. 


\section{Contents}

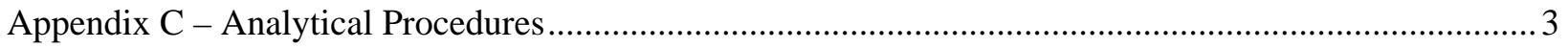

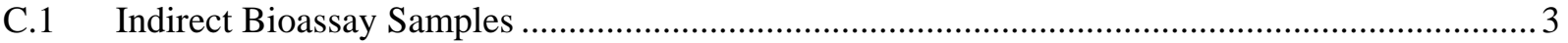

C.1.2 DOELAP Category II. Beta Activity, Average Energy > 100 keV …............................... 3

C.1.3 DOELAP Category III. Alpha Activity Isotopic Analysis ................................................ 3

C.1.4 DOELAP Category IV. Elemental Analysis (by mass) .................................................. 4

C.1.5 DOELAP Category V. Gamma (Photon) Activity Analysis .............................................. 4

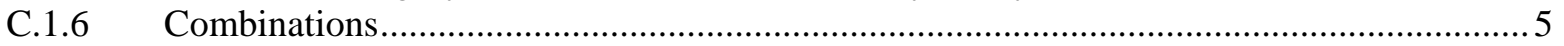

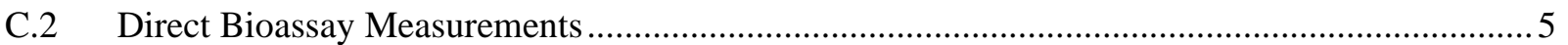

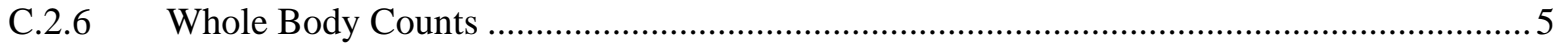

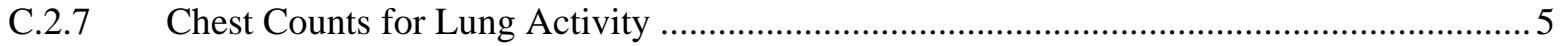

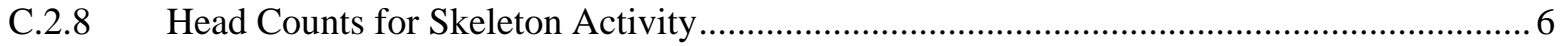

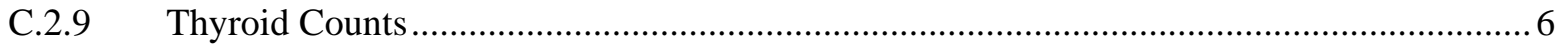

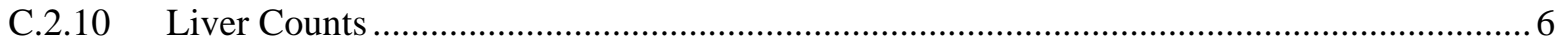

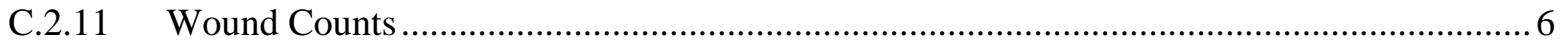




\section{Appendix C - Analytical Procedures}

This appendix summarizes selected procedures that the Analytical Services Laboratory (Lab) uses to analyze indirect bioassay samples. The procedures used by the In Vivo Monitoring Program (IVMP) to perform direct bioassay measurements are also summarized here.

\section{C.1 Indirect Bioassay Samples}

All indirect bioassay samples are analyzed to determine their content of various radionuclides, according to detailed procedures written and maintained by the Lab. A brief description of most frequently used procedures follows.

\section{C.1.1 DOELAP Category I. Beta Activity, Average Energy $<100 \mathrm{keV}$.}

${ }^{3} \mathrm{H} \quad$ Sample distillation and subsequent liquid scintillation counting. Analytical results are calculated by a computational program proprietary to the analytical contractor.

${ }^{14} \mathrm{C} \quad$ Conversion of carbon to carbon dioxide and distillation. Liquid scintillation counting. Analytical results are calculated by a computational program proprietary to the analytical contractor.

Calibration The instrument is normalized according to the procedure given in the vendor instrument manual using commercially prepared calibration and quench standards. Calibrations for specific analytes are performed annually with creation of a quench curve for efficiency correction.

\section{C.1.2 DOELAP Category II. Beta Activity, Average Energy $>100 \mathrm{keV}$.}

$\mathrm{Sr}$

Wet and dry ashing, calcium phosphate precipitation, analyte separation via organic extraction, carbonate co-precipitation. Counted on gas proportional counter. If ${ }^{90} \mathrm{Sr}$ identification is desired, Y separation chemistry with ingrowth and recounting is performed. Analytical results calculated by a computational program proprietary to the analytical contractor.

Calibration Counting efficiencies for detectors are determined by counting a NISTtraceable reference source with varying attenuation masses. The calibration curves created are verified with independently prepared sources utilizing a separate NIST-traceable sources.

\section{C.1.3 DOELAP Category III. Alpha Activity Isotopic Analysis}

Urine

Pre-concentrated by calcium phosphate precipitation, wet ashed, dried, and dissolved. Chemical separation via ion exchange or organic extraction. Prepared for alpha spectrometry counting using a rare earth fluoride coprecipitation. Applicable to americium, curium, californium, plutonium, strontium, and uranium separately or sequentially in urine and tissue samples. Thorium and neptunium are analyzed separately, but not sequentially with other analytes. Counting time is 2520 minutes for routine 
and priority processing, and 10,000 minutes for the low-level plutonium (IPUL) analysis.

Fecal Dry then wet ashed, HF digestion, and co-precipitation by lanthanum fluoride. Chemical separation via ion exchange or organic extraction. Prepared for alpha spectrometry counting using a rare earth fluoride coprecipitation. Applicable to americium, plutonium, strontium and uranium in fecal and tissue samples. Counting time is 960 minutes for routine and priority processing.

Calibration Detection efficiency is determined by counting a calibrated activity reference source. Sufficient counts are accumulated to make the counting uncertainty less than $1 \%$. Energy resolution is measured with the detection efficiency, and serves primarily as a relative bench mark of detector performance. Successive measurements with the same source will reveal any significant changes in the detector's resolution. The energy calibration is performed at three different energies in the energy range of interest, between 4 and $7 \mathrm{Mev}$. A reference source containing several NIST-traceable radionuclides is used for calibration. The calculation is performed by the computer software that controls the spectrometer.

\section{C.1.4 DOELAP Category IV. Elemental Analysis (by mass)}

Uranium Sample acidified and $2 \mathrm{ml}$ aliquot analyzed by Inductively Coupled PlasmaMass Spectrometry (ICP-MS).

Calibration Instrument calibrated each day with three calibration points, a calibration blank solution to define the lower calibration point and at two standard calibration solutions at the analyte concentrations to define the higher calibration points. Calibration verification standards and blanks are analyzed after every 10 samples to ensure acceptable instrument performance. Three aliquots are analyzed for each sample to obtain the uncertainty estimate.

\section{C.1.5 DOELAP Category V. Gamma (Photon) Activity Analysis}

Gamma

A standard volume is directly counted on a germanium detector for urine samples. Fecal samples are wet and dry ashed, then dissolved. Canberra counting system used for nuclide identification. Analytical results calculated by a computational program proprietary to the analytical contractor.

Calibration

A calibration standard containing sufficient radionuclides to provide photopeaks spanning the entire energy region to be calibrated is counted annually. The calibration standard is purchased directly from a standards provider and maintains NIST-traceability. An efficiency curve is created using the efficiency at each photopeak energy. The efficiency is verified with a verification standard from a separate source. 


\section{C.1.6 Combinations}

Usually, more than one procedure can be performed on one sample. For instance, a urine sample can be extracted for tritium analysis before any of the other analyses are begun. Some of the other more common combinations of sequential analyses are:

- plutonium and strontium

- plutonium and americium

- plutonium and uranium

- plutonium, strontium, and americium.

In special cases a single sample may be spilt for separate, non-sequential analyses.

\section{C.2 Direct Bioassay Measurements}

Details concerning procedures, equipment, and data processing for direct bioassay measurements are provided in the In-Vivo Monitoring Program Manual. ${ }^{\text {(a) }}$ Pertinent information is provided as follows.

\section{C.2.6 Whole Body Counts}

Whole body counts are performed using the stand-up counter (a five-detector NaI system in a standup position within a shielded booth) or a high resolution germanium detector system involving an array of coaxial high-purity germanium (HPGe) detectors in a shielded counting room. Most radionuclides with gamma-ray energies from about 200 to $3000 \mathrm{keV}$ can be quantified (e.g., ${ }^{137} \mathrm{Cs}$, ${ }^{60} \mathrm{Co}$ ). The germanium detectors have much better photopeak resolution, which generally eliminates interferences from medical radionuclides and natural radon progeny. The stand-up counter uses a 200 -second count and can make some determination of spatial distribution of radioactivity as being in the head, chest, abdomen, or legs by identifying the detector with the most counts. The coaxial system uses a 600-second count time, with the option of longer counts, and can be used in either a moving scan or static position mode.

If a radionuclide other than ${ }^{40} \mathrm{~K}$ is detected, the person is asked to shower, change into clean coveralls, and be recounted. The recount may be performed either on the same system as the initial measurement, or on a more sensitive system.

\section{C.2.7 Chest Counts for Lung Activity}

The presence of high-energy gamma-emitting radionuclides in the chest is determined by whole body counting or stationary counting using the coaxial germanium system. The presence in the chest of gamma- or x-ray-emitting radionuclides with energies in the range of a few tens of $\mathrm{keV}$ to $200 \mathrm{keV}$ is determined by chest counting. The chest counter routinely reports ${ }^{241} \mathrm{Am},{ }^{235} \mathrm{U}$, and ${ }^{234} \mathrm{Th}$ (as an indicator of ${ }^{238} \mathrm{U}$ ). A peak search program is used to identify the presence of other significant photon energies.

The two chest counting systems used to detect nuclides that emit low energy photons each consist of an array of four planar HPGe detectors and associated electronics. The detectors are positioned anteriorly over the lungs in light contact with the chest. The subject is seated in a slightly reclining position. The

(a) Internal manual, PNL-MA-574, Pacific Northwest Laboratory, Richland, Washington. 
routine counting time is 3000 seconds. Longer count times are employed where a lower detection level is required.

If a radionuclide is detected, the person is asked to shower, change into clean coveralls, and be recounted. The recount will usually be slightly longer in duration to improve sensitivity.

If material is detected in the chest, then an ultrasound measurement of the thickness of the chest is made, and the calculated activity in the lung is corrected for the absorption of the low-energy rays in the chest wall.

Additional corrections can be performed when activity such as ${ }^{241} \mathrm{Am}$ can exist simultaneously in the lung, liver, and bone. Such correction will usually be made based on additional measurements, notably head counts and liver counts. The final corrected activity represents a best estimate of the activity actually in the lung.

\section{C.2.8 Head Counts for Skeleton Activity}

Head counts are performed to quantify the skeletal activity of low-energy x-or gamma-ray-emitting radionuclides, such as ${ }^{241} \mathrm{Am}$. The head count consists of planar germanium detectors placed on the forehead. The typical count time is 3000 seconds. The results of the head count are converted to activity in the total skeleton based on the distribution of ${ }^{241} \mathrm{Am}$ observed in the skeleton of a total body donation to the U.S. Transuranium Registry.

\section{C.2.9 Thyroid Counts}

Thyroid measurements are routinely performed using a single HPGe detector positioned $10 \mathrm{~cm}$ above the thyroid. The routine counting time is 600 seconds.

\section{C.2.10 Liver Counts}

Liver measurements are performed using arrays of HPGe detectors positioned anteriorly over the liver in light contact with the subject. The routine counting time is 3000 seconds. Routine calibrations are performed for ${ }^{241} \mathrm{Am}$. If a significant amount of activity is also present in the skeleton, then the measurement count rate over the liver is corrected for contribution from the skeleton. The liver calibration factors are determined based on the thickness of the tissue over the liver.

\section{C.2.11 Wound Counts}

Wound counts may be performed at the 747-A Building (IVRRF) or in field locations, depending on the circumstances. For low-energy $\mathrm{x}$ - or gamma rays, a single germanium detector is used. A portable germanium spectroscopy system is also available for making low energy wound counts. For small, localized puncture wounds, a large volume coaxial HPGe detector is usually used at IVRRF to estimate the activity for nuclides that emit high-energy photons. The typical count time is 10 minutes. The activity of plutonium isotopes should be considered approximate, unless the depth of the activity in the tissue and relative abundance of each plutonium isotope are known. 


\section{HANFORD INTERNAL DOSIMETRY PROGRAM MANUAL PNL-MA-552}

\section{APPENDIX D - SAMPLE KIT INSTRUCTIONS}

Issued for implementation effective 01/01/2010

Supersedes: $10 / 2003$

Use Category: Not applicable

\section{Approval Signatures:}

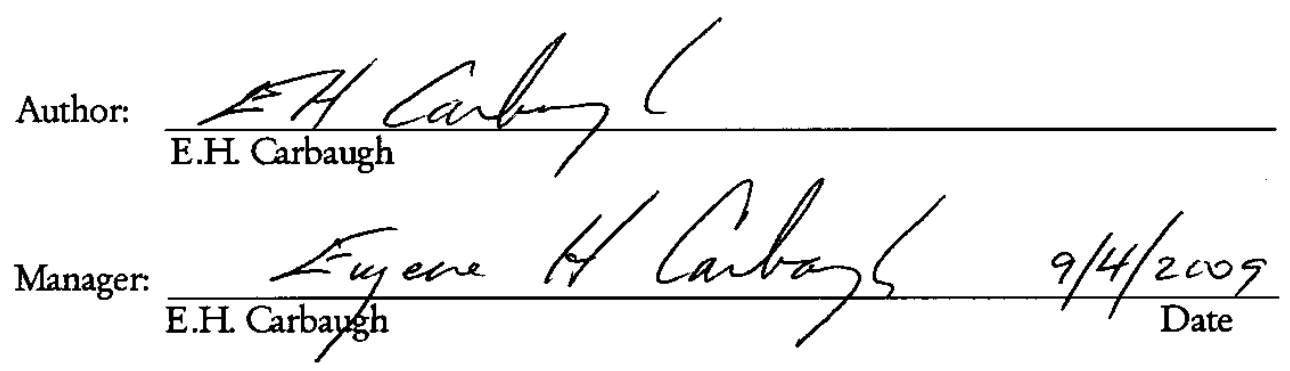

Reviewer Signatures:

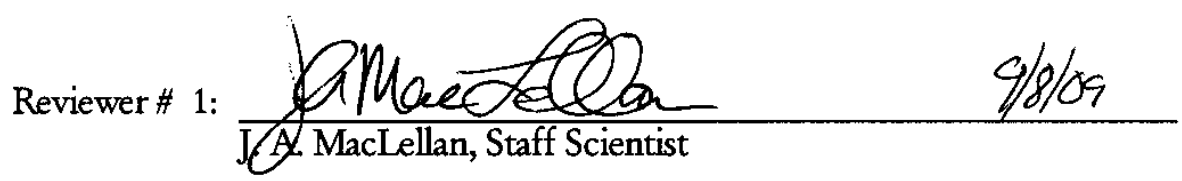

Approval by the Hanford Personnel Dosimetry Advisory Committee is not required per Section 1.0 of this manual. 


\section{Contents}

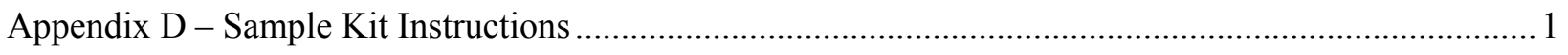




\section{Appendix D - Sample Kit Instructions}

User instructions for each of the Analytical Services Laboratory's sample kits are reproduced in this appendix.

\begin{tabular}{|c|c|c|}
\hline Exhibit & Kit Code & Application \\
\hline D.1 & 1 & $\begin{array}{l}\text { Approximate 24-hr Routine At-Home Urine Sampling } \\
\text { (laboratory delivery and pick-up) }\end{array}$ \\
\hline D.2 & 2 & Termination Urine Sampling (laboratory delivery and pick-up) \\
\hline D.3 & 3 & $\begin{array}{l}24 \text { Hour Total Urine Sampling Home Fraction } \\
\text { (laboratory delivery and pick-up) }\end{array}$ \\
\hline D.4 & 4 & Single-Void Urine Sampling (laboratory delivery and pick-up) \\
\hline D.5 & 5 & Collecting a Fecal Sample (laboratory delivery and pick-up) \\
\hline D.6 & 6 & Special Urine Sampling (laboratory delivery and pick-up) \\
\hline D.7 & 7 & $\begin{array}{l}\text { Soluble-Uranium-in-Urine Sampling } \\
\text { (laboratory delivery and pick-up) }\end{array}$ \\
\hline D.8 & 8 & Collecting a Fecal Sampling (laboratory delivery and pick-up) \\
\hline D.9 & 9 & Collecting a Urine Sample for Mailing \\
\hline D. 10 & A & $\begin{array}{l}\text { Approximate } 48 \text {-hr Routine At-Home Urine Sampling } \\
\text { (laboratory pick-up and delivery) }\end{array}$ \\
\hline D.11 & $\mathrm{B}$ & $\begin{array}{l}\text { 12-hour urine collection for termination sample } \\
\text { (laboratory delivery Only) }\end{array}$ \\
\hline D.12 & $\mathrm{P}$ & $\begin{array}{l}\text { Approximate } 24-\mathrm{hr} \text { Routine At-Home Urine Sampling } \\
\text { (laboratory pick-up only) }\end{array}$ \\
\hline D.13 & Q & Termination Urine Sampling (laboratory pick-up only) \\
\hline D.14 & $\mathrm{R}$ & $\begin{array}{l}24 \text { Hour Total Urine Sampling Home Fraction } \\
\text { (laboratory pick-up only) }\end{array}$ \\
\hline D.15 & $\mathrm{S}$ & Single-Void Urine Sampling (laboratory pick-up only) \\
\hline D.16 & $\mathrm{T}$ & Collecting a Fecal Sample (laboratory pick-up only) \\
\hline D.17 & $\mathrm{U}$ & Special Urine Sampling (laboratory pick-up only) \\
\hline D. 18 & V & Soluble-Uranium-in-Urine Sampling (laboratory pick-up only) \\
\hline D.19 & $\mathrm{W}$ & Collecting a Fecal Sampling (laboratory pick-up only) \\
\hline D.20 & $\mathrm{X}$ & Collecting a Urine Sample for Mailing \\
\hline D.21 & Y & $\begin{array}{l}\text { Approximate 48-hr Routine At-Home Urine Sampling } \\
\text { (laboratory pick-up only) }\end{array}$ \\
\hline
\end{tabular}

The actual instruction cards are printed on different colors of card stock for easy visual discrimination. The color is noted parenthetically in the exhibits.

See Appendix B (Table B.4) for a description of the application for each sample kit. 


\section{EXHIBIT D.1}

\section{GEL RICHLAND SERVICE CENTER}

524-A Warehouse Street Richland, WA 99352 (509) 943-2121- www.gel.com

GEL Kit ID:
Delivery Date:

Sample Date:

Pick-Up Date:

\section{INSTRUCTIONS FOR ROUTINE BIOASSAY AT-HOME SAMPLING}

\section{PLEASE READ AND FOLLOW CAREFULLY}

* Check the kit box and bottles for your correct name, address and payroll number BEFORE collecting a sample. DO NOT USE this kit if it is not addressed to you. Please notify GEL Richland Service Center of any problems or discrepancies in the information on the label.

* Please collect ALL urine excreted starting $1 / 2$ hour before retiring, all voids through the night, and ending $1 / 2$ hour after arising the next morning for two (2) consecutive nights.

\begin{tabular}{|l|l|l|l|}
\hline If kit was delivered on: & Start collection on: & End collection morning of: & Kit will be picked up: \\
\hline Monday & Monday & Wednesday & Wednesday \\
\hline Tuesday & Tuesday & Thursday & Thursday \\
\hline Wednesday & Wednesday & Friday & Friday \\
\hline Thursday & Saturday & Monday & Monday \\
\hline Friday & Saturday & Monday & Monday \\
\hline
\end{tabular}

* Urine passed only during the specified periods should be collected.

* Keep the bottles capped when not in use.

* Each kit consists of three (3) bottles. Begin with any bottle and use as many as necessary. Each bottle may be filled until approximately $3 / 4$ full.

* After final sampling has been completed, tighten each cap, place the bottles in the cardboard box and leave outside of your residence in the place it was delivered. It will be retrieved on the pickup date indicated in the chart above.

* If you will NOT have your kit ready before 8am on the day of pick-up, please call the number below and arrange for a later pick-up.

GEL Richland Service Center

524-A Warehouse Street

Richland, WA 99352

509) 943-2121

Kit Code 1 


\title{
EXHIBIT D.2
}

\section{GEL RICHLAND SERVICE CENTER}

524-A Warehouse Street Richland, WA 99352 (509) 943-2121- www.gel.com

\section{GEL Kit ID:}

\section{Delivery Date:}

Sample Date:

Pick-Up Date:

\section{INSTRUCTIONS FOR TERMINATION BIOASSAY SAMPLING}

\author{
PLEASE READ AND FOLLOW CAREFULLY
}

\begin{abstract}
* Check the kit box and bottles for your correct name, address and payroll number BEFORE collecting a sample. DO NOT USE this kit if it is not addressed to you. Please notify GEL Richland Service Center of any problems or discrepancies in the information on the label.
\end{abstract}

* Your employer has requested from you a final urine specimen to complete your individual radiation exposure history record. This is part of your employer's termination procedure.

* Please collect ALL urine excreted starting $1 / 2$ hour before retiring, all voids through the night, and ending $1 / 2$ hour after arising the next morning.

* Keep the bottles capped when not in use.

* Three (3) containers are provided in the kit. Begin with any container and use as many as necessary. Each container may be filled until approximately $3 / 4$ full.

* After final sampling has been complete, tighten each cap, place the containers in the cardboard box and return the kit to the same place from which you received it.

* The sampling kit will be picked up from the same place it was delivered on the pickup date indicated above. If you will NOT have your sample ready by 8am on the pickup date, please call to arrange a later pickup.

GEL Richland Service Center

524-A Warehouse Street

Richland, WA 99352

(509) 943-2121

Kit Code 2 


\title{
EXHIBIT D.3
}

\author{
GEL RICHLAND SERVICE CENTER \\ 524-A Warehouse Street Richland, WA 99352 (509) 943-2121 - www.gel.com
}

GEL Kit ID:

Delivery Date:

Sample Date:

Pick-Up Date:

\section{INSTRUCTIONS FOR 24 HOUR TOTAL URINE SAMPLING HOME FRACTION}

\section{PLEASE READ AND FOLLOW CAREFULLY}

* Check the kit box and bottles for your correct name, address and payroll number BEFORE collecting a sample. DO NOT USE this kit if it not addressed to you. Please notify GEL Richland Service Center of any problems or discrepancies in the information on the label.

* Please collect ALL urine passed from MIDNIGHT TO MIDNIGHT on the sample date as shown above and on the kit label. This kit is provided for home collection. A second kit may be provided for your use while at work.

* Keep the containers capped when not in use.

* Three (3) bottles are provided in the kit. Begin with any bottle and use as many as necessary. Each bottle may be filled until approximately $3 / 4$ full.

* After final sampling has been completed, tighten each cap, place the bottles in the cardboard box and return the kit to the same place it was delivered.

* The kit will be picked up from the same place to which it was delivered on the pickup date indicated above.

* If you will NOT have your kit ready before 8am on the day of pick-up, please call the number below and arrange for a later pick-up.

GEL Richland Service Center

524-A Warehouse Street

Richland, WA 99352

(509) $943-2121$

Kit Code 3

Issued for implementation effective $01 / 01 / 2010$ 


\title{
EXHIBIT D.4
}

\section{GEL RICHLAND SERVICE CENTER}

524-A Warehouse Street Richland, WA 99352 (509) 943-2121- www.gel.com

GEL Kit ID:

\author{
Delivery Date: \\ Sample Date: \\ Pick-Up Date:
}

\section{INSTRUCTIONS FOR SINGLE VOID URINE SAMPLING}

\author{
PLEASE READ AND FOLLOW CAREFULLY
}

* Check the kit box and bottles for your correct name, address and payroll number BEFORE collecting a sample. DO NOT USE this kit if it not addressed to you. Please notify GEL Richland Service Center of any problems or discrepancies in the information on the label.

* Unless you have been instructed otherwise, please collect a single NORMAL voiding of urine in one of the containers provided.

* Cap the container tightly. Place the container in the cardboard box and return the kit to the same place from which it was received.

* The kit will be picked up from the place to which it was delivered on the sample date or the following day.

* If you will NOT have your kit ready before 8am on the day of pick-up, please call the number below and arrange for a later pick-up.

GEL Richland Service Center

524-A Warehouse Street

Richland, SC 99352

(509) 943-2121

Kit Code 4 


\title{
EXHIBIT D.5
}

\section{GEL RICHLAND SERVICE CENTER}

524-A Warehouse Street Richland, WA 99352 (509) 943-2121- www.gel.com

GEL Kit ID:

Delivery Date:

Sample Date:

Pick-Up Date:

\section{INSTRUCTIONS FOR COLLECTING A FECAL SAMPLE}

\section{PLEASE READ AND FOLLOW CAREFULLY}

* Check the kit box and container for your correct name, address and payroll number BEFORE collecting a sample. DO NOT USE this kit if it not addressed to you. Please notify GEL Richland Service Center of any problems or discrepancies in the information on the label.

* Please collect a stool specimen (fecal sample) on the above date. If there is no voiding on the sample date, collect the next voiding and indicate in writing the correct sample date on the label.

* Place the kit in the place to which it was delivered after samples have been collected and kit completed.

* Please call the GEL Richland Service Center for sample pick-up.

\author{
GEL Richland Service Center \\ 524-A Warehouse Street \\ Richland, WA 99352 \\ (509) 943-2121
}

\section{Directions for Use:}

1. Remove container and frame-holder from the sample kit. Remove the container lid.

2. Insert the container into the frame holder.

3. Lift up the toilet seat. Place the container unit on the bowl in the center toward the rear of the toilet.

4. Lower the toilet seat onto the frame to hold the container unit in place.

CAUTION: Stool specimen must not contain urine.

5. After the stool specimen has been collected, replace the container lid and return the sample to the sample box.

Kit Code: 5 


\title{
EXHIBIT D.6
}

\section{GEL RICHLAND SERVICE CENTER}

524-A Warehouse Street Richland, WA 99352 (509) 943-2121 - www.gel.com

GEL Kit ID:

\author{
Delivery Date: \\ Sample Date: \\ Pick-Up Date:
}

\section{INSTRUCTIONS FOR SPECIAL URINE SAMPLING}

\section{PLEASE READ AND FOLLOW CAREFULLY}

\begin{abstract}
* Check the kit box and bottles for your correct name, address and payroll number BEFORE collecting a sample. Please contact the GEL Washington Service Center of any problems or discrepancies in the information on the label.
\end{abstract}

* Unless you have been instructed otherwise, please collect ALL urine excreted starting 1/2 hour before retiring, all voids through the night, and ending $1 / 2$ hour after arising the next morning

* Keep the bottles capped when not in use.

* Three (3) bottles are provided in the kit. Begin with any bottle and use as many as necessary. Each bottle may be filled until approximately $3 / 4$ full.

* After final sampling has been completed, tighten each cap, place the bottles in the cardboard box and return the kit to the same place to which it was delivered.

* The kit will be picked up from the same place to which it was delivered on the date indicated above.

* If you will NOT have your kit ready before 8am on the day of pick-up, please call the number below and arrange for a later pick-up.

GEL Richland Service Center

524-A Warehouse Street

Richland, WA 99352

(509) 943-2121

Kit Code: 6 


\section{EXHIBIT D.7}

\section{GEL Richland Service Center}

524-A Warehouse Street Richland, WA 99352 (509) 943-2121 - www.gel.com

GEL Kit ID:

Delivery Date:

Sample Date:

Pick-Up Date:

\section{INSTRUCTIONS FOR SOLUBLE URANIUM IN URINE SAMPLING PLEASE READ AND FOLLOW CAREFULLY}

Routine collection and analysis of urine samples is an important part of the radiation dosimetry program for individuals working with soluble uranium. Therefore, it is requested that you read and carefully follow the instructions below.

* Check the kit box and bottles for your correct name, address and payroll number BEFORE collecting a sample. DO NOT USE this kit if it not addressed to you. Please notify GEL Richland Service Center of any problems or discrepancies in the information on the label.

* Unless you have been instructed otherwise, please collect ALL urine passed beginning one-half hour before retiring on Sunday evening, all voids through the night, and ending one-half hour after rising Monday morning.

* Keep the bottles capped when not in use.

* Three (3) bottles are provided in the kit. Begin with any bottle and use as many as necessary. Each bottle may be filled until approximately $3 / 4$ full.

* After final sampling has been completed, tighten each cap, place all bottles, used and unused, in the cardboard box, close the handles to close the box, and return the kit to the same place to which it was delivered.

* The kit will be picked up from the same place to which it was delivered on Monday morning.

* If you will NOT have your kit ready before 8am on the day of pick-up, please call the number below and arrange for a later pick-up

GEL Richland Service Center

524-A Warehouse Street

Richland, WA 99352

(509) 943-2121

Kit Code: 7 


\title{
EXHIBIT D.8
}

\section{GEL RICHLAND SERVICE CENTER}

524-A Warehouse Street Richland, WA 99352 (509) 943-2121 - www.gel.com

GEL Kit ID:

\section{INSTRUCTIONS FOR \\ ROUTINE BIOASSAY AT-HOME SAMPLING}

\author{
PLEASE READ AND FOLLOW CAREFULLY
}

\begin{abstract}
IMPORTANT!
IF POSSIBLE, DO NOT USE UNTIL 24 HOURS AFTER LEAVING WORK PLACE.
\end{abstract}

* Check the kit box and container for your correct name, address and payroll number BEFORE collecting a sample. DO NOT USE this kit if it not addressed to you. Please notify GEL Richland Service Center of any problems or discrepancies in the information on the label.

* Please collect a stool specimen (fecal sample) on the above date. If there is no voiding on the sample date, collect the next voiding and indicate in writing the correct sample date on the label.

* Place the kit in the place it was delivered after samples have been collected and kit completed.

* The kit will be picked up on the date indicated above. If the kit is not completed by the pick-up date, please call and arrange for a later pick-up.

CHECK TIME OUT OF ZONE:

\begin{tabular}{|l}
$\square \quad$ Less than 1 day \\
$\square \quad 1-3$ days \\
$\square \quad$ More than 3 days \\
\hline
\end{tabular}

\author{
GEL Richland Service Center \\ 524-A Warehouse Street \\ Richland, WA 99352 \\ (509) 943-2121
}

\section{Directions for Use:}

1. Remove container and frame-holder from the sample kit. Remove the container lid.

2. Insert the container into the frame holder.

3. Lift up the toilet seat. Place the container unit on the bowl in the center toward the rear of the toilet.

4. Lower the toilet seat onto the frame to hold the container unit in place.

CAUTION: Stool specimen must not contain urine.

5. After the stool speciment has been collected, replace the container lid and return the sample to the sample box. 
EXHIBIT D.9

\section{GEL RICHLAND SERVICE CENTER}

524-A Warehouse Street Richland, WA 99352 (509) 943-2121 - www.gel.com

GEL Kit ID:

Delivery Date:

Sample Date:

\section{INSTRUCTIONS FOR COLLECTING A URINE SAMPLE FOR MAILING}

\section{PLEASE READ AND FOLLOW CAREFULLY}

* Check the kit box and bottles for your correct name, address and payroll number BEFORE collecting a sample. DO NOT USE this kit if it is not addressed to you. Please notify GEL Richland Service Center of any problems or discrepancies in the information on the label.

* Please collect ALL urine passed while at home until all bottles are used.

* Discard the outer box. Write the date of sampling on the line provided above.

* Three bottles are provided in the kit. Begin with any bottle and fill each to at least the fill line but no higher than the bottle neck.

* Keep the bottles capped when not in use.

* After sampling is completed, be certain each bottle lid is sealed tightly. Place the bottles and this instruction sheet in the cardboard box.

* Seal the box by moistening the gummed surface of the tape provided and centering over the box closure.

* Return use the enclosed FedEx shipping label to return the sample kit to:

General Engineering Laboratories, LLC

Sample Receiving - Bioassay Department

2040 Savage Road

Charleston, SC 29407

(843) 556-8171

* If you have any questions, please contact the GEL Richland Service Center.

GEL Richland Service Center

524-A Warehouse Street

Richland, WA 99352

(509) 943-2121

Kit Code 9

Issued for implementation effective 01/01/2010 


\title{
EXHIBIT D.10
}

\section{GEL RICHLAND SERVICE CENTER}

524-A Warehouse Street Richland, WA 99352 (509) 943-2121 - www.gel.com

GEL Kit ID:

Delivery Date:

Sample Date:

Pick-Up Date:

\section{INSTRUCTIONS FOR ROUTINE BIOASSAY AT-HOME SAMPLING}

\author{
PLEASE READ AND FOLLOW CAREFULLY
}

\begin{abstract}
* Check the kit box and bottles for your correct name, address and payroll number BEFORE collecting a sample. DO NOT USE this kit if it not addressed to you. Please notify GEL Richland Service Center of any problems or discrepancies in the information on the label.
\end{abstract}

* Please collect ALL urine excreted starting $1 / 2$ hour before retiring, all voids through the night, and ending $1 / 2$ hour after arising the next morning for four (4) consecutive nights.

\begin{tabular}{|l|l|l|l|}
\hline If kit was delivered on: & Start collection on: & End collection morning of: & Kit will be picked up: \\
\hline Monday & Monday & Friday & Friday \\
\hline Tuesday & Thursday & Monday & Monday \\
\hline Wednesday & Thursday & Monday & Monday \\
\hline Thursday & Thursday & Monday & Monday \\
\hline Friday & Friday & Tuesday & Tuesday \\
\hline
\end{tabular}

* Urine passed only during the specified periods should be collected.

* Keep the bottles capped when not in use.

* Each kit consists of two (2) boxes containing three (3) bottles each. Begin with any bottle and use as many as necessary. Each bottle may be filled until approximately $3 / 4$ full.

* After final sampling has been complete, tighten each cap, place the bottles in the cardboard box and leave outside of your residence in the place it was delivered. It will be retrieved on the pickup date indicated in the chart above.

* If you will NOT have your kit ready before 8am on the day of pick-up, please call the number below and arrange for a later pick-up.

GEL Richland Service Center

524-A Warehouse Street

Richland, WA 99352

(509) 943-2121

Kit Code A 
EXHIBIT D.11

\section{GEL RICHLAND SERVICE CENTER}

524-A Warehouse Street Richland, WA 99352 (509) 943-2121 - www.gel.com

GEL Kit ID:

Delivery Date:

Sample Date:

Pick-Up Date:

\section{INSTRUCTIONS FOR TERMINATION BIOASSAY SAMPLING}

\section{PLEASE READ AND FOLLOW CAREFULLY}

* Check the kit box and bottles for your correct name, address and payroll number BEFORE collecting a sample. DO NOT USE this kit if it not addressed to you. Please notify GEL Richland Service Center of any problems or discrepancies in the information on the label.

* Your employer has requested from you a final urine specimen to complete your individual radiation exposure history record. This is part of your employer's termination procedure.

* Please collect ALL urine passed beginning one-half hour before retiring the evening before the above sample date, all voids through the night, and ending 1/2 hour after arising the next morning.

* Keep the bottles capped when not in use.

* Three (3) bottles are provided in the kit. Begin with any bottle and use as many as necessary. Each bottle may be filled until approximately $3 / 4$ full.

* After final sampling has been completed, tighten each cap, place the bottles in the cardboard box and return the kit to the locations specified in the SPECIAL TERMINATION BIOASSAY INSTRUCTIONS provided by your employer. DO NOT LEAVE THE KIT AT YOUR RESIDENCE.

GEL Richland Service Center

524-A Warehouse Street

Richland, WA 99352

(509) 943-2121

Kit Code B 


\section{EXHIBIT D.12}

\section{GEL RICHLAND SERVICE CENTER}

524-A Warehouse Street Richland, WA 99352 (509) 943-2121 - www.gel.com

GEL Kit ID:

Sample Date:

Pick-Up Date:

\section{INSTRUCTIONS FOR \\ ROUTINE BIOASSAY AT-HOME SAMPLING \\ PLEASE READ AND FOLLOW CAREFULLY}

* Check the kit box and bottles for your correct name, address and payroll number BEFORE collecting a sample. DO NOT USE this kit if it not addressed to you. Please notify the office issuing the kit of any problems or discrepancies in the information on the label.

\begin{tabular}{|l|l|l|l|}
\hline If kit was delivered on: & Start collection on: & End collection morning of: & Kit will be picked up: \\
\hline Monday & Monday & Wednesday & Wednesday \\
\hline Tuesday & Tuesday & Thursday & Thursday \\
\hline Wednesday & Wednesday & Friday & Friday \\
\hline Thursday & Saturday & Monday & Monday \\
\hline Friday & Saturday & Monday & Monday
\end{tabular}

* Please collect ALL urine excreted starting $1 / 2$ hour before retiring, all voids through the night, and ending $1 / 2$ hour after arising the next morning for two (2) consecutive nights.

* Urine passed only during the specified periods should be collected.

${ }^{*}$ Keep the bottles capped when not in use.

* Each kit consists of three (3) bottles. Begin with any bottle and use as many as necessary. Each bottle may be filled until approximately $3 / 4$ full.

* After final sampling has been completed, tighten each cap, place all bottles, used and unused, in the cardboard box, close the handles to close the box, and place the kit in the location specified in the instructions provided by your employer. It will be retrieved on the pickup date indicated in the chart above.

* If you work a shift other than the day shift and will NOT have your kit out before 8 AM on the day of sample pick-up, please call the number below to arrange for a later pick-up.

GEL Richland Service Center

524-A Warehouse Street

Richland, WA 99352

(509) 943-2121

Kit Code P 


\section{EXHIBIT D.13}

\section{GEL RICHLAND SERVICE CENTER}

524-A Warehouse Street Richland, WA 99352 (509) 943-2121 - www.gel.com

\section{GEL Kit ID:}

Sample Date:

Pick-Up Date:

\section{INSTRUCTIONS FOR TERMINATION BIOASSAY SAMPLING}

\section{PLEASE READ AND FOLLOW CAREFULLY}

* Check the kit box and bottles for your correct name, address and payroll number BEFORE collecting a sample. DO NOT USE this kit if it not addressed to you. Please notify the office issuing the kit of any problems or discrepancies in the information on the label.

* Your employer has requested from you a final urine specimen to complete your individual radiation exposure history record. This is part of your employer's termination procedure.

* Please collect ALL urine excreted starting $1 / 2$ hour before retiring the evening of the sample date, all voids through the night, and ending $1 / 2$ hour after arising the next morning.

* Keep the bottles capped when not in use.

* Three (3) containers are provided in the kit. Begin with any container and use as many as necessary. Each container may be filled until approximately $3 / 4$ full.

* After final sampling has been completed, tighten each cap, replace the bottles in the cardboard box and return the kit to one of the locations specified in the SPECIAL TERMINATION BIOASSAY INSTRUCTIONS provided by your employer.

* If you will NOT have your sample ready by 8am on the pickup date, please call the number below to arrange for a later pickup.

GEL Richland Service Center

524-A Warehouse Street

Richland, WA 99352

(509) 943-2121

Kit Code Q 
EXHIBIT D.14

\author{
GEL RICHLAND SERVICE CENTER \\ 524-A Warehouse Street Richland, WA 99352 (509) 943-2121 - www.gel.com
}

GEL Kit ID:

Sample Date:

Pick-Up Date:

\title{
INSTRUCTIONS FOR \\ 24 HOUR TOTAL URINE SAMPLING \\ HOME FRACTION
}

\section{PLEASE READ AND FOLLOW CAREFULLY}

* Check the kit box and bottles for your correct name, address and payroll number BEFORE collecting a sample. DO NOT USE this kit if it not addressed to you. Please notify the office issuing the kit of any problems or discrepancies in the information on the label.

* Please collect ALL urine passed from MIDNIGHT TO MIDNIGHT on the sample date as shown above and on the kit label. This kit is provided for home collection. A second kit may be provided for your use while at work.

* Keep the bottles capped when not in use.

* Three (3) bottles are provided in the kit. Begin with any bottle and use as many as necessary. Each bottle may be filled until approximately $3 / 4$ full.

* After final sampling has been completed, tighten each cap, place all bottles, used and unused, in the cardboard box, close the handles to close the box, and place the kit in the location specified in the instructions provided by your employer.

* The kit will be picked up on the pickup date indicated above.

* If you will NOT have your kit ready before 8am on the day of pick-up, please call the number below and arrange for a later pick-up.

GEL Richland Service Center

524-A Warehouse Street

Richland, WA 99352

(509) 943-2121

Kit Code R 


\title{
EXHIBIT D.15
}

\section{GEL RICHLAND SERVICE CENTER}

524-A Warehouse Street Richland, WA 99352 (509) 943-2121 - www.gel.com

GEL Kit ID:

Sample Date:

Pick-Up Date:

\section{INSTRUCTIONS FOR SINGLE VOID URINE SAMPLING}

\section{PLEASE READ AND FOLLOW CAREFULLY}

\begin{abstract}
* Check the kit box and bottles for your correct name, address and payroll number BEFORE collecting a sample. DO NOT USE this kit if it not addressed to you. Please notify the office issuing the kit of any problems or discrepancies in the information on the label.
\end{abstract}

* Unless you have been instructed otherwise, please collect a single NORMAL voiding of urine in one of the containers provided.

* Cap the container tightly. Place the container in the cardboard box and place the kit in the location specified in the instructions provided by your employer.

* The kit will be picked up on the sample date or the following day.

* If you will NOT have your kit ready before 8am on the day of pick-up, please call the number below and arrange for a later pick-up.

GEL Richland Service Center

524-A Warehouse Street

Richland, WA 99352

(509) 943-2121 
EXHIBIT D.16

\title{
GEL RICHLAND SERVICE CENTER
}

524-A Warehouse Street Richland, WA 99352 (509) 943-2121 - www.gel.com

GEL Kit ID:

Sample Date:

Pick-Up Date:

\section{INSTRUCTIONS FOR COLLECTING A FECAL SAMPLE}

\section{PLEASE READ AND FOLLOW CAREFULLY}

* Check the kit box and container for your correct name, address and payroll number BEFORE collecting a sample. DO NOT USE this kit if it not addressed to you. Please notify the office issuing the kit of any problems or discrepancies in the information on the label.

* Please collect a stool specimen (fecal sample) on the above date. If there is no voiding on the sample date, collect the next voiding and indicate in writing the correct sample date on the label.

* Place the kit in the location specified in the instructions provided by your employer after samples have been collected and kit completed.

* Please call the GEL Richland Service Center for sample pick-up.

\author{
GEL Richland Service Center \\ 524-A Warehouse Street \\ Richland, WA 99352 \\ (509) 943-2121
}

\section{Directions for Use:}

1. Remove container and frame-holder from the sample kit. Remove the container lid.

2. Insert the container unit into the frame holder.

3. Lift up the toilet seat. Place the container unit on the bowl in the center toward the rear of the toilet.

4. Lower the toilet seat onto the frame to hold the container unit in place.

CAUTION: Stool specimen must not contain urine.

5. After the stool specimen has been collected, replace the cover and return the sample to the sample box.

Kit Code: T 


\section{EXHIBIT D.17}

\section{GEL RICHLAND SERVICE CENTER}

524-A Warehouse Street Richland, WA 99352 (509) 943-2121 - www.gel.com

GEL Kit ID
Sample Date:

Pick-Up Date:

\section{INSTRUCTIONS FOR SPECIAL URINE SAMPLING}

\section{PLEASE READ AND FOLLOW CAREFULLY}

* Check the kit box and bottles for your correct name, address and payroll number BEFORE collecting a sample. DO NOT USE this kit if it not addressed to you. Please contact the office issuing the kit of any problems or discrepancies in the information on the label.

* Unless you have been instructed otherwise, please collect ALL urine excreted starting 1/2 hour before retiring, all voids through the night, and ending $1 / 2$ hour after arising the next morning

* Keep the bottles capped when not in use.

* Three (3) bottles are provided in the kit. Begin with any bottle and use as many as necessary. Each bottle may be filled until approximately $3 / 4$ full.

* After final sampling has been completed, tighten each cap, place all bottles, used and unused, in the cardboard box, close the handles to close the box, and place the kit in the location specified in the instructions provided by your employer.

* The kit will be picked up on the date indicated above.

* If you will NOT have your kit ready before 8am on the day of pick-up, please call the number below and arrange for a later pick-up.

GEL Richland Service Center

524-A Warehouse Street

Richland, WA 99352

(509) 943-2121

Kit Code: U 


\section{EXHIBIT D.18}

\section{GEL RICHLAND SERVICE CENTER}

524-A Warehouse Street Richland, WA 99352 (509) 943-2121 - www.gel.com

GEL Kit ID:
Sample Date:

Pick-Up Date:

\section{INSTRUCTIONS FOR SOLUBLE URANIUM IN URINE SAMPLING PLEASE READ AND FOLLOW CAREFULLY}

Routine collection and analysis of urine samples is an important part of the radiation dosimetry program for individuals working with soluble uranium. Therefore, it is requested that you read and carefully follow the instructions below.

* Check the kit box and bottles for your correct name, address and payroll number BEFORE collecting a sample. DO NOT USE this kit if it not addressed to you. Please notify the office issuing the kit of any problems or discrepancies in the information on the label.

* Unless you have been instructed otherwise, please collect ALL urine passed beginning one-half hour before retiring on Sunday evening, all voids through the night, and ending one-half hour after rising Monday morning.

* Keep the bottles capped when not in use.

* Three (3) bottles are provided in the kit. Begin with any bottle and use as many as necessary. Each bottle may be filled until approximately $3 / 4$ full.

* After final sampling has been completed, tighten each cap, place all bottles, used and unused, in the cardboard box, close the handles to close the box, and place the kit in the location specified in the instructions provided by your employer.

* The kit will be picked up on Monday morning.

* If you will NOT have your kit ready before 8am on the day of pick-up, please call the number below and arrange for a later pick-up.

GEL Richland Service Center

524-A Warehouse Street

Richland, WA 99352

(509) 943 - 2121

Kit Code: $\mathrm{V}$ 


\section{EXHIBIT D.19}

\section{GEL RICHLAND SERVICE CENTER}

524-A Warehouse Street Richland, WA 99352 (509) 943-2121 - www.gel.com

GEL Kit ID:

\section{INSTRUCTIONS FOR COLLECTING A FECAL SAMPLE}

PLEASE READ AND FOLLOW CAREFULLY

IMPORTANT!

IF POSSIBLE, DO NOT USE UNTIL 24 HOURS AFTER LEAVING WORK PLACE.

* Check the kit box and container for your correct name, address and payroll number BEFORE collecting a sample. DO NOT USE this kit if it not addressed to you. Please notify the office issuing the kit of any problems or discrepancies in the information on the label.

* Please collect a stool specimen (fecal sample) on the above date. If there is no voiding on the sample date, collect the next voiding and indicate in writing the correct sample date on the label.

* Place the kit in the place it was delivered after samples have been collected and kit completed.

* Please contact GEL Richland Service Center to schedule pick-up for your sample kit.

CHECK TIME OUT OF ZONE:

$\square \quad$ Less than 1 day

1-3 days

More than 3 days
GEL Richland Service Center

524-A Warehouse Street

Richland, WA 99352

(509) 943-2121

\section{Directions for Use:}

1. Remove container \& frame-holder from the sample kit. Remove the container lid.

2. Insert the container unit into the frame holder.

3. Lift up the toilet seat. Place the container unit on the bowl in the center toward the rear of the toilet.

4. Lower the toilet seat onto the frame to hold the container unit in place.

CAUTION: Stool specimen must not contain urine.

5. After the stool specimen has been collected, replace the cover and return the sample to the sample box.

Kit Code: W 


\section{EXHIBIT D.20}

\section{GEL RICHLAND SERVICE CENTER \\ 524-A Warehouse Street Richland, WA 99352 (509) 943-2121 - www.gel.com}

GEL Kit ID:

Sample Date:

Pick-Up Date:

\section{INSTRUCTIONS FOR \\ COLLECTING A URINE SAMPLE FOR MAILING}

\section{PLEASE READ AND FOLLOW CAREFULLY}

* Check the kit box and bottles for your correct name, address and payroll number BEFORE collecting a sample. DO NOT USE this kit if it is not addressed to you. Please notify GEL Richland Service Center of any problems or discrepancies in the information on the label.

* Please collect ALL urine passed while at home until all bottles are used.

* Discard the outer box. Write the date of sampling on the line provided above.

* Three bottles are provided in the kit. Begin with any bottle and fill each to at least the fill line but no higher than the bottle neck.

* Keep the bottles capped when not in use.

* After sampling is completed, be certain each bottle lid is sealed tightly. Place the bottles and this instruction sheet in the cardboard box.

* Seal the box by moistening the gummed surface of the tape provided and centering over the box closure.

* Return the sample kit using the enclosed FedEx shipping label to the following address:

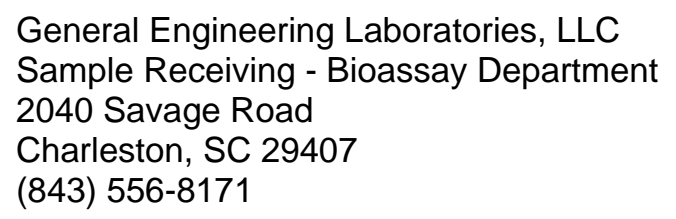

* If you have any questions, please contact the GEL Richland Service Center.

GEL Richland Service Center 524-A Warehouse Street Richland, WA 99352

(509) 943-2121 


\title{
EXHIBIT D.21
}

\author{
GEL RICHLAND SERVICE CENTER \\ 524-A Warehouse Street Richland, WA 99352 (509) 943-2121 - www.gel.com
}

GEL Kit ID:

Sample Date:

Pick-Up Date:

\section{INSTRUCTIONS FOR ROUTINE BIOASSAY AT-HOME SAMPLING PLEASE READ AND FOLLOW CAREFULLY}

* Check the kit box and bottles for your correct name, address and payroll number BEFORE collecting a sample. DO NOT USE this kit if it not addressed to you. Please notify the office issuing the kit of any problems or discrepancies in the information on the label.

* Please collect ALL urine excreted starting $1 / 2$ hour before retiring, all voids through the night, and ending $1 / 2$ hour after arising the next morning for four (4) consecutive nights.

\begin{tabular}{|l|l|l|l|}
\hline If kit was delivered on: & Start collection on: & End collection morning of: & Kit will be picked up: \\
\hline Monday & Monday & Friday & Friday \\
\hline Tuesday & Thursday & Monday & Monday \\
\hline Wednesday & Thursday & Monday & Monday \\
\hline Thursday & Thursday & Monday & Monday \\
\hline Friday & Friday & Tuesday & Tuesday \\
\hline
\end{tabular}

* Urine passed only during the specified periods should be collected.

${ }^{*}$ Keep the bottles capped when not in use.

* Each kit consists of two (2) boxes containing three (3) bottles each. Begin with any bottle and use as many as necessary. Each bottle may be filled until approximately $3 / 4$ full.

* After final sampling has been complete, tighten each cap, place the bottles in the cardboard box and leave outside of your residence in the place it was delivered. It will be retrieved on the pickup date indicated in the chart above.

* If you will NOT have your kit ready before 8am on the day of pick-up, please call the number below and arrange for a later pick-up.

GEL Richland Service Center

524-A Warehouse Street

Richland, WA 99352

(509) 943-2121 


\section{HANFORD INTERNAL DOSIMETRY PROGRAM MANUAL \\ PNL-MA-552}

\section{APPENDIX E - EXAMPLE POTENTIAL INTAKE RESPONSES}

Issued for implementation effective 01/01/2010

Supersedes: $10 / 2003$

Use Category: Not applicable

Approval Signatures:

Author:

Donald Bihl

D.E. Bihl

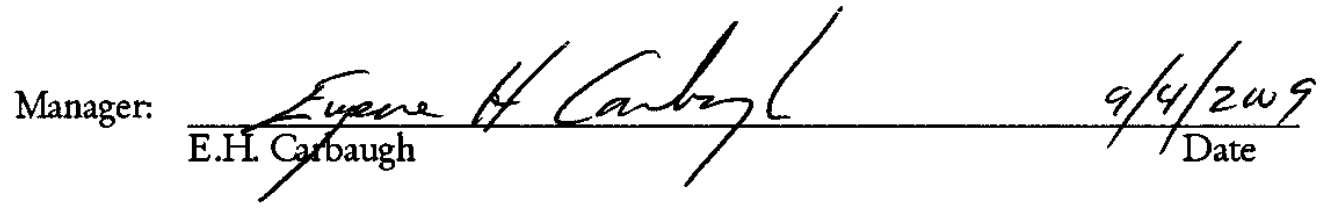

Reviewer Signatures:

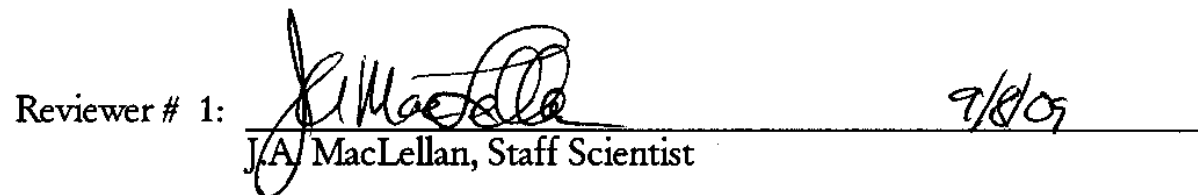

Approval by the Hanford Personnel Dosimetry Advisory Committee is not required per Section 1.0 of this manual. 


\section{Contents}

Appendix E - Example Potential Intake Responses ..................................................................... 3

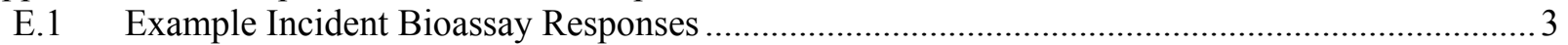

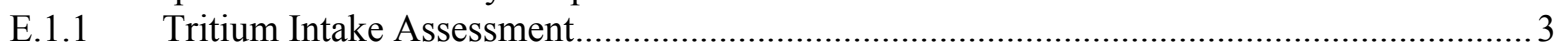

E.1.2 Mixed Fission and Activation Product Intake Assessment .............................................. 3

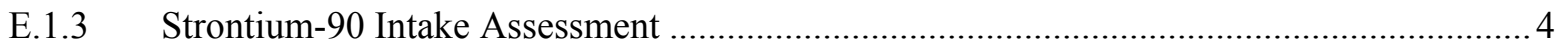

E.1.4 Uranium Intake Assessment, Soluble Forms ..................................................... 4

E.1.5 Uranium Intake Assessment, Insoluble Forms............................................................ 5

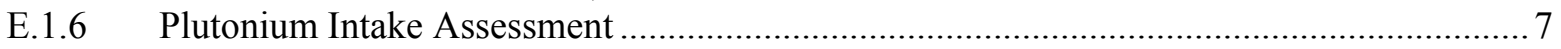

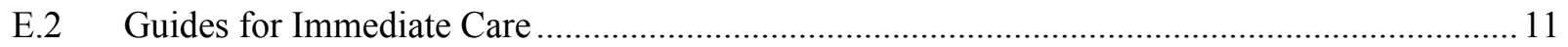

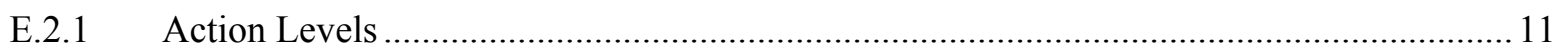

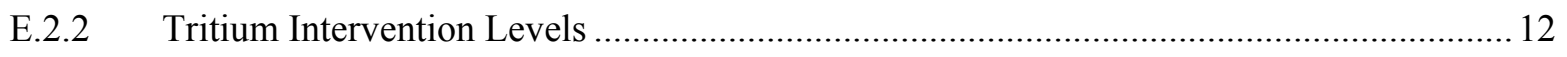

E.2.3 Mixed Fission Products Intervention Levels.................................................................. 14

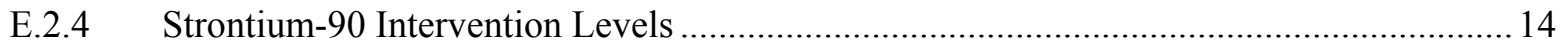

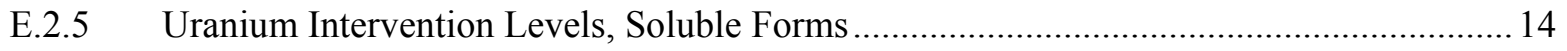

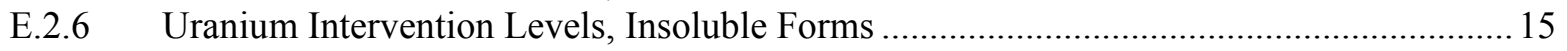

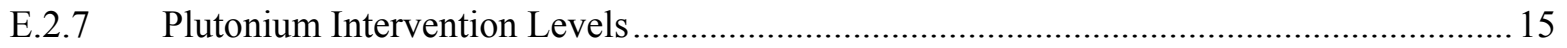

E.2.8 Intervention for Ingestion of Radioactive Materials ................................................... 16

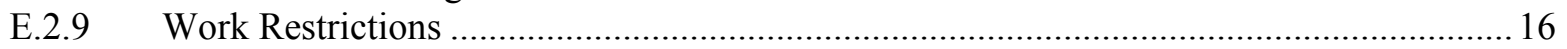

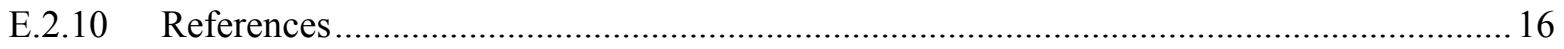




\section{Appendix E - Example Potential Intake Responses}

This appendix describes some example responses to potential intakes. It focuses on bioassay measurements, their capability and application to the dose assessment process, and action levels for consideration of dose reduction therapy. It is not intended that these examples be considered comprehensive or absolute. They are provided as examples of the kind and quality of dose estimates that can be made based on data available at various times following an intake. The exposure evaluator is responsible for interpreting the data available and estimating dose for actual cases, based on the unique aspects and data obtained for that case. Likewise, the discussion of dose reduction therapy is provided for general information. Occupational Medicine contractor staff are the Hanford Site authorities responsible for dose reduction therapeutic measures.

\section{E.1 Example Incident Bioassay Responses}

The Hanford Internal Dosimetry Program (HIDP) has a wide range of bioassay measurements and processing categories available. Following an incident of potential intake, the exposure evaluator recommends an investigation bioassay protocol to the contractor dosimetry representative. Factors considered in this recommendation include the type of intake, radionuclides involved, probable severity of intake, information needs of the physician and the worker's management, and the relative costeffectiveness of reasonable alternatives. There is a trade-off between the promptness by which estimates of intake or dose can be made and the accuracy of those estimates. Some example responses for the most probable radionuclides and scenarios at Hanford follow. The discussion also provides estimates of minimum detectable dose (in terms of the resulting committed effective dose) that can be determined at various stages of response.

\section{E.1.1 Tritium Intake Assessment}

Single-void or overnight urine sampling is the recommended bioassay method for an unplanned intake of tritium. A single-void sample obtained 2 or more hours after the intake can be adequate for dosimetry (second voiding after start of exposure is preferred). Generally, an overnight sample or nextmorning single-void sample provides adequate response for dosimetry. Dose assessment can be made based on either of these two samples, with a minimum detectable dose of about $1 \mathrm{mrem}$. However, if the dose estimated at that time is greater than 100-mrem committed effective dose, then additional samples collected over the next 2 weeks should be obtained to improve the precision of the dose assessment.

It is unlikely that an intake of tritium could occur at Hanford that would require emergency processing of urine samples for purposes of treatment, but emergency processing might be important for reporting purposes. Priority processing (3-day analysis time) is usually adequate. This decision can best be made at the time the sample is collected.

\section{E.1.2 Mixed Fission and Activation Product Intake Assessment}

Mixed fission and activation products emitting gamma-rays with energies $>300 \mathrm{keV}$ are easily measured by whole body counting. A whole body, wound, or thyroid count (if radioiodine is suspected) within the first week after intake is sufficiently sensitive to confirm an intake resulting in a few mrem committed effective dose. Counts taken on the same day as the intake should generally not be used for dose assessment because of the possible interference from external contamination and because of the rapidly changing biokinetics of the material. If a same-day count results in an estimated dose $>10$-mrem 
committed effective dose, then an additional count should be obtained during the next 7 days. If the estimated dose is $>100$ mrem, several more counts should be obtained over a period approximately the same as the effective retention half-time in the body (or 6 months, whichever is shorter) to quantify the dose.

Excluding special research projects, the only high-energy gamma-emitting nuclides likely to be of concern now at the Hanford site are ${ }^{137} \mathrm{Cs},{ }^{60} \mathrm{Co}$, and ${ }^{154 / 155} \mathrm{Eu}$. With the exception of ${ }^{90} \mathrm{Sr}$ (addressed below) other mixed fission or activation products have either decayed away or are mixed with and produce much less dose than these radionuclides. However, in many places at Hanford, alpha-emitting radionuclides may be part of the radioactive mix and may contribute the most to committed effective dose. If ${ }^{137} \mathrm{Cs}$ is detected, consideration should be given to other nuclides potentially involved and the appropriateness of excreta bioassay.

\section{E.1.3 Strontium-90 Intake Assessment}

There are some places onsite where workers may be exposed to ${ }^{90} \mathrm{Sr}$ without accompanying ${ }^{137} \mathrm{Cs}$ or other gamma-emitting radionuclides. Generally, a 12-hour urine sample analyzed by expedite processing is sufficient to give a prompt indication of the severity of the intake down to a few mrem. Actual dose assessment should be based on at least one 24-hour (or approximate 24-hour) urine sample taken a few days after the intake and analyzed by priority processing. If the preliminary dose estimate is $>100$ mrem, then several urine samples should be obtained during the next couple of months.

If workplace monitoring indicates a potential for a very large intake, then same-day and next-day in vivo counts should be made and a second-void urine sample should be obtained and analyzed by emergency processing. In vivo bremsstrahlung counting should be able to detect an intake down to 1-rem committed effective dose within a few hours after intake, and the urine sample should be able to detect an intake to within a few mrem within 24 hours after intake. Therefore, a decision to begin or end treatment can easily be made within a few hours after intake.

\section{E.1.4 Uranium Intake Assessment, Soluble Forms}

Because most uranium at Hanford is natural, depleted, or just slightly enriched (up to $1.2 \%{ }^{235} \mathrm{U}$ ), soluble forms of uranium (e.g., $\mathrm{UO}_{3}$ and uranyl nitrate) can pose a chemical as opposed to a radiological hazard. If a major intake is suspected, early response is focused on the kidney burden relative to the threshold for transient toxicity. A same-day chest count should be made as quickly as possible, and a second-void urine sample should be obtained and analyzed by emergency processing. The second-void urine sample should be followed by an overnight or 12-hour sample. Peak kidney concentration occurs around 24 hours after a Type $\mathrm{F}$ inhalation so the second sample should be timed to include the peak concentration. Twenty-four-hour samples would follow if the worker is being treated. The chest count should be able to detect an intake of about 80-90 $\mathrm{mg}$ (Type M) depending on how soon after intake the measurement is made, and the spot urine sample should be able to detect an intake of about $0.5-5 \mathrm{mg}$ Type $\mathrm{F}$ and $\mathrm{M}$. If anything is detected in a chest count, or if the spot urine and 12-hour urine samples exceed $0.1 \mathrm{mg}$ or $0.5 \mathrm{mg}$, respectively, then Occupational Medicine should be notified. Monitoring of kidney function is recommended.

If workplace monitoring or prompt urine results indicate that the threshold for toxicity was not approached, then actual dose assessment should be based on at least one 24-hour (or approximate 24-hour) urine sample taken at least 3 days after the intake and analyzed by priority processing. The 3-day delay allows for elimination from the body of the unabsorbed fraction of the intake, which can introduce a large 
error in the dose calculation. Doses down to fractions of a mrem (Type F) or a few mrem (Type M) can be detected at that time.

\section{E.1.5 Uranium Intake Assessment, Insoluble Forms}

Uranium that is more slowly transferred from the lung or wound site could be encountered during cleanup of facilities or underground pipes or soil contamination in the 300 Area or 200 Area burial grounds. Because of historical special projects, uranium with higher levels of enrichment (more $\left.{ }^{235} \mathrm{U}\right)$ than the nominal 1\% might be encountered, and these will produce higher doses per unit intake. It is important to ascertain the expected enrichment of the uranium mixture as soon as possible.

An inhalation of Type S uranium is considered the most difficult to detect. Details of the response capabilities are given in Table E.1. Early fecal samples are essential for good estimates of Type S intakes. The presence of a small Type F component can improve the early urine sampling sensitivity but also if dose calculations are based on urine samples alone, a small uncertainty in the percentage of Type $\mathrm{F}$ material present in an intake could lead to a large miscalculation of the dose.

If activity in urine remains above normal after the first couple of days, then additional urine samples should be obtained at about 5,10 and 30 days after intake. 
Table E.1. Inhalation of Recycled Type S Uranium, No Treatment

\begin{tabular}{|c|c|c|c|c|}
\hline $\begin{array}{c}\text { Days } \\
\text { Post-intake } \\
\end{array}$ & Measurements & $\begin{array}{c}\text { When Results } \\
\text { Are Known } \\
\end{array}$ & $\begin{array}{c}\text { What Can Be Said At } \\
\text { That Point } \\
\end{array}$ & $\begin{array}{l}\text { Problems or } \\
\text { Comments }^{(a)} \\
\end{array}$ \\
\hline Same day & 3000 -s chest count & Same day & $\begin{array}{l}\text { Can say if committed } \\
\text { effective dose is }<\text { or }> \\
5 \text { rem. }\end{array}$ & $\begin{array}{l}\text { If }{ }^{235} \mathrm{U} \text { or }{ }^{234} \mathrm{Th} \text { detected, } \\
\text { advise Occupational } \\
\text { Medicine for treatment } \\
\text { decision. }\end{array}$ \\
\hline Same day & $\begin{array}{l}\text { 2nd voiding spot } \\
\text { urine emergency } \\
\text { processing. }\end{array}$ & $\begin{array}{l}\text { About } 24 \\
\text { hours. }\end{array}$ & $\begin{array}{l}\text { Can say if committed } \\
\text { effective dose is }<\text { or }>1 \\
\text { rem. }\end{array}$ & $\begin{array}{l}\text { If spot urine }>5 \mu \mathrm{g} \text {, } \\
\text { advise Occupational } \\
\text { Medicine. Note this } \\
\text { level may not be } \\
\text { detectable using } \\
\text { emergency processing. } \\
\text { However, because lung } \\
\text { and ET are critical } \\
\text { organs, treatment } \\
\text { unlikely unless intake is } \\
\text { much higher. }\end{array}$ \\
\hline 1 & $\begin{array}{l}\text { If chest count detects } \\
\text { activity, then collect } \\
\text { a } 12 \text {-h urine, } \\
\text { emergency } \\
\text { processing, and a } \\
\text { second chest count. }\end{array}$ & $\begin{array}{l}\text { End of second } \\
\text { day or } \\
\text { morning of } \\
\text { third day. }\end{array}$ & $\begin{array}{l}\text { No real change in } \\
\text { detectable dose, but } \\
\text { second chest count will } \\
\text { help determine split } \\
\text { between Type F and S, } \\
\text { and 12-h urine will } \\
\text { improve accuracy of } \\
\text { dose estimate and } \\
\text { efficacy of treatment. }\end{array}$ & $\begin{array}{l}30 \mu \mathrm{g} \text { in } 12 \text {-h urine } \approx 2 \\
\text { rem committed effective } \\
\text { dose. }\end{array}$ \\
\hline 1 & $\begin{array}{l}\text { If first chest count } \\
\text { did not detect } \\
\text { activity, then collect } \\
\text { 24-h total urine and } \\
\text { expedite processing. }\end{array}$ & $\begin{array}{l}\text { Morning of the } \\
\text { fifth day. }\end{array}$ & $\begin{array}{l}\text { If nothing in sample, } \\
\text { then dose is most likely } \\
<100 \text { mrem. }\end{array}$ & $\begin{array}{l}\text { If nothing in } 24-\mathrm{h} \\
\text { sample, collect at least } \\
\text { one more and analyze } \\
\text { priority processing. }\end{array}$ \\
\hline $1-3$ & $\begin{array}{l}\text { Two fecal samples; } \\
\text { priority processing. }\end{array}$ & $\begin{array}{l}12 \text { to } 14 \text { days } \\
\text { after intake. }\end{array}$ & $\begin{array}{l}\text { Capable of determining } \\
\text { a few mrem above } \\
\text { background. }\end{array}$ & $\begin{array}{l}\text { Used to determine Type } \\
\text { S component of intake. }\end{array}$ \\
\hline
\end{tabular}

If there is only normal activity in urine but the activity is $>100$ times the minimum detectable amount (MDA) in feces, then as a minimum an additional fecal sample should be obtained at about 20 days after intake. Two samples, at 10 and at 20 to 30 days, are preferred.

Fecal samples are not required for intakes of insoluble uranium by wounds because there is little transfer of systemic uranium to the gastrointestinal tract. However, for a very significant intake of uranium via a wound, a fecal sample is suggested to verify this assumption.

Because of the lower specific activity of uranium relative to plutonium, workplace monitoring is a more reliable indicator of the severity of a uranium intake. For instance, the Type $S$ intake resulting in a 500 -mrem committed effective dose is about $23 \mathrm{mg}$, which should be readily detectable in the workplace. 
Consequently, the bioassay protocol is less automatic than for plutonium and can be tailored to reflect the seriousness of the intake as indicated by workplace monitoring. The decision to perform emergency processing of a spot urine sample on one extreme versus priority processing of a 24-hour sample on the other, or collection of a fecal sample for maximum sensitivity to inhalation intake detection is made based on the circumstances surrounding the intake.

\section{E.1.6 Plutonium Intake Assessment}

Plutonium at Hanford tends to be a mixture characterized by its weight percentage of ${ }^{240} \mathrm{Pu}$ and the time elapsed since its chemical separation and purification. In general for Hanford plutonium the time since the plutonium was purified varies from about 20 years to many decades, hence, there has been ample time for ${ }^{241} \mathrm{Am}$ to grow into the mixture from ${ }^{241} \mathrm{Pu}$ decay. For purposes of this discussion, a 20 year aged $6 \%{ }^{240} \mathrm{Pu}$ mixture is assumed. The incident responses for various ages or types of $\mathrm{Pu}$ are not significantly different, however, the bioassay capabilities can vary substantially for the same response.

Details of the bioassay options and minimum detectable doses at various stages after an inhalation intake are provided in Tables E. 2 and E.3. The response capabilities consider both inhalation Type M and S. Evidence exists to suggest that Type M plutonium becomes more and more like Type $\mathrm{S}$ as it ages, i.e., as it oxidizes at normal room temperature and humidity.

Generally, for low-level exposures (i.e., anticipated committed effective dose of less than $100 \mathrm{mrem}$ ), the bioassay protocol consists of fecal and urine sampling within the first 5 days following the intake. For super-Type S material or exposure levels greater than $100 \mathrm{mrem}$, the bioassay protocol may consist of a same-day chest count, a second-voiding urine sample, and one or more of the following:

- A 12-hour urine sample collected after the second voiding.

- A 24-hour urine sample collected immediately after the 12-hour sample.

- $\quad$ All of the fecal excretion for the first 3 to 5 days after the incident.

Analysis of the ${ }^{241} \mathrm{Am}$ content of a fecal sample by expedite or emergency processing using lowenergy photon detection (LEPD) methods may be preferred over emergency processing for plutonium in feces, due to the complex chemistry associated with $\mathrm{Pu}$ analysis.

The fecal samples are essential if sensitivity at a 100-mrem committed effective dose is to be obtained for Type S or Super S plutonium. However, 24-hour, priority-processed urine samples obtained within the first 10 days is sufficient for Type $\mathrm{M}$ plutonium. If activity has been detected in urine during the early sampling listed in Tables E.2 and E.3, then additional urine samples should be obtained at about 5, 10, and 30 days after intake. If there has been no activity in urine but activity was $>100$ times the MDA in feces, then as a minimum an additional fecal sample should be obtained at about 20 days after intake. Two samples are preferred, at 10 days and at 20 to 30 days. Additional fecal samples at longer times post intake may be appropriate for verifying the excretion rate.

Details of the bioassay capability for a plutonium-contaminated wound are provided in Table E.4. Basically, the protocol consists of same-day wound counts and at least one urine sample. The decision on the type of urine sample (e.g., spot or 12-hour) and processing time will depend not only on what the wound count indicates but also on other contamination data (e.g., the results of the blood sample or the level of contamination on the wound source or on skin around the wound). A fecal sample is desirable for large intakes to verify that there was not some inhalation as well, but is not essential.

Issued for implementation effective $01 / 01 / 2010$

PNL-MA-552 Appendix E

Supersedes: $10 / 03$

Page 7 of 16 
Table E.2. Bioassay Capabilities for an Inhalation Intake of 20-year Aged 6\% Pu Mixture, $5 \mu \mathrm{m}$ AMAD Particle Size, No DTPA Given At Worksite

\begin{tabular}{|c|c|c|c|c|}
\hline $\begin{array}{c}\text { Days } \\
\text { Post-Intake }\end{array}$ & Measurements & $\begin{array}{l}\text { When Results } \\
\text { Are Known }\end{array}$ & $\begin{array}{c}\text { What Can Be } \\
\text { Said At What } \\
\text { Point } \\
\end{array}$ & $\begin{array}{c}\text { Problems Or } \\
\text { Comments }\end{array}$ \\
\hline \multirow[t]{2}{*}{ Same day } & $\begin{array}{l}\text { 3000-s chest } \\
\text { count; } \\
\text { second voiding } \\
\text { spot urine; } \\
\text { emergency }\end{array}$ & $\begin{array}{l}\text { Same day for chest } \\
\text { count; } 24 \text { hours for } \\
\text { urine sample. }\end{array}$ & $\begin{array}{l}\text { Can say if } \\
\text { committed } \\
\text { effective dose is } \\
<\text { or }>5 \text { rem. }\end{array}$ & $\begin{array}{l}\text { If anything detected, } \\
\text { should consider } \\
\text { DTPA. }\end{array}$ \\
\hline & processing. & & $\begin{array}{l}\text { Urine: can say if } \\
<\text { or }>5 \text { rem } \\
\text { Type } M .\end{array}$ & \\
\hline \multirow[t]{2}{*}{1} & $\begin{array}{l}\text { 12-h urine, } \\
\text { emergency } \\
\text { processing; } \\
\text { second chest } \\
\text { count if first } \\
\text { result detected } \\
\text { activity. }\end{array}$ & $\begin{array}{l}\text { End of second day } \\
\text { or morning of third } \\
\text { day. }\end{array}$ & $\begin{array}{l}\text { If nothing in } \\
\text { urine or chest, } \\
\text { then committed } \\
\text { effective dose is } \\
\text { Type } M<1 \text { rem, } \\
\text { Type } \mathrm{S}<2 \text { rem. }\end{array}$ & $\begin{array}{l}\text { Type M: bone } \\
\text { surface committed } \\
\text { dose } \sim 10 \text { rem still } \\
\text { possible. If anything } \\
\text { detected, can still } \\
\text { consider DTPA. }\end{array}$ \\
\hline & & & & $\begin{array}{l}\text { If } \mathrm{Pu} \text { alpha in urine } \\
>2 \mathrm{dpm} \text { in half-day } \\
\text { sample, then } \\
\text { consider initiating } \\
\text { DTPA. }^{\text {(a) }}\end{array}$ \\
\hline 2 & $\begin{array}{l}\text { 24-h total urine, } \\
\text { expedite } \\
\text { processing. }\end{array}$ & $\begin{array}{l}\text { Morning of fifth } \\
\text { day. }\end{array}$ & $\begin{array}{l}\text { If nothing in } \\
\text { sample (and } \\
\text { previous chest } \\
\text { counts), then } \\
\text { committed } \\
\text { effective dose } \\
<500 \text { mrem. }\end{array}$ & $\begin{array}{l}\text { From bioassay data, } \\
\text { still will not know } \\
\text { absorption type of } \\
\text { material. }\end{array}$ \\
\hline \multirow[t]{2}{*}{$1-3$} & $\begin{array}{l}\text { Fecal excretion } \\
\text { for first } 3 \text { days } \\
\text { after intake. }\end{array}$ & $\begin{array}{l}\text { LEPD results: 6-7 } \\
\text { days after intake. }\end{array}$ & $\begin{array}{l}\text { If nothing in } \\
\text { LEPD analysis, } \\
\text { then committed } \\
\text { effective dose }\end{array}$ & \\
\hline & $\begin{array}{l}\text { Two processings } \\
\text { by lab: } \\
\text { 1) LEPD } \\
\text { expedited } \\
\text { processing, } \\
\text { 2) IPA priority } \\
\text { processing. }\end{array}$ & $\begin{array}{l}\text { IPA priority: } \\
\text { 16-17 days after } \\
\text { intake. }\end{array}$ & $\begin{array}{l}\text { If nothing in IPA, } \\
\text { then committed } \\
\text { effective dose } \\
<<100 \text { mrem. }\end{array}$ & \\
\hline
\end{tabular}

(a) DTPA will enhance excretion about 10-100 times; $400 \mathrm{dpm}$ excreted averts about 400 mrem committed effective dose or about 14,000 mrem committed bone surface dose. These are smaller doses than the guidance stated in E.2.1 below; however, a single dose of DTPA has low risk of side effects. 
Table E.3. Bioassay Capabilities for an Inhalation Intake of 20-year Aged 6\% Pu Mixture, $5 \mu \mathrm{m}$ AMAD Particle Size with DTPA Promptly Administered Based on Workplace Data

\begin{tabular}{|c|c|c|c|c|}
\hline $\begin{array}{c}\text { Days } \\
\text { Post-Intake }\end{array}$ & Measurements & $\begin{array}{c}\text { When Results Are } \\
\text { Known }\end{array}$ & $\begin{array}{c}\text { What Can Be } \\
\text { Said At What } \\
\text { Point } \\
\end{array}$ & $\begin{array}{l}\text { Problems Or } \\
\text { Comments }\end{array}$ \\
\hline Same day & $\begin{array}{l}3000-\text { s chest } \\
\text { count; second } \\
\text { voiding spot } \\
\text { urine, emergency } \\
\text { IPU processing. }\end{array}$ & $\begin{array}{l}\text { Same day for chest } \\
\text { count; } 24 \text { hours for } \\
\text { urine sample. }\end{array}$ & $\begin{array}{l}\text { If committed } \\
\text { effective dose is }< \\
\text { or }>5 \text { rem. Much } \\
\text { lower dose if sure } \\
\text { material is Type } \\
\text { M. }\end{array}$ & $\begin{array}{l}\text { Consider second } \\
\text { DTPA shot if } \\
\text { anything detected in } \\
\text { spot urine. }\end{array}$ \\
\hline 1 & $\begin{array}{l}\text { 12-h urine, } \\
\text { emergency IPU } \\
\text { processing; } \\
\text { second chest } \\
\text { count if first } \\
\text { detected activity. }\end{array}$ & $\begin{array}{l}\text { End of second day } \\
\text { or morning of third } \\
\text { day }\end{array}$ & $\begin{array}{l}\text { If nothing in urine } \\
\text { or chest, then } \\
\text { committed } \\
\text { effective dose is } \\
\text { Type } \mathrm{M}<1 \text { rem, } \\
\text { Type } \mathrm{S}<2 \text { rem. }\end{array}$ & $\begin{array}{l}\text { If nothing in urine or } \\
\text { chest, then DTPA } \\
\text { can be discontinued. } \\
\text { If Pu alpha in urine } \\
\text { is } \geq 200 \mathrm{dpm} \text {, then } \\
\text { consider continuing } \\
\text { DTPA }^{(\text {a) }} \text {. }\end{array}$ \\
\hline 2 & $\begin{array}{l}\text { 24-h total urine, } \\
\text { expedite IPU } \\
\text { processing. }\end{array}$ & Morning of 5th day. & $\begin{array}{l}\text { If nothing in } \\
\text { sample (and } \\
\text { previous chest } \\
\text { counts), then } \\
\text { committed } \\
\text { effective dose for } \\
\text { Type } \mathrm{M} \text { is } \\
<100 \text { rem, or Type } \\
\mathrm{S} \text { is }<1500 \text { rem. }\end{array}$ & $\begin{array}{l}\text { From bioassay data, } \\
\text { still will not know } \\
\text { absorbtion type of } \\
\text { material. If Pu alpha } \\
\text { in urine is } \geq 400 \mathrm{dpm} \text {, } \\
\text { then consider } \\
\text { continuing DTPA }^{(\mathrm{a})} \text {. }\end{array}$ \\
\hline \multirow[t]{2}{*}{$1-3$} & $\begin{array}{l}\text { Total fecal } \\
\text { excretion for first } \\
3 \text { days post } \\
\text { intake. }\end{array}$ & $\begin{array}{l}\text { LEPD results: } 6-7 \\
\text { days after intake; } \\
\text { IPA priority: } 17-18 \\
\text { days after intake; }\end{array}$ & $\begin{array}{l}\text { If nothing in } \\
\text { LEPD analysis, } \\
\text { then committed } \\
\text { effective dose }\end{array}$ & \\
\hline & $\begin{array}{l}\text { Two lab } \\
\text { processings: } \\
\text { 1) LEPD } \\
\text { expedited, } \\
\text { 2) IPA priority } \\
\text { processing (or } \\
\text { routine } \\
\text { processing if cost } \\
\text { is a factor). }\end{array}$ & $\begin{array}{l}\text { IPA routine: about } \\
6 \text { weeks after } \\
\text { intake. }\end{array}$ & $\begin{array}{l}<100 \text { mrem, if } \\
\text { nothing in IPA, } \\
\text { then }<<100 \text { mrem. }\end{array}$ & \\
\hline
\end{tabular}

(a) $400 \mathrm{dpm}$ excreted in urine averts about 400 mrem effective dose and about 14,000 mrem equivalent dose to the bone surface. This rule of thumb applies to any urine sample at any time. 
Table E.4. Wound Contamination by 20 -year Aged, 6\% Pu Mixture, No DTPA Given at Worksite

\begin{tabular}{|c|c|c|c|c|}
\hline $\begin{array}{c}\text { Days } \\
\text { Post-Intake }\end{array}$ & Measurements & $\begin{array}{c}\text { When Results Are } \\
\text { Known }\end{array}$ & $\begin{array}{l}\text { What Can Be } \\
\text { Said At What } \\
\text { Point } \\
\end{array}$ & $\begin{array}{c}\text { Problems Or } \\
\text { Comments }\end{array}$ \\
\hline Same day & $\begin{array}{l}\text { One or more wound } \\
\text { counts; second } \\
\text { voiding spot urine; } \\
\text { emergency IPU } \\
\text { processing. }\end{array}$ & $\begin{array}{l}\text { Same day for } \\
\text { wound count; } 24 \\
\text { hours for urine } \\
\text { sample. }\end{array}$ & $\begin{array}{l}\text { Can say if } \\
\text { committed } \\
\text { effective dose is }< \\
>3 \text { rem. }\end{array}$ & $\begin{array}{l}\text { If anything } \\
\text { detected in wound } \\
\text { or urine, should } \\
\text { consider DTPA. } \\
\text { If activity in wound } \\
\text { is }>0.5 \mathrm{nCi} \text {, } \\
\text { excision should be } \\
\text { considered }^{(\mathrm{a})} \text {. }\end{array}$ \\
\hline 1 & $\begin{array}{l}\text { 12-h urine, } \\
\text { emergency IPU } \\
\text { processing; second } \\
\text { wound count if first } \\
\text { detected activity. }\end{array}$ & $\begin{array}{l}\text { End of second day } \\
\text { or morning of third } \\
\text { day. }\end{array}$ & $\begin{array}{l}\text { Minimum } \\
\text { detectable } \\
\text { effective dose } \\
\text { somewhat } \\
<3 \text { rem, but } \\
\text { cannot say } \\
\text { exactly due to } \\
\text { uncertainty in } \\
\text { transfer rate from } \\
\text { wound. }\end{array}$ & $\begin{array}{l}\text { If nothing in urine } \\
\text { or wound, then } \\
\text { DTPA is not } \\
\text { indicated. If } \mathrm{Pu} \\
\text { alpha in urine }>2 \\
\text { dpm in half-day } \\
\text { sample, then } \\
\text { consider initiating } \\
\text { DTPA. }\end{array}$ \\
\hline 2 & $\begin{array}{l}\text { If nothing was } \\
\text { detected in previous } \\
\text { samples, then one } \\
\text { additional urine } \\
\text { sample (24-h- } \\
\text { simulated) is } \\
\text { collected; priority } \\
\text { processing. }\end{array}$ & 11 days & $\begin{array}{l}\text { If nothing in } \\
\text { sample, then } \\
\text { committed } \\
\text { effective dose } \\
<100 \text { mrem. }\end{array}$ & \\
\hline 2 & \multicolumn{4}{|c|}{$\begin{array}{l}\text { If activity was detected in previous samples, then additional wound and urine } \\
\text { measurements will be needed. Processing will depend on the activity in the } \\
\text { samples. }\end{array}$} \\
\hline
\end{tabular}

(a). $0.5 \mathrm{nCi}$, if it eventually goes systemic, will result in about $1 \mathrm{rem}$ committed effective dose and about 32 rem bone surface equivalent dose. Such doses should not be harmful so excision will depend on visibility of the scar, depth of the cut, patient's preference, and rate of transfer to the blood. If there is a rapid transfer rate, DTPA treatment without excision may be sufficient.

For wounds, the issue is not so much the sensitivity of early bioassay measurements, especially for shallow wounds, but the time involved to determine the biological behavior of the material. For instance, it may take months to determine the transfer rate of plutonium from the wound to blood and the quantity of plutonium transferred to the lymph system instead of to blood. Prolonged DTPA treatment will also prolong the time until the dose can be quantified.

The dose estimates in the tables assume that ${ }^{241} \mathrm{Am}$ has had about 20 years to build into the mixture. Longer ingrowth times will provide slight improvement for the chest count and LEPD fecal detection capabilities. However, shorter in-growth times can significantly reduce the sensitivity of chest and LEPD 
fecal counting. Intakes of freshly separated plutonium or pure isotopes of plutonium are especially difficult to detect via bioassay.

\section{E.2 Guides for Immediate Care}

\section{E.2.1 Action Levels}

Two kinds of action levels are described in this section. Notification levels are used to advise that an intake may have occurred. Intervention levels are used to assist with the decision to use medical therapy for dose reduction.

Notification levels based on workplace indicators for reacting to a potential intake are provided in Section 7 (Table 7.1) of this manual. The intent of these notification levels is to provide guidance for field response to any potential intake of radioactive material with a potential for a committed effective dose that is $>100$ mrem. Table 7.2 provides notification levels for possible early medical intervention for intakes. These tables are based on general considerations and significant experience with past intakes of radioactive material. They do not correspond with any specifically calculated value for intake or dose commitment to the worker.

Intervention levels are developed in this appendix to assist in the medical decision to treat an intake. These action levels, based on early bioassay results, have a strong correlation with the dose commitment received by the worker for different intake situations, although the degree of uncertainty is high especially in early bioassay sample results.

The decision to administer dose reduction therapy and the treatment protocol used are the responsibility of the physician in charge. Guidelines for the medical intervention of a radionuclide intake can be found in several publications. NCRP Report No. 65 (NCRP 1980) and the joint publication of the Commission on European Communities (CEC) and the DOE Guidebook for the Treatment of Accidental Internal Radionuclide Contamination of Workers (Bhattachaaryya, et al 1992) both contain detailed guidance in intervention and medical procedures useful in mitigating radiation overexposures. The CEC/DOE Guidebook expressed its guidance in terms of the annual limit on intake (ALI) levels, rather than on dose. In doing so, it used the 2-rem (20-mSv) effective dose concept of ALI found in ICRP Publication 60 (1991a) and in ICRP Publication 61 (1991b). The basic guidance can be summarized as follows:

- When the estimated intake is below one ALI, treatment should not be considered.

- When the estimated intake is between 1 and 10 times the ALI, treatment should be considered. Under these situations, short-term administration will usually be appropriate, except for intake of materials poorly transported from the lung (Type S).

- When the estimated intake exceeds 10 times the ALI, then extended or protracted treatment should be implemented, except for materials poorly transported from the lung.

- For poorly transported material in the lung, lung lavage is the only recommended treatment, and should only be considered for intakes exceeding 100 times the ALI.

Because the dose associated with the ALI in the CEC/DOE Guidebook is 2 rem committed effective dose and because the upper administrative level used by DOE is also 2 rem committed effective dose, the

Issued for implementation effective $01 / 01 / 2010$

PNL-MA-552 Appendix E

Supersedes: 10/03

Page 11 of 16 
Hanford Site uses 2 rem and 20 rem as intervention level guidance in the manner presented in the CEC/DOE Guidebook:

- When the estimated intake is below 2-rem committed effective dose, treatment is not generally recommended.

- When the estimated intake is between 2-rem and 20-rem committed effective dose, treatment should be considered, especially if there is low risk of side effects. Under these situations, short-term administration will usually be appropriate.

- When the estimated intake exceeds 20-rem committed effective dose, then extended or protracted treatment is strongly recommended, except for poorly transported material in the lung.

General guidelines for when treatment may be considered reasonable, based on specific bioassay results, are presented below for radionuclides common at Hanford (see Table E.5). Except for plutonium and insoluble uranium, they have been derived from internal dosimetry models of intakes that result in committed effective doses of 2 rem and 20 rem, corresponding to the intervention-level guidance discussed above.

\section{E.2.2 Tritium Intervention Levels}

Tritium cannot be measured by in vivo bioassay because it emits only a low-energy beta. The most sensitive method for bioassay measurement is the amount of tritium in urine, used to estimate the total tritium in body water.

Treatment (2 rem and 20 rem)

If the results of either a single-void urine sample taken 3 to 4 hours after exposure (to ensure equilibrium of tritium in body water and a representative concentration in the bladder) or a following overnight sample exceeds $10^{6} \mathrm{dpm} / \mathrm{mL}$ (implying an intake resulting in a committed effective dose of about 2 rem), Occupational Medicine should be notified. If the urine content exceeds $10^{7} \mathrm{dpm} / \mathrm{mL}$ (implying an untreated committed effective dose of 10 to $20 \mathrm{rem}$ ), treatment is strongly indicated. 
Table E.5. General Guidelines for When Treatment May be Considered Reasonable for Radionuclides Common at Hanford

\begin{tabular}{|c|c|c|c|c|}
\hline Isotope & Measurement & Result & Action & Possible Treatment \\
\hline \multicolumn{5}{|l|}{ Tritium } \\
\hline 2 rem & $\begin{array}{l}\text { Single-void urine } \\
3-4 \mathrm{~h} \text { after } \\
\text { exposure. }\end{array}$ & e $10^{6} \mathrm{dpm} / \mathrm{mL}$ & $\begin{array}{l}\text { Notify Occupational } \\
\text { Medicine. }\end{array}$ & Fluids, diuretics \\
\hline $20 \mathrm{rem}$ & Same & $10^{7} \mathrm{dpm} / \mathrm{mL}$ & $\begin{array}{l}\text { Strongly recommend } \\
\text { treatment. }\end{array}$ & $\begin{array}{l}\text { Fluids, } \\
\text { diuretics }\end{array}$ \\
\hline \multicolumn{5}{|l|}{ Mixed Fission Products } \\
\hline $\begin{array}{l}2 \mathrm{rem} \\
\text { (assumes } 2: 1 \mathrm{Sr} / \mathrm{Cs} \text { ratio) }\end{array}$ & $\begin{array}{l}{ }^{137} \text { Cs whole body } \\
\text { count. }\end{array}$ & $\begin{array}{l}\mathrm{y}>3,000 \mathrm{nCi} \text { or } \\
>48,000 \mathrm{nCi} \text { if } \\
\text { no Sr present. }\end{array}$ & $\begin{array}{l}\text { Notify Occupational } \\
\text { Medicine. Be alert for } \\
\text { alphas in the mixture. }\end{array}$ & $\begin{array}{l}\text { Prussian blue } \\
\mathrm{Ca},(\mathrm{Sr}), \text { ammonium } \\
\text { phosphate, others }\end{array}$ \\
\hline $\begin{array}{c}20 \mathrm{rem} \\
\text { (assumes } 2: 1 \mathrm{Sr} / \mathrm{Cs} \text { ratio) }\end{array}$ & Same & $\begin{array}{l}>30,000 \mathrm{nCi} \\
\text { or } \\
>480,000 \mathrm{nCi} \\
\text { if no } \mathrm{Sr} \\
\text { present. }\end{array}$ & $\begin{array}{l}\text { Treatment strongly } \\
\text { recommended. Be alert } \\
\text { for alphas in the mixture. }\end{array}$ & Same \\
\hline \multicolumn{5}{|l|}{${ }^{90} \mathrm{Sr}$} \\
\hline $2 \mathrm{rem}$ & $\begin{array}{l}\text { Second-void spot } \\
\text { urine or in vivo } \\
\text { detection. }\end{array}$ & $\begin{array}{l}>200,000 \mathrm{dpm} \\
\text { in spot urine, } \\
\text { or } \\
>\mathrm{MDA} \text { in } \\
\text { vivo. }\end{array}$ & $\begin{array}{l}\text { Notify Occupational } \\
\text { Medicine. Be alert for } \\
\text { other fission products or } \\
\text { alphas in the mixture. }\end{array}$ & $\begin{array}{l}\text { Alginate, Ca gluconate, } \\
\text { Sr lactate, others }\end{array}$ \\
\hline $20 \mathrm{rem}$ & Same & $\begin{array}{l}>2,000,000 \\
\text { dpm in spot } \\
\text { urine, or } \\
>50 \mu \mathrm{Ci} \text { in } \\
\text { vivo. }\end{array}$ & $\begin{array}{l}\text { Treatment strongly } \\
\text { recommended. Be alert } \\
\text { for other fission products } \\
\text { or alphas in the mixture. }\end{array}$ & Same \\
\hline \multicolumn{5}{|l|}{ Uranium, Soluble } \\
\hline \multirow[t]{3}{*}{ Potential kidney toxicity } & Chest count & $\begin{array}{l}>\mathrm{MDA} \text { for } \\
{ }^{234} \mathrm{Th}\end{array}$ & $\begin{array}{l}\text { Notify Occupational } \\
\text { Medicine. }\end{array}$ & $\begin{array}{l}\mathrm{Na} \text { or } \mathrm{Ca} \text { bicarbonate; } \\
\text { intestinal adsorbents }\end{array}$ \\
\hline & $\begin{array}{l}\text { Second-void } \\
\text { urine sample. }\end{array}$ & $>100 \mu \mathrm{g}$ & & \\
\hline & $\begin{array}{l}\text { 12-hour urine } \\
\text { sample. }\end{array}$ & $>500 \mu \mathrm{g}$ & & \\
\hline \multicolumn{5}{|l|}{ Uranium Insoluble $^{(a)}$} \\
\hline $2 \mathrm{rem}$ & Chest count & $\begin{array}{l}>\mathrm{MDA} \text { for } \\
{ }^{235} \mathrm{U} \text { or }{ }^{234} \mathrm{Th}\end{array}$ & $\begin{array}{l}\text { Notify Occupational } \\
\text { Medicine. }\end{array}$ & None recommended \\
\hline $200 \mathrm{rem}$ & Same & $\begin{array}{l}>200 \mathrm{nCi} \\
{ }^{234} \mathrm{Th}\end{array}$ & $\begin{array}{l}\text { Treatment strongly } \\
\text { recommended. }\end{array}$ & Lung lavage \\
\hline \multicolumn{5}{|l|}{ Plutonium } \\
\hline
\end{tabular}

(a) If soluble component is present, then urine sampling is appropriate. Use same action levels as above for soluble uranium. 


\section{E.2.3 Mixed Fission Products Intervention Levels}

Mixed fission products can be detected easily by whole body counting. Minimum detectable doses for the major radionuclides encountered at Hanford are on the order of a few mrem committed effective dose, although a small presence of alpha-emitting radionuclides in the intake can significantly increase the total dose. In severe intakes, other bioassays such as urine or fecal sampling can be implemented to provide a complete picture of the modes of clearance and retention of fission products. Cesium-137 and ${ }^{90} \mathrm{Sr}$ are the most prevalent fission products left at the Hanford Site, with ${ }^{154} \mathrm{Eu}$ still present at N Reactor.

\section{Treatment (2 rem and 20 rem)}

Assuming a 2:1 ratio for ${ }^{90} \mathrm{Sr}$ to ${ }^{137} \mathrm{Cs}$, if the whole body content exceeds $3000 \mathrm{nCi}$ of ${ }^{137} \mathrm{Cs}$ at 1-day following a wound or inhalation intake, Occupational Medicine should be notified and a spot urine sample should be analyzed for radiostrontium by emergency processing. If the whole body content exceeds $30,000 \mathrm{nCi}$ at $1-\mathrm{d}$ following intake, treatment is strongly indicated and a spot urine sample should be analyzed for radio-strontium by emergency processing. If it is likely that only ${ }^{137} \mathrm{Cs}$ is present, then the whole body contents suggesting or indicating treatment become $30,000 \mathrm{nCi}$ and $300,000 \mathrm{nCi}$, respectively.

For ${ }^{154} \mathrm{Eu}$ at 1 day post intake (assuming 0.5 AMAD particle size), if the whole body content exceeds $2,600 \mathrm{nCi}(1,000 \mathrm{nCi}$ wound), Occupational Medicine should be notified. If the whole body content exceeds $26,000 \mathrm{nCi}$ (inhalation) or 10,000 $\mathrm{nCi}$ (wound), treatment is strongly indicated. A little ${ }^{155} \mathrm{Eu}$ may also be present, which may or may not show in the whole body count.

\section{E.2.4 Strontium-90 Intervention Levels}

Strontium is normally associated with mixed fission products at Hanford although there are some locations where it can be found without this association. Although urine sampling is most sensitive, for larger intakes measurements of the skull or whole body can be undertaken to detect the bremsstrahlung radiations from the beta emissions.

\section{Treatment (2 rem and 20 rem)}

If a second-void spot urine sample exceeds 200,000 dpm (either inhalation or wound) or if anything is detected in vivo, Occupational Medicine should be notified. If the second-void spot urine sample exceeds $2,000,000 \mathrm{dpm}$, treatment is strongly indicated.

\section{E.2.5 Uranium Intervention Levels, Soluble Forms}

Soluble uranium materials at Hanford pose a problem from chemical toxicity rather than from radiological toxicity due to the low enrichment found on the site $\left(<1.2 \%{ }^{235} \mathrm{U}\right.$.) A major intake of uranium should focus on kidney content and potential nephrotoxicity.

\section{Treatment (nephrotoxicity)}

An inhalation intake of about $10 \mathrm{mg}$ Type $\mathrm{F}$ or $80 \mathrm{mg}$ Type $\mathrm{M}$ uranium should be considered potentially large enough to produce a kidney burden at or near the threshold for transient toxicity, and treatment (or at least monitoring of kidney function) should be considered. A same-day chest count should be made, and a second-void urine sample should be obtained and analyzed by emergency processing. If anything is detected in a chest count, or if the spot urine and 12-hour urine samples exceed 
$100 \mu \mathrm{g}$ or $500 \mu \mathrm{g}$, respectively, then Occupational Medicine should be notified. Usually, the treatment for intervention is sodium or calcium bicarbonate. Monitoring of kidney function is recommended.

For wounds, excision by surgery is not usually recommended, due to the high transportability of the material. A wound with about 2 to $3 \mathrm{nCi}(3 \mathrm{mg})$ of uranium or urine samples containing uranium at 100 $\mu \mathrm{g}$ (for spot urine samples) or $500 \mu \mathrm{g}$ (for 12-hour samples) should involve notification of Occupational Medicine and kidney function monitoring.

\section{E.2.6 Uranium Intervention Levels, Insoluble Forms}

Uranium found in the 300 Area may exhibit much less transportable behavior, because it is predominantly Type S material. Both 3000-second same-day chest counts and second-void spot urine samples are used for rapid estimation of the intake.

\section{Treatment}

There is no simple treatment for Type $\mathrm{S}$ components of the intake retained in the lung. If anything is detected in a chest count (implying a potential committed effective dose of 2 rem or more), then Occupational Medicine should be notified, although it is doubtful that any treatment will be appropriate. Lung lavage should be considered only for extremely large intakes. If the chest burden exceeds $300 \mathrm{nCi}$ $(93 \mathrm{mg}){ }^{238} \mathrm{U}$ or $20 \mathrm{nCi}(9 \mathrm{mg}){ }^{235} \mathrm{U}$, then treatment for removal of activity in the lung should be considered. These burdens imply a potential committed effective dose of 200 rem or approximately 1200-rem committed equivalent dose to the lung.

Because there can be some soluble material associated with the intake, nephrotoxicity can still be of concern for large intakes. If the second-void urine sample or the 12-hour urine sample exceeds $100 \mu \mathrm{g}$ or $500 \mu \mathrm{g}$, respectively, then Occupational Medicine should be notified. (This excretion would imply that the threshold for transient chemical toxicity might have been exceeded.) Monitoring of kidney function is recommended.

Wounds that contain uranium metal exhibit a serious surface dose consequence to surrounding tissue due to beta particles $(>200 \mathrm{mrad} / \mathrm{h})$. Excision should be considered in these cases if the wound contains $>15 \mathrm{nCi}$. Based on the 2-rem committed effective dose criterion, treatment should be considered for wounds containing about $80 \mathrm{nCi}$ of ${ }^{238} \mathrm{U}$ and/or about $5 \mathrm{nCi}$ of ${ }^{235} \mathrm{U}$ (assuming recycled uranium oxide form). At the same time, the urinary excretion should be watched closely because, if the material leaves the wound quickly, nephrotoxicity may be of concern.

\section{E.2.7 Plutonium Intervention Levels}

\section{Treatment}

Plutonium is treated by removal from blood and systemic organs using DTPA chelation via injection (by Occupational Medicine). This means that treatment does not affect activity in the lung to any appreciable extent, so treatment based on dose per unit intake (which is influenced by lung dose, especially for Type S material) is not as reliable an indicator of benefit. On the other hand, there is a direct correlation between DTPA, urinary excretion, and dose averted because of plutonium excreted. The committed effective dose averted per dpm excreted in urine is about $1 \mathrm{mrem}$, and the excretion enhancement factor using DTPA can vary from about 10 to 100 . So if DTPA is administered when untreated excretion is $4 \mathrm{dpm} /$ day, excretion should increase to 40 to $400 \mathrm{dpm}$ for a committed effective dose savings of 40 to 400 -mrem/day or 1,300 to $14,000 \mathrm{mrem} /$ day committed equivalent dose to the bone

Issued for implementation effective 01/01/2010

PNL-MA-552 Appendix E

Supersedes: 10/03

Page 15 of 16 
surface. It is probable that the efficacy of treatment will decrease with continued administration as plutonium is removed from the liver and the rate of transfer from lung to blood decreases. Ceasing DTPA treatment when excretion drops to below $40 \mathrm{dpm} /$ day probably sacrifices less than $40 \mathrm{mrem} /$ day committed effective dose.

For wounds, refer to the preceding Table E.4. Generally, any detectable plutonium in the wound or in spot urine samples should warrant considering administration of DTPA. If the activity in the wound is $>0.5$ to $1 \mathrm{nCi}$, excision of tissue should also be considered, with a saving of about 1 rem committed effective dose for each $0.5 \mathrm{nCi}$ removed.

\section{E.2.8 Intervention for Ingestion of Radioactive Materials}

Similar considerations for treatment or intervention levels apply to ingestion of radioactive materials as to inhalation. Exposure of the lower large intestine for poorly transported chemical species can be considerable in large intakes, but rapid clearance through the gastrointestinal (GI) tract to feces occurs. If an intake could potentially result in dose to an organ in the GI tract exceeding $50 \mathrm{rem}$, treatment should be considered.

\section{E.2.9 Work Restrictions}

Under any of the foregoing intake circumstances, a work restriction should be considered to prevent the worker from receiving further occupational radiation dose until an estimate of his/her dose is completed.

\section{E.2.10 References}

Bhattacharyya, M.H., B.D. Breitenstein, H. Metivier, B.A. Muggenburg, G.N. Stradling, and V. Volf.. 1992. Guidebook for the Treatment of a Accidental Internal Radionuclide Contamination of Workers. EUR 14320 EN. A joint publication for the Commission of the European Communities DirectorateGeneral for Science, Research, and Development, and the U.S. Department of Energy, in Rad. Prot.Dosimetry 41:1.

International Commission on Radiological Protection (ICRP). 1991a. 1990 Recommendations of the International Commission on Radiological Protection. ICRP Publication 60, Pergamon Press, New York.

International Commission on Radiological Protection (ICRP). 1991b. Revised Annual Limits on Intake Based on the New Recommendations of the International Commission on Radiological Protection. ICRP Publication 61, Pergamon Press, New York.

National Council on Radiation Protection and Measurements (NCRP). 1980. Management of Persons Accidentally Contaminated with Radionuclides. NCRP Report No. 65, Washington, D.C. 


\section{HANFORD INTERNAL DOSIMETRY PROGRAM MANUAL}

PNL-MA-552

\section{GLOSSARY}

Issued for implementation effective $01 / 01 / 2010$

Supersedes: $10 / 2003$

\section{Use Category: Not applicable}

\section{Approval Signatures:}

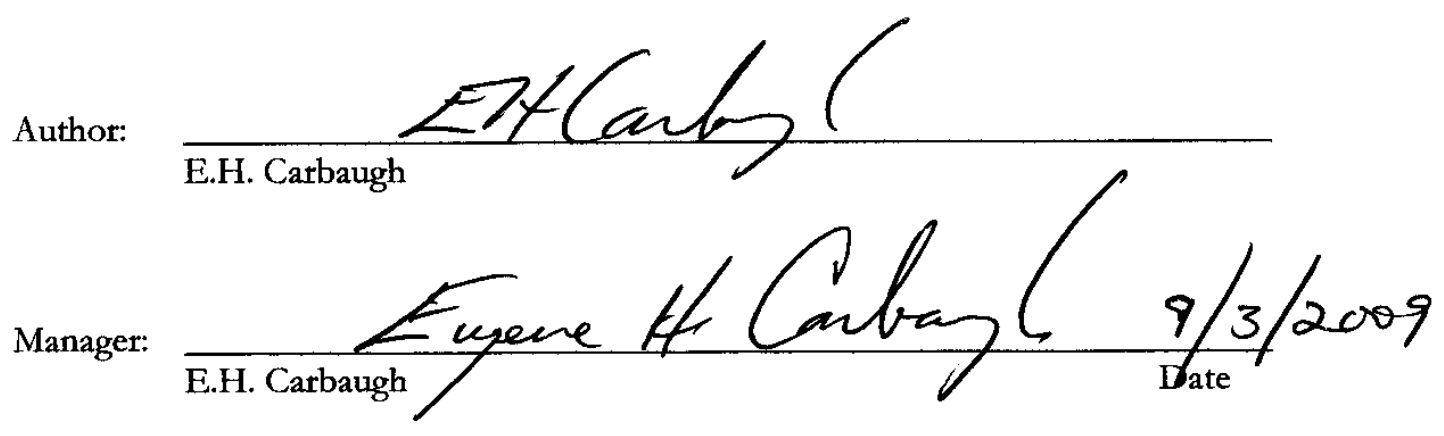

Reviewer Signatures:

Reviewer \#1:

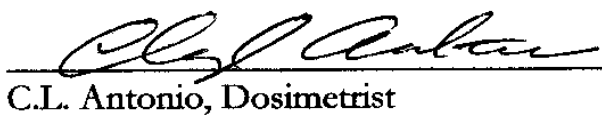

Approved by the Hanford Personnel Dosimetry Advisory Committee on June 9, 2009. 


\section{Glossary}

This glossary is a limited compilation of specialized terms used in this manual which are pertinent to internal dosimetry and, in particular, the Hanford Internal Dosimetry Program. It is not intended to be a general glossary of health physics or internal dosimetry definitions. For more detailed compilations or cross references for health physics definitions, see the references at the end of this compilation. Most terms used in this manual are generally consistent with standard technical usage by the International Commission on Radiological Protection (ICRP), National Council on Radiation Protection and Measurements, Health Physics Society, DOE, and the Nuclear Regulatory Commission. Wording may differ slightly because of common site historical usage; however, no incompatibility from regulatory requirements is intended. For terms defined in 10CFR835, the 10CFR835 definitions must be used for regulatory compliance application as oppose to terms used in this glossary.

analysis code

annual limit on
intake (ALI)

bioassay

chest measurement

committed equivalent

committed effective dose, $E$ (50)

container-not-out (CN)

contractual detection level (CL)
A code for computerized scheduling of the type of analysis desired. For example, IPU denotes analysis for ${ }^{238} \mathrm{Pu}$ and ${ }^{239+240} \mathrm{Pu}$.

The quantity of a single radionuclide which, if inhaled or ingested in a working year, would irradiate a person represented by ICRP 23 Reference Man, to the limiting dose value for control of occupational exposure. The stochastic ALI (SALI) is based on the stochastic dose limit for effective dose. The deterministic ALI (DALI) is based on the deterministic dose limit for equivalent dose to single organs or tissues.

The determination of kinds, quantities, or concentrations, and, in some cases, locations of radioactive material in the human body, whether by direct (in vivo) measurement or by indirect analysis of material removed or excreted from the body.

Direct measurement of radioactivity deposited in the chest region. The chest measurement includes contributions from activity in the lungs and skeleton.

The sum of the committed equivalent doses to various organs and tissues multiplied by the respective tissue weighting factors. It does not include contributions from external dose.

The effective dose calculated for a 50-year period following an acute intake or onset of chronic intake. It does not include contributions from external dose.

A term denoting that the worker took the sample kit inside his/her residence but did not put it out on collection day.

The required minimum detection level which is equivalent to the highest acceptable MDA. The CL applies to the overall process and not to individual samples. 


\section{DAC-hours}

\author{
decision level, $D L$ \\ or $L_{c}$ \\ derived air \\ concentration (DAC)
}

dose assessment

evaluation report

Exposure Evaluator (EE)

failed analysis (FA)

Field Dosimetry

field monitoring

head measurement

insufficient sample (IS)

internal dose

Internal Dosimetry

Internal Dosimetrist

in vivo measurement
The product of the concentration of radioactivity in air (expressed as a fraction of the DAC for each nuclide) and the duration of exposure, in hours. Exposure to 1 DAC-hour implies one hour equivalent exposure to air at the DAC value. See also derived air concentration (DAC).

The quantity of material in a measurement above which the analyte is interpreted as being present (i.e., analyte is detected). Also called the critical level for decision.

The concentration of a radionuclide in air which, if breathed over a working year, would irradiate a person represented by ICRP 23 Reference Man, to the limiting dose value for control of occupational exposure. See also DAC-hours.

The evaluation and assignment of a specific dose associated with a specific intake scenario. The dose assessment is documented using an evaluation report.

The formal documentation of an assessment of internal dose. The evaluation report is filed in the worker's radiation exposure file.

The emergency point of contact for the Hanford Internal Dosimetry Program or for sitewide dosimetry assistance.

Due to analytical problems, a valid analytical result could not be obtained. No results reported.

The components within a contractor organization having bioassay and internal dosimetry radiation protection responsibilities.

Monitoring performed at facilities, including air sampling and personal contamination surveys.

Direct bioassay measurement of the radioactive content of the head. This measurement is used to estimate the total skeleton content, and to correct a chest count to provide an estimate of lung content.

A sample below the minimum contractual volume or mass for routine analysis. This sample will not be analyzed and another sample should be submitted.

The equivalent dose to an organ or tissue, or the effective dose to the whole body, from radionuclides taken into the body.

The staff within the Pacific Northwest National Laboratory who are assigned to the Hanford Internal Dosimetry Program.

The individual responsible for assessing and documenting internal dose.

Direct measurement of radioactivity in the body. 
kit

kit code

lost container (or lost kit)

lung count

minimum detectable activity (MDA)

no sample (NS)

not evaluated

oral reporting level

organ equivalent dose

processing code

Radiation Records

reason code

screening level
A package containing bioassay sample containers. Usually one kit is used for each sample, but sometimes two kits are used to obtain one 24-hour total sample (work fraction and home fraction).

A code designating the type of sample to be collected. (See Appendix B, Table B.4, for a comprehensive list of kit codes.)

A sample kit that was not retrievable by the Analytical Services Laboratory. A “container-not-out” becomes a lost kit if it is not retrieved in 5 days.

Direct bioassay measurement to determine the activity in the lung. The measurement is determined from the results of a chest count minus the activity that is contributed from the skeleton.

An estimate of the smallest quantity that can be measured in a sample such that the risk for false detection and false nondetection are at a specified level of confidence, typically $5 \%$ or less for each.

A kit that was not used and remained outside the residence on collection day. The Analytical Services Laboratory notifies Internal Dosimetry of a "no sample" within one day so that rescheduling can occur, if necessary.

Sample was collected but not analyzed. Typically used when a backup sample was obtained but analysis was determined to be unnecessary and the sample discarded.

The minimum level of a bioassay measurement result at which the measurement laboratory shall provide prompt verbal or electronic notification to Internal Dosimetry.

The assessed equivalent dose to an organ or tissue of the body.

The desired turnaround time for the analysis. A shorter turnaround time results in less sensitivity and/or higher cost. Four processing categories exist, but not all radionuclide analyses are available for each category. (See Section 6.0, Tables 6.1 through 6.5.)

The sitewide support program, operated by Pacific Northwest National Laboratory, which maintains occupational radiation records for the Hanford Site.

A computer code used to describe the reason that a bioassay measurement is performed. (See Appendix B, Table B.3)

The minimum level of a bioassay measurement at which some further review or action is required to determine whether follow-up measurements or dose assessment is needed. 
sequential analyses

statement of work (SOW)

stochastic effects

total effective dose

whole body

measurement

\section{REFERENCES}

More than one radiochemical analysis performed on a single sample. For example, IPS is the analysis code for an IPU analysis and a SR analysis performed on the sample.

The technical and administrative specification of work to be performed under a contract.

Effects for which the probability of an effect occurring, rather than its severity, is a function of dose, without threshold.

The sum of the effective dose (for external exposures) and the committed effective dose (for internal exposures).

Direct bioassay measurement to determine the amount of high-energy, gamma-emitting radionuclides in the total body.

10 CFR 835.2. 2008. U.S. Department of Energy, "Occupational Radiation Protection, Definitions.” U.S. Code of Federal Regulations. Accessed July 23, 2009 at http://www.gpoaccess.gov

Health Physics Society. 2001. American National Standard - Design of Internal Dosimetry Programs. ANSI/HPS N13.39-2001. Health Physics Society. McLean, VA.

U.S. Department of Energy (DOE). 1998. DOE Standard: The Department of Energy Laboratory Accreditation Program for Radiobioassay. DOE-STD-1112-98, Washington, D.C. Accessed July 23, 2009 at http://www.directives.doe.gov

U.S. Department of Energy (DOE). 2008a. Radiation Protection Programs Guide for Use with Title 10, Code of Federal Regulations, Part 835, Occupational Radiation Protection. DOE G 441.1-1C, Washington, D.C. Accessed July 23, 2009 at http://www.directives.doe.gov

U.S. Department of Energy (DOE). 2008b. DOE Standard Internal Dosimetry. DOE-STD-1121-2008, Washington, D.C. Accessed July 23, 2009 at http://www.standards.doe.gov

U.S. Department of Energy (DOE). 2008c. DOE Standard: Radiological Control. DOE-STD-10982008, Washington, D.C. Accessed July 23, 2009 at http://www.standards.doe.gov 


\section{Acronyms and Abbreviations}

\begin{tabular}{|c|c|}
\hline AMAD & activity median aerodynamic diameter \\
\hline ANSI & American National Standards Institute \\
\hline ALI & annual limit on intake \\
\hline $\mathbf{C L}$ & contractual detection level \\
\hline $\mathbf{C N}$ & container-not-out \\
\hline DAC & derived air concentration \\
\hline DAC-hours & time-integrated exposure to airborne contamination \\
\hline DALI & deterministic annual limit on intake \\
\hline DEMS & Dose Evaluation Management System \\
\hline DOE & U.S. Department of Energy \\
\hline DPI & days post-intake \\
\hline DTPA & diethylenetriamine pentaacetic acid \\
\hline $\mathbf{E E}$ & Exposure Evaluator \\
\hline EPA & U.S. Environmental Protection Agency \\
\hline FA & failed analysis \\
\hline GI & gastrointestinal \\
\hline HIDP & Hanford Internal Dosimetry Program \\
\hline HPS & Health Physics Society \\
\hline HPDAC & Hanford Personnel Dosimetry Advisory Committee \\
\hline HRRP & Hanford Radiation Records Program \\
\hline HRRPL & Hanford Radiation Records Program Library \\
\hline ICRP & International Commission on Radiological Protection \\
\hline INTERTRAC & Internal Dose Tracking System \\
\hline IS & insufficient volume sample \\
\hline
\end{tabular}


IVMP

IVRRF

Lab

LC

MDA

MDD

NCRP

ND

NIST

NS

ORL

ORP

PNNL

PNSO

POC

QA

QC

RCT

REIRS

REMS

REX

RL

SALI

SOW

WB

WBC
In Vivo Monitoring Program

In Vivo Radioassay and Research Facility

analytical services laboratory

lost container

minimum detectable activity/amount

minimum detectable dose

National Council on Radiation Protection and Measurements

not delivered

National Institute of Standards and Technology

no sample

oral reporting level

DOE Office of River Protection

Pacific Northwest National Laboratory

DOE Pacific Northwest Site Office

Patrol Operations Center

quality assurance

quality control

Radiation Control Technician

Radiation Exposure Information and Reporting System

Radiation Exposure Monitoring Systems

Radiation Exposure (System)

DOE Richland Operations Office

stochastic annual limit on intake

statement of work

whole body

whole body count 